MÓDULOS EDUCATIVOS PARA NIÑOS EN CONDICIONES DE VULNERABILIDAD DESDE EL CONSTRUCTIVISMO SOCIAL Y LA EDUCACIÓN POPULAR

JULIE MILENA CÓMBITA RODRIGUEZ

LUIS ALBERTO PARÍS ECHEVERRY

UNIVERSIDAD SANTO TOMÁS

MAESTRÍA EN FILOSOFIA LATINOAMERICANA

BOGOTÁ D.C,

2013 


\title{
MÓDULOS EDUCATIVOS PARA NIÑOS EN CONDICIONES DE VULNERABILIDAD DESDE EL CONSTRUCTIVISMO SOCIAL Y LA EDUCACIÓN POPULAR
}

\section{JULIE MILENA CÓMBITA RODRIGUEZ LUIS ALBERTO PARÍS ECHEVERRY}

\section{Trabajo de Tesis presentado como requisito para optar al título de Magíster en Filosofía Latinoamericana}

\author{
Asesor: \\ ALBERTO ISAAC RINCÓN
}

\author{
UNIVERSIDAD SANTO TOMÁS \\ MAESTRÍA EN FILOSOFIA LATINOAMERICANA \\ BOGOTÁ D.C, \\ 2013 \\ Nota de aceptación
}




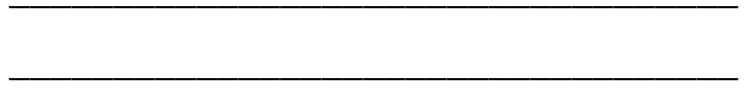

Presidente del Jurado

Jurado

Jurado

Jurado

Bogotá, D.C. 14 de Enero de 2013 
Módulos Educativos para Niños en Condiciones de Vulnerabilidad

Al destino, por dejarme llegar hasta aquí, A mis padres, por el ser, A Luis, por ser mi complemento. Julie Cómbita.

A mi familia, por apoyar mis ganas de filosofar, $Y$ a Julie por apoyar mis ganas de vivir. Luis París. 
Para llevar a cabo nuestro trabajo de grado de manera exitosa queremos manifestar nuestros agradecimientos a:

Alberto Rincón por guiar nuestro trabajo, a Yezid Garzón por abrirnos las puertas del centro de Proyección social en Altos de Cazucá.

Luis París y Julie Cómbita 


\section{TABLA DE CONTENIDO}

INTRODUCCIÓN

1. DIAGNOSTICO DE LA POBLACIÓN DE ALTOS DE CAZUCA 12

1.1 BREVE CONTEXTO HISTÓRICO SOCIAL 12

Antecedente 12

1.2 PRESENCIA DE LA USTA EN ALTOS DE CAZUCÁ 13

$\begin{array}{llr}1.3 & \text { PERFIL POBLACIONAL } & 13\end{array}$

$\begin{array}{lll}1.4 & \text { FORTALEZAS DEL CDC } & 15\end{array}$

1.5 OBJETIVO DEL CENTRO DE PROYECCIÓN SOCIAL 15

Altos de Cazucá $\quad 15$

Misión 15

Visión $\quad 16$

Proyectos que se desarrollan en el CPS altos de Cazucá 16 Convenios con entidades aliadas 16

Otras organizaciones directas en el desarrollo de proyectos. 17

1.6 ORGANIZACIÓN INTERNACIONAL DE LAS MIGRACIONES- OIM PROYECTO ID-FP-0097 18

Población y cobertura $\quad 18$

Caracterización del municipio de Soacha 18 $\begin{array}{ll}\text { Barrios comuna IV de Soacha } & 19\end{array}$

Razones por las cuales no se estudia 20

1.7 OFERTAS EDUCATIVAS EN LA COMUNIDAD 20

Instituciones oficiales de la comuna IV 20

Instituciones de educación superior $\quad 21$

SENA $\quad 21$

Otras instituciones públicas $\quad 22$

Fundaciones 22

Programa Soacha joven $\quad 22$

Programa adulto mayor activo y feliz 23

Otras empresas 23

1.8 CRITERIOS DE PRIORIZACIÓN 24

2. GENERALIDADES DE LA TEORÍA CONSTRUCTIVISTA 25

2.1. BIOGRAFÍA 25

2.1.1 Lev Semionovich Vigotsky 25

2.1.1.1 Conceptos de la teoría del desarrollo cultural 27

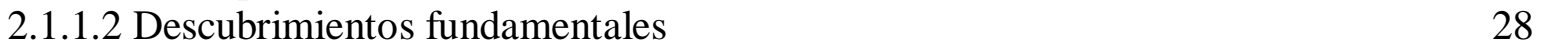

2.1.1.3 Teoría Socio histórica de Lev Vigotsky 34

2.1.1.3.1. El origen de los procesos biológicos superiores 34

2.1.1.3.2. Dominios genéticos y líneas de desarrollo 35 
2.1.1.3.4. El dominio de los procesos de interiorización: la mediación semiótica y el dominio de si

2.1.1.3.5. Internalización

2.1.1.3.6. Filogénesis, historia socio cultural, ontogénesis y microgénesis 38

2.1.1.3.6.1 Filogénesis

2.1.1.3.6.2Teoría del punto crítico

2.1.1.3.6.3. Historia Socio cultural

2.1.1.3.6.4. Ontogénesis

2.1.1.3.6.5. Microgénesis

2.1.2. El cambio cognitivo

2.1.3. Carácter histórico y cultural de la dirección y meta del cambio cognitivo $\quad 40$

2.1.4. Andamiaje e interacción semiótica $\quad 41$

2.1.4.1. Andamiaje actividad y control 41

2.2. CONSTRUCTIVISMO 42

2.3. SUPUESTOS DE LA TEORÍA DE LEV VIGOTSKY

2.4. PRINCIPIOS VIGOTSKIANOS 45

2.4.1 Los principios Vigotskianos en el aula $\quad 45$

2.4.2 Funciones mentales $\quad 45$

2.4.3 Mediación $\quad 46$

2.4.4 El proceso de mediación: Las tecnologías del pensamiento y la comunicación social47

2.4.5 La mediación social $\quad 48$

2.4.6 El proceso de interiorización $\quad 50$

2.4.7 Concepción de aprendizaje $\quad 51$

2.4.8 Concepción de docente $\quad 51$

2.5. ALGUNAS IMPLICACIONES EDUCATIVAS 51

2.5.1 Algunos aspectos que facilitan los procesos de aprendizaje en la escuela $\quad 51$

2.5.2 Posición culturalista de Lev Vigotsky

2.6 CONSTRUCTIVISMO SOCIAL

2.7 EL CONSTRUCTIVISMO DE LEV VIGOTSKY O CONSTRUCTIVISMO SOCIAL $\quad 54$

2.8 PRINCIPIOS Y CONCEPTOS DE LA TEORÍA DEL CONSTRUCTIVISMO SOCIAL $\quad 55$

2.8.1 El desarrollo de la inteligencia y su construcción social 55

2.8.2 Zona de desarrollo próximo $\quad 56$

2.8.2.1 La zona de desarrollo próximo y la dirección del desarrollo

2.9 VIGOTSKY Y EL MATERIALISMO HISTÓRICO

2.9.1 Otras consideraciones en torno a Vigotsky 60

2.10 Sobre la educación popular y la pedagogía de Paulo Freire 64

2.10.1 La Educación Popular $\quad 64$

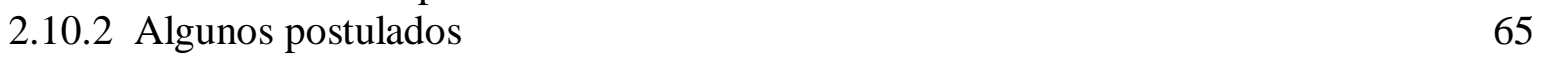

$\begin{array}{ll}2.10 .3 \text { La propuesta pedagógica de Paulo Freire } & 71\end{array}$

2.10.3.1La educación como posibilidad histórica en el pensamiento de Paulo Freire 72 
2.10.3.2Vigencia de la propuesta metodológica de Paulo Freire 73

2.10.3.3Educación y cambio en Paulo Freire 74

2.10.3.4 La educación un proyecto social para la liberación

$\begin{array}{ll}2.10 .4 \text { Nuevas tendencias educativas } & 76\end{array}$

2.10.4.1 Una diversidad más reconocida

2.10.4.2Los desafíos de la construcción curricular para la educación en América Latina 81

2.10.4.3La tensión entre los nuevos y los viejos contenidos $\quad 84$

2.10.4.4El acceso equitativo, inclusión social, igualdad de género 87

2.10.4.5 El multiculturalismo y el interculturalismo 89

2.10.4.6. El desarrollo del conocimiento y la investigación 91

2.10.4.7 La enseñanza-aprendizaje 94

3. SOBRE LA CATEGORÍA SUJETO POPULAR DESDE EL PENSAMIENTO

LATINOAMERICANO 110

3.1 LA CONSTITUCIÓN DEL SUJETO EN LA FILOSOFÍA LATINOAMERICANA 110

3.1.1 La filosofía latinoamericana como constitución del sujeto 111

3.1.2Los comienzos y recomienzos: Del sujeto a la filosofía y de la filosofía al sujeto 115

3.1.3 El sujeto cognoscente y el sujeto actuante 118

$\begin{array}{ll}3.1 .4 \text { Sujeto práctico } & 120\end{array}$

3.1.5 Sujeto vivo y Sujeto como sujeto 121

3.2. SUJETO POPULAR LATINOAMERICANO 126

3.2.1 Pensar desde Latinoamérica 126

3.2.2 El sujeto popular en la filosofía de la liberación $\quad 129$

3.2.3 El sujeto popular y la teología de la liberación 133

3.2.4 Sujeto popular en Altos de Cazucá 142

4. CRECIENDO Y HACIENDO CRECER MI MUNDO 143

4.1. CARTILLA "ME CONSTRU-YO”" 144

4.1.1 Cartilla de trabajo Creciendo y haciendo crecer mi mundo 144

4.1.1.1 Módulo 1: Eje de auto construcción: YO 144

4.1.1.1.1 Temática 1: Conozco y reconozco mi cuerpo 144

4.1.1.1.2 Temática 2: Siento lo que siento 146

4.1.1.1.3 Temática 3: Me pongo en el espejo 148

4.1.1.1.4 Temática 4: Estoy sano y vivo feliz $\quad 150$

4.1.1.2 Módulo 2: Eje de autoconstrucción: La Sociedad 151

4.1.1.2.1Temática 1: Mi familia, mi primera idea de sociedad 151

4.1.1.2.2 Temática 2: Mi barrio y sus habitantes 153

4.1.1.2.3 Temática 3: Mi ciudad, territorio humano 154

4.1.1.2.4 Temática 4: Soy Colombia 157

4.1.1.3 Módulo 3: Eje de autoconstrucción: Medio Ambiente 158

4.1.1.3.1 Temática 1: Yo soy parte de los recursos naturales 158

4.1.1.3.2 Temática 2: Si te cuidas, cuidas el ambiente 160

4.1.3.3 Temática 3: Ecología 162 
4.1.3.4 Temática 4: Mi tierra, mi identidad

4.1.4 Módulo: Eje de Autoconstrucción: YO, SOCIEDAD, MEDIO AMBIENTE 167

4.1.4.1 Temática 1: Pintando y moldeando el mundo

167

4.1.4.2 Temática 2: Construyendo herramientas para romper el silencio 169

4.1.4.3 Temática 3: Mi mundo es del tamaño de mis palabras 170

4.1.4.4 Temática 4: Actúo, represento y soy 171

4.1.5 Módulo 5: Eje de Autoconstrucción: Refuerzo académico teórico 173

4.1.5.1 Temática 1: Matemáticas 173

4.1.5.2 Temática 2: Lenguaje 174

4.1.5.3 Temática 3: Ciencias Naturales 176

4.1.5.4 Temática 4: Ciencias Sociales 179

4.1.6 Módulo 6: Eje de autoconstrucción: Responsabilidad Social 181

4.1.6.1 Temática 1: Derecho de los niños y las niñas 181

4.1.6.2 Temática 2: Derechos e Infancia 182

4.1.6.3 Temática 3: Dignidad Humana 186

5. CONCLUSIONES 194

REFERENCIAS BIBLIOGRÁFICAS 202

$\begin{array}{ll}\text { ANEXOS } & 209\end{array}$ 


\section{INTRODUCCION}

La ausencia de instituciones educativas con programas que apliquen un modelo pedagógico educativo constante, ha producido un vacío en el ejercicio de educar a niños desplazados ubicados en altos de Cazucá.

Teniendo en cuenta la problemática social y de orden público que no permiten la ubicación de las suficientes instituciones educativas en la zona, es necesario diseñar una propuesta pedagógica utilizando como sustento la aplicación del modelo constructivista de Vigotsky y la educación popular para aprovechar las experiencias individuales en pro de la construcción de conocimiento acercando al estudiante a los estándares educativos a partir de la interacción social y de la misma manera generar un conocimiento de doble vía donde el docente-guía y el aprendizconstructor descubren realidades, fortaleciendo las relaciones sociales que permiten el reconocimiento del otro como ser humano, mejorando las condiciones en las cuales se encuentran inmersos, bien sea por desplazamiento forzado u otras circunstancias.

Por lo tanto nuestra investigación refiere al cómo mejorar las condiciones educativas de la población infantil vulnerable a partir de la implementación de algunos de los aspectos más relevantes planteados en el constructivismo social de Vigotsky y la educación popular a través de una cartilla didáctica aplicable a niños y niñas de altos de Cazucá, buscando el rescate del sujeto y la reconstrucción del tejido social.

Para ello se traza como objetivo base el diseñar una cartilla didáctica que trate temas de interés general y contengan elementos del constructivismo social de Vigotsky que parta del conocimiento construido por la población infantil de altos de Cazucá, y así, facilitar el aprendizaje por medio de la lúdica, además de permitir el mejoramiento de las relaciones sociales.

Para esto han de seguirse algunas directrices, en primer lugar la realización de un diagnóstico de la población de altos de Cazucá, en segundo lugar el análisis de los postulados constructivistas y la edificación dela categoría de sujeto desde el pensamiento latinoamericano y 
por último la generación de procesos de aprendizaje significativo mediante la elaboración de una cartilla fragmentada en módulos que permita el afianzamiento y la producción de conocimiento.

Todo esto con el fin de generar una herramienta que contribuya el desarrollo integral de la población vulnerable, la reconstrucción de su condición humana, la categoría de sujeto y a su vez del tejido social recogiendo elementos de corte pedagógico y filosófico logrando así la interacción entre pensadores latinoamericanos y la propuesta pedagógica de Vygotsky en la consolidación de una herramienta eficaz y de fácil implementación para ello. 


\section{DIAGNÓSTICO DE LA POBLACIÓN DE ALTOS DE CAZUCÁ}

\subsection{BREVE CONTEXTO HISTÓRICO SOCIAL}

\subsubsection{Antecedente}

En el presente capítulo se pone a la vista la situación actual de la población de altos de Cazucá, a nivel de densidad demográfica, condiciones de vida, educación e instituciones que intervienen en el sector, haciendo énfasis en el grupo que viene adelantando trabajo con el centro de proyección social de la universidad, y que hace parte fundamental de nuestro trabajo, pues son los niños de esta parte de la población hacia quien va dirigido el producto final de la investigación a través de la cartilla de los módulos "me constru-yo", a continuación veremos el diagnóstico general facilitado por el centro de proyección de la universidad.

Altos de Cazucá comenzó en 1975 en este sector del sur oriente de Bogotá, Municipio de Soacha, Departamento Cundinamarca. La historia se remonta cuando el Partido Comunista de Colombia, través de Pro Vivienda, invadió esta parte baja de estas lomas y fundó el Barrio Julio Rincón. Las familias asentadas allí estaban conformadas por personas "desechados" procedentes de los Barrios Bosa, el Perdomo y otros periféricos del Distrito Capital, poco a poco fueron constituyéndose como Barrio Villa Mercedes. Después continuó el poblamiento del sector Altos de Cazucá, de esta manera se presentó el fenómeno de invasión de predios o lotes de la zona del Barrio Terreros para construir vivienda, ya no sólo para familias procedentes de Bogotá, sino también de distintas Regiones del País.

Hace uno 22 años, un grupo de jóvenes estudiantes, religiosos o frayles de la Comunidad Dominicana, del Convento de Santo Domingo de Bogotá, hicieron presencia en estos lugares que apenas estaban en procesos sociales de formación como comunidades o asentamientos humanos. Estos frailes dominicos estaban sensibilizados por la problemática de extrema pobreza de estos sectores, e iniciaron un proyecto pastoral de acompañamiento a estas familias. La sede de este proyecto fue el Barrio Villa Mercedes. 


\subsection{PRESENCIA DE LA USTA EN ALTOS DE CAZUCÁ}

El Centro de Desarrollo Comunitario Altos de Cazucá surge hace más de diez años. Su origen está en la conciencia que deben asumir los profesores y estudiantes frente a la realidad de pobreza, violencia y desigualdad social de estas comunidades: un compromiso, desde la academia, de proyección social como función sustantiva de sus programas académicos.

Este nace durante la Rectoría del Padre Eduardo Gonzales Gil. El CPS funciona como espacio físico, en una casa de dos niveles en el Barrio Minuto de Dios, cuenta con los servicios de agua, luz y teléfono. En la administración del Centro encontramos una persona de servicios generales y un coordinador con perfil profesional, que figura en la Nómina Académica de la Universidad.

La presencia nutrida de programas académicos de la USTA ha generado procesos

tendientes a cambiar el nivel de vida de sus moradores, mediante proyectos orientados a contribuir al mejoramiento de sus condiciones de vida. Ha propiciado espacios de comunicación, participación e integración entre los diferentes actores sociales: entidades gubernamentales, no gubernamentales, juntas de acción comunal, organizaciones comunales y empresas privadas.

\subsection{PERFIL POBLACIONAL}

Estas poblaciones poco cuentan para la administración local del municipio. Para ésta, estos lugares son un sector "inexistente", por la forma ilegal como ocuparon los terrenos. Por esta razón no se realizan proyectos o alguna inversión para mejorar las condiciones de vida de sus habitantes. Para estos "barrios subnormales", las implicaciones son tan graves que ni siquiera tienen derecho a dotación de los servicios básicos. En pocas palabras, los habitantes de estas comunidades son consideradas por la sociedad y el Estado son como habitantes altamente "vulnerables".

Algunos ejemplo para advertir la escasa injerencia de la administración local es la inexistencia del trazado de una red vial que delimite las calles, andenes y en general el espacio público. Pero las mayores dificultades se manifiestan en el acceso y dotación de la vivienda, los servicios de agua, alcantarillado, lo mismo que la insuficiencia de centros educativos a nivel 
secundaria. En lo referente a las viviendas, es fácil observar hacinamiento de personas en una misma familia. Casas y en muchos pasos "cambuches o ranchos son con cualquier clase de materiales para su construcción, pues estos varían desde el uso del ladrillo hasta cartones, retazos de tela asfáltica, plásticos, madera, cobijas, telas y otros.

La gran mayoría de sus habitantes carecen de un empleo estable y los que lo tienen, se dedican a ventas ambulantes, albañilería, la construcción y la celaduría, en el caso de los hombres, en tanto que las mujeres que trabajan, lo hacen principalmente en el servicio doméstico.

El servicio del agua es uno de los más difíciles del sector, pues ante la carencia de éste, las personas se ven obligadas a proveerse de él, recurriendo principalmente al uso de mangueras. Es importante anotar que esta situación ha hecho que algunas personas especulen con la "venta" de este servicio y se dediquen a hacer negocio, menguando así el escaso presupuesto de las familias.

Además de las anteriores dificultades que padecen las familias allí asentadas, la inseguridad se presenta como uno de los aspectos de mayor influencia sobre la vida de éstas. La presencia en el sector de los denominados grupos de "limpieza social" y de algunos actores del conflicto colombianos, lo mismo que la llamada delincuencia común, hacen que los habitantes teman por sus vidas o que, en muchos casos se abstengan de tomar parte en procesos comunitarios.

En lo que tiene que ver con el lugar de procedencia de las familias se puede afirmar que provienen principalmente de los departamentos de Antioquia, Tolima y Santander. En menor porcentaje, de Cundinamarca, Huila, Caquetá, Meta, Boyacá. Valle y Putumayo. Si bien es cierto que a todas las familias las identifica el hecho de ser desplazadas, de todas maneras la configuración de la cultura de las distintas regiones colombianas es un elemento que puede pesar demasiado en la convivencia social o a la hora de poner en marcha determinados proyectos.

Por otra parte un 64\% de la población es menor de 20 años; el 20\% corresponde a niños menores de 5 años, lo cual hace suponer, para ambos casos, que se trata de una población demasiado dependiente y que requiere de los cuidados y a la preparación necesaria para hacer frente a las difíciles condiciones del entorno. 
En lo referente al nivel de los ingresos se puede apreciar que un $90 \%$ de las familias viven con un salario mínimo o menos, el cual proviene generalmente de las ventas ambulantes, la construcción, guardas de seguridad o el servicio doméstico.

\subsection{FORTALEZAS DEL CDC}

- Reconocimiento y sentido de pertenencia por parte de la comunidad de Organizaciones Gubernamentales y no gubernamentales entre otras.

- Reuniones periódicas con JAC e instituciones educativas que posibilitan desarrollar conjuntamente los planes de Desarrollo Comunitario.

- Contar con una escuela deportiva con énfasis en la no violencia y la equidad de género que esta integrada por jóvenes de diferentes sectores de la comuna IV.

- Se promueven proyectos productivos que propician el empleo y el desarrollo integral de las personas a través una empresa de galletería y confección.

- Se cuenta con el apoyo de alianzas estratégicas de otras instituciones universitarias que complementan y potencializan los proyectos que se desarrollan.

Estas fortalezas están al servicio de los estudiantes de las diferentes facultades que desarrollan sus prácticas como experiencia a nivel profesional o de extensión de cátedra orientadas por docentes de la misma USTA.

\subsection{OBJETIVO DEL CENTRO DE PROYECCIÓN SOCIAL}

\subsubsection{Altos de Cazucá}

Transformar el pensamiento, el actuar y la forma de relacionarse de la comunidad, en torno a los procesos sociales, económicos, educativos, políticos y culturales, con el fin de incidir en las condiciones de vida de los habitantes de la Comuna IV del Municipio de Soacha.

\subsubsection{Misión}

El Centro de Proyección Social "Altos de Cazucá” es un escenario de la Universidad Santo Tomas, en el cual se busca que los estudiantes conozcan, reflexionen, apliquen sus 
conocimientos y actúen con la comunidad en los procesos sociales, económicos, educativos y culturales de la Comuna IV de Soacha, para que así estén en condiciones de aportar soluciones a las problemáticas de manera ética, creativa y crítica a las exigencias humanas.

\subsubsection{Visión}

El Centro de Proyección Social “Altos de Cazucá” en el 2015, ha incidido en la calidad de vida de los habitantes de la Comuna IV de Soacha y se convertirá en nodo de procesos sociales, económicos, educativos y culturales, con la comunidad y con las instituciones que se encuentran en la Comuna.

\subsubsection{Proyectos que se desarrollan en el CPS Altos de Cazucá}

\begin{tabular}{|c|c|c|}
\hline Facultad & Proyectos & ubicación \\
\hline DERECHO & $\begin{array}{c}\text { Consultorio Jurídico } \\
\text { Docencia comunitaria }\end{array}$ \\
\hline CULTURA FISICA & $\begin{array}{c}\text { Escuela de formación deportiva } \\
\text { (micro futbol) }\end{array}$ & CPS - El Arroyo- \\
\hline FILOSOFIA & Refuerzo escolar, Filosofía para & CPS Minuto de Dios, \\
\hline niños(as), Literatura y Ludoteca & Balkanes \\
\hline COMUNICACIÓN & Reporteritos & El Arroyo \\
\hline
\end{tabular}


1.5.4.1 Convenios con entidades aliadas.

\begin{tabular}{|l|c|l|}
\hline \multicolumn{1}{|c|}{ Aliado } & \multicolumn{1}{|c|}{ Proyecto } & Ubicación \\
\hline Universidad Minuto de Dios & -Informatica & \multicolumn{1}{|c|}{ CPS } \\
\hline Universidad Piloto de Colombia & -Primera Infancia & $\begin{array}{l}\text { Balkanes } \\
\text { Carlos Pizarro } \\
\text { Arroyo }\end{array}$ \\
& - Arte y Cultura & -Escuela deportiva \\
\hline Colectivo Hombres y Masculinidades & -Escuela deportiva & CPS \\
\hline
\end{tabular}

JAC que han participado directamente de los proyectos:

- Minuto de Dios

- Carlos Pizarro

- Villa Mercedes

- El Arroyo

- Luis Carlos Galán

- Santo Domingo

- Colegios que han participado con estudiantes en servicio social o participando en los proyectos:

- Colegio san mateo

- Colegio Dios Es Amor

\subsubsection{Otras organizaciones directas en el desarrollo de proyectos}

- Asociación Colectivo hombres y Masculinidades CHM -Escuela deportiva

- Asociación Cristiana de Jóvenes ACJ - Encuentros Juveniles KZK

- Fundehi-Emprendimiento

- Clínica Monserrate - Salud Mental 


\subsection{ORGANIZACIÓN INTERNACIONAL PARA LAS MIGRACIONES - OIMPROYECTO: ID-FP-0097}

"Apoyo y acompañamiento para la inclusión social de familias vulnerables y en situación de desplazamiento de la comuna cuatro de Soacha".

\subsubsection{Población y Cobertura}

$\checkmark$ Municipio de Soacha - Comuna 4 (El Arroyo, La Isla, Alto del Pino, Corinto, El Oasis).

$\checkmark 150$ familias (aprox. 750 personas), de 200 familias preinscritas y caracterizadas a través de la línea base familia, persona y psicosocial.

$\checkmark$ La mayoría de beneficiarios son personas con alto índice de vulnerabilidad y Necesidades Básicas Insatisfechas - NBI, como la falta de oportunidades laborales, desatención en salud, alto índice de desescolarización, entre otros, generando desarraigo, exclusión social y que están en constante riesgo de: vinculación a grupos armados al margen de la ley, consumo de sustancias psicoactivas, prostitución y violencia intrafamiliar y social, entre otros.

\subsubsection{Caracterización municipio Soacha}

Según el Acuerdo No. 12 de 1997, el área rural la comprenden dos corregimientos, y el área urbana 6 comunas:

Comuna 1: Suroccidente

Comuna 2: Centro-Occidente

Comuna 3: Noroccidente

Comuna 4: Nororiente

Comuna 5: Centro-Oriente

Comuna 6: Centro-Oriente 


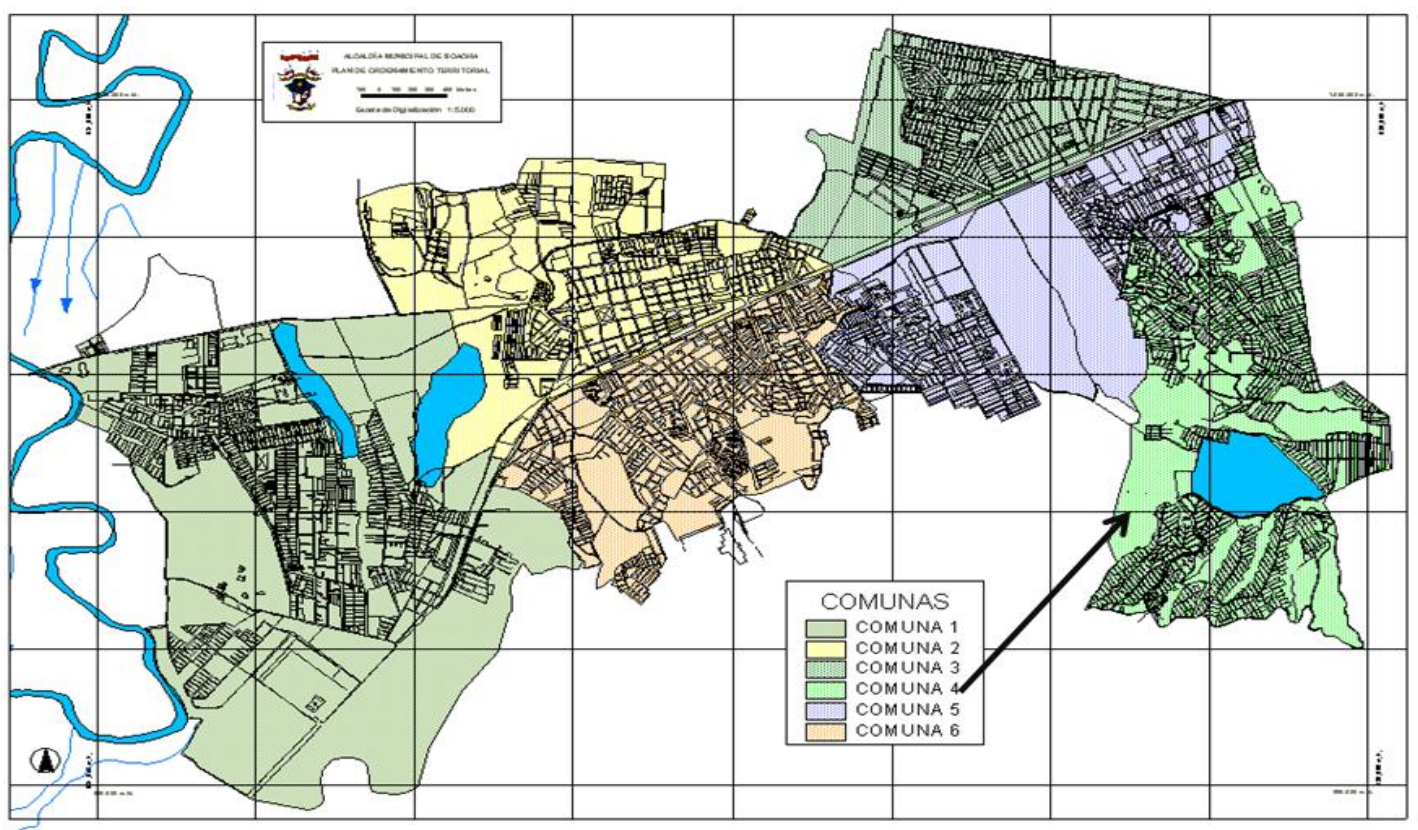

\subsubsection{Barrios Comuna IV Soacha}

\begin{tabular}{|l|l|l|}
\hline Altos del Pino & Julio Rincón & Minuto de Dios \\
\hline Buenavista & La Capilla & Mirador de Corinto \\
\hline Buenavista Bajo & La Esperanza del nort & Paraíso de Corinto \\
\hline BuenosAires & La Isla & Rincón del Lago \\
\hline Carlos Pizarro & Nueva Unión & San Rafael \\
\hline Casa Loma & Laguna Terreros & Santo Domingo \\
\hline Ciudadela Sucre Tercer Sector & Las Margaritas & Villa Cano \\
\hline Corinto & Lorna Linda & Villa Mercedes \\
\hline El Arroyo & Los Balkanes & Villa Sandra \\
\hline El Oasis & Los Pinos & \\
\hline El Progreso & Luis Carlos Galán & \\
\hline
\end{tabular}




\subsubsection{Razones por las cuales no estudia}

\begin{tabular}{|c|c|}
\hline Nivel Educativo & Razones por las cuales no estudia \\
\hline Preescolar (4 - 7 años) & $\begin{array}{l}\text {-Por la edad considera que no necesita estudiar } \\
\text {-Falta de cupos escolares } \\
\text {-Lejanía de establecimientos educativos }\end{array}$ \\
\hline Básica (5 - 15 años) & $\begin{array}{l}\text {-Falta de cupos escolares } \\
\text {-Lejanía de establecimientos educativos } \\
\text {-Costos educativos altos }\end{array}$ \\
\hline $\begin{array}{l}\text { Media (14 - } 20 \text { años) } \\
\text { Superior (17 en adelante }\end{array}$ & $\begin{array}{l}\text {-Necesidad de trabajar } \\
\text {-Costos educativos altos } \\
\text {-Por embarazo }\end{array}$ \\
\hline
\end{tabular}

\subsection{OFERTAS EDUCATIVAS EN LA COMUNIDAD}

Con relación a la educación de primaria y secundaria en el municipio, se cuenta con un total de 192 colegios privados, de los cuales 25 se encuentran en la comuna 4; y 22 instituciones educativas oficiales, 7 de las cuales están en la comuna 4.

\subsubsection{Instituciones oficiales en la Comuna 4}

\begin{tabular}{|l|}
\hline INSTITUCION EDUCATIVA BUENOS AIRES \\
\hline SEDE LOS ROBLES \\
\hline SEDE EL OASIS \\
\hline SEDE RINCÓN DEL LAGO \\
\hline SEDE PAZ Y PATRIA \\
\hline INSTITUCION EDUCATIVA CIUDADELA SUCRE \\
\hline SEDE LA ISLA \\
\hline SEDE EL PROGRESO \\
\hline INSTITUCION EDUCATIVA CAZUCA \\
\hline SEDE LA CAPILLA \\
\hline INSTITUCION EDUCATIVA GABRIEL GARCIA MARQUEZ \\
\hline SEDE EL MINUTO DE DIOS \\
\hline INSTITUCION EDUCATIVA ANTONIO NARIÑO
\end{tabular}




\begin{tabular}{|l|}
\hline INSTITUCION EDUCATIVA JULIO CESAR TURBAY AYALA \\
\hline SEDE EL ARROYO \\
\hline INSTITUCION EDUCATIVA LUIS CARLOS GALAN \\
\hline SEDE CASALOMA \\
\hline SEDE CONCENTRACIÓN ALTO DEL PINO \\
\hline
\end{tabular}

\subsubsection{Instituciones de Educación Superior}

\begin{tabular}{|c|c|c|}
\hline INSTITUCION & $\begin{array}{c}\text { TIPO DE } \\
\text { INSTITUCION }\end{array}$ & $\begin{array}{l}\text { NOMBRE DEL } \\
\text { PROGRAMA }\end{array}$ \\
\hline $\begin{array}{l}\text { POLITECNICO MARCO FIDEL } \\
\text { SUAREZ }\end{array}$ & Institución Universitaria & $\begin{array}{lc}\text {-Técnica Profesional } & \text { en } \\
\text { procedimientos judiciales } & \end{array}$ \\
\hline $\begin{array}{l}\text { CORPORACION } \\
\text { UNIVERSITARIA MINUTO DE } \\
\text { DIOS }\end{array}$ & $\begin{array}{l}\text { INSTITUCION } \\
\text { UNIVERSITARIA }\end{array}$ & $\begin{array}{l}\text {-Tecnología en Comunicación } \\
\text { gráfica } \\
\text {-Tecnología en electrónica } \\
\text {-Tecnología en costos y } \\
\text { auditoría } \\
\text {-Tecnología en Logística }\end{array}$ \\
\hline $\begin{array}{ll}\text { UNIVERSIDAD } & \text { DE } \\
\text { CUNDINAMARCA - UDEC } & \end{array}$ & UNIVERSIDAD & $\begin{array}{l}\text {-Ingeniería Industrial } \\
\text {-Profesional en ciencias del } \\
\text { deporte y la educación física }\end{array}$ \\
\hline $\begin{array}{c}\text { UNIVERSIDAD } \\
\text { PEDAGÓGICA NACIONAL }\end{array}$ & UNIVERSIDAD & $\begin{array}{c}\text {-Licenciatura } \\
\text { Educación Infantil }\end{array}$ \\
\hline
\end{tabular}

\subsubsection{SENA}

Centro Industrial y Desarrollo Empresarial: 42 programas técnicos y tecnológicos de formación titulada en diferentes áreas.

- Formación complementaria.

- $\quad$ Formación Virtual. 


\subsubsection{Otras instituciones públicas}

- Casa de la cultura

- 3 ludotecas comuna 4: niños de 3 a 12 años.

- Centro de Educación Física: aprovechamiento del tiempo libre a niños y adolescentes desescolarizados.

- Programa de Exploración Motora - IMRDS.

- Corporación Infancia y Desarrollo: Círculos de Aprendizaje: Formación a NNA desescolarizados. Aceleración, Nivelación y refuerzo escolar.

- Fundación San Antonio: Programa Redes: actividades de educación formal y aprovechamiento del tiempo libre, refuerzo escolar, asesoría de tareas, actividades deportivas y culturales.

\subsubsection{Fundaciones}

- Fundación San Juan Bautista: procesos educativos no formales, refuerzo escolar, apoyo en tareas.

- Asociación Cristiana de Jóvenes -ACJ: Refuerzo escolar, apoyo en tareas, actividades vocacionales.

- Fundación Batuta: Actividades y programas de aprovechamiento del tiempo libre, enfocado a la educación artística.

- Ecoparque Minuto de Dios: Procesos de capacitación y formación (confección, belleza, sistemas, entre otros).

\subsubsection{Programa Soacha Joven}

- Golombiao

- Despacio y con cuidado: estrategia para prevenir el consumo de SPA.

- Centro de Desarrollo Juvenil: formación integral, apoyo en salud, participación, actividades culturales y artísticas.

- De-mentes y con razón: Actividades de convivencia

- Fundación Jedidías

\subsubsection{Programa Adulto Mayor Activo y Feliz}


- Programa Centros Vida: atención psicosocial, bienestar físico, desempeño ocupacional.

- Programa Nacional de alimentación para el Adulto Mayor JUAN LUIS LONDOÑO DE LA CUESTA.

- Programa nacional de protección social al adulto mayor PPSAM

- Programas de actividad física y rítmica

- Programa Municipal de institucionalización

- Casa de Justicia

- Comisaría de Familia

- Inspección de Policía

- Personería Municipal

- Consultorio Jurídico

- Conciliación en equidad

- Jueces de Paz

- Defensoría del Pueblo

- Fiscalía local

- Inspección del Trabajo

- Equipo de trabajo social y psicología

- Centro Proyección Social Santo Tomas

- Salud mental preventiva

- Refuerzo escolar

- Ludoteca

- Capacitaciones

- Asesoría jurídica

- Talleres comunitarios

- Prevención y tratamiento

\subsubsection{0tras empresas}

- Oficina de participación comunitaria

- Programa de discapacidad

- Instituto municipal para la recreación y el deporte. 
- Corporación Centro de Apoyo Popular

- Un Techo para mi país

\subsection{CRITERIOS DE PRIORIZACION}

La priorización de 150 familias, de las 200 identificadas en la comuna 4, obedece a criterios de selección concertados con el equipo, y se plantean de acuerdo con los objetivos del proyecto, en relación a los componentes de salud, educación y generación de ingresos. Para tal fin se han establecido algunos criterios que permitan seleccionar a las familias con mayor vulnerabilidad y alta prioridad:

- Prioridad población desplazada registrada

- Que no haya tenido servicios con OIM de Vivienda, Generación de Ingresos y Seguridad Alimentaria.

- Mujeres cabeza de familia

- Que el número de miembros de familia sea superior a la media (4 personas, se inicia por el corte más alto de arriba hacia debajo de miembros)

- Capacidad económica

- No tengan afiliación a salud

- Menores de edad no vinculados a educación

- Miembros de la familia con discapacidad

- Adultos mayores sin vinculación a programas

- Miembro de la familia con enfermedades de "alto costo"

- Tipo de vivienda

- Miembros de la familia económicamente activa.

Hemos visto entonces, las principales características de la población hacia la cual va dirigida la propuesta, sus rasgos más relevantes y las condiciones en las que se encuentran, a continuación veremos el enfoque pedagógico de la investigación, basado en los postulados de Lev Vigotsky. 


\section{GENERALIDADES DE LA TEORÍA CONSTRUCTIVISTA}

Como parte de la investigación dentro del componente pedagógico y la innovación misma del trabajo, se presenta por medio de la teoría del constructivismo social de Lev Vigotsky una herramienta eficaz para subsanar muchas de las necesidades a nivel humano y pedagógico que se vienen presentando en el trabajo desarrollado con los niños del centro de proyección social de

altos de Cazucá, pues si bien se ofrecen refuerzos escolares, hace falta un norte pedagógico dentro del programa que no solo refuerce los contenidos vistos por los niños en sus aulas de clase, sino que posibilite la apertura de otros espacios que faciliten el aprendizaje desde diversos puntos de vista que vayan más allá de lo conceptual y académico y se enfoquen más hacia lo humano y lo social, para ello, los postulados de Vigotsky desde su visión constructivista facilita el abordaje de ambos componentes (humano y académico) así como la reconstrucción del sujeto en sí mismo y en el entorno donde se encuentra.

A continuación se abordarán los principales planteamientos que desde el constructivismo social nos aporta el autor para la investigación.

\subsection{BIOGRAFÍA}

\subsubsection{Lev Semionovich Vigotsky}

La vida de Lev Semionovich Vigotsky (1896-1934) se puede dividir en dos períodos fundamentales: el primero desde su nacimiento en 1896 hasta 1924, el año en que hizo su primera aparición como relevante figura intelectual en la URSS; el segundo desde 1924 hasta su muerte, causada por la tuberculosis, en 1934. Lev Vygotsky nació el 17 de noviembre de 1896 en Orsha, relativamente cercano a Minsk, en Bielorrusia, donde además pasó su infancia y juventud.

Tuvo una vida feliz y llena de estímulos intelectuales, a pesar del hecho de que, al igual que otros miembros de la familia, fue excluido del disfrute de otras oportunidades por ser judío. En la Rusia zarista ser judío quería decir vivir en territorio restringido, estar sujeto a cuotas estrictas para acceder a la universidad, quedar excluido de ciertas profesiones y muchas otras formas más 
de discriminación. Estas circunstancias eran, sin duda, la fuente de la mayor parte la amargura del padre.

Sin embargo tanto él como su esposa fueron capaces de proporcionar un ambiente intelectualmente estimulante para sus hijos. A los 15 años Lev Vigotsky, había pasado a ser conocido como el pequeño maestro, ya que siempre guiaba las discusiones entre estudiantes sobre materias intelectuales. Por ejemplo examinaba el contexto histórico del pensamiento a través de debates y juicios simulados en los que sus compañeros interpretaban el papel de figura como Aristóteles y Napoleón. Estos debates eran una manifestación de uno de los principales intereses durante esa etapa de su vida: la filosofía. Siendo todavía un niño y viviendo en Gomel, también empezó a mostrar un ferviente interés por el teatro y la literatura, no hubo ningún período en su vida que no pensara o escribiera sobre el teatro.

La noción de significación elevada de una forma lingüística abreviada estaría destinada a desempeñar un papel fundamental en su concepción de lenguaje y la mente. Se graduó con una medalla de oro en 1913, aunque había sido ampliamente reconocido como un estudiante sobresaliente, tuvo enormes dificultades para acceder a la universidad de su elección, y esto es básicamente por lo que se menciono anteriormente por ser judío. Sin embargo en 1917 se graduó en leyes por la Universidad de Moscú. Aunque no recibió ningún título oficial de la Universidad, él extrajo un gran provecho de su formación en Filosofía, Psicología y literatura, también dirigió las clases de estética e historia del arte en un conservatorio, lo que alternaba con conferencias de literatura y ciencia. Más adelante fundó un laboratorio de psicología.

Desde una visión retrospectiva, todo este caudal de trabajo parece haber sido la preparación de un acontecimiento que en 1924, habría de cambiar la vida de este ilustre pensador. Su brillante alocución impresionó de tal manera al director del instituto de Psicología de Moscú que inmediatamente lo invito a este Mozart de la Psicología a unirse a él mismo y a otros colegas en la restructuración de la institución.

Los años transcurridos entre 1924 y 1934 fueron altamente densos y productivos tras su llegada a Moscú, Alexander Romanovich, Luria y Aleksei Nikolaevich Leontiev se le unieron como discípulos y colegas. Juntos los tres llegaron a ser conocidos como la troika de la Escuela Vygotskyana. Muchos otros discípulos y seguidores de Lev Vygotsky formaron parte de la 
escuela, pero fueron Luria y Leontiev los que, tras su muerte, estarían destinados a ser los principales continuadores de sus ideas.

La última década de su vida fue extraordinariamente agitada y productiva. Se incorporó al Instituto Psicológico de la Universidad de Moscú en la modesta posición de personal científico ayudante o personal científico de segunda clase, como se denominaba entonces abordó su trabajo en ese nuevo entorno institucional animado por un doble propósito.

En primer lugar, quería reformular la teoría psicológica desde una perspectiva marxista. Este tema de su obra es en ocasiones, considerado, por los lectores occidentales, como un trabajo de compromiso respecto a algo en lo que no creía. Este no era, en absoluto, el caso de Lev Vygotsky. Aunque la Psicología soviética padecería más tarde la inmersión en un clima político dogmático, pero él murió antes de que ésta situación se convirtiera en un hecho que impregnara en su vida. El segundo objetivo era el desarrollar formas concretas de hacer frente a algunos problemas prácticos con que, masivamente, tenía que enfrentase la URSS, básicamente la Psicología de la educación.

Vygotsky se interesó por niños con déficit auditivo, retraso mental o utilizando la terminología actual con problemas de aprendizaje, en 1925, empezó a organizar el Laboratorio de Psicología para la infancia anormal de Moscú. En 1929, éste se convirtió en el Instituto "Defectológico Experimental", fue el primer director de este instituto, y continuó considerablemente inmerso en sus trabajos hasta su muerte. En 1925 concluyó una versión escrita de su presentación al segundo congreso de Psiconeurología, en 1926 mientras se encontraba en un hospital, víctima de otro ataque de tuberculosis, escribió una crítica filosófica a los fundamentos teóricos de la Psicología. El significado histórico de la crisis de la Psicología y en 1926 publicó Psicología y Pedagogía.

Desde finales de los años veinte, viajó ampliamente por toda la URSS dedicado a la docencia y a la ayuda en la constitución de nuevos laboratorios de investigación, impartió un curso para formar a los educadores como Psicólogos para el departamento oriental de la primera Universidad Estatal de Asia Central. Comenzó a asistir a clases de medicina, especialmente de neurología. Ingreso a la facultad de medicina y asistía a clases tanto en Moscú como en Jarkov, su interés por la medicina parece haberse desarrollado a partir de su interés por los desórdenes 
neurológicos relacionados con el habla y el pensamiento, no solamente dio clases, sino que, además, dirigía trabajos clínicos y organizaba trabajos de investigación. Inmediatamente después de su desaparición fueron publicados varios de sus escritos, pero, por razones políticas, su trabajo fue prohibido para todo tipo de usos por un período de veinte años. En total, llegó a escribir alrededor de 180 obras. De éstas, 135 fueron publicadas en una u otra forma antes de los seis volúmenes de recopilación. Algunas de ellas aparecían en estos volúmenes por primera vez.

\subsubsection{Conceptos de la teoría del desarrollo cultural de las funciones psíquicas de Lev} Vigotsky

Para él los procesos psicológicos son cambiantes (nunca fijos) y dependen en gran medida del entorno vital. Creía que la asimilación de las actividades sociales y culturales era la clave del desarrollo humano y que esta asimilación era lo que distingue a los hombres de los animales. La idea central de su obra se basa en que el desarrollo de los humanos únicamente puede ser explicado en términos de interacción social, lo que tiene amplias implicaciones en la reflexión teórica de la Psicología, la Pedagogía, la Filosofía y la Linguiística. Su obra más importante está plasmada en el libro "Pensamiento y lenguaje" publicada en 1934. En su teoría podemos encontrar varias ideas importantes, en primer lugar se refiere al lenguaje como un instrumento imprescindible para el desarrollo cognitivo del niño y posteriormente a la consciencia progresiva que va adquiriendo el niño que le proporciona un control comunicativo, además de que confirma que el desarrollo lingüístico es independiente del desarrollo del pensamiento.

\subsubsection{Descubrimientos fundamentales}

1- El análisis de unidades o "generalizador"

Vigotsky considera que el lenguaje y el pensamiento tienen relaciones funcionales interconectadas, y que en lugar de estudiarlos de forma independiente, deben de integrarse sus funciones (estructural y evolutiva) en un mismo análisis denominado "de unidades" que permite considerarlos a ambos y sus interacciones

Dado que la verdadera comunicación requiere de significado, esta solo puede darse mediante un sistema "mediatizador" de razones, intenciones, experiencias y pensamientos como lo es el 
lenguaje. El lenguaje es en este sentido una forma superior de intercambio humano y refleja la realidad de forma conceptualizada; en donde cada palabra en sí es la unidad, que integra tanto un significado generalizado como su intercambio social, plasmados en un signo lingüístico.

2- El lenguaje y el pensamiento en el niño

Con base a los estudios realizados por Piaget mediante su método clínico, en el estudio de la lógica y de la percepción del niño, Vigotsky desentraña y analiza nuevos hechos. Según Piaget el egocentrismo es lo que unifica toda la lógica del pensamiento del niño, pero esta lógica no es todo lo que hace a la inteligencia; siendo que la forma más espontánea de pensamiento se da en el juego. Vigotsky se da cuenta de que el adulto piensa socialmente aun estando solo y de que el niño piensa egocéntricamente aún estando inmerso en la sociedad. Según Piaget esta forma egocéntrica en el habla desaparece durante el desarrollo, apareciendo posteriormente el llamado "lenguaje interiorizado"; sin embargo Vigotsky propone que más bien se minimiza y ahí comienza el desarrollo del "lenguaje interiorizado". Desafortunadamente Piaget no experimentó con niños de diferentes medios sociales, para poder distinguir entre el impacto de lo social y de lo individual en este desarrollo. Vigotsky se da cuenta de que el lenguaje social emerge cuando el niño transfiere formas de comportamiento social a la esfera personal e interior de las funciones psíquicas. Por tanto descubre que el lenguaje antes de ser egocéntrico, es meramente social y posteriormente se "interioriza" como lo indica Piaget. De esta forma Vigotsky confirma y complementa estos estudios realizados por Piaget.

3- El desarrollo del lenguaje

Vigotsky reconoce los experimentos de Stern, quien considera tres tendencias como raíces del lenguaje: la expresiva, la social y la intencional. Las primeras dosel hombre las comparte con los animales y la última es solo humana. En estos experimentos Stern indica que el "factor lógico" es la clave del desarrollo, inclusive en la adquisición de la habilidad del hombre de darse a entender. Sin embargo mientras que Stern considera que el niño descubre el significado del lenguaje una vez y para siempre, Vigotsky considera que se realiza a través de un proceso de historia natural y de historia cultural. 


\section{1- Raíces genéticas del pensamiento y del lenguaje}

Koehler en sus investigaciones con chimpancés descubre que el pensamiento y el habla se desarrollan en diferentes líneas; y que aunque estos animales tienen un lenguaje, este es diferente del humano, porque esencialmente no es objetivo y porque su fonética se basa en sus deseos y estados subjetivos, lo que lo constituye en un mero lenguaje emocional; esto confirma a Vigotsky que los animales tienen expresiones afectivas y emociones sociales. Wundt a su vez en sus experimentos con animales pudo darse cuenta de que los chimpancés nunca representan algo en sus dibujos y no tienen significado en lo que hacen. Pudo percatarse de que el éxito en las acciones de los animales depende de cómo puedan ver todos los elementos de una situación de forma simultánea; siendo que sus limitaciones ("inhabilidades") básicas radican en la carencia de imaginación ("ideación”) y en la falta de imitación de sonidos. Con base a estos experimentos, Vigotsky se da cuenta de que el habla no depende necesariamente del sonido; como sucede en los lenguajes de sordomudos o en la lectura de los labios. Los experimentos de von Frish con abejas, permiten descubrir funciones de intercambio "comunicativo", pero que no son intelectuales.

Posteriormente Koehler y Buhler al hacer estudios con niños de forma similar al experimento con los chimpancés, descubren el mismo principio: que antes del lenguaje aparece la acción de una forma intencional; de donde Vigotsky lo trasfiere a reconocer quelas risas, sonidos y movimientos en los primeros meses de vida del niño son meros medios de contacto social de esta "forma intencional". Vigotsky de forma experimental reconoce que el desarrollo tanto del pensamiento como del lenguaje se da en el niño a partir de los dos años, además de queel lenguaje no puede ser descubierto sin el pensamiento. También se da cuenta de que el lenguaje en el desarrollo del niño se "interioriza" de forma psicológica, porque cambia de función, estableciendo de esta manera que la propuesta de Piaget es correcta en cuanto al lenguaje egocéntrico; pero que definitivamente este no desaparece como Piaget lo pensara, sino que se transforma "interiorizándose". Con toda esta información, Vigotsky se da cuenta de que en la interacción del lenguaje con el pensamiento surge el pensamiento verbal; aunque el pensamiento es eminentemente no verbal y el lenguaje es no intelectual. 


\section{2- El estudio experimental de la formación de conceptos}

En esta aspecto, antes de Vigotsky, solo se efectuaban dos tipos de estudios: el descriptivo (aislando el contenido de los conceptos) y el formativo (proceso psíquico). La alternativa propuesta por él, es la de investigar las "condiciones funcionales" de la formación de los conceptos. Experimentos de Ach y de Rimat indican que las asociaciones entre símbolos verbales y objetos no son suficientes para formar conceptos; además de que la formación de conceptos aparece hasta la etapa de la pubertad en el ser humano. Se dan cuenta de que los conceptos surgen de una formación creativa/activa en la solución de problemas, mediante lo que dan en llamar "una tendencia determinante", y no en forma de eslabones sino por objetivos. Se descarta que los conceptos se den por la memorización, dado que es un proceso mecánico y pasivo. Vigotsky interviene con su nuevo método experimental, el de "doble estimulación", en donde se presentan al sujeto dos tipos de estímulos: los primeros como objetos de actividad y los segundos como signos para organizar la actividad, de donde obtiene mucha información experimental nueva y relevante.

En una primera fase el niño agrupa y organiza objetos de forma visual e incoherente ("sincréticamente"), en una segunda fase tiende a agruparlos con vínculos concretos ("pensamiento en complejos") asociando , contrastando y no jerarquizando ; para finalmente llegar al "pseudo-concepto" que es el puente o eslabón con el concepto, cuando finalmente el niño agrupa mediante atributos de una forma abstracta. En estos experimentos Vigotsky se da cuenta de que el niño es capaz de desarrollar significados de las palabras y de formar "complejos" de acuerdo a sus preferencias, estableciendo así este pensamiento en "complejos" como la base del desarrollo lingüístico. Este proceso explica de una forma clara porqué las palabras del niño y del adulto, coinciden en cuanto a referente pero difieren en cuanto a significado. Para el niño, los nombres nunca son conceptos al inicio; la palabra primaria es una imagen basada en enlaces de complejos; por ejemplo: "pata" de mesa, "cuello" de botella, etc. Cuando puede agrupar por conceptos ha llegado al nivel de abstracción, en donde puede aplicarlos y generalizarlos e inclusive sintetizarlos. Es por eso que solo mediante el dominio de la abstracción y del uso del pensamiento complejo avanzado se llega a la formación de conceptos genuinos, según Vigotsky. 


\section{3-3. El desarrollo de conceptos científicos en la infancia}

Piaget en sus investigaciones, reconoce dos tipos de ideas en el niño: aquellas de desarrollo propio (“espontáneas") y aquellas influidas por los adultos ("no espontáneas"); en donde la instrucción es la fuente principal de los conceptos infantiles y la fuerza que da la dirección en el desarrollo mental. Además en esta etapa, la mente enfrenta dos tipos de problemas diferentes: los conceptos de la escuela y los conceptos voluntarios o propios. Es hasta la pubertad (7 a 12 años)cuando las funciones intelectuales superiores(conocimiento reflexivo y control deliberado) pasan a un primer plano en el proceso del desarrollo, siendo variables importantes en el proceso de formación de conceptos. Antes de esta etapa, el niño no tiene consciencia de sus operaciones conceptuales. Vigotsky complementa sus experimentos descubriendo que los conceptos científicos, junto con su jerarquía sistemática, operan en la primera etapa del conocimiento y del desarrollo de destrezas; siendo que más tarde se transfieren a otros conceptos y áreas. Vigotsky está convencido de que la consciencia reflexiva en el niño llega a darse mediante el contacto con los conceptos científicos. De esta forma los conceptos que inicialmente son espontáneos, no conscientes y asistemáticos se transforman en voluntarios, conscientes y sistemáticos. Según los estudios de Vigotsky y sus asociados en cuanto al desarrollo defunciones psicológicas, a través de su experimentación con base a la exposición de los niños a las diferentes materias escolares, se puede concluir que: la instrucción precede al desarrollo y las diferentes materias definitivamente influyen en mayor o menor grado en el desarrollo de las funciones psíquicas superiores, motivando de esta forma la aparición de los primeros conceptos "generalizados" en las operaciones intelectuales.

\section{4- Pensamiento y palabra}

Por tanto Vigotsky con sus experimentos y con el aprovechamiento de otros efectuados en su época, logra amplias conclusiones de la relación entre el pensamiento y la palabra. Confirma que en los animales no hay una relación entre la palabra y el pensamiento; mientras que el niño puede conectar ambos y desarrollarlos. Encontrando que, psicológicamente el signific ado de las palabras, se refiere a generalizaciones provenientes del pensamiento. Vigotsky demuestra que el desarrollo del pensamiento verbal se posibilita mediante el uso del significado de la palabra como unidad analítica y que el significado de la palabra está sujeto a un proceso evolutivo. Este 
pensamiento verbal va más allá de la generalización básica, hasta llegar a los conceptos más abstractos: cambiando el contenido de las palabras y el modo de generalizar durante el proceso. Vigotsky confirma que la "teoría de la asociación" (entre símbolos verbales y objetos) es inadecuada para explicar el significado de los vocablos en la infancia, además de que el pensamiento y el lenguaje cambian estrechamente ligados en función de nuestra etapa de desarrollo y de acuerdo a la forma de funcionar del pensamiento. Por tanto, la relación entre pensamiento y palabra no es un hecho, sino un proceso en que los cambios son su desarrollo en el sentido funcional.

Se da cuenta Vigotsky de que existen diversos planos del lenguaje: uno interno (significativo, semántico) y otro externo (vocal, fonético) que aunque coexisten unidos, se desarrollan de forma independiente; de tal forma que la estructura del lenguaje no refleja la del pensamiento. Estos planos, semántico y fonético, se separan a medida que el niño crece y aumentan su distancia posteriormente. Es por eso, según Vigotsky, que la capacidad del niño para comunicarse por medio del lenguaje, está en función de la diferenciación de significados y de la consciencia, entendida esta última como la actividad misma de la mente. Para poder conocer la relación entre el pensamiento y la palabra, indica Vigotsky, debemos conocer la naturaleza psicológica del "lenguaje interior", el cuales: el habla para uno mismo no vocalizada y el habla transformada en pensamiento. De esta forma una frase puede expresar diferentes pensamientos o un pensamiento puede ser expresado a través de diferentes oraciones. Una aplicación clara de lo complejo que es el pensamiento y su relación con el lenguaje, se da cuando tratamos de expresar un pensamiento:

El pensamiento ya está, pero el lenguaje para expresarlo debe ser desarrollado en forma sucesiva.; porque la transmisión directa del pensamiento con palabras es prácticamente imposible. Es por todo esto que Vigotsky categóricamente afirma, que "la relación entre el pensamiento y la palabra es un proceso viviente", en donde tanto el pensamiento como el lenguaje reflejan la realidad con una distinta forma de percepción y son clave en la naturaleza de la consciencia humana. También expresa Vigotsky que "una palabra es un microcosmos de consciencia humana". 
El niño no se expresa por escrito porque es más hábil para la actividad espontánea y no consciente, además de que carece de destreza en actividades abstractas y deliberadas. Estos cambios de percepción son todo un reto y logro, pues me considero una persona más bien analítica y escéptica. Sin embargo todos los experimentos de Vigotsky y de los colegas de áreas afines en su tiempo, son contundentes y traen conclusiones por si mismos. Sin duda, Vigotsky fue un genio de su tiempo y una prueba viviente de cómo a 75 años de su muerte, siguen vigentes muchos de sus estudios y conclusiones; y aún más, apenas se están "redescubriendo" sus implicaciones en la ciencia moderna y sus diversos campos de aplicación. Vigotsky es claramente controversial con las dos posturas tradicionales que establecían que: el pensamiento genera el lenguaje, o bien, que el lenguaje genera al pensamiento; postulando él de esta forma una teoría "dual y unificadora" de ambos conceptos y de sus implicaciones. Lo que le faltó fue tiempo de vida, por un lado, para continuar sus estudios y por otro lado, para desarrollar su “esbozada" teoría de la consciencia que apenas y menciona ensu obra.

\subsubsection{Teoría socio-histórica de Lev Vigotsky}

\subsection{El origen de los Procesos Psicológicos Superiores}

Los PPS se originan en la vida social, es decir, en la participación de sujeto en las actividades compartidas con otros. La TSH propone analizar el desarrollo de los procesos psicológicos superiores a partir de la internalización de prácticas sociales específicas.

El proceso es en verdad mucho más complejo toda vez que el desarrollo parece involucrar cambios en la estructura y función de los procesos que se transforman.

Principales características de los Procesos Psicológicos Superiores (PPS):

- Están constituidos en la vida social y son específicos de los seres humanos

- Regulan la acción en función de un control voluntario, superando su dependencia y control por parte del entorno

- Están regulados conscientemente o la necesitaron en algún momento de su constitución (pueden haberse automatizado)

- Utilizaron durante su organización, formas de mediación, particularmente, mediación semiótica. 


\subsection{Dominios genéticos y líneas de desarrollo}

La evolución de los Procesos Psicológicos Elementales no porta en sí misma ningún rumbo que los lleve a una transformación en PPS (si así fuera no habría necesidad de postular una segunda línea de desarrollo). La introducción de una línea de desarrollo cultural obedece al hecho de que lo social intervendrá como un factor inherente a la constitución de los PPS.

\subsection{Los procesos de interiorización}

La constitución de los PPS requiere la existencia de mecanismos y procesos psicológicos que permitan el dominio progresivo de los instrumentos culturales y la regulación del propio comportamiento.

Ley de doble formación: En el desarrollo cultural del niño, toda función aparece dos veces, primero a nivel social (interpsicológica) y luego a nivel individual (intrapsicológica). Esto puede aplicarse igualmente a la atención voluntaria, a la memoria lógica y a la formación de conceptos. Todas las funciones psicológicas se originan como relaciones entre seres humanos.

El lenguaje es el ejemplo paradigmático puesto que cumple el doble papel de ejemplificar los PPS y es el instrumento central de mediación para la interiorización de los PPS.

Principales características del proceso de interiorización:

- No es un proceso de copia de la realidad en un plano interno

- La realidad externa es de naturaleza social-transacional

- El mecanismo específico de funcionamiento es el dominio de las formas semióticas externas

- El plano interno de conciencia resulta de naturaleza casi social.

\subsection{El dominio de los instrumentos de mediación: La mediación semiótica y el dominio de sí}

Vigotsky otorgaba el valor de "herramientas psicológicas" por analogía con las herramientas físicas a los sistemas de signos, particularmente el lenguaje. Mientras las herramientas físicas, a los sistemas de signos, particularmente el lenguaje. 
Mientras las herramientas físicas se orientan esencialmente a la acción sobre el mundo externo, colaborando en la transformación de la naturaleza o el mundo físico, los instrumentos semióticos parecen estar principalmente orientados hacia el mundo social, hacia los otros.

- El lenguaje puede cumplir funciones diferentes, en principio una función comunicativa y, luego, otra referida a la regulación del propio comportamiento.

- El lenguaje sirve como instrumento para producir efectos sobre el entorno social

- El lenguaje puede a su vez plegarse sobre el propio sujeto y también de acuerdo con su secundaridad sobre sí mismo

- Esta implicado centralmente en la reorganización de la propia actividad psicológica Aprendizaje y desarrollo en la TSH

Para Vigotsky, la analogía básica entre signo y herramienta, descansa en la función mediadora que caracteriza a ambas. Desde la perspectiva psicológica, pueden ser incluídas dentro de la misma categoría.

En el plano lógico de la relación entre ambos conceptos, este enfoque representa los dos medios de adaptación como líneas divergentes de actividad mediata.

Una diferencia central entre signo y herramienta es la que puede observase en el modo en que orientan la actividad humana.

Mientras que la herramienta tiene la función de servir de conductor de la influencia humana en el objeto de la actividad, ésta se halla externamente orientada y debe acarrear cambios en los objetos, el signo no cambia nada en el objeto de una operación psicológica. Se trata pues de un medio de actividad interna que aspira a dominarse a sí mismo; el signo está internamente orientado.

Pero el dominio de la naturaleza y el de la conducta están sumamente relacionados (de ahí el lazo real de desarrollo filogenético y ontogenético) La alteración de la naturaleza por parte del hombre altera a su vez, la propia naturaleza del hombre.

Así como la primera utilización de las herramientas rechaza la noción de que el desarrollo representa un simple despliegue del sistema de actividad orgánicamente predeterminado, la 
primera utilización de los signos manifiesta que no puede haber un único sistema de actividad interno determinado orgánicamente para cada función psicológica. El uso de medios artificiales cambia fundamentalmente todas las funciones, al tiempo que el uso de herramientas ensancha de modo ilimitado la serie de actividades dentro de la que operan las nuevas funciones psicológicas. $\mathrm{Y}$ es en este sentido que podemos hablar de función psicológica superior o conducta superior, al referirnos a la combinación de herramienta y signo en la actividad psicológica.

\subsection{Internalización}

Vigotsky llama internalización a la reconstrucción interna de una operación externa. Esto proceso de internalización supone una serie de transformaciones a saber:

1. Una operación inicialmente representa una actividad externa se reconstruye y comienza a suceder internamente.

2. Un proceso interpersonal queda transformado en otro intrapersonal. En el desarrollo cultural del niño toda función aparece dos veces: la primera a nivel social (interpsicológica) y luego en el interior del propio niño (intrapsicológica)

3. La transformación de un proceso interpersonal en un proceso intrapersonal es el resultado de una prolongada serie de sucesos evolutivos. El proceso, aún siendo transformado, continúa existiendo y cambia como una forma externa de actividad durante cierto tiempo antes de internalizarse definitivamente.

La internalización de las formas culturales de conducta implica la reconstrucción de la actividad psicológica en base a las operaciones con signos. Los procesos psicológicos, tal como aparecen en los animales, dejan de existir, se incorporan al sistema de conducta y se desarrollan y reconstruyen culturalmente para formar una nueva entidad psicológica.

Interacción entre aprendizaje y desarrollo

Vigotsky sistematiza en tres, las posiciones teóricas respecto al aprendizaje y el desarrollo. Estas son:

1. Cuando los procesos de desarrollo del niño son independientes del aprendizaje: El aprendizaje se considera como un proceso puramente externo que no está complicado de 
modo activo en el desarrollo. Simplemente utiliza los logros del desarrollo en lugar de proporcionar un incentivo para modificar el curso del mismo.

El desarrollo o maduración se considera como una condición previa del aprendizaje pero nunca como el resultado del mismo.

2. Cuando el aprendizaje es desarrollo: Teorías como las basadas en el concepto del reflejo, esto es una reducción del proceso de aprendizaje a la formación de hábitos, identificándolos con el desarrollo.

3. Cuando el desarrollo se basa en dos procesos distintos pero relacionados entre sí: Por un lado está la maduración, que depende directamente del desarrollo del sistema nervioso y por otro lado el aprendizaje, que a su vez, es también un proceso evolutivo.

El proceso de aprendizaje estimula y hace avanzar el proceso de maduración. El punto nuevo y más notable de esta teoría, según la perspectiva de Vigotsky es que se le atribuye un extenso papel al aprendizaje dentro del desarrollo del niño.

\subsection{Filogénesis, Historia socio cultural, Ontogénesis y Microgénesis}

Vigotsky es considerado un psicólogo genético en la medida que puede ser ubicado en una perspectiva descriptiva (genotípica) o no mera mente descriptiva (fenotípica).

El argumento central de análisis genético de Vigotsky es que los procesos psicológicos humanos solamente pueden comprenderse a través de la consideración de la forma y el momento de su intervención en el curso del desarrollo. Así es que, contrastó su enfoque genético con otros que intentaban analizar los fenómenos psicológicos sin considerar su lugar en el desarrollo.

2.1.1.3.6.1 Filogénesis. Vigotsky consideró el uso de herramientas como condición necesaria aunque no suficiente para el uso de las funciones psicológicas superiores específicamente humanas lo que le permitía reconocer la estrecha proximidad filogenética entre los simios y los humanos al mismo tiempo insistía en el cualitativo abismo que los separa.

Desde su perspectiva, el problema de lo animal vs. lo humano, no podía resolverse desde la teoría de la evolución, ya que ésta es solamente un requisito previo para la construcción científica de la psicología humana, por lo tanto proponía otro enfoque. 
Mirar hacia las formas de mediación y sus cambios asociados en la vida social y psicológica. Argumentaba que el empleo de herramientas psicológicas, proporcionó las bases para el trabajo socialmente organizado. En esta línea, resulta interesante recordar que mientras que para el marxismo el surgimiento del trabajo y la producción organizadas socialmente son la clave para distinguir entre el ser humano y el animal, para Vigotsky otorgaba la misma importancia será dada a la aparición del habla.

2.1.1.3.6.2Teoría del punto crítico. Vigotsky sostuvo que la evolución orgánica se desarrolla de manera tal que llega un momento en que surge la cultura. Geertz ha cuestionado este razonamiento sugiriendo que en lugar de suponer que la evolución orgánica y el proceso sociocultural son procesos aislados y éste último solamente tiene lugar después de que el primero se haya completado, resulta esencial considerar la forma en que la evolución orgánica puede haber sido influida por las primeras formas culturales.

2.1.1.3.6.3Historia sociocultural. Vigotsky consideraba las funciones psicológicas superiores avanzadas y rudimentarias en términos de una progresión genética.

Dentro de una concepción histórica de los signos como mecanismos mnemotécnicos y medios de cálculo, concibió algo semejante a un principio de descontextualización de los instrumentos de mediación. Este principio reemplazaría, una vez aparecida la cultura, al principio darwiniano de la evolución. La descontextualización de los procesos de mediación es el proceso mediante el cual el significado de los signos se vuelve cada vez menos dependiente del contexto espacio-temporal en el que son utilizados.

Por ejemplo, en el cálculo, la descontextualización se halla ligada a la aparición de un sistema numérico en el que una cantidad puede ser representada independientemente en cualquier contexto perceptivo. De hecho, la cantidad puede convertirse en un objeto abstracto en sí mismo.

2.1.1.3.6.4Ontogénesis. Al contrario que en la filogénesis, donde se pude estudiar la operación de un conjunto determinado de principios explicativos al margen de otros implicados en otros dominios genéticos, la ontogénesis implica necesariamente la operación simultánea de 
más de una fuerza del desarrollo. En este sentido, Vigotsky diferenciaba una línea "natural" y otra "cultural" del desarrollo.

La distinción Vigotskiana entre línea de desarrollo cultura y natural, se halla estrechamente vinculada a la distinción entre funciones psicológicas elementales y la línea cultura a las funciones psicológicas superiores. Mientras que las primeras se refieren a la línea natural, las segundas se vinculan a la cultura.

Entre las críticas que se realizan a esta dimensión del enfoque de Vigotsky, se encuentra el tratamiento superficial que realiza respecto al desarrollo natural:

a. La noción misma de "natural" no está expuesta claramente en su obra

b. El énfasis excesivo en el desarrollo social da lugar a un sistema explicativo en el que en realidad, los principios referentes al desarrollo natural no desempeñan ningún papel.

2.1.1.3.6.5Microgénesis. El primer tipo de microgénesis identificado por Vigotsky hace referencia a la formación a corto plazo de un proceso psicológico determinado.

El segundo tipo, consiste en el descubrimiento de un acto individual perceptivo o conceptual a menudo de una duración de milisegundos. Sus expresiones en este sentido tuvieron influencia de neurolingüístas soviéticos como Luria.

\subsubsection{El cambio cognitivo}

La zona de construcción del conocimiento: trabajando por un cambio cognitivo en educación

El cambio cognitivo caracteriza un proceso que supone una interacción dialéctica entre el mundo social y el cambio individual. En el proceso que denominamos cambio cognitivo, incluimos las nociones de reestructuración, invención y direccionalidad que implica el desarrollo, sin que le demos el carácter exclusivamente individual, interno que suele acompañar a las consideraciones evolutivas.

\subsubsection{Carácter histórico y cultural de la dirección y meta en el cambio cognitivo}

La utilización del sistema funcional como unidad de análisis para el estudio del cambio cognitivo incluye sobre la dirección que observamos adopta dicho cambio. Como consecuencia 
de las interacciones que se producen en la ZDP, es probable que modifique la organización de las funciones psicológicas que penetra en el niño.

Colocar el origen del cambio cognitivo en el mundo social no supone que el niño adquiera simplemente una copia del saber cultural mediante un proceso de transmisión directa. De un modo semejante a la teoría de Piaget, Vigotsky hacía hincapié en poner los orígenes del conocimiento en las interacciones sociales en las que participa el niño.

\subsubsection{Andamiaje e interacción semiótica}

Existe una necesaria tensión constitutivas de la practicas andamiadas en las que el aprendiz se involucrará en actividades o tareas que quedan por encima de su competencia individual pero en las que podrá no obstante desempeñarse gracias al suporte o andamiaje suministrado por el sujeto más experto.

La transferencia de habilidades o de posibilidades de desempeño autónomo, no se produce desde un individuo experto a uno novato, sino que, en sentido estricto, se transfieren de una diada en funcionamiento al desempeño individual del novato. Se destaca el aspecto intersubjetivo del funcionamiento interior de una practica andamiada con su propia legalidad.

\subsubsection{Andamiaje, actividad y control}

La práctica andamiada presume una asimetría constitutiva definida en principio por la desigual competencia sobre un dominio particular de los sujetos que entran en interacción.

Tal asimetría parece implicar un lugar heterónomo dependiente, del sujeto de menor competencia. Esto se enfatiza en la medida en que la asimetría entre los sujetos no descansa solo en la existencia de competencias desiguales sino que en su acceso diverso a los recortes que permiten regular actividades, definir entre otras cosas, el objetivo de tareas, los pasos a seguir de resolución, los criterios para evaluar, la calidad de los logros.

Cabe distinguir:

a. El nivel de las prácticas pedagógicas en general con sus dispositivos instituidos, como puede ser el caso de las prácticas de escolarización. 
b. El nivel estrechamente relacionado, conformado por las interrelaciones cara a cara y sus propios mecanismos de regulación, como podrían ser las dinámicas del salón de clase.

De esta forma, algunas de las características descriptas en las situaciones de andamiaje, forman parte de la lógica del propio espacio escolar. Por ejemplo, la existencia de espacios relativamente protegidos para el ejercicio donde se producen los costos del error, se acotan los grados de libertad y se reduce la complejidad de contexto. Pueden atribuirse indistintamente a las situaciones escolares o a la práctica del andamiaje.

\subsection{CONSTRUCTIVISMO}

El constructivismo es una posición compartida por diferentes tendencias de la investigación psicológica y educativa. Entre ellas se encuentran las teorías de Jean Piaget (1952), Lev Vigotsky (1978), David Ausubel (1963), Jerome Bruner (1960), y aun cuando ninguno de ellos se denominó como constructivista sus ideas y propuestas claramente ilustran las ideas de esta corriente.

El Constructivismo, dice Méndez (2002) “es en primer lugar una epistemología, es decir una teoría que intenta explicar cuál es la naturaleza del conocimiento humano". El constructivismo asume que nada viene de nada. Es decir que conocimiento previo da nacimiento a conocimiento nuevo.

El constructivismo sostiene que el aprendizaje es esencialmente activo. Una persona que aprende algo nuevo, lo incorpora a sus experiencias previas y a sus propias estructuras mentales. Cada nueva información es asimilada y depositada en una red de conocimientos y experiencias que existen previamente en el sujeto, como resultado podemos decir que el aprendizaje no es ni pasivo ni objetivo, por el contrario es un proceso subjetivo que cada persona va modificando constantemente a la luz de sus experiencias. 


\subsection{SUPUESTOS DE LA TEORÍA DE LEV VIGOTSKY}

\section{Los tres principales supuestos de Lev Vigotsky son:}

* Construyendo significados

* La comunidad tiene un rol central

* El pueblo alrededor del estudiante afecta grandemente la forma que él o ella "ve" el mundo

* Instrumentos para el desarrollo cognoscitivo

* El tipo y calidad de estos instrumentos determina el patrón y la tasa de desarrollo

* Los instrumentos deben incluir: adultos importantes para el estudiante, la cultura y el lenguaje.

* La Zona de Desarrollo Próximo.

De acuerdo a la teoría del desarrollo de Vigostky, las capacidades de solución de problemas pueden ser de tres tipos:

Aquellas realizadas independientemente por el estudiante

Aquellas que no puede realizar aún con ayuda

Aquellas que caen entre estos dos extremos, las que puede realizar con la ayuda de otros.

Para Lev Vigotsky son, pues, Instrumentos psicológicos: todos aquellos objetos cuyo uso sirve para ordenar y reposicionar externamente la información de modo que el sujeto pueda escapar de la dictadura del aquí y ahora y utilizar su inteligencia, memoria o atención en lo que se podría llamar una situación de situaciones, una representación cultural de los estímulos que se pueden operar cuando se quiere tener éstos en nuestra mente y no sólo y cuando la vida real nos los ofrece. Son para Lev Vigotsky instrumentos psicológicos el nudo en el pañuelo, la moneda, una regla, una agenda o un semáforo y, por encima de todo, los sistemas de signos: el conjunto de estímulos fonéticos, gráficos, táctiles, etc., que se construyen como un gran sistema de mediación instrumental: el lenguaje.

El estado del desarrollo mental de un niño puede determinarse únicamente sí se lleva a cabo una clasificación de sus dos niveles: del nivel real del desarrollo y de la zona de desarrollo potencial. 
Se puede ver, que estos conceptos suponen una visión completamente renovadora de muchos supuestos de la investigación psicológica y de la enseñanza, al menos tal y como se los ha entendido durante mucho tiempo, puesto que parten de la idea de que lo que un individuo puede aprender no sólo depende de su actividad individual. Por tanto, como podría esperarse, la

Concepción Vigotskyana sobre las relaciones entre desarrollo cognitivo y aprendizaje difiere en buena medida de la Piagetiana. Mientras que Jean Piaget sostiene que lo que un niño puede aprender depende de su nivel de desarrollo cognitivo, Lev Vigotsky piensa que es este último está condicionado por el aprendizaje social. Así, mantiene una concepción que muestra la influencia permanente del aprendizaje en la manera en que se produce el desarrollo cognitivo.

Por tanto, un alumno que tenga más oportunidades de aprender que otro, no sólo adquirirá más información, sino que logrará un mejor desarrollo cognitivo. Algunos autores han considerado que las diferencias entre Piaget y Viygotsky son más bien de matiz, argumentando que en la obra de estos autores los términos «desarrollo cognitivo» y «aprendizaje» poseen, en realidad, connotaciones muy diferentes. En palabras del autor Carretero (1997): “Mi opinión, si bien no son posiciones tan divergentes como algunos autores han querido ver, sí implican maneras muy distintas de concebir al alumno y a lo que sucede en el aula de clase. En este sentido, resulta bastante claro que Lev Vigotsky pone un énfasis mucho mayor en los procesos vinculados al aprendizaje en general y al aprendizaje escolar en particular.. pp. 39-71.

Otro aspecto de discrepancia entre estas posiciones ha versado sobre la influencia del lenguaje en el desarrollo cognitivo en general y más concretamente en relación con el pensamiento. Quizá esta controversia puede verse con claridad en el caso del lenguaje egocéntrico. Para Piaget, el lenguaje característico de la etapa preoperatoria, entre los dos y los siete años, no contribuye apenas al desarrollo cognitivo. Más bien muestra justamente la incapacidad del niño de esta edad para comprender el punto de vista del otro. Vigotsky, por el contrario, fue capaz de ver que dicho lenguaje realizaba unas contribuciones importantes al desarrollo cognitivo del niño.

En primer lugar, porque era un paso para que se produjera el lenguaje interiorizado, que resultará esencial en etapas posteriores, y en segundo lugar, porque dicho lenguaje posee posibilidades comunicativas mucho mayores de lo que Jean Piaget había postulado. En cierta 
medida, esta visión Vigotskiana de la función del lenguaje egocéntrico se encuentra relacionada con la importancia de los procesos de aprendizaje en la medida en que es un instrumento que cumple una clara función en la mejora del desarrollo cognitivo del alumno desde los primeros años.

La contribución de Lev Vigotsky ha significado para las posiciones constructivistas que el aprendizaje no sea considerado como una actividad individual, sino más bien social.

Además, en la última década se han desarrollado numerosas investigaciones que muestran la importancia de la interacción social para el aprendizaje. Es decir, se ha comprobado como el alumno aprende de forma más eficaz cuando lo hace en un contexto de colaboración e intercambio con sus compañeros. Igualmente, se han precisado algunos de los mecanismos de carácter social que estimulan y favorecen el aprendizaje, como son las discusiones en grupo y el poder de la argumentación en la discrepancia entre alumnos que poseen distintos grados de conocimiento sobre un tema.

\subsection{PRINCIPIOS VIGOTSKIANOS}

\subsubsection{Los principales principios Vigotskianos en el aula}

* El aprendizaje y el desarrollo son una actividad social y colaborativa que no puede ser "enseñada" a nadie. Depende del estudiante construir su propia comprensión en su propia mente.

* La Zona de Desarrollo Próximo puede ser usada para diseñar situaciones apropiadas durante las cuales el estudiante podrá ser provisto del apoyo apropiado para el aprendizaje óptimo.

* El docente debe tomar en consideración que el aprendizaje tiene lugar en contextos significativos, preferiblemente el contexto en el cual el conocimiento va a ser aplicado.

\subsubsection{Funciones Mentales}

Como lo menciona Lev Vigotsky establece que hay dos tipos de funciones mentales: las inferiores y las superiores. 
* Las funciones mentales inferiores: Las funciones mentales inferiores son aquellas con las que nacemos, son las funciones naturales y están determinadas genéticamente. El comportamiento derivado de las funciones mentales inferiores es limitado; está condicionado por lo que podemos hacer. Estas funciones nos limitan en nuestro comportamiento a una reacción o respuesta al ambiente.

* Las funciones mentales superiores: Las funciones mentales superiores se adquieren y se desarrollan a través de la interacción social. Puesto que el individuo se encuentra en una sociedad específica con una cultura concreta. Las funciones mentales superiores están determinadas por la forma de ser de esa sociedad: Las funciones mentales superiores son mediadas culturalmente.

Para Lev Vigotsky, a mayor interacción social, mayor conocimiento, más posibilidades de actuar, más robustas funciones mentales.

La atención, la memoria, la formulación de conceptos son primero un fenómeno social y después, progresivamente, se transforman en una propiedad del individuo. Cada función mental superior, primero es social (interpsicológicas) y después es individual, personal (intrapsicológicas).

Interiorización: es la distinción entre las habilidades o el paso de habilidades interpsicológicas a intrapsicológicas (Frawley, 1997).

El desarrollo del individuo llega a su plenitud en la medida en que se apropia, hace suyo, interioriza las habilidades interpsicológicas. En un primer momento, dependen de los otros; en un segundo momento, a través de la interiorización, el individuo adquiere la posibilidad de actuar por si mismo y de asumir la responsabilidad de su actuar.

\subsubsection{Mediación}

Lev Vigotsky considera que el desarrollo humano es un proceso de desarrollo cultural, siendo la actividad del hombre el motor del proceso de desarrollo humano. El concepto de actividad adquiere de este modo un papel especialmente relevante en su teoría. Para él, el proceso de formación de las funciones psicológicas superiores se dará a través de la actividad 
práctica e instrumental, pero no individual, sino en la interacción o cooperación social. La instrumentalización del pensamiento superior mediante signos, específicamente los verbales, clarifica la relación entre el lenguaje y el pensamiento (Frawley, 1997).

"El pensamiento y la palabra no están cortados por el mismo patrón. En cierto sentido existen más diferencias que semejanzas entre ellos". (Vigotsky, 1962 p. 126). El habla es un lenguaje para el pensamiento, no un lenguaje del pensamiento.

Lev Vigotsky propone que el sujeto humano actúa sobre la realidad para adaptarse a ella transformándola y transformándose a sí mismo a través de unos instrumentos psicológicos que los denomina "mediadores". Este fenómeno, denominado mediación instrumental, es llevado a cabo a través de "herramientas" (mediadores simples, como los recursos materiales) y de "signos" (mediadores más sofisticados, siendo el lenguaje el signo principal). También establece que la actividad: es un conjunto de acciones culturalmente determinadas y contextualizadas que se lleva a cabo en cooperación con otros y la actividad del sujeto en desarrollo es una actividad mediada socialmente.

La actividad que propone Lev Vigotsky, es una actividad culturalmente determinada y contextualizada, en el propio medio humano, los mediadores que se emplean en la relación con los objetos, tanto las herramientas como los signos, pero especialmente estos últimos, puesto que el mundo social es esencialmente un mundo formado por procesos simbólicos, entre los que destaca el lenguaje hablado. El lenguaje es la herramienta que posibilita el cobrar conciencia de uno mismo y el ejercitar el control voluntario de nuestras acciones. Ya no imitamos simplemente la conducta de lo demás, ya no reaccionamos simplemente al ambiente, con el lenguaje ya tenemos la posibilidad de afirmar o negar, lo cual indica que el individuo tiene conciencia de lo que es, y que actúa con voluntad propia. En ese momento empezamos a ser distintos y diferentes de los objetos y de los demás.

\subsubsection{El proceso de mediación: las tecnologías del pensamiento y la comunicación social}

La mediación instrumental: se ha referido ya al concepto psicológico con el que Lev Vigotsky caracterizaba la actividad humana, continuando y extendiendo así la observación hecha por Marx 
de que la actividad de nuestra especie se distingue por el uso de instrumentos con los que cambia la naturaleza. Pero a Vigotsky le preocupan más bien los cambios que el hombre provoca en su propia mente y se fija en aquellos apoyos externos que le permiten mediar un estímulo, esto es, representarlo en otro lugar o en otras condiciones.

Vigotsky concentrará así su esfuerzo en el lenguaje como medio para desarrollar más rápidamente su modelo de mediación aunque en ningún momento dejará de interesarse por los otros medios o tecnologías del intelecto, actualmente investigados por autores que se ocupan de estos nuevos instrumentos psicológicos de representación, como los audiovisuales o el ordenador.

En esta perspectiva, para Lev Vigotsky las tecnologías de la comunicación son los útiles con los que el hombre construye realmente la representación externa que más tarde se incorporará mentalmente, se interiorizará. De este modo, el sistema de pensamiento sería fruto de la interiorización de procesos de mediación desarrollados por y en la cultura.

Pese a la escasez de investigaciones, el tema es de importancia central para la educación, puesto que es a través de ella cómo el niño puede incorporar de una manera más controlada y experta los procesos de representación, cuya identidad y cuyo papel difícilmente pueden establecerse, sino desde esa perspectiva. De hecho, la educación ha abierto una línea de producción de instrumentos psicológicos de finalidad estrictamente educativa, es decir, concebidos implícitamente como mediadores representacionales en la Zona de Desarrollo Próximo. Al decir esto se hace referencia a los llamados materiales didácticos y a los juguetes educativos. Y así mismo la educación ha adscrito, desde su implantación generalizada en el siglo XIX, un papel central a tres de las viejas o clásicas tecnologías de la representación: lectura, escritura, aritmética, papel central que la pedagogía anglosajona conoce bajo el acrónimo de las tres RRR: Reading, Writing, Arithmetics.

\subsubsection{La Mediación Social}

La mediación social instrumental converge en otro proceso de mediación que la hace posible y sin ella el hombre no habría desarrollado la representación externa con instrumentos. 
Lev Vigotsky distingue entre mediación instrumental y mediación social. Sería precisamente la mediación interpersonal, entre dos o más personas que cooperan en una actividad conjunta o colectiva, lo que construye el proceso de mediación que el sujeto pasa a emplear más tarde como actividad individual. Este proceso de mediación social es el que define el autor ruso en su ley de la doble formación de los procesos psicológicos.

Esta ley de la doble formación explica, extendiéndola a la mediación instrumental que se realiza articuladamente con lo social, tanto en el desarrollo de las funciones psicológicas superiores en la historia o en el devenir de un niño concreto o del niño en una cultura determinada. Lev Vigotsky analiza la actividad conjunta padre-hijo y la interacción entre ambos señalando que el adulto impone al niño el proceso de comunicación y representación aprovechando las acciones naturales de éste; de esa manera, convierte su movimiento para alcanzar un objeto inalcanzable o difícilmente alcanzable en un gesto para señalar, en la medida en que el niño advierte que siempre que hace tal movimiento el adulto le alcanza el objeto. Por eso, comenta Lev Vigotsky, el camino de la cosa al niño y de ésta a aquélla, pasa a través de otra persona, el camino a través de otra persona es la vía central del desarrollo de la inteligencia práctica.

Puede apreciarse indirectamente así la estrecha articulación entre ambos tipos de mediación, instrumental y social. Se puede decir sin riesgo de mal interpretar a Lev Vigotsky que esa frase se podría completar con su simétrica: el camino del niño a otra persona pasa a través del objeto. Efectivamente, el adulto utiliza los objetos reales para establecer una acción conjunta y, de este modo, una comunicación con el niño, de modo que la comunicación inicial del niño con el adulto se construirá con objetos reales o con imágenes y sonidos físicos claros, con entidades físicas que se asocian a las primeras, esto es a los instrumentos psicológicos.

Este proceso de mediación gestionado por el adulto u otras personas permite que el niño disfrute de una conciencia impropia, de una memoria, una atención, unas categorías, una inteligencia, prestadas por el adulto que suplementan y conforman paulatinamente su visión del mundo y construyen poco a poco su mente que será así, durante bastante tiempo, una mente social que funciona en el exterior y con apoyos instrumentales y sociales externos. Solo a medida de que esa mente externa y social va siendo dominada con maestría y se van construyendo 
correlatos mentales de los operadores externos, esas funciones superiores van interiorizándose y conformando la mente del niño.

Emplear conscientemente la mediación social implica dar educativamente importancia no solo al contenido sino también mediadores instrumentales esto es, qué es lo que se enseña y con qué, sino también a los agentes sociales esto es quién enseña en sus peculiaridades.

\subsubsection{El proceso de interiorización}

Lev Vigotsky niega que la actividad externa e interna del hombre sean idénticas, pero niega igualmente que estén desconectadas. La explicación a esto es que su conexión es genética o evolutiva: es decir, los procesos externos son transformados para crear procesos internos. Los procesos de interiorización no son la transferencia de una actividad externa a un plano de conciencia interno preexistente: es el proceso en el que se forma ese plano de conciencia.

Efectivamente, la sustitución del habla en voz alta por el habla interna supone cambios estructurales. De lo ya dicho se desprende con claridad que el proceso de interiorización se mejora y optimiza cuando los procesos de mediación están mas escalonados y permiten al niño una educación más precisa a su nivel de actividad posible. Esta graduación del proceso de interiorización de la zona de desarrollo próximo ha sido referido como la interiorización por etapas y en él se facilita el paso de la actividad externa a la mental gracias al escalonamiento de la proporción de interiorización, dosificación entre lo interno y lo externo, en los puntos de poyo de la mediación. Se define estos escalones en las tareas escolares haciendo hincapié en los cinco aspectos o etapas básicas siguientes:

1. Crear una concepción preliminar de la tarea.

2. Dominar la acción utilizando objetos

3. Dominar la acción en el plano del habla audible.

4. Transferir la acción al plano mental.

5. Consolidar la acción mental. 


\subsubsection{Concepción de aprendizaje}

Partiendo de las ideas constructivistas, el aprendizaje no es un sencillo asunto de transmisión y acumulación de conocimientos, sino "un proceso activo" por parte del alumno que ensambla, extiende, restaura e interpreta, y por lo tanto "construye" conocimientos partiendo de su experiencia e integrándola con la información que recibe.

\subsubsection{Concepción de docente}

En este proceso de aprendizaje constructivo, el profesor cede su protagonismo al alumno quien asume el papel fundamental en su propio proceso de formación. Es él mismo quien se convierte en el responsable de su propio aprendizaje, mediante su participación y la colaboración con sus compañeros. Para esto habrá de automatizar nuevas y útiles estructuras intelectuales que le llevarán a desempeñarse con suficiencia no sólo en su entorno social inmediato, sino en su futuro profesional. Es el propio alumno quien habrá de lograr la transferencia de lo teórico haciaámbitos prácticos, situados en contextos reales. Es éste el nuevo papel del alumno, un rol imprescindible para su propia formación, un protagonismo que es imposible ceder y que le habrá de proporcionar una infinidad de herramientas significativas que habrán de ponerse a prueba en el devenir de su propio y personal futuro.

\subsection{ALGUNAS IMPLICACIONES EDUCATIVAS}

\subsubsection{Algunos aspectos que facilitarán los procesos de aprendizaje en la escuela}

El aprendizaje escolar ha de ser congruente con el nivel de desarrollo del niño. En este aspecto el modelo de Vigotsky no se separa de Piaget, aunque hemos de reconocer que va más allá de él. El maestro debería ser capaz de determinar la "Zona del Desarrollo Próximo" en la que se encuentra el niño y formular en relación a ese nivel los objetivos que se propone lograr en el proceso de enseñanza-aprendizaje.

El aprendizaje se produce más fácilmente en situaciones colectivas que favorecen conductas de imitación.

La interacción con los pares, en el contexto de la escuela, facilita el aprendizaje, y ello por las siguientes razones: 
1. La necesidad de verificar el pensamiento surge en situaciones de discusión.

2. La capacidad del niño para controlar su propio comportamiento nace en situaciones de

3. discusión.

Importancia de los procesos de "Internalización". Lo que la persona aprende en situaciones colectivas debe ser internalizado. En este sentido cuando la persona es capaz de utilizar un lenguaje interno sus interacciones con el entorno social se enriquecen y se van haciendo cada más complejas.

\subsubsection{Posición Culturalista}

Cada proceso psicológico superior se construye dos veces primero en el mundo y luego en el individuo.

El cambio se promueve a partir del medio social (proceso interpersonal). Un proceso interpersonal se transforma en un proceso interpersonal. Cada función aparece dos veces en el desarrollo cultural del niño; primero en el nivel social y, después en el nivel individual. Primero entre individuos (ínter psicológica) y luego, dentro del niño (intrapsicológica).

El lenguaje tiene un origen cultural y precede al pensamiento. El lenguaje se hace pensando y el pensamiento se verbaliza. Significa esto que se construye primero el lenguaje en el exterior y luego se construye el pensamiento en el individuo.

Los significados provienen del medio social externo, pero deben ser asimilados o interiorizados, él medio esta compuesto de objetos y de personas que median en la interacción del niño con los objetos. Se incorpora de un modo claro y explícito la influencia del medio social.

El aprendizaje debe ser congruente con el nivel de desarrollo del niño, se toma como punto de partida el hecho fundamental e incontrovertible de que hay una relación entre determinado nivel de desarrollo y la capacidad potencial del aprendizaje.

Se concentró en establecer que las acciones son indisociables de los medios que se utilizan para realizarlas.

Propuso la reorganización de la psicología desde la tradicional filosófica del marxismo, para estructurar una teoría científica de la mente humana. Destaca en este sentido el papel del trabajo en la producción de un salto cualitativo de lo biológico a lo social. 
Las investigaciones de Vigotsky intentaban establecer cómo la gente, con ayuda de instrumentos y signos, dirige su atención, organiza la memorización consiente y regula su conducta. Los humanos modifican activamente los estímulos con los que es enfrentan, utilizándolos como instrumentos para controlar las funciones ambientales y regular su propia conducta.

La teoría de Lev Vigotsky, enmarcada en el constructivismo, fomenta el desarrollo del ser humano tanto en la parte individual (factores endógenos), como en la parte externa (factores sociales) la interrelación con el medio y la sociedad.

Podemos decir que todas estas investigaciones son de suma importancia para la educación ya que estos trabajos aportan herramientas para el desarrollo del aprendizaje del individuo pudiendo ser utilizadas por un educador o por el aprendiz ya que los mismos pueden aplicar la mejor metodología de estudio de acuerdo a sus necesidades.

\subsection{CONSTRUCTIVISMO SOCIAL}

Constructivismo Social es aquel modelo basado en el constructivismo, que dicta que el conocimiento además de formarse a partir de las relaciones ambiente-yo, es la suma del factor entorno social a la ecuación: Los nuevos conocimientos se forman a partir de los propios esquemas de la persona producto de su realidad, y su comparación con los esquemas de los demás individuos que lo rodean.

El constructivismo social es una rama que parte del principio del constructivismo puro y el simple constructivismo es una teoría que intenta explicar cuál es la naturaleza del conocimiento humano.

El constructivismo busca ayudar a los estudiantes a internalizar, reacomodar, o transformar la información nueva. Esta transformación ocurre a través de la creación de nuevos aprendizajes y esto resulta del surgimiento de nuevas estructuras cognitivas (Grennon y Brooks, 1999), que permiten enfrentarse a situaciones iguales o parecidas en la realidad.

Así “el constructivismo“" percibe el aprendizaje como actividad personal enmarcada en contextos funcionales, significativos y auténticos. 
Todas estas ideas han sido tomadas de matices diferentes, se pueden destacar dos de los autores más importantes que han aportado más al constructivismo: Jean Piaget con el "Constructivismo Psicológico" y Lev Vigotsky con el "Constructivismo Social".

\subsection{EL CONSTRUCTIVISMO DE LEV VIGOTSKY O CONSTRUCTIVISMO SOCIAL}

De acuerdo a Méndez (2002) Lev Vigotsky filósofo y psicólogo ruso que trabajó en los años treinta del Siglo XX, es frecuentemente asociado con la teoría del constructivismo social que enfatiza la influencia de los contextos sociales y culturales en el conocimiento y apoya un "modelo de descubrimiento" del aprendizaje. Este tipo de modelo pone un gran énfasis en el rol activo del maestro mientras que las habilidades mentales de los estudiantes se desarrollan "naturalmente" a través de varias "rutas" de descubrimientos.

En esta teoría, llamada también constructivismo situado, el aprendizaje tiene una interpretación audaz: Sólo en un contexto social se logra aprendizaje significativo. Es decir, contrario a lo que está implícito en la teoría de Jean Piaget, no es el sistema cognitivo lo que estructura significados, sino la interacción social. El intercambio social genera representaciones interpsicológicas que, eventualmente, se han de transformar en representaciones intrapsicológicas, siendo estas últimas, las estructuras de las que hablaba Jean Piaget.

El constructivismo social no niega nada de las suposiciones del constructivismo psicológico, sin embargo considera que está incompleto. Lo que pasa en la mente del individuo es fundamentalmente un reflejo de lo que pasó en la interacción social.

El origen de todo conocimiento no es entonces la mente humana, sino una sociedad dentro de una cultura dentro de una época histórica. El lenguaje es la herramienta cultural de aprendizaje por excelencia. El individuo construye su conocimiento porque es capaz de leer, escribir y preguntar a otros y preguntarse a si mismo sobre aquellos asuntos que le interesan.

Aun más importante es el hecho de que el individuo construye su conocimiento no por que sea una función natural de su cerebro sino porque literalmente se le ha enseñado a construir a través de un dialogo continuo con otros seres humanos. No es que el individuo piense y de ahí construye, sino que piensa, comunica lo que ha pensado, confronta con otros sus ideas y de ahí 
construye. Desde la etapa de desarrollo infantil, el ser humano está confrontando sus construcciones mentales con su medio ambiente.

Hay un elemento probabilístico de importancia en el constructivismo social. No se niega que algunos individuos pueden ser más inteligentes que otros. Esto es, que en igualdad de circunstancias existan individuos que elaboren estructuras mentales más eficientes que otros.

Pero para el constructivismo social esta diferencia es totalmente secundaria cuando se compara con el poder de la interacción social. La construcción mental de significados es altamente improbable si no existe el andamiaje externo dado por un agente social. La mente para lograr sus cometidos constructivistas, necesita no sólo de sí misma, sino del contexto social que la soporta. La mente, en resumen, tiene marcada con tinta imborrable los parámetros de pensamiento impuestos por un contexto social.

\subsection{PRINCIPIOS Y CONCEPTOS BÁSICOS DE LA TEORÍA DEL CONSTRUCTIVISMO SOCIAL}

\subsubsection{El desarrollo de la inteligencia y su construcción social}

La aportación de las ideas de Jean Piaget y Lev Vigotsky, ha sido fundamental en la elaboración de un pensamiento constructivista en el ámbito educativo. En las páginas que siguen se realiza una presentación general de las principales aportaciones Lev Vygotsky con el fin de facilitar la comprensión de la teoría

Vigotsky fue un auténtico pionero al formular algunos postulados que han sido retomados por la psicología varias décadas más tarde y han dado lugar a importantes hallazgos sobre el funcionamiento de los procesos cognitivos. Quizá uno de los más importantes es el que mantiene que todos los procesos psicológicos superiores (comunicación, lenguaje, razonamiento, etc.) se adquieren primero en un contexto social y luego se internalizan. Pero precisamente esta internalización es un producto del uso de un determinado comportamiento cognitivo en un contexto social.

Uno de los ejemplos más conocidos al respecto es el que se produce cuando un niño pequeño empieza a señalar objetos con el dedo. Para el niño, ese gesto es simplemente el intento de agarrar el objeto. Pero cuando la madre le presta atención e interpreta que ese movimiento 
pretende no sólo coger sino señalar, entonces el niño empezará a interiorizar dicha acción como la representación de señalar. En palabras del propio Lev Vigotsky: "Un proceso interpersonal queda transformado en otro intrapersonal. En el desarrollo cultural del niño, toda función aparece dos veces: primero, a escala social, y más tarde, a escala individual; primero, entre personas (interpsicológica), y después, en el interior del propio niño (intrapsicológica). Esto puede aplicarse igualmente a la atención voluntaria, a la memoria lógica y a la formación de conceptos.

Todas las funciones psicológicas superiores se originan como relaciones entre seres humanos.. (Lev Vigotsky, 1978. pp. 92-94).

\subsubsection{Zona de desarrollo próximo}

La zona de desarrollo próximo, está determinada socialmente. Se aprende con la ayuda de los demás, se aprende en el ámbito de la interacción social y esta interacción social como posibilidad de aprendizaje es la zona de desarrollo próximo. (Frawley, 1997).

La teoría Vigotskiana es muy específica respecto a cómo se deben estudiar las perspectivas del crecimiento individual en cualquier caso de actividad ínter subjetiva. Esto se hace examinando la zona del desarrollo próximo (ZDP). La ZDP surge generalmente como el contexto para el crecimiento a través de la ayuda.

Otros de los conceptos esenciales en la obra de Vigotsky (1978) según sus propios términos Son:

* La zona de desarrollo próximo: "No es otra cosa que la distancia entre el nivel real de desarrollo, determinado por la capacidad de resolver independientemente un problema“.

* El nivel de desarrollo potencial: es determinado a través de la resolución de un problema bajo la guía de un adulto o en colaboración con un compañero más capaz.

Como vemos los aportes de Vigotsky dentro del marco del constructivismo social, dejan claro que es el sujeto el agente directo y responsable de su proceso de construcción de conocimiento tanto en niveles de corte que se pueden denominar académicos, como dentro de su vida cotidiana, siendo esto el punto neurálgico dentro del cual los módulos planteados dentro de esta investigación y el aporte del pensamiento latinoamericano frente a la recepción de la idea de sujeto desde Kant, Hegel y otros autores occidentales en pensadores latinoamericanos como 
Arturo Roig entre otros generando así factores que complementan e inciden dentro de dicho proceso de construcción y en la medida en que la edificación humana se implemente en un paso a paso, así mismo el tejido social donde interactúa el sujeto constructor se verá afectado de manera positiva con los aportes que este tenga para brindar desde su proceso de aprendizaje.

Así mismo dentro de cada una de las variables presentadas por el autor, es el mundo en sus diferentes contextos (el aula, la familia, los amigos, la ciudad, el país etc) la gran escuela de donde se obtienen los elementos claves del aprendizaje y la construcción integral del ser humano y es justamente con la inclusión directa de diferentes trabajos que apunten al desarrollo de estos contextos, hacia donde apunta el interés central de nuestro trabajo, a continuación se examinará el componente filosófico latinoamericano, referenciando la recepción que se hace del sujeto Kantianoen la voz de autores latinoamericanos y cómo esto se ajusta a la población y a las necesidades mismas planteadas desde el presente trabajo.

\subsubsection{La Zona de Desarrollo próximo y la dirección del desarrollo}

Los procesos de tipo superior no resultan la versión superada de los elementales sino que poseen un curso evolutivamente relativamente independiente. Los elementales se motorizan por procesos regulados naturalmente mientras que los de tipo superior requieren de emplazamientos culturales concretos para su despliegue.

Para desplegar este dominio sobre el desarrollo infantil, la cultura se vale de herramientas específicas -especialmente pedagógicas, psicológicas o semióticas- y de implicar a los sujetos en actividades culturales.

Al efecto del tema en cuestión debemos reconocer que las practicas de escolarización resultan actividades culturales específicas que permiten implicar a los sujetos en el uso de un sofisticado área de instrumentos semióticos y en modalidades particulares de uso como es el caso del uso de los lenguajes matemáticos o la escritura.

El acceso a los procesos psicológicos superiores de tipo avanzando es producto de la participación en actividades sociales específicas como la escolarización:

- Permitiendo a los sujetos el acceso al dominio de instrumentos semióticos específicos 
- Desarrollando formas de control voluntario y consiente de los procesos psicológicos como se diferencias en la figura del trabajo intelectual.

- Tal apropiación parece descansar en la promoción de interacciones que generan Zonas de Desarrollo Próximo en los sujetos involucrados

- Las metas que se deben alcanzar en los procesos de desarrollo culturalmente inducidos están culturalmente motivadas.

Del mismo modo que el trabajo humano se vale de un conocimiento de las leyes naturales a efectos de dominarlas y arribar a metas culturalmente establecidas y no reducibles a la evolución natural, haciéndose uso de herramientas técnicas y del establecimiento de relaciones sociales del trabajo, en forma análoga concibe Vigotsky que las prácticas educativas son una suerte de trabajo específico que permite producir subjetividad humana sobre la base de dominar las leyes del desarrollo infantil.

\subsection{VIGOTSKY Y EL MATERIALISMO HISTÓRICO}

Vigotsky dedicó su corta vida a la construcción de lo que consideraba una psicología científica apoyada en la posición del materialismo dialéctico e histórico. Lo hizo desde una compenetración profunda con una filosofía humanista a la vez que de una extraordinaria sensibilidad estética. A su vez, en contra de la psicología subjetiva e idealista y de muchos otros que intentaban, así se decía, la nueva psicología soviética, pero que a juicio de Lev Vigotsky recaían en un materialismo vulgar o mecanicista.

Siguiendo el lineamiento del materialismo histórico-dialéctico, en un texto de 1928, Vigotsky postula que los procedimientos culturales pueden descomponerse totalmente y ser reducidos a los procesos psíquicos naturales (...) Desde el punto de vista de la psicología científica natural, toda composición del acto instrumental puede ser reducida al sistema de estímulos reacciones. La especificidad de su estructura interna determina su naturaleza como totalidad. 
Esto quiere decir que por avanzado que sean los procesos psíquicos, tales como el pensamiento y el lenguaje, pueden reducirse a una composición de estímulos y respuestas.

Descomponerse" y "reducidos" son términos que, a primera vista, pueden ubicar a Vigotsky en una concepción mecanicista al contrario de su pregonado materialismo dialéctico. Pero no es el caso. Lo que está en juego es el evitar un sustancialismo cual es el de creer que hay un mundo psíquico en si, que nada tiene que ver con lo biológico.

Para Vigotsky, y en esto similar a J. Piaget, el psiquismo es el funcionamiento avanzado de la biología. Este aserto no cae en un reduccionismo en tanto Vigotsky concibe a la biología humana como filogenéticamente prepara para ser influida y funcionar en consecuencia por el desaarrollo histórico-cultural. No se trata entonces de meros mecanismos de estímulorespuesta aislados, sino de procesos de alta complejidad.

Ahora bien, lo que dice ese autor, es que por muy complejos que sean los resultados como el nivel de pensamiento conceptual de la ciencia, siempre es, teóricamente posible, descomponerlos en un sistema de estímulos-respuestas. Hay aquí también una similitud con Piaget cuando el fundador de la epistemología genética plantea que la fuente de todo conocimiento (por elevado que sea)son las acciones.

Continuando hacia un análisis más específico de esta postura epistemológica sobre los procesos psíquicos, y coherente con el legado de Marx y Engels, Vigotsky consideraque lo que diferencia al hombre del animal es el uso de herramientas. La actividad es el motor de la humanización. Es mediante la actividad herramental que el hombre no se limita, sin más, a responder ante los estímulos sino que actúa gracias a los mediadores. Distingue dos tipos diferentes de mediadores: la herramienta mediante la cual el hombre actúa sobre los estímulos y los signos que modifican al sujeto y a través de este a los estímulos.

De esta manera, al igual que para Marx y Engels, para Vigotsky la actividad o más precisamente el trabajo es el motor de la humanización.Esta afirmación representa un cambio radical respecto al sujeto trascedental de I. Kant.

El trabajo es un proceso de transformación del medio en la cual el hombre se vale de instrumentos. Pero el autor ruso hace una analogía entre el uso de herramientas y el signo. Por un lado estarían las herramientas que actúan directamente sobre los estímulos. Éstas modifican 
materialmente al objeto. Por otro lado está el signo lingüístico que modifica al sujeto y a través de éste a los estímulos.

Si la actividad es el motor de la humanización y es mediante el uso de instrumentos que ésta se lleva a cabo Vigotsky propone el término de actividad instrumental y haciendo referencia al método por el cual debe analizarse los PPS, el término de método instrumental.

\subsubsection{Otras consideraciones en torno a la obra de Vigostsky}

Vigotsky traduce las influencias de su contexto en aprehensión a lo dialéctico materialista de Marx y Engels, la comprensión del método histórico del primero y las consideraciones del papel de la ciencia del segundo. Logra producir sobre ello un novedoso aparato teórico -metodológico de gran aplicabilidad y una coherente y general propuesta axiológica en el campo de la Psicología. Nada queda exento a ella: otorga un papel justo a lo biológico, lo social (al ver lo primero como la base natural sobre lo que se construye lo psíquico a través de un proceso dialéctico de interrelación. Al tener lugar el desarrollo humano en un medio cultural, lo biológico resulta históricamente determinado), la historia y la cultura cuya influencia reconoce sin devaluar la percepción selectiva del sujeto. Puede denominarse su trabajo como una Metateoría del desarrollo psicológico, ya que no pudo demostrar todas las hipótesis que nominó y las que se desprendían espontáneamente de sus investigaciones. Su postura científica es la de explicar, de establecer nexos, de rastrear el origen y desarrollo de esas conductas o mejor: funciones psíquicas superiores de las que en su aspecto último se ocupaba el resto de la Psicología.

Mucho se ha criticado en él la valoración excesiva de lo cultural y lo histórico, pero analizando sus concepciones fundamentales, es perceptible una ponderación sin excesos de los determinantes biológicos de la psique. Cabría citar sus conceptos de situación social de desarrollo, período sensitivo, maduración en los que se considera el nivel de desarrollo biológico alcanzado por el sujeto.

Como aspectos esenciales de su teoría del desarrollo, establece las relaciones existentes entre las funciones naturales y las funciones psíquicas superiores (atención voluntaria, memoria lógica, pensamiento en conceptos) y la característica fundamental de ellas de estar supeditadas a 
las herramientas culturales. Propone, además, una periodización del desarrollo humano visto como "un proceso dialéctico donde el paso de un estadio a otro no se realiza por vía evolutiva, sino revolucionaria" (Vigotsky, 1984,258). Así mismo resalta la situación vital concreta (situación social del desarrollo), como indisolublemente vinculada a la percepción subjetiva del medio circundante (vivencia) poseedora de un carácter irrepetible. Otras categorías de su concepción evolutiva son: crisis, período sensitivo, neoformación como adquisición nueva inexistente en estadios anteriores. Esta armazón conceptual permitió un acceso explicativo, a la evolución hacia la adultez, con una construcción más detallada de tan complejo proceso.

Ahora bien, ¿Es posible hablar de otro humanismo en Vigotsky distinto del enfoque así autodenominado en Psicología? Para abordar este cuestionamiento, seleccionamos cuatro aspectos del enfoque Histórico -Cultural que en nuestra opinión pueden otorgarle el calificativo de "Neohumanismo", "humanismo científico", o simplemente "humanismo":

1- Importancia dada a los efectos subjetivos de la creación artística:

La primera obra de este psicólogo fue "Psicología del arte" (1924). "El arte surge primitivamente como un poderoso instrumento por la existencia" (1987). El organismo debe hallar el equilibrio con el medio ambiente el balance debe nivelarse y he aquíque el arte es al parecer, el instrumento para lograr este equilibrio explosivo con el medio en los momentos críticos. Esta obra incompleta por demás tiene un profundo contenido humanista y permitió a su autor elaborar hipótesis desarrolladas posteriormente en torno al carácter activo del sujeto y de las potencialidades aún en fases de maduración. (Febles, 1994).

2- Valoración correcta de la comunicación y la actividad en el desarrollo como fuentes de crecimiento personal:

Para Vigotsky la evolución del individuo ha de analizarse teniendo en cuenta no solo su estado actual, su desarrollo real sino también la dinamización que sobre él ejercen las interacciones. Dos categorías en que se cristaliza especialmente esta idea son: situación social del desarrollo y zona de desarrollo próximo. El primero define las relaciones específicas para cada edad, exclusivas e irrepetibles entre el niño y el entorno social. Nos habla de relaciones sociales y del sistema de actividad pues en ese entorno hay personas y objetos, y se desprende que de la calidad de esas relaciones depende el ulterior desarrollo del niño. Dentro de cada situación social del desarro1o considera las condiciones internas del niño en su nivel real de desarrollo, físico 
(fisiológico), en el que está presente todo su desarrollo anterior. Este nivel es el punto de partida para el desarrollo actual y futuro. En cada situación social del desarrollo rige la ley fundamental del desarrollo que expresa la disparidad en la maduración de partes aisladas de la personalidad y de sus diferentes propiedades: "en lo que unos procesos del desarrollo ya tienen sus frutos y realizan su ciclo, otros procesos se encuentran solo en estadío de maduración" (Vigotsky, 1984,266). Esta ley hace patente la desigualdad u originalidad que puede manifestar cada niño en la apropiación de las características psicológicas correspondientes' y puede explicar la calidad de su origen y desarrollo. Con la categoría zona de desarrollo próximo no sólo señala el valor dinamizador de la relación social, de la cooperación en el proceso de la enseñanza y de la aprehensión cognoscitiva, sino también recibimos la posibilidad de investigar e intervenir (facilitar) directamente en aquello que determina más exactamente toda la maduración, lo que debe realizarse en el período actual y futuro del desarrollo psíquico. "Aquello que hoy puede realizar en colaboración con el adulto y bajo su dirección, podrá realizarlo por sí mismo mañana" (Vigotsky, 1984,268). También en este concepto vemos el tratamiento de la individualidad que descubre el potencial disponible y por desarrollar a través de la comunicación las acciones conjuntas del adulto con el niño.

3- Imbricación de lo biológico y lo social en el activismo psíquico:

En los postulados de Vigotsky apreciamos una justa consideración de estos determinantes del desarrollo. En primer lugar materializa la interrelación humana como heredera y transmisora de las adquisiciones fundamentales de su evolución; así como de las herramientas y signos que se convertirán en las armas de la propiedad fundamental del ser humano: la psique.

Las funciones psíquicas superiores no son únicamente producto de la actividad de un psiquismo autónomo, sino como antes expresamos, de un proceso dialéctico de interrelación entre la base biológica (el cerebro) y lo construido histórica y socialmente, que deviene en el sujeto activo que individualiza la acción externa y se realiza, autodetermina, y crece.

El entorno social en que se inscribe el sujeto para tener un influjo desarrollador ha de ser capaz de insertarse en el nivel de desarrollo biológico y las posibilidades a él dadas para elevar al sujeto en su desempeño cognitivo. Ni lo biológico ni lo social por separado determinan la evolución del hombre.

4- Consideración de lo histórico y cultural: 
Vigotsky entiende por historia y cultura conceptos qué se realizan permanentemente, que reproducen de forma constante en el presente, en la compleja interacción del individuo con otros hombres y objetos de la realidad. Este carácter histórico cultural del que se apropia la psique humana no coexiste, ni se superpone a lo biológico, sino que lo transforma dejando de ser lo que era virtualmente en sí mismo, empezando a regir el comportamiento.

La inclusión de la cultura como variable en investigaciones psicológicas es, en nuestra opinión, uno de los aspectos más trascendentes de la obra de este teórico bielorruso. Retoma aquí un carácter específicamente humano y social en la organización de lo cognitivo. La cultura es gracias al hombre y el hombre lo es gracias a su relación con la cultura. La cultura ordena, encierra, enceguece, identifica y también nos hace pensar diferente. Este último aspecto nos muestra la profundidad de la mirada vigotskyana al develar la relatividad y condicionamiento cultural de los conocimientos.

Lo histórico en Vigotsky aparece en distintos niveles de análisis: en el ontogenético primordialmente, en el filogenético y en la cristalización de la historia humana, vista sobre todo en la evolución de sus mecanismos culturales.

5- La conciencia y el valor de la actividad práctica:

En los últimos años de su labor científica, Vigotsky se encaminó a develar conceptualmente la conciencia humana como sistema psicológico, ello no llegó a completarse por su temprana muerte. Pero sin duda el próximo derrotero de su trabajo era la consideración de la conciencia como móvil integrativo de la motivación y orientador de las funciones psíquicas superiores por su relación con la actividad práctica. Ello responde a la pregunta elemental de: ¿Para qué las funciones psíquicas superiores?. Un intento de respuesta ir en la dirección de la explicación de las mismas en su relación con la personalidad, y entre ellas mismas en el llamado sistema psicológico de la conciencia. "Hay que tomar el cambio de la conciencia en su conjunto -escribía Vigotsky- como explicación de cualquier cambio interfuncional "(1982). Así mismo hipotetizaba que los cambios interfuncionales se debían a los signos y a estos les era inherente un significado. A su vez," el significado se determina por las relaciones interfuncionales, por la conciencia, por la actividad de la conciencia". "La estructura del significado se determina por la estructuración sistémica de la conciencia. Los sistemas estables caracterizan la conciencia" concluía en sus 
últimos escritos. Todo ello hablaba de su concepción sistémica, holística, dinámica, optimista y abierta de la conciencia humana que equivale a decir del hombre, de su propia conciencia.

\subsection{SOBRE LA EDUCACIÓN POPULAR Y LA PEDAGOGÍA DE PAULO FREIRE.}

Dadas las condiciones dentro de las cuales se enmarca nuestro trabajo de investigación, se hace necesario abordar otras miradas que puedan enriquecer el contexto dentro del cual se desarrolla la misma, luego entonces, después de examinar los planteamientos Vigotskianos, dirigiremos la mirada en el escenario pedagógico que ofrecen tanto los postulados de la educación popular como los supuestos elaborados por Paulo Freire, ya que ambos pueden entrar en diálogo con el constructivismo social así como con las condiciones mismas de los niños de altos de Cazucá, protagonistas dentro de nuestro trabajo.

\subsubsection{Lo que entendemos por educación popular}

Entendemos la Educación Popular como "...un enfoque educativo alternativo dirigido hacia la promoción del cambio social". No promueve la estabilidad social, sino dirige su acción "...hacia la organización de actividades que contribuyan a la liberación y la transformación". El propósito central de este paradigma se vincula con la necesidad de que el proceso de cambio sea asumido por el pueblo. En consecuencia, "uno de los esfuerzos más relevantes es el de la educación de los grupos populares que son potencialmente capaces de actuar como agentes conscientes del proceso de cambio social".(Paulo Freire) La Educación Popular no ha de confundirse con aquella que se lleva adelante en centros educativos de gestión oficial, gratuitos, cuyos destinatarios son la gente del pueblo, los pobres, los marginados. No basta el que los destinatarios sean miembros de las clases populares, implica algo más: todo un estilo educativo diferente a aquel elitismo, reproductor del sistema social de injusticia, que genera hombres y mujeres que se amoldan a la sociedad sin transformarla, sin ser agentes de cambio.

"Perdidos están los que no sueñan apasionadamente, que no son románticos. Yo sueño con que nunca más se vacíen las calles. Que nunca más los líderes políticos se sirvan de las plazas llenas para poder negociar arriba. Sueño con que aprendamos todos a asumir democráticamente 
los cambios. Sueño con una sociedad reinventándose de abajo hacia arriba, donde todos tengan derecho a opinar y no apenas el deber de escuchar. Este es un sueño históricamente viable, pero demanda que la gente anteayer hubiese descruzado sus brazos para reinventar esa sociedad". (Paulo Freire, de La Pedagogía De Los Sueños).

\subsubsection{Algunos postulados}

De manera esquemática, queremos resumir algunos postulados de la Educación Popular para los tiempos actuales.

1. La educación debe asumirse de manera inseparable como un fin y como un medio, en la medida que se relaciona al sujeto individual y/o al sujeto colectivo. Para la persona individual, la educación es desarrollo de sus potencialidades y es un fin: garantiza tener sujetos que recrean y crean saber. Para el colectivo, grupo o sociedad, la práctica educativa es un medio que permite tener personas con capacidades requeridas para el desarrollo económico social.

El individualismo reduce a la educación como fin; mientras el neoliberalismo la asume simplemente como medio.

2. La educación -como fin y como medio- es derecho humano: del sujeto individual y del sujeto colectivo. Es parte de los Derechos de la Persona; pero al mismo tiempo es parte de los Derechos Económico, Sociales y Culturales (DESC) de los Pueblos. Importa asumir la educación como derecho individual y como derecho colectivo.

3. La educación como derecho individual-colectivo se plasma en servicios. Éstos son concreción social del primero, no existen de manera aislada. El neoliberalismo intenta reducir a la educación como simple servicio. De esta manera, desconoce el derecho y puede hablar de "racionalización del servicio educativo" aunque este proceso implique anulación del derecho.

4. La práctica educativa tiene como eje a las personas, en la medida que ellas posibilitan que el saber social e históricamente acumulado (saber objetivo) se transforme en saber asumido por las personas (saber subjetivo), el cual se aplica creativamente en la práctica social (saber objetivado). 
5. El derecho y los servicios educativos se dan dentro y fuera de la escuela. Sin embargo, la actividad escolar garantiza el desarrollo orgánico, intencional y sistemático del desarrollo del saber.

Espacio importante para plasmar la educación popular son las instituciones educativas formales (que genéricamente le llamamos escuela)

6. Importa cambiar la escuela y el contexto de la escuela. Sin cambio en la equidad social, es muy relativa la equidad en la escuela. Esto implica postular un nuevo enfoque de sociedad, ajeno a la propuesta neoliberal.

7. La educación debe asumirse como parte de la construcción social y política de una nueva hegemonía, para pugnar por una renovada utopía popular.

8. La EP promueve centralmente la capacidad de problematización de toda persona. Esto supone que todos los aprendices deberían saber contrastar situaciones presentes con situaciones posibles y/o deseables (utopía). Establecer la discrepancia entre ambas situaciones es encontrar un problema.

Si no existe la problematización tampoco hay conciencia en la necesidad de transformación (se asume que la situación vigente o real se confunde con la situación deseable).

9. Resolver un problema es transitar de la situación real existente a la situación deseable. En el campo social y educativo, esta transformación significa erradicar las mismas raíces de modelos atentatorios al desarrollo humano.

10. Hay modelos de sociedad que conllevan modelos de educación. Ellos no siempre están escritos, ni formal y socialmente aceptados. En el campo específico de la educación, así como a nivel micro existe un "currículo oculto", de igual manera, a nivel macro, hay un "proyecto educativo nacional" oculto, que ni ha sido escrito por nacionales ni responde a los intereses y necesidades de las diversas nacionalidades que hay en el país.

11. Revisando la realidad de la sociedad peruana, la EP plantea que para las grandes mayorías nacionales no solamente debe resolverse problemas aún vigentes de cantidad en los servicios educativos, sino también construir un modelo de educación con calidad, pertinencia y equidad. 
12. La EP asume que la educación es práctica social mediadora para formar personas que sean capaces de transformar su en un y éste en un con-identidad cultural, mientras se construye un de autonomía, libertad y desarrollo humano.

13. La EP se reconoce que, como práctica social, es fundamentalmente interacción de sujetos: Los padres de familia, la comunidad y los docentes deben ser considerados como sujetos.

14. Los estudiantes deben ser considerados con un enfoque de desarrollo integral. Ya no basta analizar solamente sus rendimientos, ni descontextualizar sus bajos niveles formativos.

15. Los maestros no son insumos o recursos del sistema (educativo), sino sujetos del mismo y como tal deben ser tratados. Debe postularse su desarrollo integral.

16. La EP se construye básicamente desde fuera del aparato oficial, pero no excluye a trabajadores del mismo. En este sentido, no está organizando la "oferta" educativa (los servicios), sino más bien la "demanda" (el derecho a la educación). Pero una demanda con criterio ideológico, social y político,

17. Hay necesidad de promover hábitos organizativos en nuestros estudiantes. Pero estos hábitos deben ir más allá de lo meramente instrumental al sistema.

18. La EP recoge la experiencia de los maestros y maestras peruanos que -a lo largo y ancho del país- han realizado y hasta cierto punto validado innovaciones que combinan lo funcional y estratégico

19. El desarrollo de los valores y de la ética en nuestros alumnos es componente estratégico para promover un nuevo tipo de sociedad.

20. Los trabajadores de la cultura deben ser incluidos en la EP. Basta de convocarlos solamente para inaugurar o clausurar eventos educativos. La EP asume que sus integrantes no solamente deben ser sujetos de cambios externos a ellos como personas, sino que deben ellos mismos transformarse a sí mismo. Todo educador popular debe ser testimonio, mediador y germen del nuevo tipo de educador y de hombre que se busca construir de manera generalizada. 
21. Nuestra opción supone una vivencia personal y colectiva que denuncie las limitaciones de la educación actual para nuestro Pueblo y que anuncie -con sus propuestas y práctica organizada- un nuevo tipo de educación y de sociedad

22. La EP señala que debe promoverse la ruptura con el pensamiento único y convergente. Por ello, convoca a replantear la idea del texto escolar como "la biblioteca que los ricos han inventado para los pobres".

23. La EP asume la realidad donde se trabaja educacionalmente no solamente como un contexto de referencia para la enseñanza y el aprendizaje, sino también como un contexto de transformación.

24. La EP busca articularse como "frente", usando criterios y métodos democráticos. Por ello, aún la forma de gestación busca ser fiel a esta opción.

25. La EP busca aportar en el diálogo intercultural. La pérdida de la identidad cultural no se da solamente por el impacto de la globalización y más específicamente por los mensajes mediáticos, como bien lo observa Néstor García . La misma práctica educativa cotidiana, al promover su propuesta de ciencia y tecnología, carcome los fundamentos de creencias populares.

26. Se asume que la actual educación generalmente - de manera directa o indirectacontribuye a restar los fundamentos de las creencias ancestrales. Por ello, importa sentar las bases de un diálogo de interculturalidad, con un renovado enfoque de ciencia y de cultura.

27. La EP busca asumir una política precisa respecto a los medios de comunicación social. Sabe que la actividad mediática es gravitante en la formación de la conciencia nacional.

28. La EP reconoce la justicia en las luchas magisteriales. Sin embargo, asume que -a veces- estas luchas sin quererlo vulneran los derechos de los estudiantes y de la sociedad a una educación de calidad y pertinencia. Por ello, se buscará armonizar los derechos de los sujetos que enseñan y los derechos de los sujetos que aprenden.

29. La EP quiere recoger la rica experiencia latinoamericana de movimientos sociales. Juntamente con ellos se deben conjugar esfuerzos para construir una nueva hegemonía en la Patria Grande. De manera práctica, se deben señalar estrategias comunes para lograr 
este cometido, buscando una educación diferente, en una sociedad diferente, que de prioridad a los intereses de los excluidos.

30. Importa avanzar en la construcción de un gran movimiento pedagógico popular que organice al sujeto social de las transformaciones educativas en el país. Este movimiento debe estar integrado por docentes, intelectuales, artistas, estudiantes, padres de familias y organizaciones sociales con vocación de cambio.

31. La EP postula elaborar desde abajo un Proyecto Educativo Nacional con enfoque popular. Las diversas propuestas existentes (del SUTEP, del Consejo Nacional del SUTEP, del Plan EPT y otros) deben ser asumidos por el movimiento pedagógico popular, para construir su propia alternativa. De esta manera, los sectores populares no estarán simplemente a la defensiva (en actividades de protesta o contrahegemónicas), sino pasarán a la ofensiva, buscando una nueva hegemonía.

32. Lo central en una acción educativa es el aprendizaje intencional. Toda práctica educativa apunta a que los estudiantes (participantes o alumnos) logren determinados desempeños, con propósitos definidos.

33. Todo aprendizaje es conversión del saber objetivo de una disciplina o tema, en saber subjetivo, de tal manera que se pueda transformar en saber objetivado. Es decir, el saber objetivo -que sobre un tema tiene la sociedad- debe ser interiorizado por el alumno (saber subjetivo), para traducirlo en práctica cotidiana (saber objetivado).

34. En el desarrollo de toda acción educativa se promueven dos tipos de aprendizajes:

- Aprendizajes de contenidos; y

- Aprendizaje de capacidades (proceso internos del sujeto). Cuando los participantes, hacen suyos los nuevos saberes y los convierten en parte de sus estructuras internas (cognitivas, afectivo-valorativas y volitivas); cuando los participantes plasman sus aprendizajes en desempeños... entonces hablamos que hay desarrollo de capacidades.

35. Sobre el aprendizaje, hay principios básicos de la pedagogía contemporánea que importa recordar para poder aplicarlos.

Todo aprendizaje es reestructuración de saberes. Es decir, todo nuevo aprendizaje "reestructura" los que ya tiene una persona. En este sentido, se habla de considerar el 
saber previo, en la medida que todo nuevo aprendizaje se construye desde lo que el alumno ya sabe o tiene experiencia.

- Finalmente todos los saberes corresponden a intereses técnicos, sociales y emancipatorios. Por ello, toda acción educativa se relaciona a: trabajo (saber técnico) / comunicación de sujetos (saber social) y / poder (saber emancipatorio).

- El maestro o docente es un mediador que posibilita que el alumno pase de una "zona real de desarrollo" hacia una "zona próxima de desarrollo", en la perspectiva de arribar a una "zona potencial de desarrollo"

- Cuanto más significativo es el contenido de un aprendizaje para el alumno, el aprendizaje gana en calidad

- En el desarrollo de los aprendizajes, lo afectivo actúa como acelerador o inhibidor

- El aprendizaje avanza por sensaciones y percepciones del alumno y esto se da cuando él tiene experiencia, manipula o transforma lo que está aprendiendo

- El aprendizaje -como resultante de un intencional proceso de comunicación- es más potente cuanto más estímulos y medios se combinan

- Cuanto más un alumno percibe la utilidad del yo, social y cognitiva de un tema, mejor predisposición tiene para su estudio

- Todo aprendizaje supone "conflicto cognitivo" (Piaget) y actitud problemica

- El aprender a aprender se da cuando el alumno comprendió los procesos de su propio aprendizaje y decide ponerlos en operación con autonomía, llegando a la "metacognición"

35. En una sesión de aprendizaje intervienen siete elementos centrales, los cuales pueden organizarse de diversas maneras, pero siempre están presentes:

- Propósitos a lograr.

- Estos propósitos o finalidad se traducen en: Ideario, Perfiles y Objetivos

- Contenidos y capacidades a promover;

- Acciones a desarrollar;

- Métodos. Procesos y técnicas para desarrollar los aprendizajes;

- Recursos: medios y equipos de enseñanza / medios y equipos de aprendizaje / tiempo.

- Sistema de evaluación del aprendizaje.

- Clima institucional: Adecuada interacción de los sujetos 
36. La opción en los propósitos de la acción educativa resulta gravitante, pues ella supone optar por el tipo de sociedad y de persona que se busca construir y al mismo tiempo determina la opción de contenidos, acciones, métodos, recursos, evaluación y clima institucional. En este sentido, desde una óptica de los trabajadores, la opción de los propósitos de su acción educativa define inclusive opciones de carácter doctrinario, político e ideológico.

Desde nuestro enfoque, la población deberían combinar su formación técnico-ocupacional, social-organizativa y político-ideológica.

\subsubsection{La propuesta pedagógica de Paulo Freire}

Mucho se ha insistido en que la concepción pedagógica de Paulo Freire constituyó, en el momento de su formulación, una propuesta revolucionaria caracterizada, particularmente, por ser pronunciada desde América Latina y para América Latina en un contexto histórico de insurgencias. Su carácter provocativo e interpelante obligó a revisar no sólo los fundamentos filosóficos de las concepciones pedagógicas con las que confrontaba sino, necesariamente, a examinar las consecuencias éticas, políticas y sociales que surgían de su aplicación. La educación como práctica político-social alienadora era denunciada a partir de las concepciones de hombre y de mundo en que se sustentaba.

Sin embargo, a la facilidad de la denuncia Paulo Freire opuso la esforzada y consecuente construcción teórica y práctica del anuncio. En sucesivas formulaciones y reformulaciones, admitiendo críticas y autocríticas, su praxis pedagógica fue transitando el camino que va desde la opresión a la esperanza, desde la concientización a la autonomía, y en este trayecto es posible identificar una senda que no se ha perdido: su concepción de la "alteridad".

Su manera de posicionarse frente a la radical problematicidad del otro puede reconocerse de un modo inalterable a lo largo de toda su obra, trascendiendo aún los diferentes contextos históricos de su formulación.

Ante la "otredad" puede procederse deductivamente, haciéndola desaparecer, objetivándola de múltiples maneras, o bien asumiéndola como condición de posibilidad de la propia existencia. Esta última es la opción de Freire y es, a nuestro juicio, la que ha hecho de su pedagogía 
humanizante y humanizadora su mayor legado y la razón por la que se muestra hoy, en nuestro aquí y ahora de latinoamericanos, más actual y vigente que nunca.

Nos proponemos fundamentar que es en la concepción antropológica, en la comprensión de "alteridad" que sustenta Freire desde donde se despliegan innovadoras formulaciones pedagógicas, con sus necesarias consecuencias éticas y políticas. Para ello, examinaremos esta concepción de la "alteridad" presente en sus escritos, a partir de tres dimensiones: en las relaciones intersociales, en las relaciones intrasociales, en las relaciones pedagógicas.

\subsubsection{La educación como posibilidad histórica en el pensamiento de Paulo Freire}

En la actualidad, la educación latinoamericana requiere el fortalecimiento de un discurso filosófico-educativo de carácter crítico y utópico que evite las acomodaciones simplistas tanto con los sectarismos basados en verdades universales y únicas, como con las adaptaciones "pragmáticas" a los hechos, como si éstos se hubieran vuelto inmutables. Para ello, la ponencia reflexiona sobre los supuestos filosóficos de la educación como posibilidad histórica en la obra de P. Freire, quien consideró, en sus últimas obras, este tema decisivo para finales del siglo veinte. Así, se establecen los alcances de las posturas extremas caracterizadas por Freire como voluntarismo idealista y objetivismo mecanicista y, entre ambas, se dilucida la posición del pedagogo brasileño frente a la historia como posibilidad. Se profundiza cómo Freire sostiene que la invención de la posibilidad de liberación radica en la capacidad de percepción del hombre como ser inconcluso, limitado, condicionado e histórico; pero que esta percepción sola no basta. Es preciso sumarle la acción política de transformación del mundo. Así se constituye una relación dialéctica entre la conciencia y el mundo, entre la subjetividad y la objetividad, entre "la lectura de la palabra" y "la lectura del mundo" que permite establecer la posición de una educación liberadora con respecto al tiempo, particularmente con el futuro.

Ciertamente, es en la comprensión del futuro como problema y en la tarea de ser más como expresión de la naturaleza humana en su devenir donde se encuentran los fundamentos para la acción y no para la resignación y los argumentos de que es posible cambiar aunque sea difícil.

Posteriormente, se desprenden consecuencias con respecto a la relación de la pedagogía con el poder, la comprensión del mundo, el cambio histórico, el lenguaje, la enseñanza y la 
democracia. De esta manera, se procura contribuir desde la filosofía de la educación con una imprescindible reflexión de la educación como acontecimiento específicamente sociopolítico.

\subsubsection{Vigencia de la propuesta metodológica de Paulo Freire}

Este apartado se propone analizar algunos alcances de la propuesta metodológica de Paulo Freire en alfabetización, Freire caracteriza su método como activo, dialogal, de espíritu crítico, utilizando, a partir de palabras generadoras, técnicas como la reducción y la codificación.

Además el autor plantea la existencia de diferentes tipos de conciencia: la ingenua (que se cree superior a los hechos dominándolos desde afuera y por eso se juzga libre para entenderlos como conforme mejor le agrada), la mágica (que capta los hechos otorgándoles un poder superior al que teme), y la crítica conceptualizada como "la representación de las cosas y de los hechos como se dan en la existencia empírica, en sus correlaciones causales y circunstanciales".

Es aquí donde nos preguntamos sobre las relaciones entre el lenguaje y los procesos de pensamiento de las personas involucrados en el momento de aprender el sistema de escritura y sobre el impacto de la alfabetización en su psiquismo.

Con respecto al primer aspecto para Freire enseñar el sistema de escritura de una lengua implica el reconocimiento de la relación sílaba-sonido. El hecho de seleccionar a la sílaba como unidad de análisis se ha visto reforzado desde la psicolingüística por considerarse la unidad sonora mínima que un hablante analfabeto puede reconocer.

Con respecto al segundo consideramos, con Freire, que la alfabetización de adultos posibilitaría el paso de una conciencia mágica o ingenua a una conciencia crítica. Es desde estos planteos que el método de Freire aparece vigente desde dos perspectivas, tanto desde el punto de vista teórico, ya que los resultados de las investigaciones desarrolladas en el ámbito de la lingüística y la psicolingüística corroboran las discriminaciones por él propuestas, como desde el punto de vista práctico, es decir para su utilización en el quehacer de los que se dedican al trabajo alfabetizador. 


\subsubsection{Educación y cambio en Paulo Freire}

Presentaremos a continuación un breve análisis de las concepciones tanto explícitas como subyacentes posibles de ser reconocidas en la perspectiva de Paulo Freire. En tanto en su pensamiento la concepción de cambio individual y social se haya indisolublemente ligado a sus concepciones de hombre, de sociedad y de educación, esta exposición presenta brevemente, desde la perspectiva del cambio, el pensamiento del educador brasileño.

En Paulo Freire el cambio individual y social se requieren mutuamente, y ambos se relacionan con su concepción de educación, ya que sólo son posibles si en los oprimidos se produce un cambio de percepción del mundo, a través de una educación concientizadora.

A la vez, y en sentido inverso, la educación se identifica con el cambio, no sólo del sujeto, sino también de las estructuras sociales y culturales. La "educación liberadora", definida como reflexión y acción del hombre sobre el mundo, engendra un proceso de cambio radical de los educandos de la posición de oprimidos a la de hombres liberándose y, en último término, impulsa a la transformación revolucionaria. Por eso para Freire es impensable una educación verdadera que no sea una fuerza impulsora del cambio individual y social. Esta identificación de la educación con el cambio es posible porque sus representaciones de la educación incluyen la mediación, el orden simbólico y el acceso al tiempo historial y al espacio local, permitiendo la aceptación de la existencia de los procesos de cambio.

Al mismo tiempo, esta articulación entre educación y cambio se vinculan con su concepción de hombre y de sociedad. Freire piensa en una educación para las "condiciones especiales de la sociedad brasileña", sociedad a la que caracteriza como "en transición" de una sociedad "cerrada" a una sociedad "abierta". Sociedad en la cual el pueblo se encuentra en situación de

oprimido, debiendo concientizarse para poder asumir su organización y la responsabilidad por la transformación social. Ello conlleva una representación del hombre como un ser de la praxis que se integra en el mundo por medio de sus actos de creación, re-creación y cambio del mundo, la historia y la cultura. Actos de creación en los que interviene la palabra, en tanto, como

Comportamiento humano significante del mundo, no sólo designa las cosas, sino que también es praxis. 


\subsubsection{La educación: un proyecto social para la liberación}

América Latina a partir de los 90 y sus resonancias en los sistemas educativos y en las instituciones, para recuperar desde allí la función de la educación, en el sentido freiriano, como práctica para la concientización y la transformación de la sociedad.

Se plantea la necesidad de comprender los cambios producidos por los procesos de reforma económica ya que ellos inciden sobre las prácticas cotidianas y generan interrogantes, problemas y desafíos a encarar. Desde aquí se sostendrá, sin ingresar en una análisis exhaustivo, de qué manera el proceso de concentración de la riqueza trajo aparejado el desempleo, la exclusión, la pobreza, dando origen a la necesidad de contener socialmente a un número cada vez mayor de la población.

Se subrayan las diferencias entre las formas de exclusión del capitalismo industrial que originaron la figura del "explotado" y "oprimido", de las formas actuales de las cuáles devienen el "excluido"; considerando que en tales relaciones sociales, el explotado era sujeto necesario en el vínculo social, mientras que el excluido no, en esta lógica del sistema.

En tales circunstancias la escuela, se presenta como el lugar aparente de la "inclusión". En este punto se hace necesario dejar planteado desde una mirada crítica cómo puede entenderse la escuela en la vinculación con la sociedad y la postura de Freire acerca que la dominación no puede reducirse exclusivamente a una forma de dominación clasista, y con la noción de diferencia como hilo teórico conductor, rechazar la idea de la existencia de una forma universalizada de opresión que la escuela reproduce, reconociendo y localizando modos particulares de dominación, pero también formas de lucha y resistencia colectivas.

Se propone recuperar la idea de la educación como algo más que la formulación del pesimismo crítico, sino como un discurso que crea el punto de partida que intenta hacer realidad la esperanza y eliminar la desesperación.

Se presenta a la educación, continuando con el soporte teórico freiriano como ideal y referente de cambio al servicio de un nuevo tipo de sociedad. Así, como ideal la educación dará cuenta de una forma de política cultural que trasciende los límites de las doctrinas políticas específicas, al tiempo que conecta la teoría y la práctica sociales con los aspectos más profundos de la liberación. Por tanto, la educación incluye y va más allá de la noción de instrucción escolar, 
siendo la escuela el lugar donde la educación se verifica, donde hombres y mujeres producen y al mismo tiempo son el producto de relaciones sociales y pedagógicas específicas.

Se intentará mostrar a la educación como forma de acción asociada al lenguaje de la crítica y la posibilidad; como la necesidad de una entrega por parte de los/as educadores / as para hacer que lo político sea más pedagógico, y lo pedagógico más político. Es decir, para que la reflexión y la acción crítica sean partes fundamentales de un proyecto social que supere las formas de opresión sino que además, desarrolle una fe profunda y duradera en el esfuerzo por humanizar la vida misma.

\subsubsection{Nuevas tendencias en pedagogía}

A continuación presentaremos algunas de las nuevas tendencias que se han dado en los últimos años en cuestión de pedagogía, con el fin de contrastar lo que se presentó posteriormente con Vigotsky y Freire.

La década de los 90's en América Latina es particularmente creativa en términos de producción de reformas e innovaciones educativas. La reforma y las innovaciones van poco a poco instalándose como una necesidad, un discurso y una práctica en todos y en cada uno de los niveles y modalidades de los sistemas educativos, aunque a un ritmo y por iniciativas diferentes.

Este movimiento comienza a abarcar a la educación secundaria. Esto es a los tramos de los sistemas educativos concebidos hacia fines del siglo XIX como no obligatorios y como preparatorios para la Universidad o para el ingreso al mundo del trabajo (Mueller y otros, 1992). Esos tramos se ubican ya desde hace algunas décadas a continuación de una educación primaria de más de 5 años de duración y en proceso de transformación y de extensión (Braslavsky, 1995).

Antes de esta década se otorgaba a la ubicación de cada nivel o ciclo en la estructura de estudios y a la ubicación de los cortes entre uno y otro una importancia crucial. Actualmente, en cambio, parecería que las preocupaciones principales se están trasladando hacia otros temas. Ellas están dejando de ser la búsqueda de la identidad de cada uno de los viejos niveles del sistema educativo, incluido el secundario, y el momento en el que se introducen los cortes entre uno y otro; para pasar a ser la definición de una oferta educativa de 12 años de duración y organizada sin tránsitos bruscos entre sus diferentes tramos, dedicada a garantizar la educación básica de toda la población. En consecuencia se puede proponer que cada vez más se tiende a 
asumir que lo más relevante es evitar que los alumnos y las alumnas tengan que atravesar por cortes abruptos entre modelos institucionales creados para diferentes clases y sectores sociales y con distintas finalidades y que la oferta de educación general básica de 12 años para todos se pueda organizar en ciclos de diferente duración de acuerdo a las condiciones socioeconómicas, a las tradiciones e incluso a las preferencias de las comunidades educativas.

Se tiende a asumir también que una determinada ubicación de los cortes puede ser mejor o peor según cada contexto, y que no se la puede definir con homogeneidad para todos los países ni aún dentro de un mismo país. La diversidad de estructuras, antes considerada una herejía contra la equidad pasa a ser concebida como una alternativa para lograr una mayor pertinencia organizativa para atender a poblaciones diversas, es decir como una eventual herramienta de diferenciación positiva para construir mayor equidad. Pero el requisito es que curricularmente no se promuevan formas educativas que en el marco de esas diferencias organizativas contribuyan a consolidar las desigualdades de origen de los estudiantes.

En el contexto de pérdida de relevancia de las cuestiones estructurales es necesario encontrar otro criterio para hablar de la educación secundaria, que no sea la referencia a un viejo nivel en la vieja estructura de los sistemas educativos. Latransferencia de los establecimientos educativos del nivel desde la Nación hacia las provincias interrumpió la puesta en práctica de esa política. Quedaron sin embargo instalados algunos problemas y reflexiones que se irían retomando en algunas provincias hacia fines de los `80 y a comienzos de los `90 y a nivel nacional hacia 1995.

En un segundo momento se incorporaron otros países al movimiento por el mejoramiento de la calidad de la educación secundaria, en particular Chile y Uruguay. Actualmente ya la mayor parte de los países de América latina comienzan a colocar en la agenda la cuestión de la transformación de la educación secundaria. Brasil, Perú y Bolivia, entre otros; han iniciado la formulación de programas de mejoramiento y de expansión de la educación secundaria que se encuentran en diferentes momentos de su elaboración.

Pero más allá de los momentos y de las estrategias que cada país se da a sí mismo para avanzar en la expansión y en la transformación de la educación secundaria, en todos ellos la cuestión de la renovación curricular ocupa un lugar destacado que se resuelve además con cada vez mayor intervención e interacción de los distintos niveles institucionales de gobierno: el 
nacional, el provincial e incluso el municipal. En efecto, en los grandes países federales la transformación curricular se va desarrollando

en distintos planos simultáneamente: el nacional, el de cada provincia o estado y el de las instituciones inscriptas en sus ámbitos locales, en tanto que en los países unitarios el plano departamental no tiene el mismo dinamismo y los cambios se dan en la articulación e interpenetración entre las políticas nacionales y las innovaciones institucionales. En esta nueva dinámica no es tan claro como hace algunas décadas en qué escala se resuelve la responsabilidad por los contenidos de la educación, como eje vertebrador del curriculum escolar.

Históricamente se asumió que la responsabilidad por la definición de los principales contenidos de enseñanza estaba depositada en el Estado Nacional. El curriculum, en tanto contrato cuyo eje son los contenidos de enseñanza, debía ser el centro del proyecto educativo nacional. La fuerte expansión, descentralización y redistribución de responsabilidades presupuestarias en los sistemas educativos de América Latina puso en cuestión esa asunción. Actualmente en algunos países la responsabilidad principal por la definición del curriculum es del Estado Nacional, pero en otros es de los estados provinciales. Esta diferencia se traduce en la condición jurídica que adquieren los marcos curriculares de carácter nacional en cada país.

Pero más allá de la escala política que formalmente tiene una mayor responsabilidad en la definición curricular, crecientemente en esa producción curricular se evidencian algunas tendencias compartidas. La existencia de tendencias compartidas en la producción curricular de países muy distintos puede incluso inducir la suposición de que en algún lugar de dentro o de fuera de la región se elaboran propuestas idénticas para ser desarrolladas en contextos diversos.

Pero en realidad parecería que actualmente la búsqueda de soluciones a los problemas de la educación secundaria en América Latina tiene mucho de construcción compartida y de búsqueda de referencias en los mismos espacios externos, sobre todo en los países europeos.

Los materiales curriculares chilenos tomaron, por ejemplo, algunos elementos de las propuestas argentinas, que a su vez en algunos aspectos se nutrieron de aquellos. En Bolivia circulan definiciones tomadas de la Argentina y así de seguido. En todos los casos se identifica bibliografía española y francesa y - en menor medida - norteamericana, portuguesa y de otros países externos a la región.

El presente documento se propone avanzar en un primer análisis de los procesos y de los 
productos curriculares para la educación secundaria en América Latina a partir del reconocimiento de las tendencias comunes del desarrollo contemporáneo que afectan a toda la región, tomando como fuente privilegiada a los documentos de orden nacional y poniendo énfasis en la producción de los países de América del Sur. Su propósito es contribuir a enriquecer el diálogo y el debate acerca de la situación y de los cambios curriculares en el mundo, con la finalidad de fortalecer la capacidad de aprendizaje compartido y de mejoramiento del impacto de los cambios que se proponen y promueven.

\subsubsection{Una diversidad más reconocida}

Históricamente los sistemas educativos fueron concebidos para "transferir la cultura de las generaciones adultas a las generaciones más jóvenes", más fuertemente incluso en el caso de la educación secundaria que en el caso de la educación primaria. Esta posición contenía cinco supuestos actualmente discutibles. El primero es que las generaciones más jóvenes no poseen una cultura propia y, en consecuencia, no ofrecen ningún tipo de resistencia al aprendizaje de contenidos y a la asunción de pautas culturales de los adultos. El segundo es que la cultura adulta es homogénea. El tercero es que las culturas de los jóvenes también son homogéneas, el cuarto es que la cultura adulta y, como parte de ella, las características de la producción y de las estructuras de los conocimientos son estables a través del tiempo; y el quinto es que los sistemas educativos y las escuelas son el principal sistema experto en la transmisión de información.

En los últimos años se asiste al reconocimiento de la heterogeneidad cultural latinoamericana y al reconocimiento de las culturas históricamente subordinadas, en particular a las culturas originarias (Calderón y Dos Santos, 1998; Martín-Barbero, 1998).

En este sentido se asiste en muchos países a la demanda de atención a esa diversidad también en los procesos de cambio de la educación secundaria, planteándose temas tales como la posibilidad de la enseñanza de lenguas originarias como parte del curriculum de la educación secundaria.

Se asiste también en todo el mundo, y como parte de este movimiento también en América Latina, a un creciente proceso de emergencia y de fortalecimiento de culturas juveniles a través de producciones y de consumos que tienen lugar en circuitos diferentes a los escolares (Véase por ejemplo Semán y Vila, 1999). Algunas reflexiones e investigaciones sugieren que la falta de 
adecuación del modelo de escuela secundaria a las características de los nuevos grupos y sectores sociales que ahora asisten a ella más la falta de consideración de la existencia de necesidades y de demandas propias de los jóvenes son factores relevantes a la hora de interpretar las razones de la deserción y de los bajos logros de aprendizaje de los púberes y de los jóvenes (Finkielkraut, 1987; Obiols y otros, 1994).

Esto significaría que para que los jóvenes asistan, permanezcan y aprendan en los colegios tienen que encontrar allí oportunidades de despliegue de su condición protagónica a través de prácticas muy variadas que les permitan hacer de las escuelas espacios de vida juvenil. Por otra parte esa juventud no es un conglomerado homogéneo, sino un conjunto de grupos de personas con intereses, necesidades y saberes diversos, por momentos convergentes y por momentos divergentes respecto de los adultos y entre sí (Braslavsky, 1987; Touraine, 1988). Su cultura no es, por último, una alternativa perfecta ni puede ser el único punto de referencia de la educación secundaria.

Por otra parte la educación secundaria surgió en una etapa en la cual los saberes se estructuraban en disciplinas académicas que se consideraban fuertemente separadas entre sí y con una perspectiva de permanencia significativa a través del tiempo. Con la emergencia de un nuevo sistema científico-tecnológico-productivo (Lesourne, 1993) también se desdibujan y redibujan permanentemente los límites entre las disciplinas académicas y se producen fuertes articulaciones internas que - sin embargo - tienen baja permanencia temporal. En ese contexto grandes campos disciplinarios estructurados durante la segunda mitad del siglo XX han quedado fuera de la educación secundaria y campos disciplinarios de dudosa vigencia siguen permaneciendo en ella. Asimismo también en ese contexto es necesario plantearse qué debe contener el curriculum, si conceptos y datos que caducan, procedimientos fértiles para seguir aprendiendo durante toda la vida, o una combinación de ambos estructurada de acuerdo a un principio organizador externo a ambos.

Por último la revolución de las comunicaciones abrió paso a nuevos sistemas expertos en la transmisión y el acceso a la información y aún a valores y pautas culturales que son mucho más eficaces para cumplir esas funciones que los sistemas educativos y los colegios (Harasim y otros, 1995; Palloff y Pratt, 1999). En consecuencia es imprescindible que los colegios se planteen los riesgos y las oportunidades que la existencia de esos nuevos sistemas expertos les plantean, en 
especial a través de la emergencia del concepto de conectividad de las inteligencias (de Kerckhove, 1997). Esa revolución de las comunicaciones permite también detectar más claramente el impacto local de las tendencias regionales y mundiales.

\subsubsection{Los desafios de la construcción curricular para la educación en américa latina}

Sistematizando los aspectos que surgen de la presentación de las tendencias de cambio en América Latina y en el mundo, cabe afirmar que los currículos para la educación secundaria debieron comenzar a reformarse para atender fuertes demandas de incorporación de más jóvenes a la educación y de mejoramiento de la calidad y también de la eficiencia de la oferta orientada a satisfacer las necesidades educativas de los jóvenes, ofreciendo una combinación de orientaciones para producir tanto una mayor flexibilización y modernización estructural como cambios en los contenidos y en las metodologías de enseñanza y de aprendizaje.

En algunos países, en particular en Chile y en la Argentina ya asistían a la educación secundaria en 1995 más del 70\% de los jóvenes (UNESCO, 1998). En otros el porcentaje de jóvenes que se está incorporando se acelera muy rápidamente. En casi todos los países la velocidad de expansión de este nivel del sistema educativo es mucho mayor que la velocidad de expansión de la educación primaria. Por otra parte los y las jóvenes que ahora acceden a la "educación secundaria" provienen de sectores sociales diferentes.

Muchos de ellos son miembros de familias que por primera vez toman contacto con la educación secundaria, no poseen libros u otro material impreso en sus casas ni tampoco acceso a las nuevas tecnologías de la comunicación y de la información.

En muchos países de América Latina los adultos y los jóvenes sienten - aunque no comprendan muy bien por qué - que el curriculum de la educación secundaria es profundamente inadecuado. La profundización de las desigualdades sociales y la vivencia de la inadecuación curricular convergen en la vida cotidiana de los establecimientos educativos alimentando situaciones de violencia, de apatía o de complicidad demagógica entre los alumnos y alumnas y los profesores y profesoras también desarmados frente a la novedad y a la envergadura de los desafíos para cuya atención no fueron formados. Estas situaciones adquieren además ciertas peculiaridades cuando los profesores tienen una edad muy cercana a la de los estudiantes o, por el contrario, cuando son ya muy grandes. 
Tradicionalmente en América latina no había un "curriculum" para la educación secundaria. Lo que actualmente llamaríamos "materiales curriculares" característicos de la educación secundaria latinoamericana fueron los planes y programas.

A comienzos de los '90 se tomó poco a poco conciencia respecto de la conveniencia de producir otro tipo de materiales curriculares y se iniciaron los ya mencionados procesos de transformación curricular. Como resultado de estos procesos ya en varios países de América Latina, en particular en Chile, Argentina, Uruguay se cuenta ahora con nuevos lineamientos curriculares que asumen distintas formas, denominaciones y estatuto jurídico.

En Chile se elaboraron los Objetivos Fundamentales y Contenidos Mínimos (República de Chile, Ministerio de Educación, 1998a). Esos lineamientos fueron aprobados como Ley de la Nación. En ese país el sistema educativo está privatizado y municipalizado.

Pese a ser una Ley de la Nación, los Objetivos Fundamentales y Contenidos Mínimos no son allí de cumplimiento obligatorio. Sin embargo, la necesidad de asumir un compromiso con una orientación educativa compartida indujo al 95\% de los establecimientos educativos a adscribirse a ellos. Estos materiales no resultaron a juicio de los técnicos ministeriales ni de numerosos profesores suficientemente orientadores. En consecuencia con posterioridad se elaboraron programas de estudio que constituyen "hojas de ruta" con opciones, actividades, bibliografía y otra serie de apoyos a los profesores (República de Chile, Ministerio de Educación, 1998b).

En la Argentina el Consejo Federal de Cultura y Educación, integrado por los Ministros de las 24 provincias del país y presidido por el Ministro Nacional, acordó Contenidos Básicos Comunes graduados por ciclos (República Argentina, Ministerio de Cultura y Educación, 1997). Esos Contenidos se deben recuperar obligatoriamente en los Diseños Curriculares Provinciales y se pueden reorganizar para su mejor enseñanza.

En el Uruguay, pequeño país centralizado de aproximadamente 3 millones de habitantes se elaboraron Planes y Programas de progresivo cumplimiento obligatorio (República Oriental del Uruguay, Administración Nacional de Educación Pública, 1999).

Los procesos de elaboración de los nuevos materiales curriculares difieren de los procesos de elaboración de los tradicionales planes y programas. Los planes y programas eran elaborados desde los orígenes de la educación secundaria hasta la década de los '50 exclusivamente por una comisión de profesores expertos en las distintas disciplinas, en un contexto de prácticas 
pedagógicas en el cual la actualización permanente no estaba incorporada como una rutina. La inercia respecto de esta metodología de promoción del cambio curricular conllevaba el riesgo de sostener una organización institucional y una selección de campos y de metodologías de enseñanza legitimadas, de no permitir atender las actuales necesidades a través de la eventual incorporación de contenidos provenientes de disciplinas o campos de nuevos saberes y de mejoramiento de la calidad de la educación.

Como reacción a esa modalidad de construcción curricular, que profundizaba la fragmentación de los colegios secundarios en disciplinas balcanizadas entre sí (Hargreaves, 1982) se recurrió en la década de los '50 y ‘60 a pedagogos, técnicos y funcionarios especializados en el diseño institucional de los establecimientos y del sistema educativo. La inercia respecto de esta metodología de promoción del cambio curricular conllevaba el riesgo de desdibujar las necesidades, posibilidades y limitaciones de la actualización disciplinar y metodológica, ya que en ocasiones esos perfiles profesionales se encuentran alejados de los procesos de creación de nuevos conocimientos en los diferentes campos académicos y de la producción económica y cultural.

Frente a estas situaciones en la década de los '90 se intentó reconocer la existencia de dos grupos diferentes de personas que deben intervenir en los procesos de construcción curricular. Por un lado los actores o protagonistas y por el otro los referentes.

Los procesos recientes de construcción curricular de nivel nacional buscaron avanzar en propuestas de construcción curricular que incorporaran a los profesores como actores protagónicos, pero no exclusivos del cambio tanto del curriculum como norma como del curriculum en acción. Pero al mismo tiempo se asumió que los profesores requieren del diálogo con otros no profesores para recuperar sus mejores prácticas con horizontes más amplios. Se asumió además que esos otros no profesores no pueden ser sólo pedagogos y técnicos especializados en curriculum o en cuestiones afines. Se recurrió también a equipos de científicos y de académicos que legitimaran las propuestas de cambio desde su actualidad epistemológica y científica.

Crecientemente se admite que la "actualización" académica no es un criterio suficiente para legitimar los cambios curriculares porque los contenidos académicos se desactualizan rápidamente y porque además la actualización de los contenidos no es el Único criterio válido 
para promover un cambio curricular. Se buscan criterios más Cercanos a la pertinencia y a la fertilidad para formar competencias. Por eso se recurre en algunos casos y en forma más parcial, por ejemplo en el rediseño de la educación técnico-profesional en México o en la Educación General en Río de Janeiro, a algunos grupos entre quienes con anterioridad han sido denominados interlocutores o referentes: el empresariado, las Organizaciones No Gubernamentales, dirigentes políticos, artistas y profesionales de los medios, para dialogar con ellos más ampliamente acerca de las demandas hacia la educación secundaria.

Estas búsquedas de diálogos con interlocutores externos al propio sistema educativo y al mundo académico en los procesos de cambio curricular encuentran metodologías de trabajo más apropiadas para el diseño de las ofertas que deben reemplazar a las viejas escuelas técnicas, donde se avanza en el agrupamiento de una gran cantidad de carreras para conformar menos especialidades que correspondan a amplias familias profesionales y que garanticen perfiles laborales más flexibles y polivalentes, que para el diseño de la educación general de los adolescentes y de los jóvenes. Todavía no se encuentran formas satisfactorias de incorporar a los padres y a los propios jóvenes a los procesos de construcción curricular.

Más allá del estatuto jurídico, del grado de prescripción y de la cantidad y variedad de actores y de interlocutores que se incorporó a los procesos de elaboración de los nuevos materiales curriculares para la educación secundaria en América latina, todos ellos proponen cambios para facilitar la gestación de una educación para jóvenes más flexible, sin tantas rigideces estructurales como en el pasado; y para actualizar los contenidos de enseñanza y las metodologías pedagógicas. Para eso casi todos ellos parten de asumir la necesidad de formar las competencias de los jóvenes, y no de transmitir información. Los logros en esa dirección son significativos si se comparan los nuevos diseños curriculares con los antiguos planes y programas, pero insuficientes si se tiene en perspectiva la formación de jóvenes que sepan aprender, convivir y emprender en las condiciones del siglo XXI.

\subsubsection{La tensión entre nuevos y viejos contenidos}

Más allá de las decisiones que en cada caso se toman respecto de si organizar los nuevos currículos de la educación secundaria por áreas o por disciplinas, el abanico de disciplinas de 
referencia, y aún de disciplinas que directamente se incorporan a los currículos y la orientación de los contenidos y de las metodologías que se priorizan también tienden a ser revisados.

En varios países están adquiriendo presencia, al menos como fuentes académicas para la construcción de disciplinas escolares, la geología entre las ciencias naturales y la sociología, la ciencia política, la antropología y la economía entre las ciencias sociales.

Al mismo tiempo están siendo cuestionadas como disciplinas escolares la geografía por un lado y la física y la química, por el otro.

En todo caso allí donde por temor a las reacciones corporativas de los profesores de las asignaturas afectadas no se modifican formalmente las inclusiones y las exclusiones curriculares, se revisa la selección de los contenidos propuestos en las materias con tradición escolar para incluir perspectivas correspondientes a nuevas disciplinas académicas sin tradición escolar y para excluir otras de disciplinas escolares que habrían perdido vigencia.

Entre las ciencias naturales se hace presente la influencia de la ecología. En ciencias sociales se abordan temas contemporáneos y se introducen perspectivas más investigativas y analíticas, frente a las anteriores orientaciones fuertemente descriptivas.

En ambos casos se introducen explícitamente temas traumáticos, aún cuando todavía se inscriben en los márgenes del curriculum.

Cuestiones referidas a la sexualidad, la pobreza, las desigualdades sociales, los golpes de estado o las crisis religiosas adquieren con diversa intensidad estatuto curricular.

También numerosas cuestiones referidas a la formación ética y ciudadana de los jóvenes ingresaron con mayor énfasis en estos currículos que en los planes y programas anteriores. La forma de incorporación de las cuestiones conflictivas es diferente en distintos casos. En el ciclo equivalente a la educación secundaria inferior algunos currículos optan por incluirlos como "temas transversales" que deben ser tratados en todas las áreas, disciplinas o talleres que sea posible. En otros casos ingresan áreas, disciplinas o talleres específicos.

Sin embargo existe cierto consenso entre los especialistas respecto de que los currículos no han logrado todavía encontrar fórmulas para promover la formación de los aspectos más vinculados a las identidades. En algunos trabajos se hace referencia a este déficit como un déficit en la promoción de la "subjetividad" (Tedesco, 1995). La concepción de "subjetividad" en este caso se asocia no sólo al manejo de información sobre cuestiones que afectan la vida privada de 
cada estudiante, sino a la promoción del establecimiento de criterios y valores propios y compatibles con una buena vida en común para el uso de esa información en la vida privada y comunitaria.

Por otra parte en la mayor parte de los países comienza a cobrar estatuto escolar la "tecnología", aunque con enfoques diferentes entre sí. Mientras que en la Argentina, por ejemplo, se enfatiza la propuesta de enseñar la tecnología entendida como detección de demandas, análisis de productos, diseño de proyectos y un abordaje sistémico en los años superiores (10, 11 y 12); en el caso de Chile tienen mayor presencia las tecnologías gestionales y en otros países se concibe a la tecnología casi indiscriminadamente de la informática y de la computación.

También en varios países se comienzan a revisar las concepciones de la educación artística y de la educación física, intentando acercar ambas a la promoción de la sensibilidad y de la expresión en los jóvenes, y no concibiéndolas como espacios de entrenamiento del cuerpo, el oído o la habilidad para dibujar.

El abordaje originario de la educación artística, de acuerdo al cual todos los estudiantes debían aprender música y plástica, tiende a ser revisado en una triple dirección. En primer lugar a través de la incorporación de otros lenguajes artísticos tales como el teatro y la expresión corporal. En segundo lugar a través de la búsqueda de propuestas de enseñanza de "artes" y "lenguajes" combinados y en tercer lugar, aunque en menor medida, a través de la aceptación aquí también del criterio de opcionalidad entre distintos lenguajes.

La concepción de la educación física, tradicionalmente apegada al entrenamiento militar (Aisenstein, 1996), se reemplaza por una formación más integral de las capacidades físicas en estrecha interacción con las emocionales y con el disfrute del movimiento y de la vida al aire libre.

En todos los países de la región existe una tendencia a modificar la tendencia a la enseñanza de una matemática muy deductiva y formalista, con énfasis en los teoremas y en el formuleo, por la enseñanza de una matemática más orientada a la resolución de problemas y con mayor presencia de la probabilidad y de la estadística.

También en todos los países se modifica la enseñanza de la lengua nacional, sustituyendo la enseñanza formalista estructurada en torno a la gramática por una enseñanza centrada en el discurso y en el texto. En la mayor parte de los casos se amplía el espectro de tipos de texto que 
se considera incluyendo el tratamiento de textos informativos y de otros no literarios. Existen variantes respecto de la inclusión o no de un canon de obras literarias de lectura obligatoria. En algunos casos se mantiene, lo cual indica que se sigue otorgando a la lectura compartida de un cierto conjunto de producciones culturales un papel relevante en la formación de aspectos de la identidad nacional compartida, y en otros no.

La revisión de las propuestas de enseñanza de la lengua nacional se inscribe en un proceso de diálogo y debate respecto de la cuestión más amplia de la enseñanza de las lenguas.

\subsubsection{El acceso equitativo, inclusión social, igualdad de género}

La UNESCO (2005), en su Informe Mundial titulado Hacia las sociedades del Conocimiento, refiere que el acceso a la educación y la calidad de ésta son necesidades y derechos interdependientes e inseparables; la educación debe preparar a los educandos para afrontar los desafíos del siglo XXI, fomentando en particular el desarrollo de la creatividad, de los valores de ciudadanía y democracia, y de las competencias imprescindibles para la vida diaria y profesional; así mismo, la inversión en educación debe apuntar a la mejora de los contextos.

"Las tendencias derivadas de recientes estudios como los del Programa PISA sugieren centrarse, de manera prioritaria en levantar el piso de calidad de las escuelas con mal desempeño, sin que ello signifique abandonar a las escuelas con más alto rendimiento, sino más bien aprovecharlas para apoyar a las primeras". (Hugo Díaz, 2006)

En este aspecto del acceso, la equidad y la igualdad de género, la UNESCO en la Conferencia Internacional de Educación en Ginebra (2004) enfatiza en los siguientes aspectos:

o La definición de una educación de calidad desde una perspectiva de los derechos humanos incluye una revisión sistemática de los factores que facilitan u obstaculizan los derechos de diversos grupos. La mejor manera de hacerlo es concentrándose en el estudiante como alguien con derecho a la educación, y revisando los factores relativos al acceso, a la asistencia, a la finalización de la escolarización y al logro de aprendizajes relevantes por parte de diferentes grupos de estudiantes.

○ En los países en desarrollo se percibe la educación de calidad como el acceso a la educación; mientras que en las sociedades modernas se enfoca en los resultados y en la preparación de los niños para la oferta y la demanda relacionada con la globalización. 
Se deben establecer los mecanismos nacionales e internacionales que mezclan los modelos modernos con las percepciones tradicionales. En este sentido, el acceso equitativo involucra reconocer y atender las necesidades de aprendizaje de los jóvenes y adultos, mediante un aprendizaje adecuado y con programas de preparación para la vida activa.

○ Focalizar los esfuerzos en la educación y la inclusión social exige una mejor comprensión de las situaciones de exclusión, que representan un obstáculo a la realización del derecho a una educación de calidad para todos. Requiere además que se identifiquen los obstáculos a la participación de los individuos y grupos en situación de discriminación, marginalización y exclusión, y que se compartan las experiencias prácticas creativas e innovadoras para superar estas barreras.

o La exclusión de grupos vulnerables de niños y jóvenes no se limita a una cuestión de educación, requiere un abordaje holístico que considere los factores culturales, sociales y económicos que caracterizan el entorno de los estudiantes.

O A fin de alcanzar la calidad, es necesario hacer una planificación estratégica en función del contexto, de las cuestiones de igualdad entre los sexos y de los recursos disponibles.

○ La educación básica y la alfabetización de adultos, sobre todo para las mujeres, se tornan una inversión vital, si se desea romper el ciclo delanalfabetismo, la ignorancia y la pobreza.

o De la capacidad de los modelos educativos para garantizar condiciones de equidad, dependerá una participación igualitaria en la producción, recreación y apropiación de contenidos socialmente significativos.

○ La educación de calidad no podrá existir sin la igualdad de género. El concepto de calidad educativa debe tomar en cuenta las dimensiones de género en todos los aspectos de selección, organización, y exposición a experiencias de aprendizaje relevantes y significativas para los estudiantes.

o La calidad de la educación también debería tomar en cuenta el tema de la igualdad entre hombres y mujeres desde la edad temprana, y debería incluir el desarrollo de competencias para vivir juntos en armonía, así como la adquisición de los conocimientos y de las competencias. 
Desde la última década del siglo XX se han venido realizando experiencias de educación por género en escuelas de Estados Unidos y Europa:

- Algunas de las razones que argumentan las escuelas en Estados Unidos, acerca del cambio de la educación mixta hacia la diferenciada, se centran en los problemas que ha generado la educación mixta; la naturaleza misma de las mujeres y de los hombres imponen unos modelos que no se pueden homogenizar. En Estados Unidos, por ejemplo, se pasó de seis escuelas de educación diferencial a 2.870 en la actualidad. Escuelas en California, Texas, Nuevo México, Georgia, Washington, han optado por la educación diferenciada en razón a la delincuencia juvenil y al incremento de abusos sexuales.

- La opción que han tomado las escuelas por este tipo de educación, no tiene nada que ver con el aspecto doctrinal, pues tradicionalmente se ha asociado con las escuelas de comunidades religiosas. En el caso norteamericano ese es el factor menos preponderante.

- En países como Italia y Francia, caracterizados por ser más liberales, hay escuelas por género que no tienen más de diez años. Existe un fenómeno, aún sin explicar, que está haciendo ver que es conveniente este tipo de educación.

\subsubsection{El multiculturalismo y el Interculturalismo}

La UNESCO en la reunión de Ginebra (2004) menciona la amenaza de que la globalización borre las diferencias entre individuos y culturas, es por esto, que la multiculturalidad necesita insertarse en una perspectiva más amplia que, garantizando su desarrollo, promueva y potencie al mismo tiempo su comunicación y su intercambio, su apertura y su hibridación. Se trata de apostar por el sostenimiento de la singularidad cultural, de las diversidades nacionales, locales y regionales, dentro de un diálogo entre las culturas, orientándonos así a la conformación de un horizonte común a partir del cual diseñar una cobertura más acorde con nuestras necesidades. Es necesario concretar el pasaje del multiculturalismo como reconocimiento previo de las identidades, de la diferencia entre "nosotros" y "ellos", al interculturalismo como las condiciones de comunicación en un futuro compartido.

En el mismo documento la UNESCO indica que para consolidar unas democracias socialmente participativas, capaces de resolver las profundas situaciones de inequidad, es necesario conseguir una interculturalidad pensada como comunicación con el otro. Una 
comunicación que radica en conciliar el respeto por las diferencias culturales y de valores, con políticas económicas y sociales que hagan viables los diferentes proyectos de vida.

Pérez Bonet (2006) en la Revista Educación y Futuro, anota que en el multiculturalismo el deseo de integración mercantil conlleva la idea de configuración de una cultura única, uniforme y universal, sin embargo, a esta tendencia expansionista del modelo económico neoliberal se le suman como contrapeso modelos de reivindicación de la identidad local, regional y nacional.

El tema de la emigración se ha convertido en un deber forzoso para millones de personas debido a los desastres bélicos, la ausencia de sistemas democráticos y las persecuciones étnicas, entre otros. De este modo, hay una tendencia a la homogenización de las sociedades, pero a la vez un fuerte llamado a la conservación de la identidad cultural, constituyendo así el tema del multiculturalismo un reto hacia el replanteamiento de nuevas relaciones entre culturas, donde la educación juega un rol protagónico como agente mediador y de cambio.

La diversidad cultural existe, tanto dentro de la propia cultura como dentro de la sociedad multicultural, esta infinita riqueza hace necesario comprender la dinámica de las relaciones entre las culturas y lograr un diálogo entre ellas, a fin de ir más allá de una simple tolerancia del otro donde no es posible una convivencia entre culturas, porque prima la protección de lo propio frente a lo ajeno. Establecer una vía de relación constructiva entre las culturas significa promover la interculturalidad mas que el multiculturalismo, ya que sólo en la comunicación y el reconocimiento mutuo se da la apertura, la toma de conciencia de cambio y el mismo intercambio. Además, es en el diálogo intercultural donde se logran auténticos consensos, flexibilidad y comprensión empática.

El autor en mención plantea que sólo en el marco de la interculturalidad es posible la flexibilidad, la apertura al cambio, la autocrítica, la construcción de un mundo más igualitario, la solidaridad entre las culturas, la igualdad en el desarrollo de personas y grupos, la exigencia de una posición comprometida con valores éticos e ideológicos y, en definitiva, una reconfiguración global de la percepción de la realidad, cuyo objetivo es encontrar desde todas las cosmovisiones culturales posibles respuestas consensuadas que resuelvan los problemas más importantes de nuestro tiempo, posibilitando miradas universales y más humanas. 


\subsubsection{El desarrollo del conocimiento y la investigación}

El experto Héctor Casanueva (2007), en la revista del Instituto de Globalización y Prospectiva, haciendo referencia al Proyecto del Milenio, reflexiona sobre algunos aspectos del desarrollo científico-tecnológico esperados para los siguientes cuarenta años, que exigen hoy urgentes definiciones éticas y políticas:

· La posibilidad de una pronta mutación desde nuestra actual condición humana ("bio-org"), hacia una nueva especie humana ("Cyb-org") "rediseñada" tecnológicamente en lo físico, potenciada cerebralmente mediante la implantación de chips con capacidad de procesamiento cinco mil veces mayor que los actuales, conectada a la Internet, y capaz de obtener una información en tiempo real.

- La creación de una generación de vida artificial inteligente, robots y symborgs, que superen en capacidad de procesamiento de información al cerebro humano, e incluso con "pensamiento" propio.

- El advenimiento de mundos virtuales en la Internet entrelazados con el real, con "ciudadanos virtuales" y con organismos virtuales cuyo hábitat es la web.

- La intervención genética en embriones cuando la lectura del código indique predisposición a ciertas enfermedades o a conductas violentas.

Los transhumanistas creen que, a través de la acelerada marcha del desarrollo tecnológico y el entendimiento científico, estamos registrando toda una etapa en la historia humana. Los avances en inteligencia artificial, robótica, bio-ingeniería, clonación, criogenización, nanotecnología, nuevas energías, codificación del pensamiento, bebés de diseño, cyborgs, química molecular, exploración espacial, inmortalidad, y realidad virtual, nos van a conducir a un sustancial crecimiento físico y mental, posiblemente para converger a un punto de singularidad. Esto es lo que el "transhumanismo" considera como el verdadero comienzo de la evolución. El histórico deseo humano de trascender las limitaciones corporales y mentales, está profundamente entrelazado con la fascinación humana sobre el nuevo conocimiento, el cual es tan inspirador como aterrador. La forma en que estas tecnologías sean utilizadas, podría cambiar profundamente el carácter de nuestra sociedad, e irrevocablemente alterar las definiciones de 
nosotros mismos, y la manera como hemos determinado nuestro lugar en el gran esquema de las cosas.

El autor en mención, plantea algunas preguntas que surgen al interior del Proyecto del Milenio, y realmente son inquietantes: ¿tenemos el derecho de cambiar genéticamente para transformarnos en nuevas especies? ¿Resulta ético crear élites mejoradas con inteligencia artificial e ingeniería genética? ¿Somos capaces de evitar el mal uso de la tecnología, por ejemplo por el crimen organizado? Como no existe una gobernabilidad global de estos temas, que sin embargo repercutirán globalmente, en América Latina deberíamos estar preocupados y ser capaces de encontrar posiciones comunes, ir concertadamente a los organismos internacionales y pedir nuestro lugar para participar en la gestión del futuro.

El documento Perspectivas y desafios de la educación en el mundo de Hugo Díaz (2006), con respecto a este tema realiza los siguientes planteamientos:

- El conocimiento al crecer en forma exponencial, impactará el futuro de la educación en las formas de enseñar y aprender, así como el papel de la escuela y el educador.

- Hay estudios que proyectan que, debido al imparable desarrollo del conocimiento científico y de la tecnología, el $80 \%$ de lo aprendido tendrá que ser reaprendido, desechado, o repensado.

- Las tendencias derivadas de recientes estudios como los del Programa PISA sugieren centrarse, de manera prioritaria, en hacer de la educación una profesión rica en conocimiento, que repose en el más avanzado adelanto tecnológico, que permita el acceso al conocimiento de las mejores prácticas de enseñanza que se producen en el mundo, y al desarrollo profesional de más alta calidad, de forma que educadores bien calificados y esforzados, desarrollen altas expectativas de aprendizaje, administrando con éxito estándares elevados de rendimiento, en grupos de estudiantes cada vez más diversos. De este modo, las nuevas tecnologías, ampliamente difundidas en las aulas cobran especial trascendencia.

La UNESCO (2004) en el tema del desarrollo del conocimiento y la investigación, hace énfasis en los siguientes aspectos:

- Es un rasgo importante de una economía globalizada en estado de perpetua evolución, el hecho de que los conocimientos y las aptitudes se amplían y aplican de forma novedosa. 
- La economía mundial del conocimiento modifica las demandas del mercado de trabajo de las economías de todo el mundo; también impone nuevas demandas a los individuos, que necesitan más aptitudes y conocimientos para enfrentarse a la vida cotidiana.

- La relación entre la enseñanza en las aulas y la investigación, reviste gran importancia y ha de tener un carácter bidireccional, en forma de información facilitada a los educadores sobre las últimas investigaciones en el campo de la educación, la pedagogía y la psicología, e información facilitada a los investigadores, sobre los problemas que los educadores encuentran en el aula en el ejercicio de su profesión.

El documento titulado Hacia las sociedades del conocimiento (2005), destaca los siguientes desafíos como los más importantes en relación con el conocimiento:

- Si bien, la brecha digital es una realidad innegable, hay algo más inquietante todavía: la brecha cognitiva que separa a los países más favorecidos de los países en desarrollo, y más concretamente de los países menos adelantados. Esta brecha corre el riesgo de ahondarse, al mismo tiempo que surgen o se amplían otras grietas muy profundas dentro de cada sociedad. Podemos observar cómo se multiplican paradójicamente las brechas y las exclusiones, tanto entre los países del Norte y del Sur como dentro de cada sociedad.

- La brecha cognitiva está acumulando los efectos de las distintas brechas observadas en los principales ámbitos constitutivos del conocimiento, a saber: el acceso a la información, la educación, la investigación científica y la diversidad cultural y lingüística; y representa el verdadero desafío planteado a la edificación de las sociedades del conocimiento.

- La resolución del problema de la brecha digital no bastará para resolver el de la brecha cognitiva. Poner en contacto a las poblaciones mediante cables y fibras ópticas no sirve para nada, a no ser que esa "conexión" vaya acompañada por una creación de capacidades, y una labor encaminada a producir contenidos adecuados. Las tecnologías de la información y la comunicación, necesitan todavía que se elaboren nuevos instrumentos cognitivos y jurídicos para actualizar todo su potencial.

- En la nueva fase de mundialización que está experimentando el planeta, uno de los problemas principales que se plantean a las sociedades, es el de conservar las capacidades que ya poseen, porque están mermando a causa de un éxodo de competencias cada vez mayor. La comunidad internacional debería dar prioridad a una mejor valorización de los 
conocimientos existentes, y explotar todos los puntos fuertes disponibles, por modestos que sean, en materia de educación, investigación científica y desarrollo tecnológico para luchar contra la brecha cognitiva.

La UNESCO (2005) plantea la importancia que se ha de conceder a la ciencia y la tecnología. La idea de sociedades del conocimiento debe mucho al desarrollo de la investigación y la innovación científicas. Los protagonistas y los centros de actividades científicas están experimentando actualmente una honda mutación. Teniendo en cuenta la presencia cada vez mayor del mercado en el ámbito de las actividades científicas, es a éstos a quienes corresponde crear, en el punto de intersección de los sectores científico, económico y político, sistemas de investigación e innovación que propicien el desarrollo sostenible, y redunden en beneficio tanto de los países del Norte como del Sur.

Los nuevos modelos de aprovechamiento compartido de los conocimientos, por ejemplo, el "colaborativo", representan una vía que se ha de aprovechar más a fondo. De esta manera, la ciencia y la tecnología podrán contribuir a edificar sociedades del conocimiento basadas en la integración y participación de todos.

\subsubsection{La enseñanza-aprendizaje}

Antonio Arellano Duque (2005) define el futuro de la pedagogía en una perspectiva de cambio e incertidumbre, puesto que vivimos en un mundo y en unos tiempos complejos y difíciles. Esta situación se vive desde la pedagogía como una revisión de sus conceptos fundamentales: la educación, la enseñanza, el aprendizaje y la formación. Reflexionar sobre la pedagogía significa acercarnos a una lectura de los rasgos que perfilan el espíritu de la época y establecer una relación con lo incierto e indeterminado, la complejidad, lo simultáneo, la equidad, la competitividad, el cambio, lo público y lo privado, lo local e internacional, el terrorismo y los autoritarismos.

La UNESCO (2004), define las siguientes tendencias en el tema de la enseñanza y el aprendizaje:

- La enseñanza secundaria debe centrarse, no sólo en responder a la creciente demanda sino

que debe redefinirse, renovarse y mejorarse para satisfacerfunciones como preparar a los estudiantes, formal e informalmente para la enseñanza superior, para el mundo laboral, y lo que 
puede ser aún más importante, para que se conviertan en ciudadanos responsables de un mundo en constante evolución. La prioridad debería estar marcada no solo por la renovación de contenido, de métodos y estructuras de la enseñanza secundaria, sino también por la mejora de la formación del educador y de los responsables de los distintos establecimientos, para que puedan cumplir mejor su función a la hora de aconsejar y orientar a los adolescentes.

- La educación debe poder ser impartida y adquirida por distintos medios, y constatar que el individuo ha aprendido y ha adquirido conocimientos.

- Los recursos didácticos y el material tradicional son insuficientes. Los abordajes más directamente ligados a la práctica y a la interactividad, basados en la experiencia personal y en la experimentación, tendrán que ser utilizados.

- La participación del mundo exterior en las escuelas y de la educación no-formal es necesaria para poder enseñar de manera combinada e integrada los diferentes aspectos del conocimiento y de la experiencia, que el enfoque pedagógico de competencias para la vida implica.

- Aunque el principio de "aprendizaje práctico" es el método de aprendizaje generalmente considerado superior, las nuevas investigaciones en los ámbitos de las neurociencias, la gestión de los conocimientos y la teoría del aprendizaje indican que "el verdadero aprendizaje", sólo se produce con y mediante la práctica, no existiendo diferencia entre "saber algo" y "saber hacerlo".

- En la nueva economía mundial, los individuos no sólo deben ser capaces de utilizar eficazmente sus conocimientos y habilidades, y de actuar de manera autónoma y reflexiva, sino también de evolucionar constructivamente en muchos ámbitos sociales diferentes. Para lograrlo, los países necesitan reemplazar los sistemas de aprendizaje memorísticos y directivos, por modelos que estimulen y privilegien la creación, la aplicación, elanálisis y la síntesis del conocimiento y las habilidades.

- La calidad tiene que ver con la coherencia de lo que se enseña y aprende, con el grado de adecuación a las necesidades de aprendizaje presentes y futuras de los aprendices concretos, habida cuenta de sus circunstancias y expectativas particulares.

La Unión Europea en la reunión de Ginebra (UNESCO, 2004) evaluó la calidad de la enseñanza con base en doce puntos: 
- El éxito escolar.

- El desarrollo personal y social.

- La trayectoria del alumnado.

- El uso del tiempo en el aprendizaje.

- La calidad del aprendizaje y de la enseñanza.

- El apoyo en caso de dificultades del aprendizaje.

- El centro escolar como lugar de aprendizaje.

- El centro escolar como espacio social.

- El centro escolar como espacio profesional.

- El centro escolar y el hogar.

- El centro escolar y la comunidad.

- El centro escolar y el mundo del trabajo.

El informe de la UNESCO (2005) confirma que el aprendizaje se ha difundido mucho más allá del universo de los educadores y se ha extendido a todos los niveles de la vida económica y social. Es cada vez más evidente que toda organización, con fines comerciales o sin ellos, tendrá que acrecentar su "dimensión de aprendizaje", con lo cual los centros y los medios del conocimiento están destinados a multiplicarse tanto en los países del Norte como en los del Sur.

Otra tendencia en los procesos de aprendizaje que cobra cada vez más importancia, es la neurociencia. ésta tiene sus orígenes en las ciencias naturales, en las ciencias sociales y en las ciencias exactas. Su influencia hoy ha generado mayor fluidez en el lenguaje, mayor incertidumbre y caos, ampliación de campos y relaciones, y un nuevo imperio de la mente. Así mismo, tiene unas consecuencias claras para la educación:

- Paso de la era mecanicista a la era sistémica, donde lo que realmente cuenta es la persona, el campus, la interdependencia, las relaciones y las potencialidades.

- Se establece un nuevo concepto de libertad.

- Se considera el aprender siempre, como un proceso colectivo.

- Sólo existe lo que creamos mediante el compromiso consigo mismo, con los otros y con los acontecimientos.

- Los organismos vivos crean nuevas formas de organización. 
- Todo está en proceso de descubrimiento, creación y cambio, a todos los niveles: individuos, sistemas, ambientes, reglas, procesos.

- Desarrollo de las múltiples inteligencias, configurando las "cinco mentes del futuro" (Howard Gardner): mente disciplinada, mente sintetizadora, mente creadora, mente respetuosa y mente ética.

- Desarrollo de la inteligencia genial, establecida desde los principios de Leonardo Da Vinci, así: actitud de acercarse a la vida con curiosidad insaciable y búsqueda continua del aprendizaje; compromiso de poner a prueba el conocimiento a través de la experiencia, la persistencia y la disposición a aprender de los errores; continuo refinamiento de los sentidos especialmente la vista (sensaciones); capacidad de crear vínculos (pensamientosistémico); cultivo de la corporalidad; desarrollo del equilibrio entre arte y ciencia; y voluntad de aceptar la ambigüedad, la paradoja y la incertidumbre.

El estudio de las nuevas realidades mundiales que afectan, entre otros a la educación, se circunscribe dentro de la disciplina de la prospectiva estratégica, en tanto es un instrumento para observar los cambios de la cultura y la sociedad, para tomar decisiones y construir escenarios futuros y pertinentes. Los estudios prospectivos otorgan al campo de la educación un sentido de planificación, estructuración y proyección sobre algo intangible y realmente impredecible como el futuro. Los estudios futuristas o de prospectiva permiten la anticipación al futuro como un ejercicio de acercamiento a éste con fines de construcción, no sólo de uno, sino también de múltiples sentidos que puedan hacer posible la realización del ser humano.

Los diferentes documentos analizados coinciden en la importancia de asumir el futuro desde la perspectiva de lo impredecible, reconociendo que en lo incierto hay una dinámica que obliga al ser humano, y por ende a las diferentes instituciones a considerar que ya no hay un orden inalterable. Hoy es necesario poner la mirada más allá, analizar hacia dónde va el futuro, crecer como organización en el diálogo y la diversidad, y ser concientes de que los movimientos de la sociedad civil al tiempo que están caracterizados por la probabilidad, están influidos por múltiples variables.

También se reconoce que es importante centrar la mirada en el bienestar de la humanidad y en el desarrollo social, a partir de la educación. La educación para toda la vida, en el marco de la equidad y la calidad, se constituye en la base de las transformaciones sociales y económicas. Sin 
embargo, es claro que la falta de decisión política y de participación equitativa de todos los estamentos de la sociedad no ha permitido alcanzar estos propósitos, y además, la educación no ha sido asumida con igual prioridad en todos los países.

La evolución de la organización social, política y económica de la actividad humana transforma nuestras prácticas culturales, altera la percepción que tenemos de nosotros mismos y de la sociedad, y genera los desafíos globales que ha de enfrentar la humanidad. Estos desafíos son el primer referente que los educadores, además de otros actores de la sociedad, han de considerar para avanzar en la generación de conciencia hacia la superación de los diferentes problemas del milenio, y para transformar los procesos educativos formales.

El resurgimiento de lo espiritual como un factor importante en la vida del ser humano, moviliza con mayor frecuencia a personas, colectividades y empresas, a reconocer y valorar principios éticos de actuación que aseguran el éxito. En consecuencia, los procesos educativos orientados hacia la construcción de valores individuales y colectivos, no sólo en el ámbito escolar, sino en el empresarial, tienen hoy una mayor relevancia, por las importantes inversiones de capital y la dedicación de personas a los temas de desarrollo humano.

La movilidad de personas y capitales ha generado una dinámica de rompimiento de fronteras, que si bien, por un lado contribuyen al fortalecimiento de dinámicas de integración regionales, por otro, han generado discriminación hacia personas de otras latitudes.

El crecimiento exponencial del conocimiento y de las comunicaciones han influido para que se establezcan relaciones más flexibles de cara al aprendizaje, para que las instituciones que van a la vanguardia de los cambios globales se interesen más por atraer y retener a las personas más talentosas; y propone que la educación atienda las necesidades de los estudiantes de manera individual, hacia el logro de estándares más elevados.

La globalización de la economía modifica las prioridades políticas, y por consiguiente los retos para la educación. Por esta razón, se hace indispensable plantear nuevos principios en educación que den respuesta a las necesidades de sentido que el ser humano requiere en su tarea de humanización, y oportunidades para todos, con una visión solidaria, de trascendencia, apoyo y progreso del mundo. Por consiguiente, los sistemas educativos que consideren estos nuevos principios permitirán preparar a los individuos y a las naciones para competir en la economía 
mundializada que se logrará, siempre y cuando, haya una clara y firme voluntad política de los gobiernos.

Las investigaciones sobre el cerebro humano se han centrado en descubrir cómo se produce el aprendizaje y en los métodos que podrían incrementar la inteligencia personal; se contempla incluso la posibilidad de mejorar genética y artificialmente los cerebros con miras a optimizar las funciones cerebrales.

Las megatendencias en educación, proyectadas al año 2025, plantean que la educación postmoderna se orienta hacia modelos flexibles y caracterizada por:

- La intensificación de la vinculación escuela-empresa en forma de redes de colaboración.

- La flexibilización del currículum enfocado a normas de competencia.

- El replanteamiento del actual modelo universitario.

- La orientación de la oferta por necesidad de contar con mano de obra calificada, a partir de procesos formativos definidos por la escuela.

- El educador como tutor que facilita el aprendizaje.

- La educación para la polivalencia y la multifuncionalidad.

La construcción de una sociedad de aprendizaje requerirá:

- Que los estudiantes dispongan de una computadora portátil con acceso a Internet.

- Que todas las personas accedan masivamente a los mejores maestros del mundo en cualquier materia.

- Que los padres de familia sean capacitados en el desarrollo del potencial temprano de cada niño.

- Que los educadores sean profesionales valorados y con un salario adecuado.

- Que cada persona pueda planear su propio programa de estudios a cualquier edad.

- Que la escuela sea una base para explorar el mundo de la experiencia y el conocimiento; que enseñe como materias principales "aprender cómo aprender", "aprender cómo pensar" y "aprender cómo convertirse en un administrador del propio futuro con iniciativa propia"; y que la escuela se convierta en centro del saber las 24 horas del día, ligado a negocios u organizaciones en una comunidad de aprendizaje.

- Que las Corporaciones tengan como papel principal organizar personas, no necesariamente emplearlas. 
Los modelos flexibles modificarán la oferta educativa y tenderán a investigar, enseñar y difundir lo requerido en el entorno del sector productivo, teniendo en cuenta que es necesario mantener la función sustantiva de la educación.

Para alcanzar la calidad en educación es necesario hacer una planificación estratégica en función del contexto, de las cuestiones de igualdad entre los sexos y de los recursos disponibles. La educación de calidad además de garantizar el acceso, la equidad y la igualdad de género, se enfocará en los resultados y la preparación de los niños para la oferta y la demanda relacionadas con la globalización; fomentando la creatividad, los valores de ciudadanía y democracia, y las competencias para la vida diaria y profesional; de forma tal, que se eleve el nivel de las escuelas con mal desempeño, sin que ello signifique abandonar a las de más alto rendimiento. Una educación de calidad para grupos vulnerables de niños y jóvenes requiere un abordaje holístico que considere los factores culturales, sociales y económicos que caracterizan su entorno.

El concepto de calidad educativa, desde la perspectiva de género considerará los aspectos de selección, organización, y exposición a experiencias de aprendizaje relevantes y significativas para los estudiantes.

Un hecho singular de esta época es la relación entre redes como necesidad de estar juntos, de construir juntos, de sensibilizarse, y de tener una mirada global de los problemas. El trabajo en redes presenta como reto el paso del multiculturalismo al interculturalismo, en el que la comunicación con el otro radica en conciliar el respeto por las diferencias culturales y de valores, con políticas económicas y sociales que hagan viables los diferentes proyectosde vida. Frente a un futuro cada vez más incierto, la capacidad de generar alianzas puede ser lo que marque la diferencia ante a los competidores.

La promoción de la educación como fundamento de una sociedad más viable para la humanidad, hace necesario integrar el desarrollo sostenible en el sistema de enseñanza para comprender sus principios, cómo pueden ser instaurados, los valores que implica, y las derivaciones de su implantación.

Las instituciones se encuentran cada vez más interesadas en el desarrollo personal y profesional de sus colaboradores, con miras a alinear a las personas en función de sus principios, valores y resultados. En el campo empresarial es cada vez más habitual la necesidad constante de poner al día profesionalmente a la población económicamente activa, a fin de adaptarla a los 
cambios tecnológicos o del mercado, para lo cual destina importantes recursos que son considerados inversión social, y que son comprendidos por sus colaboradores como un valor agregado que reciben de sus empleadores.

La tendencia hacia la eliminación de fronteras posibilita el aumento de la internacionalización de la educación y el riesgo de una mayor uniformidad de la educación en todo el mundo.

Con la acelerada marcha del desarrollo tecnológico y el entendimiento científico estamos llegando a una nueva etapa en la historia humana, donde el histórico deseo de trascender las limitaciones corporales y mentales, ha llevado al hombre a que los avances en inteligencia artificial y demás disciplinas asociadas conduzcan a la humanidad a un sustancial crecimiento físico y mental, posiblemente para converger a un punto considerado como el verdadero comienzo de la evolución.

El conocimiento al crecer en forma exponencial, impactará el futuro de la educación en las formas de enseñar y aprender, así como el papel de la escuela y el educador. Hay estudios que proyectan que, debido al imparable desarrollo del conocimiento científico y de la tecnología, el $80 \%$ de lo aprendido tendrá que ser reaprendido, desechado o repensado.

Las tendencias sugieren centrarse, de manera prioritaria en hacer de la educación una profesión rica en conocimiento, que repose en el más avanzado adelanto tecnológico, que permita el acceso al conocimiento de las mejores prácticas de enseñanza que se producen en el mundo, y el desarrollo profesional de más alta calidad, de forma que educadores bien calificados y esforzados desarrollen altas expectativas de aprendizaje, administrando con éxito estándares elevados de rendimiento en grupos de estudiantes cada vez más diversos.

Respecto del desarrollo del conocimiento y la investigación, es de destacar que los conocimientos y las aptitudes se amplían y aplican de forma novedosa; la economía globalizada impone nuevas demandas a los individuos que necesitan más aptitudes y conocimientos para enfrentarse a la vida cotidiana; la relación entre enseñanza e investigación reviste gran importancia y ha de tener un carácter bidireccional entre educadores e investigadores. Aquéllos informando a éstos sobre los problemas que encuentran en el aula, y éstos dando a aquéllos información pertinente y actualizada. 
La revolución tecnológica y los procesos de globalización conforman el mundo actual como una gran cultura mediática. Esto implica una capacidad para reconocer los nuevos lenguajes que pueden ayudar a una mayor humanización global. Estos nuevos lenguajes configuran un elemento articulador de los cambios en la sociedad.

La rapidez en la evolución del conocimiento ha generado una brecha cognitiva que acumula los efectos de las distintas brechas observadas en los principales ámbitos del conocimiento y representa el verdadero desafío planteado a la edificación de las sociedades del conocimiento. Los nuevos modelos de aprendizaje compartido como el "colaborativo", representan una vía que se ha de aprovechar más a fondo con el fin de cerrar esta brecha. De esta manera, la ciencia y la tecnología podrán contribuir a edificar sociedades del conocimiento basadas en la integración y participación de todos.

Las nuevas formas de relación e interacción generadas por las innovaciones tecnológicas y de la comunicación, demandan de las instituciones educativas la integración a sus procesos de formación de elementos clave como la gestión del conocimiento, el trabajo cooperativo y las tecnologías, no sólo para mejorar la efectividad de la formación, sino también como estrategia competitiva de la institución.

Esta época como escenario de transformaciones y cambios radicales en las nuevas tecnologías de la información y la comunicación, va acompañada por un cambio en el régimen de los conocimientos que viene influyendo en los medios de creación, transmisión y tratamiento de los mismos; lo anterior induce a pensar que estamos en vísperas de una nueva era digital del conocimiento. Por otra parte, las nuevas tecnologías como complemento de la tarea del educador, facilitan la creación de nuevos métodos de aprendizaje y enseñanza, en los que los educadores sean parte importante del proceso didáctico, y ayuden a consolidar el aprendizaje y el manejo de los instrumentos digitales.

El currículo, como eje del cambio educativo, busca permanentemente la mejora cualitativa del mismo, considerando el desarrollo de dos dimensiones. La primera, vincula la escuela y la realidad social, tomando en cuenta los cambios que se producen en la cultura. La segunda, integra los procesos educativos al interior de la escuela en función de garantizar la pertinencia de dichos procesos y los resultados del aprendizaje. 
Se observa una tendencia hacia el desarrollo de marcos curriculares más flexibles en los que se establecen metas, objetivos y resultados del aprendizaje en términos más amplios. Se traslada la atención de la enseñanza al aprendizaje, de la transmisión de información a la construcción de conocimiento y desarrollo de las aptitudes y competencias para aprender y seguir aprendiendo a lo largo de toda la vida, de un control centralizado a un control compartido e interdisciplinario, de un aprendizaje por categorías y memorístico a un aprendizaje integrado y aplicado, de una concepción curricular expresada en documentos y temas a un currículo como marco y como proceso. Esta concepción del currículo requerirá esfuerzos importantes por parte del conjunto de la comunidad escolar, no solamente de los gestores y de los educadores, sino también de los padres y madres, así como de los jóvenes. Estos gestores de escuela y educadores deberán estar capacitados, ser autónomos, estar motivados y ser capaces de adaptar los objetivos de los planes de estudio, a las necesidades de los estudiantes.

El diagnóstico pedagógico constituye un requisito ineludible para el mejoramiento de la calidad de la educación en el aula, en la escuela, en una zona, región o país. Deberá ser integral, es decir, tendrá que abordar el análisis de los diferentes factores clave en el éxito del trabajo educacional, y al estudiante, su personalidad y las relaciones entre éste y los distintos factores de aprendizaje.

La cohesión social como objetivo pedagógico plantea dos cuestiones. La formación de personas competentes en aquellas dimensiones que les permitan incorporarse en el mundo social, laboral y familiar de forma satisfactoria y eficaz; y la formación de personas capaces de construir su modelo de vida orientado a la competencia moral. Aprender a aprender, a saber, a hacer, a estar en este mundo, y aprender a convivir, requieren unos niveles altos de alfabetización funcional, emocional y ética. Por otra parte, para que los estudiantes desarrollen aptitudes básicas y competencias fundamentales concretas, deberán encontrarse en situaciones que les planteen desafíos pertinentes; es así, como el denominado "aprendizaje práctico" y la experiencia personal contribuirán al logro de los objetivos. Por último, la educación debe preparar a los jóvenes y a los niños para tomar parte en actividades de ámbito internacional y entenderlas, otorgando espacios a la autoevaluación, a las competencias relacionales y de comunicación, a lainterdisciplinariedad, a los intercambios, al trabajo en equipo y al profesionalismo colectivo. 
La eficacia de los sistemas educativos tiene como consigna, no tolerar el fracaso. Desde esta perspectiva, no es excusa un entorno socioeconómico desfavorecido para disminuir las exigencias académicas que permitan construir una buena base lingüística, matemática y científica, sino por el contrario, aumentar sus aspiraciones.

Las nuevas tendencias del proceso educativo indican que cambiará el sentido y el rol de los educadores. La enseñanza se impartirá en forma de asesoramiento y orientación de las actividades del estudiante. El aprendizaje alcanzado se evaluará en función de las modalidades pedagógicas. El seguimiento y la evaluación permanente, y el asesoramiento a lo largo de todo el curso formarán parte integral de la enseñanza.

El cambio en el rol del docente pasará de "transmisor de saberes" a "mediador de la construcción del conocimiento", a favorecer el desarrollo de competencias sociales y un clima de vida escolar que permita a los jóvenes aprender a vivir juntos y llegar a ser ciudadanos responsables. Igualmente, de la masificación de la enseñanza secundaria se pasará a la creciente heterogeneidad de los estudiantes, a la redefinición de los objetivos y de los currículos, de los métodos de trabajo y de la evaluación, a la creciente autonomía de los establecimientos, y a la mayor participación de los jóvenes en las decisiones tomadas en la escuela; algunos no dudan en hablar de una "nueva profesión docente", mucho más exigente y compleja.

La calidad del educador se verá como un conjunto dinámico de calidades, y no como un conjunto finito de comportamientos mensurables, que se ejercen cada uno con independencia de los demás. Por otra parte, el educador mejorará la calidad de la educación en la medida en que tenga la capacidad de evaluar su propia labor educativa, examinar con talante crítico los métodos empleados y plantearse otras modalidades de enseñanza. En síntesis, las claves en relación con la calidad del docente son su profesionalismo y su fortaleza ética.

La transición de la educación obligatoria a la vida activa tenderá a convertirse en una etapa muy prolongada, donde será necesario que las instituciones conozcan el contexto laboral y las necesidades del mercado, a fin de articular con la formación el desarrollo de nuevas empresas que generen empleo. En los países con pocas oportunidades de empleo, desarrollar en los estudiantes las competencias del espíritu empresarial tendrá una gran importancia, por lo cual las instituciones deberán integrar en su currículo la empresa, como tema obligatorio u optativo para todos los estudiantes. 
La educación ética y en valores es una tendencia clara y clave para una educación de calidad. Por esto, el mayor reto para la sociedad actual y en especial para la educación, es lograr una formación integral que sea trascendida por la ética y los valores, donde lo colectivo manifiesto en valores como amor, compasión, fraternidad, servicio, solidaridad, entrega e igualdad, entre otros, requiere la proyección del máximo individual sobre lo colectivo, en el marco de una conciencia humana que medie entre lo material y lo espiritual, ya que sólo a mayores niveles de conciencia será posible integrar lo individual con lo colectivo.

En general, la educación ética y en valores tiene sentido en la naturaleza misma del ser humano que como ser trascendente y social requiere ser orientado hacia la toma de conciencia de que una civilización auténticamente humana sólo se construye a partir de la vivencia de principios y valores que promuevan el desarrollo humano.

La respuesta a qué modelo de educación es el más ético, no es sólo una respuesta pedagógica, sino también política. Conviene preguntarse, ¿qué modelo de escuela, qué modelo de ciudadanía pretendemos formar y qué modelo de profesorado precisamos para ser eficaces en el logro de una escuela y una sociedad más inclusiva en que la cohesión social sea garantía de mayor felicidad, libertad, equidad y dignidad para todas las personas?

La educación en valores debe ser una propuesta que comprometa a la persona en su totalidad, no sólo en un nivel cognitivo racional, sino también en el mundo de los sentimientos y de la voluntad. Abordar una propuesta de educación en valores hace necesario un cambio de mirada del sentido y de las funciones del profesorado, quienes deben tener información sobre cuestiones éticas y estar entrenados en cómo abordar situaciones socialmente controvertidas, de forma que no se inculquen valores, sino que se contribuya a que la persona crezca y construya de manera singular su matriz de valores.

Formular un programa de educación en valores como si fuera exclusivamente un programa del desarrollo del juicio moral, o de formación del carácter, no sería suficientemente global ni integral. La realidad en la que educamos debería estar integrada a la educación en valores y tener presentes claramente aquellos valores como cualidades del contexto.

Educar en valores es crear condiciones; deberíamos ser capaces de decidir cuáles son las condiciones para que determinados tipos de aprendizaje éticos se puedan producir. Dichas condiciones son determinadas por el modelo de escuela en el que las generaciones más jóvenes 
aprenden, juegan y conviven, es el escenario en el que auténticamente se aprende por observación, imitación y práctica, estilos de vida democráticos y promotores de la cohesión social, en los que la diferencia es un valor y la inclusión social una condición para la dignidad humana.

Una educación en donde los valores universales asociados a la solidaridad, la comunicación, el apoyo mutuo, la tolerancia, la equidad, la integridad, el liderazgo, la participación, serán cada vez más importantes en un mundo en donde los conflictos religiosos y de poder, así como la lucha por competir cobran mayor presencia. Por lo tanto, una educación en valores implica aprendizajes a lo largo de toda la vida, que no siempre son formales y escolares.

El tema medioambiental sólo es posible comprenderlo desde la perspectiva del desarrollo sustentable para todos. El desafío desde una educación de calidad es la generación de conciencia ecológica y de mega acciones positivas hacia el medio ambiente, y la promoción del cambio de los patrones de consumo de las personas.

Existe una correlación entre las características del ejercicio del rol directivo con la posibilidad de gestar instituciones que promuevan aprendizajes de calidad. Entre estas características, está el valor que se otorga a la función formativa en los establecimientos educativos y la capacidad que tiene la dirección de construir sentido para la institución en su conjunto, así como para cada uno de los grupos y de las personas que la integran. Entre otras características está la capacidad que posee la dirección de construir eficacia, es decir, de que cada uno de esos grupos y personas, sientan y vivencien que el sentido que buscan se realice con una relación aceptable, entre la inversión personal de tiempo y energía, y el beneficio que se obtiene en relación con el sentido buscado.

Las instituciones educativas que son conducidas por directores que identifican la función cognitiva como función específica de la escuela, asocian también dicha función a una función formativa global, y tienen la capacidad de promover vínculos de todo tipo con el entorno, logran promover una educación de calidad.

El futuro de la pedagogía en una perspectiva de cambio e incertidumbre implica una revisión de sus conceptos fundamentales: la educación, la enseñanza, el aprendizaje y la formación. Reflexionar sobre la pedagogía significa hacer una lectura de los rasgos del espíritu de la época y establecer una relación con lo incierto e indeterminado, la complejidad, lo simultáneo, la 
equidad, la competitividad, el cambio, lo público y lo privado, lo local e internacional, el terrorismo y los autoritarismos.

Es imprescindible reconocer el concepto de formación como el eje central de la reflexión pedagógica y a partir de este reconocimiento, diseñar el mapa para desarrollar los conceptos fundamentales del marco intelectual pedagógico, que incluye la formación humana, la articulación de los modelos de niveles intermedios y la aplicación de los conceptos, su apropiación y la verificación en la práctica pedagógica.

La enseñanza secundaria requiere redefinirse, renovarse y mejorarse para satisfacer funciones como preparar a los estudiantes, formal e informalmente para la enseñanza superior, para el mundo laboral, y para que se conviertan en ciudadanos responsables de un mundo en constante evolución. La prioridad debería estar marcada no sólo por la renovación de contenido, de métodos y estructuras de la enseñanza secundaria, sino también por la mejora de la formación del profesorado y de los responsables de los distintos establecimientos, para que puedan cumplir mejor su función a la hora de aconsejar y orientar a los adolescentes.

La educación será impartida y adquirida por distintos medios, y constatará que el individuo ha aprendido y ha adquirido conocimientos. Los recursos didácticos estarán directamente ligados a la práctica y a la interactividad, basados en la experiencia personal y en la experimentación.

La evolución constructiva en ámbitos sociales diferentes requerirá reemplazar los sistemas de aprendizaje memorísticos y directivos, por modelos que estimulen y privilegien la creación, la aplicación, el análisis y la síntesis del conocimiento y las habilidades. A esto se suman las nuevas investigaciones en los ámbitos de las neurociencias, la gestión de los conocimientos y la teoría del aprendizaje, que indican que "el verdadero aprendizaje", sólo se produce con y mediante la práctica, no existiendo diferencia entre "saber algo" y "saber hacerlo".

Una educación de calidad implica hacer del centro escolar un lugar de aprendizaje, un espacio social y un espacio profesional, en constante comunicación con el hogar, integrado con la comunidad y el mundo del trabajo.

Una educación para todos (EPT) significa ir a donde se encuentra el mayor número de personas no escolarizadas y no educadas; introducir la enseñanza preprofesional y empresarial; actualizar a la población económicamente activa para adaptarla a los cambios tecnológicos o del mercado; abrir las puertas de las escuelas al mundo exterior; y educar a los adultos como 
condición esencial del desarrollo. Así, será posible una EPT a lo largo de toda la vida, que se constituya como respuesta a la creciente inestabilidad del empleo.

El concepto de un "ambiente de aprendizaje" que no sea un aula, ofrece un sin fin de oportunidades para demostrar a los estudiantes, que el aprendizaje puede suceder en cualquier parte, en cualquier momento y a cualquier edad.

Las construcciones educativas han entrado en una nueva dinámica de adaptación, en búsqueda de espacios más flexibles tanto para el aprendizaje cooperativo o individualizado, las artes y la tecnología, como para crear un ambiente estimulante, que facilite el aprendizaje de los estudiantes. Toda escuela puede convertirse en un ambiente que nutre al ser humano, refuerza la confianza entre estudiantes y educadores, al tiempo que ayuda a los estudiantes a ser más independientes y responsables de su propio aprendizaje. Estas aulas son lugares sanos, humanizados, emocionantes, donde se puede vivir, aprender y preparar para el futuro.

La falta de una visión intrépida, coherente, inspiradora pero realista, de lo que la educación puede llegar a ser en diez o veinte años, es la principal causa que impide que los sueños se conviertan en acciones. El concepto de centros de aprendizaje está dirigido a crear las condiciones para desarrollar visiones enriquecidas y realistas dirigidas a que los sueños sean una realidad, en donde sea posible tener tiempo para pensar, comunidades de personas que piensen con un propósito común, con las que se pueda compartir formas diversas de conocimiento, que alimenten el proceso de pensamiento y experiencias reales que lo mantengan bajo control.

El uso de las tecnologías de la información y la comunicación para generar, difundir y administrar contenidos educativos, afectará significativamente los ambientes y experiencias de aprendizaje futuros.

Nadie duda hoy en día de la necesidad de poder contar con un educador bien formado, cuya capacitación en el empleo sea considerada como derecho fundamental y sea de calidad; un educador con una amplia mirada proveniente de conocer otros países y otras culturas, mediante viajes de estudio y programas de intercambio; y un educador cuya remuneración sea comparable a la de otros profesionales. Con base en estas condiciones, el educador estará mejor capacitado para seguir los procesos de evolución de los conocimientos y de su propia estructura, y disponer, al mismo tiempo, de las competencias necesarias, para hacer frente a las interdependencias cada vez mayores, que afectan al mundo en general y a la escuela en particular. 
Es fundamental que desde la institución educativa se preste atención a garantizar que los educadores disfruten de un reconocimiento moral, consecuente con su nivel de aptitudes y responsabilidad, y a los factores que reducen la motivación del educador. De ese modo, se crearán las condiciones necesarias para el éxito de otras intervenciones en la esfera de la educación. La contribución efectiva del educador al aprendizaje está profundamente determinada por su motivación.

Se resalta la importancia de formar al personal administrativo y de dirección de los establecimientos educativos, con el fin de asegurar la mejor implementación de las políticas y los cambios en los principios y los sistemas educativos.

La globalización es valorada como un fenómeno de relaciones a nivel planetario, un logro de la familia humana, porque favorece el acceso a nuevas tecnologías, finanzas y mercados, y se manifiesta como la profunda aspiración del género humano a la unidad; sin embargo, comporta el riesgo de los grandes monopolios y de convertir el lucro en el valor supremo, y el riesgo de que en relación con las ciencias prescinda de los cauces éticos. De allí, que haya un fuerte llamado para promover una globalización marcada por la solidaridad, la justicia y por el respeto a los derechos humanos. 


\section{SOBRE LA NOCIÓN DE SUJETO DESDE EL PENSAMIENTO LATINOAMERICANO}

En este apartado de la investigación se realizará el abordaje de la noción de sujeto desde la filosofía occidental en algunos autores y su respectiva recepción en algunos pensadores latinoamericanos para así contar con la exposición de los fundamentos tanto pedagógicos enunciados en el capítulo anterior, como los de tipo filosófico que vienen de manera conjunta a consolidar la propuesta plasmada en los módulos "me constru-yo" desde un pensamiento latinoamericano con fundamentos pedagógicos que busquen un complemento para la formación integral de niños en condiciones de vulnerabilidad.

Lo que se pretende, es extrapolar algunas de las nociones de "sujeto" presentes en grandes autores del pensamiento occidental y ver de qué manera pueden ajustarse a una noción de sujeto dentro del contexto latinoamericano, queriendo no negar la herencia europea dentro del escenario filosófico latinoamericano, todo esto con el fin de realizar un aporte desde la filosofía al sector social en específico a la población de altos de Cazucá, la cual requiere un tipo de atención más hacia la reconstrucción del tejido social desde la academia.

\subsection{LA CONSTITUCIÓN DEL SUJETO EN LA FILOSOFÍA LATINOAMERICANA}

La cuestión dela constitución de "sujeto" no es meramente un asunto o un tema más entre otros posibles temas de desarrollo, sino que lo situamos como uno de los paradigmas "fuertes" de la filosofía latinoamericana.

Bien es sabido que el pensamiento latinoamericano ha iniciado la carrera por la construcción de aportes propios para la filosofía universal que la enmarca y en cierto modo le marca los derroteros de transito y es justamente dentro de ese derrotero donde podemos observar en el pensamiento latinoamericano un "modo de objetivación en la constitución de un sujeto a través de su auto-afirmación, auto-conocimiento y auto-reconocimiento.” (Roig 1981,p 105)

Esta constitución no es producto del azar, sino que tiene lugar a través de procesos que son históricos y emergentes en América Latina en su condición de otra cara de la modernidad y de la 
posmodernidad, frente a formas de negación o invisibilización implicadas tanto en modos dominantes de afirmación del sujeto de la modernidad como en el común denominador de su negación posmoderna, heredadas de contextos alternos como el europeo. De estos, unos y otros se han traducido a nivel discursivo a lo largo de la historia de la filosofía occidental de diversos modos: bien sea el modo sustancial (Descartes), sea el epistemológico-formal (Kant), sea el histórico-ontológico (Hegel) o en el histórico-estructural (Marx) paradigmas de la modernidad, así como la perspectiva deconstructiva de la posmodernidad, que frente a aquellos modos de afirmación de la modernidad deriva en la nihilización del sujeto a través del anuncio de su muerte y promoción de su fragmentación, legitimantes de la omnipresencia de visiones sobre si mismo.

Todos ellos articuladores intencional o no intencionalmente, de las relaciones asimétricas centro-periferia y sumándose a esto la caída de los grandes metarrelatos de la modernidad donde todos los esquemas de valores y de pensamiento se ven abocados a un replanteamiento o en su defecto a la desaparición, puesto que se abren las puertas a una pluralidad de conceptos donde las ciencias deben dar cuenta de todos los nuevos fenómenos existentes y para ello se debe desde el mismo lenguaje, según lo plantea Lyotard, generar nuevas categorías que intenten explicar nuestro nuevo mundo global.

En primer lugar, frente al universalismo abstracto de la occidentalidad en general y de la modernidad en particular como su forma secularizada, así como frente al anti-universalismo confeso y militante de la posmodernidad que no es otra cosa que la profundización de los ejes nihilistas y anti-ilustrados de la modernidad y por lo tanto modernidad extrema(Hinkelammert 1991 p. 98); esto es frente al sujeto abstracto como portador de un proyecto utópico de sociedad que debe ser realizado, frente a la muerte del sujeto y de los proyectos de sociedad a realizar que legitiman anti-utópicamente la "racionalidad" totalizante, el sujeto ya no es constructor de su utopía llamada sociedad sino que se transforma en una pieza de un proyecto más grande.

\subsubsection{La filosofía latinoamericana como constitución del sujeto}

Supuesto el logocentrismo de la civilización occidental, donde puede concebirse que la filosofía es la producción cultural en la cual el logos alcanza sus niveles de mayor abstracción y generalidad, producción cultural que atraviesa todos los momentos de la dialéctica de la 
occidentalidad, tanto desde el mundo antiguo y el medieval de eje mediterráneo, como el moderno y el contemporáneo, desde un proverbial comienzo en la Grecia clásica del siglo VI a.C. que tanto para este, como para sucesivos recomienzos, implican rupturas y también continuidades, donde encontramos mayor claridad en el ejercicio del a priori antropológico señalado por Kant y resignificado por Hegel en clave histórica y colectiva más adecuada -no obstante otro tipo de limitaciones- señalando procesos efectivamente dados en perspectivas de emancipación que emergen frente a estructuras, sistemas, instituciones y relatos establecidos de dominación.

Entrando propiamente en el pensamiento de Kant, el a priori antropológico está en tensión con el a priori epistemológico(Roig, 1981, p 17). Mientras el segundo remite a lo universal y abstracto, el primero lo hace a lo singular y concreto. Mientras que la lectura universalista eurocéntrica subordina el a priori antropológico al epistemológico, porque este universalabstracto es la trascendentalización de su particularidad concreta y por lo tanto ese universal no encaja con lo particular desde que lo expresa, incurre en una trascendentalización ilegítima como expresión, medida y fundamento de lo universal humano en relación a la alteridad de otras particularidades; la lectura desde la alteridad de las particularidades de América Latina implica la decodificación de este universal-abstracto que implica invisibilización, dominación y negación: sometimiento a una pretensión de universalidad que no dialoga con la alteridad para constituirla sin exclusiones, sino que la resuelve e impone monológicamente generando un universalismo abstracto, excluyente y por lo tanto, no universal.

Desde América Latina, el pathos y el ethos se constituyen en los espacios de decodificación del logos totalizado(Ardao, 1963,p. 80)y sus efectos de negación de lo universal en lo particular humano bajo la pretensión de afirmarlo y realizarlo, de manera tal que frente a las imposiciones del a piori epistemológico que emerge a un primer plano desde las experiencias de negación, sometimiento, dominación, exclusión, marginación de sujetos empíricos particulares, que ven la en la constitución del sujeto como un ser oprimido una paradójica liberación de su propio pensamiento ve en el a priori antropológico un tenerse a sí mismo como valioso y consecuentemente un tener como valioso el conocerse por sí mismo, el cual no supone eliminar el a priori epistemológico, sino subordinarlo a la orientación analítico-crítica emergente de estos sujetos, por la cual denuncian el falso universalismo abstracto y excluyente, aportando a la 
construcción ciertamente conflictiva y nunca acabada, de una universalidad concreta e incluyente, donde el valor antropológico del sujeto planteado en Kant le da un valor de exclusividad a la posesión de sí mismo y el valor que reviste la condición de sujeto que puede verse incluido en el mundo, en su mundo latinoamericano que guarda una realidad que merece un estudio y una vivencia profunda desde la cual pueden emerger nuevas formas de abordar categorías heredadas del nuevo mundo.

Filosóficamente, la constitución del sujeto en América Latina, procede pues desde Kant, y se proyecta, lo cual dice acerca de las relaciones y tensiones que nuestra América mantiene con el proyecto de la Ilustración en relación a su matriz eurocéntrica y las orientaciones y limitaciones desde ella implicadas, puesto que el fenómeno de ilustración en el viejo mundo se da dentro de un contexto específico y se propone sanar varios quebrantos al interior de la sociedad europea, en tanto que nuestra América Latina aún no termina de asimilar, reconocer e incluso va en camino de apropiar todo lo que la colonización dejó en la atmósfera de unas tierras con necesidades, paradigmas y sujetos diferentes.

No obstante el postulado que distorsiona o coloniza la historicidad neutralizandola bajo la figura totalizante del "espíritu absoluto", trasladando la negación kantiana no intencional de la alteridad a una forma intencional de vocación imperial que explícitamente niega la espiritualidad y por lo tanto la humanidad de la misma.

En segundo lugar, Hegel aporta las claves filosófica, histórica y colectiva del "nosotros" bajo la figura del "pueblo", que recuperada desde América Latina y liberada de las cadenas ontológicas que bloquean la afirmación, conocimiento y reconocimiento de la propia espiritualidad y humanidad, habilita categorialmente desde y para nosotros el ejercicio del a priori antropológico

por la referencia a los fundamentos históricos, sociales y culturales, sin relación con los cuales el mismo no podría pasar de una abstracción.

La nueva fórmula del a priori antropológico es ahora "querernos a nosotros mismos como valiosos" y "tener como valioso el conocernos por nosotros mismos" (Roig,p-76). El sujeto de la enunciación es un sujeto de discurso. Sin olvidar que el discurso es una práctica que hace parte de un universo que puede identificase como universo discursivo, no debe perderse de vista que este último hace parte de un universo histórico-social por lo que está atravesado por las 
relaciones, tensiones y conflictos de las prácticas constitutivas de esa totalidad, las que expresa y en las que interviene desde su propio nivel. Claramente no es un sujeto trascendente, esencial o metafísico, sino que es empírico e histórico y, su condición de sujeto de la enunciación hace que sin dejar de ser individual sea al mismo tiempo colectivo en razón de las mediaciones y relaciones que hacen a la complejidad de la dialéctica histórica entre lo social y lo individual. Sujetos que al conocerse y reconocerse dentro de un espacio y tiempo determinado hallaron el valor de "ser ellos mismos" generando nuevas formas de concepción del ser humano que pueden ser examinadas desde los postulados kantianos.

Debe al respecto además tenerse en cuenta que no se ha pasado del logocentrismo de la razón al logocentrismo del discurso en la dimensión comunicativa, sino que el conocerse y valorarse a sí mismo y de allí extraer la nocion más incluyente de sujeto es un proceso personal en términos histórico-culturales para nutrir lo colectivo y también -sin contradicción- en términos individuales, siendo los fundamentos resignificadores del logos-discurso en todo proceso de afirmación del a priori antropológico, que es proceso de afirmación y constitución de un sujeto en el que la pasión y la acción respectivamente motivan y orientan el ejercicio de la razón.

Esta última consideración no procura legitimar un sujeto irracional, sino que quiere deslegitimar la negación del sujeto cabalmente racional en nombre de la razón de un sujeto pretendidamemente tan exclusiva y excluyentemente racional, en que los efectos de totalización de la razón llegan a ser ultra-intencionalmente de carácter irracional. Si bien puede entenderse que pasión y acción sin razón serán ciegas e implicarán los riesgos que supone esa condición, también puede suscribirse que razón sin pasión y sin acción será vacía, en el sentido de que no responderá a ningún fundamento motivador y orientador radical o, peor aún, implicará su anonadamiento por incapacidad de discernimiento y proyección constructiva. Es en este sentido que frente a los efectos de una razón totalizada, la filosofía latinoamericana ha postulado el ejercicio de la inteligencia (Ardao,2000).

Mientras la referencia a la razón, reduce al sujeto al logos fetichizado que niega al sujeto en su integralidad; la perspectiva de la inteligencia permite desmontar dicho fetichismo, recuperando relaciones con el otro y con el entorno en pro de la construcción de conocimiento que hacen a la multidimensionalidad del sujeto, a su afirmación integral, propiciando además entre los extremos del irracionalismo intencional y el de la razón fetichizada y totalizada como 
irracionalismo ultra-intencional, el ejercicio de una razón razonable en la perspectiva de la sustentabilidad de dicha afirmación que permita a su vez, el progreso de esa colectividad llamada pueblo.

Este proceso de afirmación, que es histórico, contextual, discontinuo, contingente y que por lo tanto supone el ejercicio del a priori antropológico de un modo a posteriori, lo es de un sujeto cuya identidad no se recluye en la dimensión de la subjetividad sino que la trasciende y resignifica en la de la "sujetividad" que implica historicidad y por lo tanto formas de objetivación orientadas a quebrar las totalidades opresivas que porque lo niegan, justamente lo motivan en su praxis colectiva emergente con pretensión radical de autonomía.

\subsubsection{Los comienzos y recomienzos: del sujeto a la filosofía y de la filosofía al sujeto}

La lectura de ciertas afirmaciones de Hegel, aportan a la perspectiva del a priori antropológico de Kant la dimensión histórico-social que en aquél estaba ausente.

No obstante, e independientemente de tener la filosofía orígenes que en cierto modo son permanentes en la condición humana (el asombro, la duda, las situaciones límites), parece tener un único y localizado comienzo que ya hemos señalado en el siglo VI a.C. del mundo griego clásico, y desde allí una dialéctica de la totalidad, que llega sin rupturas en su continuidad hasta el mismo Hegel cuya síntesis pretende marcar los límites del horizonte en que se moverá la contemporaneidad.

Para quienes desde la exterioridad histórico-geográfico-cultural toman contacto con esa tradición, en caso de querer hacer filosofía parece no quedar otra posibilidad que integrarse a ella, a la dialéctica que presuntamente la gobierna desde aquél único comienzo fundante y se consagra en su última gran síntesis. Pero de ser así, la pretendida afirmación del sujeto implicaría en realidad su negación por sometimiento a las determinaciones de la dialéctica del sujeto de la dominación occidental en su expresión moderna y en su profundización-nihilización posmoderna.

No obstante esta visión establecida y dominante, que no hace lugar en la dialéctica de la filosofía y en la de la occidentalidad a la que ella fundamenta analítica, crítica y normativamente a ninguna alteridad propiamente tal, sino que la acepta solamente en el caso en que logra reducirla 
a su mismidad y por lo tanto la niega en su ser otra; según lo hemos presentado, la lectura desde América Latina de la filosofía latinoamericana en el que hemos consignado como su paradigma fuerte, desde Hegel, más allá de él y contra él, sustenta la tesis de los "comienzos" o "recomienzos" en plural.

Esta perspectiva supone la posibilidad de afirmar la alteridad sin subsumirla sin más en la dialéctica de la occidentalidad. No obstante el carácter expansionista y universalizante de esta dialéctica en el plano filosófico y también en los planos científico, tecnológico, cultural, político y económico - para nombrar los más relevantes-, habilita afirmarla como una trascendentalidad al interior de esa dialéctica totalizadora, que por sus efectos de totalización a posteriori provoca la emergencia del a priori antropológico que es relevante como afirmación de alteridad y de alternativa, en tanto afirmación de "sujetividad" y por lo tanto de afirmación de un sujeto otro respecto del de la occidentalidad en sus figuras de la modernidad y de la posmodernidad, procesos que involucran a nuestra América y por lo tanto a nosotros como expresión, afirmación y constitución del sujeto.

La "sujetividad" dice acerca de la "historicidad" de este "sujeto empírico", de su capacidad de irrumpir en la historia y decodificar las totalidades opresivas dominantes establecidas, llámense estas "cógito", "sujeto trascendental", "espíritu absoluto”, “estructuras", "sistemas”, "instituciones", "ley", "Estado totalitario", "mercado total" o "eticidad", y por lo tanto de una historicidad que es radical y constitutiva, que hace siempre posible un "nuevo comienzo", que a diferencia del espíritu transformado en niño en Así hablaba Zaratustra de Nietzsche que implica una nihilización del pasado, cada "recomienzo" del sujeto en América Latina en términos de "sujetividad" es de otra manera auroral, pues su sentido de futuro se asienta en el conocimiento y discernimiento de alcances y límites de anteriores comienzos y recomienzos, (Roig, p.15) donde se deconstruyen las grandes categorías postuladas en la modernidad y la posmodernidad generando asi una nueva forma de concebir al sujeto y el mundo en el cual se encuentra inmerso.

El sujeto de la modernidad en el registro de la filosofía de la historia hegeliana está prefigurado en la dialéctica cerrada que conduce al momento de la reconciliación en el espíritu absoluto, lo que significa tanto la legitimación del pasado como la inhablitación de un futuro en razón de la plenitud de dicha reconciliación. 
La crítica posmoderna al relato emancipatorio de la modernidad, no obstante aporta la visibilización de la pluralidad, la heterogeneidad y la diferencia invisibilizadas por el carácter homogeneizador de aquél, aportando por lo tanto a emancipaciones plurales posibles, histórica y narrativamente imposibilitadas por dicho relato emancipador moderno, al legitimar discursivamente la fragmentación, termina de hecho aportando a la reproducción y fortalecimiento de la lógica sistémica globalizada de dominación, tendencialmente inhabilitadora de toda emancipación. La crítica posmoderna a la modernidad, aporta al discernimiento de la modernidad, pero ella, lejos de ser la alternativa a los límites de la modernidad en términos de la emancipación humana, parece no hacer sino fortalecer lógicas que tienden a sacar de la escena todo horizonte emancipatorio.

La perspectiva de alteridad y por lo tanto de alternativa para la filosofía desde comienzos y recomienzos emergentes una y otra vez que no obstante sus limitaciones históricas se han dado en esta región del mundo desde que quedó comprendida en el proceso de expansión de

Occidente, en el sentido de orientaciones analítico-crítico-normativas respecto de las formas dominantes de la occidentalidad en la modernidad y en la posmodernidad, dice en lo que aquí interesa fundamentar acerca de los comienzos y recomienzos de un sujeto "otro" cuya constitución, identidad y sentido se procura explicitar.

Se trata de un sujeto que se constituye por el desarrollo de un punto de vista críticoconstructivo, que no es otro que el de la emancipación humana desde sus condiciones objetivas de existencia, proceso de autoconstitución que supone el desmontaje de las formas de dominación estructurales, sistémicas e institucionales, así como de los discursos de explicaciónlegitimación que las expresan y acompañan.

El ser humano se auto-concibe como sujeto en la modernidad. El modo fundante de su afirmación como sujeto individual y universal, sustancial y esencial, abstracto y metafísico opera como fetiche que invisibiliza y destruye al sujeto real (Hinkelammert, 2003, p 485). La perspectiva crítica (emancipatoria) desde América Latina fundamenta un sujeto-otro que da respuesta a la visión fundante de la modernidad, la que alcanza también a otras visiones críticoemancipatorias de la misma modernidad como a las visiones objetivamente anti-emancipatorias de la posmodernidad, un sujeto que se construye y valora a sí mismo como el constructor de su propia empresa de existir, que conoce sus carencias y precisamente por esa construcción de 
conocimiento fortalece sus debilidades y crea un entorno digno para si mismo, hijo de su tiempo y que atiende a la satisfacción de sus necesidades en todos los ámbitos de la vida.

\subsubsection{Sujeto cognoscente y sujeto actuante}

El sujeto paradigmático fundante de la modernidad, el "cógito" cartesiano, es sustancial en cuanto que existe por sí mismo y su atributo esencial es el del pensar, actividad que por sí sola parece sostener su existencia en su condición sustancial-esencial de sujeto pensante. En cuanto esencialmente pensante no es un sujeto actuante y el ejercicio de su atributo esencial proporciona en el modo directo de la intuición racional el conocimiento de sí mismo como sustancia pensante, así como el conocimiento de la realidad material como sustancia extensa y el conocimiento de la causa primera incausada, sin referencia a la cual ni la sustancia pensante ni la sustancia extensa se explicarían, esto es, Dios, sustancia divina o causa primera.

El sujeto pensante existe por sí mismo, en el sentido de que no depende de la sustancia extensa para existir; no procede de ella ni precisa relacionarse con ella para seguir existiendo como aquello que esencialmente es.

La pretensión del conocimiento en la metafísica o filosofía primera como conocimiento por la razón sola, en cuanto fundante del conocimiento científico y de sus aplicaciones técnicas, hace que el sujeto de conocimiento se autoconciba anterior, superior e independiente de la presuntamente subsidiaria condición de sujeto de acción.

Una epistemología crítica habilita visualizar el encasillamiento del sujeto pensante de la filosofía cartesiana y sus efectos de negación sobre el sujeto efectivamente existente, en tanto toda corporalidad, materialidad o naturaleza queda determinada como lo absolutamente otro respecto del sujeto, reducida por lo tanto a la condición de mero objeto del pensamiento, el conocimiento o la acción.

La visión parcializada del sujeto pensante, al habilitar su profundización, promueve la unilateralidad no solo del conocimiento en el que el yo pensante es el sujeto y todo lo demás que es la alteridad no pensante es el objeto, sino también de la acción en la figura del individuo poseedor-calculador que es la expresión en el terreno social de aquél sujeto, que reduce la racionalidad de lo real a la racionalidad del cálculo costo-beneficio en referencia a su interés individual en competencia con los otros intereses de individuos que se orientan de modo 
análogo, alimentando la racionalidad del cálculo y la competencia con los otros sujetos pensantes-individuales, para quienes de igual manera lo otro y los otros son solo objetos del mundo esperando la mirada cuantificadora de un sujeto.

Frente al pretendido carácter sustancial del yo pensante en los fundamentos metafísicos cartesianos, así como frente al pretendido carácter a priori del sujeto trascendental en los fundamentos epistemológicos kantianos, que de distintas maneras afirman la prioridad e independencia del conocimiento respecto de la acción, una epistemología crítica, lleva a determinar de modo fundado que el sujeto cognoscente en sus aproximaciones cognoscitivas a la realidad persigue determinados fines por lo que la trasciende "en el marco de lo posible" "para conocer lo posible", de manera tal que implica a la condición de "sujeto actuante" como su condición trascendental, conocer es trascender.

Si es cierta la afirmación que enuncia que los hombres se proponen siempre solamente los fines que pueden realizar, el "sujeto actuante" que es el responsable de discernir los fines “técnicamente posibles" está a la base como su condición de posibilidad y de sentido, del "sujeto cognoscente" que concibe los fines "teóricamente posibles".

La teoría es una función de la acción, sin por ello dejar de estar la acción orientada por la teoría en la realización de los fines, he aquí uno de los grandes dilemas del pensamiento moderno, que radica en las condiciones dentro de las cuales el hombre-sujeto alcanza el conocimiento, bien siendo un sujeto sustancial pensante o como un factor activo dentro del proceso del conocimiento, razón vs empiria, laberinto al cual Kant aportaría la salida con la formulación de dos tipos (o momentos si los podemos denominar de esa manera) de acceso al conocimiento que se convierten en pasos para la formulación de postulados universales, el primero el uso de la razón pura y luego el de la razón práctica.

Las posibilidades teórica y técnica no son exteriores la una a la otra por lo que el "sujeto cognoscente" y el "sujeto actuante" no son exteriores el uno al otro: el "sujeto cognoscente" es una trascendentalidad al interior del sujeto actuante cuyo aporte es acotar los "fines técnicamente posibles" desde la referencia de los "fines teóricamente posibles", pero recíprocamente, el "sujeto actuante" es una trascendentalidad al interior del "sujeto cognoscente" cuyo aporte es acotar los "fines teóricamente posibles" por la referencia a los "fines técnicamente posibles". 
El conocimiento determina las condiciones y posibilidades de la acción, pero también la acción determina las condiciones y posibilidades del conocimiento: esto que opera como fundamento en toda la historia del conocimiento humano, se hace cada vez más visible en cuanto tienden a borrarse las fronteras entre la ciencia y la tecnología, en tanto el conocimiento implica cada vez más una intervención en la realidad que habilita no solamente a "suponer" un orden del mundo distinto al que este presentaba por naturaleza según sugiere la tercera regla del método de Descartes, sino a implementarlo técnicamente.

\subsubsection{Sujeto Práctico}

No obstante la trascendentalidad de las condiciones teóricas de posibilidad respecto de las condiciones técnicas y, fundamentalmente, de éstas últimas respecto de las anteriores; tanto unas como otras reconocen diversas condiciones de posibilidad que las trascienden. Estas son las condiciones materiales de posibilidad a las que tanto los fines teóricamente posibles que el sujeto cognoscente puede concebir como los fines técnicamente posibles que el sujeto actuante puede realizar, deben someterse, desde que el producto social es el universo en el cual los fines por realizar se disputan sus condiciones materiales y la construcción de un nuevo saber.

La trascendentalidad de las condiciones materiales respecto de las condiciones técnicas, implican la trascendentalidad del "sujeto práctico" respecto del "sujeto actuante" y por lo tanto del "sujeto cognoscente". Desde que el producto socialmente producido es finito y la hipótesis es siempre la de recursos escasos, este aparece como la condición y criterio para discernir entre los fines técnicamente posibles. Este discernimiento implica a su vez como su misma condición de posibilidad y también de legitimidad, el que tiene lugar entre "necesidades" y "preferencias" y su respectivo papel en la elección de los fines, pues resulta evidente que no todos los fines teórica y técnicamente posibles, serán materialmente posibles en términos de la materialidad del producto social disponible.

Esta dimensión del "sujeto práctico" que es condición de posibilidad de las del "sujeto actuante" y el "sujeto cognoscente", es la que hace especialmente visible que "no hay un sujeto

humano, sino un conjunto de sujetos humanos que en sus interrelaciones forman la sociedad" en la cual la tensión entre "necesidades" y "preferencias" coloca en primerísimo plano la hipótesis 
del conflicto en la articulación de la convivencia, en América Latina, las posibilidades de ejercicio de un sujeto actuante, uno práctico y uno cognoscente están enmarcadas en la construcción misma de la identidad latinoamericana en todas las esferas sociales y en todos los pueblos con el fin de dar solución a problemáticas, la construcción de cultura y nuevas formas de ver y asumir el mundo dentro de nuestros propios campos de posibilidades y por que no restableciendo lazos con el pasado cultural de la América precolombina el cual nos ha dejado un legado que merece en nuestros días una re lectura crítica, analítica y propositiva con el fin de rescatar al sujeto latinoamericano que se edifica, que no desconoce su origen, su pasado y sus influencias siendo todo esto caldo de cultivo que da como fruto la diversidad que nos identifica como un pueblo único.

\subsubsection{Sujeto vivo y sujeto como sujeto}

Más allá del sujeto práctico, como su trascendentalidad inmanente y por lo tanto como su condición de posibilidad, así como del sujeto actuante y del sujeto cognoscente encontramos al sujeto vivo o, si se prefiere viviente, que por la corporalidad material y natural que lo constituye, no puede afirmarse sin hacerlo al mismo tiempo con la racionalidad y relacionalidad individuosociedad-naturaleza más aún en el caso de América Latina.

Mientras el "sujeto práctico" se define al interior de las relaciones de producción que determinan las condiciones materiales de los fines que se pueden realizar materialmente, dentro de los teórica y técnicamente posibles; el sujeto vivo las trasciende en el sentido de aquellas relaciones de reproducción entre la vida humana y la vida natural no humana, comprendiendo las relaciones de producción dadas como el modo vigente de orientar esa reproducción, en definitiva

Dicha racionalidad reproductiva no se agota en ninguna racionalidad productiva históricamente dada o posible y por lo tanto, en ningún modo de producción, entendiendo por producción todo aquello que emane del sujeto en su construcción propia y colectivo entorno a la política, la cultura, la educación etc.

El sujeto vivo remite entonces a la corporalidad concreta de seres produciendo materialmente su vida en sociedad y esta producción de los medios de vida materiales que es la forma específicamente humana de la reproducción de la vida, implica a la naturaleza no humana, 
sin una articulación sostenida y sustentable con la cual, la afirmación del sujeto vivo que es la trascendentalidad al interior del sujeto práctico, el sujeto actuante y el sujeto cognoscente, se torna actual y tendencialmente en su negación.

La referencia al sujeto vivo como fundamento categorial, conceptual y real de la afirmación del ser humano como sujeto, que se expresa en movimientos sociales diversos en términos de los reclamos por la posibilidad de vivir dignamente, expresa con nitidez la fuerte ruptura con el paradigma fundante de la modernidad y con las visiones críticas del mismo dentro del mismo horizonte, así como con la fragmentación posmoderna.

La afirmación del ser humano como sujeto vivo en el sentido indicado, quiebra con la rotulación del "ego cógito", del "sujeto trascendental", del "espíritu absoluto" y del "sujeto revolucionario".

En lugar de un sujeto individual y universal, sustancial y esencial, abstracto y metafísico que se autosostiene más allá de toda naturaleza corporal como lo absolutamente otro y que pretendidamente duda de su existencia para afirmar la evidencia de la misma; damos paso desde

América Latina a un sujeto histórico-social plural y diverso, que llega a comprenderse uno con la naturaleza no humana y que partiendo de la certeza de su existencia, en cambio tiene interrogantes cada vez más acuciantes respecto de la posibilidad de esa existencia a futuro.

Frente a un punto de vista pretendidamente universal que parece no ser sino la ilegítima trascendentalización de un punto de vista particular universalizado, con los riesgos implicados en el ejercicio de un logos y totalizado, la construcción de un punto de vista efectivamente universal que implica la afirmación de condiciones de reproducción vida humana-naturaleza no humana, que hacen a la posibilidad del universalismo concreto. Ante un imaginario totalizado de reconciliación a nivel del pretendido "espíritu absoluto", la emergencia decodificadora del sujeto vivo amenazado en su posibilidad misma de vivir al impulso de los procesos fácticos por aquella sobredeterminación.

En lo referente a la fragmentación posmoderna del sujeto de la modernidad en cualquiera de sus expresiones paradigmáticas, la perspectiva del sujeto vivo que articula humanidad y naturaleza no-humana en lugar de convalidar y consolidar la fragmentación, visualiza las experiencias fragmentarias de afirmación como expresiones del sujeto vivo que justamente no es 
un sujeto a priori como en sus distintas versiones lo es el de la modernidad, sino que se manifiesta de modo a posteriori en función del carácter de negación de dichas experiencias.

La perspectiva filosófica de la posmodernidad parece consagrar la fragmentación, negando el sujeto y el universalismo de la modernidad, pero como modernidad en extremo, negando todo sujeto y todo universalismo.

El pensamiento crítico-emancipatorio desde América Latina, en su condición de otra cara de la modernidad y de la posmodernidad como figuras vigentes de la occidentalidad, de un modo no ecléctico propone superar los efectos anti-emacipatorios del sujeto moderno y su universalismo abstracto excluyente, así como los de la fragmentación anti-universalista posmoderna, por la referencia al sujeto vivo como trascendentalidad al interior de estructuras, sistemas e instituciones, y por lo tanto fundamento y criterio de emancipación humana desde y para América Latina y para el mundo, en el contexto mundial vigente.

El sujeto vivo es en términos reales y materiales, lo que en términos ideales es el sujeto como sujeto, que sería el sujeto que "trasciende todas sus objetivaciones"(11) y por lo tanto se sostiene más allá de ellas. Mientras el sujeto vivo es de cierto modo tópico, el "sujeto como sujeto" es decididamente utópico(12).

Decir que el sujeto vivo es de cierto modo tópico, implica reconocer que, no obstante su materialidad y realidad fundante como trascendentalidad al interior de las mencionadas determinaciones u objetivaciones del sujeto, la experiencia de su trascendentalidad se da siempre mediada, tensionada o resignificada por otras determinaciones y por lo tanto al interior de ellas.

El proceso de la modernidad ha acompañado la rotulación del sujeto en las diversas expresiones de la misma, con la imposición de estructuras e instituciones cuyo sentido fundante fue la afirmación del ser humano como sujeto dentro de los límites del horizonte histórico de su autocomprensión, pero que terminaron desplazando aquél sentido, conquistando el lugar del ser humano como sujeto.

La posmodernidad convalida y apunta a consolidar objetivamente este proceso. Independientemente de cualquier intencionalidad, la disolución posmoderna del sujeto en los términos de su fragmentación y debilitamiento, se articula constructivamente con la reproducción estructural de modelos de construcción de mundo y con la promoción de la institución de un 
modelo de sujeto ordenador no-intencional, en los términos de la reproducción de un orden que no admite exterioridad ni alternativas.

Sea intencionalmente, sea no-intencionalmente, en la modernidad y más decididamente en la posmodernidad, estructuras e instituciones destinadas a emancipar al ser humano como sujeto, no han hecho sino sustituir, invisibilizar, negar y destruir al ser humano como sujeto lo que en nuestro lado del mundo resulta más que evidente al ser denominados como el tercer mundo dentro de nuestro planeta, dicho término lleva consigo una serie de cargas culturales, sociales, políticas y éticas que dejan fuertes brechas en nuestro aparente mundo global donde somos quienes tenemos las materias primas de todo gracias a nuestra riqueza natural y humana pero son otros los que cuentan con las herramientas suficientes para tecnificarlas, dando asi paso a sujetos que producen y sujetos que ejecutan.

Desde América Latina, como la otra cara de la modernidad y de la posmodernidad se aporta otra perspectiva del sujeto, la del sujeto vivo que, como no puede ser reducido a estructuras, sistemas o instituciones porque en cuanto comprende el complejo metabolismo humanidad naturaleza no humana, es una trascendentalidad al interior de las mismas, lo que lo lleva a emerger a posteriori a las experiencias de negación, con capacidad para juzgarlas así como para rectificarlas de un modo fundado.

Para este sujeto vivo, desde sus mediaciones y objetivaciones como sujeto cognoscente, sujeto actuante y sujeto práctico y desde su emergencia que lo motivan a articularse como un "nosotros" que se tiene a sí mismo como valioso en ejercicio del a priori antropológico, no obstante contextos históricos que implican confrontación objetiva de intereses, división y lucha de clases que sobredeterminan y son sobredeterminadas por luchas fragmentadas se abre la posibilidad de activarse y organizarse como actor social y educativo, para transformar las estructuras, sistemas e instituciones que tienen esos efectos de negación, en dirección al horizonte utópico del sujeto como sujeto.

Esto quiere decir que el sujeto vivo en una dirección y el sujeto como sujeto en la otra son las referencias orientadoras en la transformación de estructuras, sistemas e instituciones de manera tal que estas no sean más que mediaciones para la afirmación en términos del universalismo concreto incluyente del ser humano como sujeto. 
No se trata de eliminar estructuras, sistemas o instituciones y pretender directamente la afirmación del sujeto como sujeto. Tampoco de apostar a que estructuras, sistemas o instituciones, por su propia lógica de funcionamiento afirmarán al sujeto como sujeto.

Tal vez ni siquiera se trata de crear nuevas instituciones, sino de transformar su espíritu sobre la referencia del sujeto vivo como su criterio.

A diferencia de los proyectos de sociedad de la modernidad que determinaban cómo debería ser el mundo, la fórmula acuñada en América Latina desde los movimientos sociales, por un mundo en que quepan todos podría ser la fórmula de universalismo concreto, porque no prescribe un modelo de sociedad (de estructuras, sistemas o instituciones); aporta simplemente el criterio universal concreto del sujeto vivo cuyo referente utópico es el sujeto como sujeto, como criterio de racionalidad y factibilidad al cual deberían someterse todos los proyectos de sociedad con sus estructuras, sistemas e instituciones a los efectos de converger en torno al sentido común legitimador alternativo al de las relaciones de producción hoy totalizadas, el de afirmar la humanidad en su diversidad de expresiones como sujeto desde nuestros ojos latinoamericanos.

En el presente capítulo se encuentran desglosados algunos de los aspectos más relevantes en torno a la categoría de sujeto y su construcción desde el pensamiento occidental, donde la autoafirmación, el auto-conocimiento y el auto-reconocimiento juegan un rol vital desde dos contextos específicos: la modernidad y la inminente posmodernidad, siendo el primero un espacio donde la negación del sujeto debido al choque cultural generado por los episodios de conquista y colonia de nuestro continente y en el segundo se generan dos fenómenos importantes a saber: la aparición de la idea de "nosotros" para enmarcar al pueblo, alejando así la idea de sujeto y la fragmentación, nihilización y pluralidad pasando así de un sujeto universal a validar la existencia de muchos sujetos.

El segundo aspecto es a enunciación del concepto de sujeto emitido por varios pensadores de la filosofía europea como Descartes y el sujeto sustancial, Kant y el sujeto epistemológico formal y Hegel con el sujeto histórico ontológico donde vemos sujetos que están abocados a actuar para la realización del modelo ideal de sociedad, pero en nuestro contexto latinoamericano se lucha de manera directa por validar en primera medida, la existencia de sujetos que dentro de su unión como pueblos buscan construir sociedades con moldes europeos. 
El tercer aspecto es el de una posmodernidad plagada de sujetos que desde su individualidad ya no apuntan a un ideal común de sociedad o pueblo sino que han sido absorbidos por sucesos más importantes de nuestro tiempo como los modelos económicos, el consumismo y las grandes metrópolis donde podemos ser ciudadanos del mundo, lo que favorece la exclusión social y el nacimiento de nuevas formas de vida como por ejemplo el sujeto obligado a salir de su lugar de residencia por diferentes factores.

Como cuarto y último aspecto encontramos varias y nuevas formas de ver a este sujeto latinoamericano no como aquel que conoce, sino como el objeto mismo del conocimiento, pero dicho objeto no reposa en un centro inamovible, sino que es dinámico, práctico y actuante que se construye en el día a día y al ritmo que su contexto histórico de demarque.

\subsection{SUJETO POPULAR}

En este apartado del trabajo nos proponemos efectuar una serie de reflexiones acerca de una de las categorías fundamentales: el Sujeto Popular. Al mismo tiempo, se estudiará la relación de este sujeto en el marco del Movimiento Popular Latinoamericano y su consideración como base para la configuración de la Educación Popular.

\subsubsection{Pensar desde Latinoamérica}

En el ámbito latinoamericano muchos son los cuestionamientos que nos podemos plantear sobre la constitución y configuración de un posible sujeto. Podemos comenzar por preguntarnos cuáles son los problemas que impiden la efectivización de ese intento. Uno de ellos es la diversidad cultural que lleva en sí la discusión sobre el proyecto kantiano de confeccionar una Ética Universal. La consideración de la diversidad no es un problema al que se aboque la filosofía europea puesto que para ellos el punto culminante de su esfuerzo es reconocer que existen culturas diferentes.

El diálogo culmina cuando yo expreso a la otra cultura de acuerdo a las categorías de mi cultura pero no permito que suceda a la inversa (Etnocentrismo).El abordaje filosófico del problema latinoamericano debe ser en función de dos categorías esenciales: la interdisciplinariedad y la interculturalidad. Por la primera el filósofo debe, a efectos de constituirse en el interlocutor de su propia cultura (como propone el marxismo crítico), escuchar 
y mezclarse con los discursos provistos por las disciplinas científicas. Y por la segunda debe reconocer la validez y respetabilidad delas racionalidades propias de cada cultura lo cual constituye también una actitud ética. Las culturas son consecuencia de formas particulares de protección de la vida.

La búsqueda de modos de supervivencia produce en las sociedades mecanismos de regulación de la relación con el medio ambiente. Una vez satisfechas las necesidades naturales los individuos generan formas de regular la interacción y esos mismos mecanismos constriñen y moldean modelos particulares de organización social.

Luego, como corolario, surgen las descripciones propias de las disciplinas científicas que muchas veces desfiguran la realidad adecuándola a sus supuestos teóricos y metodológicos construidos (en Europa o Estados Unidos).Relacionado al tema del Sujeto surge la pregunta sobre la construcción de la identidad. Según Bonfil Batalla, puede hablarse de una matriz cultural porque la cultura nos programa para ordenar, valorar y jerarquizar todo aquello que pertenece al patrimonio cultural. Por tanto, el tema de la identidad solo puede ser entendido en función de una determinada cultura. A su vez estas culturas integran ámbitos diferenciados que son propias de las disciplinas que los investigan. En virtud de ello tenemos una identidad social, una identidad política, religiosa, una identidad sexual, etc. Para Roig la noción misma de Sujeto es un constructo. La respuesta a la identidad se ha dado dentro de una matriz que hace de soporte a desarrollos diversos de la categoría de Sujeto. En Latinoamérica la respuesta a la identidad se ha dado dentro de los parámetros del Sujeto moderno que se inicia con "ego cogito" cartesiano.

El Sujeto moderno como aparece en los grandes filósofos europeos contemporáneos sufre un proceso de depuración que va desde el "ego" cartesiano al "sujeto trascendental" kantiano y concluye maduro y contradictorio en la "subjetividad" hegeliana, en donde se inicia el proceso de descentramiento. Es hora de comenzar la producción de discursos sobre el Sujeto desde el descentramiento, no ya desde los parámetros clásicos sino desde aquello que es explicado por el discurso hegemónico.

El "ego" que se inicia con Descartes nunca fue ajeno a la realidad latinoamericana, y aún hoy es funcional a la formulación de reflexiones desde la perspectiva de la liberación. El Sujeto latinoamericano debe constituirse en síntesis de tres ordenes discursivos: el de la naturaleza, el del paradigma hegemónico (en el cual distinguimos la producción de los pensadores europeos y 
el discurso utilizado por los colonizadores para nuestros aborígenes, esclavos, mestizos y criollos) y el del pensamiento propio de los filósofos de la liberación.

La descripción de la cultura (subsumida en ella la noción identitaria) propone nuevamente el problema señalado al comienzo acerca de la posibilidad de una Ética Universal. Podemos concluir que ésta no puede ser: a) Etnocéntrica: dado que este tipo de éticas no puede reconocer el carácter ¿ontológicamente? diferente de otras culturas (al menos en su situación precolombina). Las éticas kantianas, procedimentalistas, deontológicas, utilitaristas o contractualistas integran e imponen la perspectiva eurocentrica fundada en el desarrollo de su filosofía a lo largo de los siglos. Si bien una perspectiva que atienda a la diversidad debe tomarlas en cuenta su configuración corresponde a las características de un proceso histórico particular por lo cual en su consideración debemos realizar un ejercicio permanente de la sospecha (Hermenéutica de la sospecha). b) Sin diálogo: no se puede construir una filosofía sin

diálogo, sin debate, sin intercambio si asumimos la diversidad. Las éticas comunicativas del tipo de Habermas y Apel constituyen un esfuerzo considerable por parte de los pensadores del primer mundo para el logro de un entendimiento con nuestra cultura pero dichos intentos quedan reducidos a la mera postulación del diálogo siendo las condiciones de la posibilidad del mismo lo que reclama una consideración urgente por parte de ellos. Con todo están mucho más cercanas a laspropuestas de los filósofos y teólogos de la liberación. c) Sin tener en cuenta a la naturaleza: La naturaleza es quién ha constreñido en mayor modo la esencia de las culturas. De acuerdo a los recursos que propone los hombres han desarrollado las culturas como modo de adaptación y transformación, por lo tanto su cuidado y protección debe ser un punto básico para la conformación de una ética de la liberación. Leonardo Boff es quien ha denunciado que a la naturaleza se la obvia como tema. La filosofía antropocéntrica solo considera a la naturaleza como algo a dominar(marxismo crítico y el problema de la Ilustración) . d) Sin tener en cuenta el carácter emancipatorio y posteriormente liberador que debe tener una filosofía y una ética para América Latina. Dentro de la perspectiva de la Filosofía de la Liberación, Enrique Dussel, Arturo Roig, Leopoldo Zea son los principales portavoces de un proyecto surgido en estas tierras. Dentro de la Teología de la Liberación como esfuerzo tendiente al logro de la superación de las condiciones de exclusión de la población de estas tierras Gustavo Gutierrez, Juan Luis Segundo, Teotonio Dos Santos y ClodovisBoff son quienes aportan los fundamentos. En función 
de estas últimas distinciones que asumen como categoría central y eje de todo proyecto liberador al Sujeto que nos hemos planteado comenzaremos un acercamiento a su caracterización.

\subsubsection{El sujeto popular en la Filosofía de la Liberación}

Con este término se designaba no solo a la filosofía hecha por los filósofos de estos países sino también a aquellas filosofías que reclamaban para sí misma el estar determinada significativamente por la realidad histórico-cultural del subcontinente. ¿Podemos pensar una filosofía pura independiente de la cultura en la que se gestó desencarnada de sus contenidos lingüísticos, desprovista de su contexto? Durante la década del 40 Leopoldo Zea (que constituye un considerable antecedente para la filosofía de la liberación) plantea que la filosofía no es un sistema de proposiciones abstractas y teóricas, sino el producto de hombres de carne y hueso en lucha con sus circunstancias. De este modo nos señala que toda filosofía sale de situaciones históricas particulares; es por eso que para entenderla hay que atender a tales circunstancias. Existe una preocupación constante de Zea en "aquello que hemos perdido". Entendemos que Zea se refiere a la crisis de la civilización que hoy vivimos.

Esto ya lo planteó Heidegger en "La superación de la metafísica": una forma metafísica que hoy identificaríamos con el Neoliberalismo; debajo de esta máscara se produce una entificación cada vez mayor y la pérdida del ser es el resultado. Como seres humanos está claro que esto nos pasó, pero como seres humanos y particularmente latinoamericanos nos atañen otros problemas más urgentes como el hambre, la desocupación, la exclusión en sentido total y ellos también son temas filosóficos. Francisco Romero señala por su parte la necesidad de que Iberoamérica empiece a preocuparse por los temas que les son propios para ello debe comenzar a escudriñar en la cultura para descubrir los tópicos que deben ocupar a los pensadores latinoamericanos. Sin embargo esta propuesta produce desacuerdos; algunos pensamos que no se necesita buscar demasiado aquellos temas si la realidad que senos presenta indican acentuados procesos de exclusión no solo del sistema económico-cultural sino de la vida misma. En torno a la búsqueda en la cultura misma se supone por parte de Romero una descripción de la misma y nosotros entendemos que la cultura está presente en el ser latinoamericano, en lo performativo.

Debemos, a propósito de estos pensadores, rescatar su intento de contextualización de la problemática latinoamericana aunque son débiles los esfuerzospor desembarazarse de uno de los 
puntos centrales que genera dicha problemática: la dominación y las estructuras generadas por el pensamiento eurocéntrico para producirla. Muchas filosofías han tratado de establecerse con su carácter universalista, a pesar de lo cual se habla de filosofía griega, alemana, francesa, etc.. Nos interesa señalar que cuando reflexionamos acerca de un determinado acontecimiento histórico que influye significativamente en el pensamiento social y filosófico no podemos dejar de destacar la importancia del contexto (incluida su dimensión espacio-temporal).

Existen temas filosóficos que han sido centrales: la vida y la muerte, dios, la naturaleza, la verdad, etc.; y esas reflexiones que son comunes en tanto que son inquietudes que tenemos todos los seres humanos no dejan de tener peculiaridades relativas a la cultura en la que se generan.

Orlando Fals Borda introduce en estas discusiones su teoría de las "antiélite". Los grupos antiélite son los integrados por personas que ocupando lugares de prestigio enfrentan a los grupos dominantes para arrebatarles el poder político. Los lugares de prestigio son el conocimiento y la educación, el poder político, el eclesiástico, la economía y la administración. Estas antiélites pueden protagonizar dos tipos de conflictos: generacionales o ideológicos. La generacional reemplaza a la élite gobernante sin desestabilizar el contexto social y económico. La ideológica que si bien proviene de la generacional puede en algún momento derribar el orden establecido. Si bien como podemos advertir se despoja al concepto de ideología de sus connotaciones críticas y hermenéuticas el verdadero problema que instala Fals Bordaes que a través de las sacudidas que introducen los conflictos ideológicos se puede advertir una interrogante ontológica. En concreto el problema de la subversión en América Latina se debe sobre todo a la pregunta sobre el "qué somos" o "a donde vamos". Con esto estamos en condiciones entender por qué muchos intelectuales comenzaron a dedicarse a investigar acerca de una ontología particular para Latinoamérica perdiendo de vista el sesgo analítico que le confería Fals Borda a esta categorización reduciendo el problema político, económico o social a una posible exploración, explicación y o descubrimiento de una ontología. Según Hugo Ortega la Filosofía de la Liberación no constituye un movimiento sino muchos, que sumamente ricos y dinámicos, imposibilitan a los investigadores la búsqueda de un núcleo conceptual común a todos. Salazar Bondy y Zea deben ser obligatoriamente considerados en todo trabajo de recopilación, luego una serie de pensadores cristianos entre los que se encuentran Enrique Dussel, Juan Carlos Scannone, Mario Casalla y Hugo Assman y por último aquellos vinculados a 
la Teoría de la Dependencia. Tomaremos como casos representativos para el análisis de la categoría Sujeto los aportes de Zea (que ya anotamos al comienzo), Dussel y Roig.

Dussel utiliza como fuente el pensamiento de Heidegger que remonta el pensamiento filosófico desde el plano óntico (o del ente) hasta el plano ontológico (ode significación del ente). El plano ontológico es el plano del "Ser" como fundamento (Grund) por tanto la tarea del filósofo es la búsqueda de un reencuentro con este fundamento. Pero para encontrar al "Ser" debe interpelar a los entes en función de constituyen ellos mismos instancias diferenciadas del "Ser". Para Heidegger ésta sería la concepción filosófica de la "identidad", es decir, la concepción misma del ente como diferencia. Ahora bien, si tenemos que la identidad se debe a la distinción debemos concluir que al Ser debe corresponderle un No-Ser que garantice su identidad misma, que le confiera significación y sentido al "Ser". Ese No-Ser es impensable puesto que según una regla ontológica "desde la nada no puede venir algo" por tanto debemos definir al No-Ser como "Exterioridad" y al "Ser" como "Totalidad".

Dussel considera que lo que puede ser entendido, analizado puesto en consideración es la Totalidad en tanto racional pero la Exterioridad en tanto fuera de la racionalidad solo puede ser escuchada por lo cual para poder comprender debemos hacer una opción ético-política. En esta acción de ir más allá de lo ontológico(Totalidad Totalizante) debemos, necesariamente, rechazar la dialéctica por que ésta parte del ente que define el plano de la Totalidad para adoptar el método analéctico (donde Ana significa: "ubicación en el más allá", y dia: movimiento desde el plano óntico al ontológico.

La existencia de ese ámbito posibilita la existencia de una filosofía primera que como vimos es política o ética. Dicho de otro modo la filosofía de Dussel propone a Latinoamérica como Exterioridad y como punto de partida para la generación de un modo distinto de pensar. La dicotomía Totalidad-Exterioridad puede llevarse a diferentes planos del ser, así tenemos EuropaAmérica, Dios-Mundo, Sí mismo-Otro, Ricos y Pobres, etc. Pretende fundar una filosofía primera que piense a través del otro, del explotado, del oprimido por el neocolonialismo económico y político vigente en estas tierras. Pero existen muchos cuestionamientos que se pueden hacer a su propuesta. El primero de ellos es ¿quién estaría en condiciones de escuchar la interpelación que realiza ese Otro (los pobres) desde su silencio? Naturalmente para el autor sería el filósofo de la liberación por tanto surge otra pregunta ¿esa asimilación del filósofo con el 
profeta no podría generar a su vez una élite de intelectuales negando la participación de ese Otro cuando esté preparado para hacerlo? Para la configuración de un sujeto popular camino a la liberación el aporte de Dussel es significativo en función de que instaura un movimiento intelectual antiacadémico preocupado por la problemática de los pobres de su tierra que cuenta además con un fundamento teórico considerable (aunque no sea propio de estos lugares). A pesar de las críticas su método analéctico coloca en el protagonismo social y político-ético al Otro al Pobre. Roig hace hincapié en el doble aspecto del "compromiso" que tienen que ver con el saber mismo y con el saber como cuestión social. De este compromiso surge la "tarea" que tiene que ver con la liberación social. Los enfoques de Roig están ligados indisolublemente al estudio del pasado (de América y el Mundo) por lo cual critica el antisustancialismo de las propuestas dusselianas. La filosofía latinoamericana debe afirmarse en un determinado saber para la praxis, para la praxis transformadora, por lo cual pone en cuestión algunas tendencias anti academicistas postuladas por su interlocutor más apropiado: Dussel. Integra una visión historicista del hombre anteponiéndola al hombre fuera de la totalidad propuesto por Dussel. Hay un "gestarse" y un "hacerse" por lo cual se realiza dicha historicidad humana.

Esa historia que organizada teóricamente como "dialéctica justificadora" intenta frenar o desconocer la irrupción del "otro". Pero la alteridad con su sola presencia es capaz de romper con la totalidad y permite el advenimiento de la liberación.

"El oprimido, el hombre que sufre dolor, miseria, hambre, tortura, persecución y muerte, el que se nos presenta como el "otro" respecto a nuestra mismidad y de las categorías de integración con las cuales intentamos sostener esa mismidad y es el que toma a su cargo la misión humanizadora de imponer la alteridad como condición esencial del hombre." (Cerutti Guldberg;, 1992:64)

A partir estos dos pensadores podemos encontrar una caracterización más o menos plausible de la idea de sujeto para la Filosofía de la Liberación. Si bien esta formulación será completada más adelante por el aporte del pensamiento cristiano y del pensamiento economicista marxista de las denominadas "Teorías de la Dependencia", estos filósofos presentan una alternativa distinguible y fundamentada a estas corrientes. Advertimos un proceso evolutivo, el sujeto comienza a ser protagonista ya sea como alteridad, ya sea como actor de los movimientos sociales en defensa de la vida pero aún se mantienen como sostiene rasgos elitistas en el 
movimiento intelectual y concepciones filosóficas que no constituyen síntesis con otras(el marxismo por ejemplo) que relegan al sujeto (al que declaran protagonista) a un papel de exterioridad cuando son parte del sistema mismo que ellos integran.

\subsubsection{El sujeto popular y la teología de la liberación}

En la obra de Gustavo Gutierrez: la "Teología de la Liberación" se aborda un conjunto de temas que a lo largo de décadas se venían planteando en las comunidades eclesiales de base consecuencia de la reflexión sobre la práctica cristiana. Dichas reflexiones tienen su punto culminante en la respuesta dada por la Iglesia en el Concilio Vaticano II donde la preocupación por el alejamiento de la fe católica por parte de grandes masas obreras a favor del socialismo quedó manifiesta en las declaraciones de los distintos asistentes. En estas reuniones se logró que se escuchara por parte de los representantes europeos a la gran mayoría de la cristiandad que es pobre y latinoamericana a la vez. No sin recelo los teólogos debieron aceptar la "irrupción del pobre" con toda su problemática y la realidad socioeconómica que la enmarca. Como declaración final se obtuvo una "opción preferencial por los pobres " que estimuló una considerable reflexión teológica. La misma pone en cuestión la teología europea al sostener que la teología no es una conclusión a partir de una serie de premisas sino que debe ser una reflexión sobre la misma acción pastoral. Todo esto fue recogido en Medellín (1968) y confirmado en Puebla (1979) donde se introduce el concepto de liberación que también se distinguen varias perspectivas: a) Liberación política: que apunta a la eliminación total de las causas de la pobreza, b) Liberación a lo largo de la historia: se trata de liberar al ser humano de todos aquellos factores que limitan su capacidad de desarrollarse libremente, y c) Liberación del pecado: que es la raíz última de la injusticia. Se consideran tres aspectos que sirven como anclaje en el mundo teórico precedente: a) Los enfoques de las "Teorías de la Dependencia", Gutierrez basa sus investigaciones en la economía y la sociología aportadas por esta corriente para afirmar en contraposición su categoría "Liberación". Dichas teorías con un marcado acento en los factores externos del subdesarrollo ha reducido el análisis a perspectivas economicistas que no reflejan el orden diverso de la realidad latinoamericana; b) Se aborda con rigor crítico la producción teológica: los estudios sobre el Antiguo Testamento de Von Rad, la teología de la esperanza de Motmann y Pannenberg y el marxismo peculiar de Bloch posibilitan que su esfuerzo logre un anclaje en el pensamiento 
anterior; c) Una total amplitud corona el pensamiento de Gutierrez, no elude los planteos de ninguna corriente marxista (principalmente la de Althuser).

Se distinguen tres niveles de liberación que se condicionan mutuamente pero no se confunden. La actitud común es reducir el "Reino" al progreso temporal (es decir al progreso del hombre particular) pero ello no es así el crecimiento del "Reino" tan solo constituye la condición última para el advenimiento de una sociedad más justa(pero hablamos del Hombre genérico en la que la historia constituye su proceso deliberación). El pecado nos es revelado como el principal obstáculo para el crecimiento del "Reino" y por ello como la raíz de toda miseria e injusticia. Es por ello que todo esfuerzo por construir una sociedad más justa es liberador (y esta liberación que en el proceso de su concreción nos va liberando de nuestras alienaciones ya es obra salvadora aunque no sea la salvación total).

Por cualquiera de los tres niveles enumerados se puede llegar a una total comunión con Dios. En el camino hacia la liberación del Hombre se va dando el crecimiento del Reino para llegar a una sociedad más justa que estaría en total comunión con Dios. La noción de acción es fundamental que esta está conectada con la marxista de praxis por definición esta vinculada a lo político. Lo político se configura como la mediación apropiada de la fe porque es lo conflictivo (por antonomasia) y porque de sí misma pueden obtenerse los resultados favorables para la construcción de una sociedad más justa. La fe solo toma cuerpo en el conflicto, en la incertidumbre, en el reino de las verdades no sería necesaria entonces, aquellos que sufren la opresión son los que deben llevar adelante la praxis. La veneración a Dios y el deseo de hacer su voluntad son condiciones necesarias para una reflexión sobre él. En el compromiso con el pobre encontramos a Dios y al mismo tiempo se hace más profunda nuestra solidaridad con los pobres.

El Sujeto que se libera son los pueblos, los pobres, los excluidos mediante la movilización política de la fe se abre la esperanza para la salvación de todo el género humano. Las experiencias cubana, nicaragüense o salvadoreña dan por sí mismas testimonios de la fe en el sentido anotado. Sin duda la teología de la liberación ha aportado a los pueblos la conciencia de su protagonismo para los cambios; La idea de pueblo elegido (el pueblo judío y sus profetas; o aquellos para quién dijo venir Jesús: los enfermos, las prostitutas, los que tienen frío y hambre, los pecadores) coloca a todos aquellos desplazados por el sistema en el centro de la acción política. Pero se plantea una distinción en la categoría que merece anotarse; Ya no hacemos 
referencia al no creyente como punto de partida sino que se comienza a ver al pobre, al excluido, al explotado como no-persona . La compromiso del cristiano consiste en la opción por aquellos que son sistemática y legalmente despojados de su condición de ser humano.

Y ello cuestiona profundamente tanto a nuestro universo religioso como nuestro mundo económico, social, político, cultural. La Teología de la Liberación sino a su nueva manera de hacer teología. Este nuevo modo de hacer teología era consecuencia de la praxis de los cristianos de las comunidades de base latinoamericanas por tanto también se introducen nuevos temas en función delas peculiaridades culturales de cada comunidad.

Para concluir preguntamos qué aporta la "Teología de la Liberación" a una Etica de la Liberación. Esta propuesta teórica y práctica supone un movimiento de avanzada dentro del proceso de liberación latinoamericano. Tomando como fundamento los análisis disciplinarios de las llamadas "Teorías de la Dependencia "traslada la posibilidad de cambio a la praxis de los cristianos en función del conocimiento de su propia cultura. El cristiano en cumplimiento de su misión de construir el Reino hace su elección a favor de quién más sufre: aquel al que le es negada tanto su porción de la riqueza como su identidad Pero esa elección exige la completa transformación del cristiano en su Otro para comenzar la construcción de una reflexión desde un Nosotros a la luz de la Palabra que nos es dada por la gracia de Dios. La Utopía unifica en su conceptualización los tres ámbitos: el político: reconocimiento del individuo y de los pueblos como sujetos constructores de las políticas de Estado; el histórico que entiende que el hombre como género camina hacia la liberación de sus propias alienaciones para establecer las condiciones para la unidad con Dios y el espiritual donde la Utopía tiene su último y más difícil obstáculo para su concreción. A nuestro entender las perspectivas política e histórica se subsumen en la tercera (a la vez que se configuran como precondiciones para poder encararla) que señala el pasaje de lo humano a lo no-humano (lo divino) cumpliendo con el fin de toda acción cristiana. El esfuerzo igualmente resulta valioso puesto que concilia posturas teóricas que han sido consideradas radicalmente diferentes(marxismo y cristianismo; materialismo e idealismo; por ejemplo). Pero no es un intento basado en la proposición de una articulación (unidad?) ingenua sino que es una acción fundada en la práctica concreta de las culturas y movimientos latinoamericanos donde confluyen en el programa liberador diversos afluentes de pensamiento. A su vez coloca en el tapete las posibilidades ciertas de una completa articulación 
de ideas en el contexto latinoamericano como una diferencia crucial con el contexto europeo . Solo la irrupción del Otro y el reconocimiento de ese Otro en el nivel teórico y práctico permite la articulación de proyectos colectivos en su total y verdadero sentido y América, con su diversidad y complejidad, ha proporcionado experiencias interesantes que pueden ser tomadas como punto de partida para políticas de resistencia al proceso globalizador.

Por otro lado, a los efectos de la praxis se aporta un método distinto (si bien los contenidos pueden ser específicos no por ello diferentes) basado las proposiciones de la llamada Escuela de Marburgo (Bultman; Heidegger y Gadamer) y Ricoeur denominada "Circulo Hermenéutico" cuya esencia es, sin lugar a dudas, la instalación en la reflexión de la sospecha como punto de partida para la comprensión de los fenómenos políticos-económicos y sociales. La comprensión, como señala Ricoeur, articula el componente subjetivo con el discurso o la forma de presentación del mismo.

En la comprensión nos apropiamos de un discurso y nuestra versión del mismo se torna absolutamente verdadera en función de que nos pertenece. A los efectos de la acción se le confiere a estas lecturas su legitimidad y por tanto la articulación de comprensión y discurso se torna una praxis permanente. Así, como lo expresa Segundo, el punto final del círculo esta cuando la interpretación de la palabra contempla en su explicitación la realidad y el punto de inicio cuando no incluye a la misma. En la praxis cotidiana la sospecha se instala cuando nuestras estructuras teóricas no contienen en sí mismas las experiencias particulares de aquellos que las utilizan por lo cual se tenderá a generar estructuras que se adecuen a la experiencia particular. Una profunda movilidad implica la aceptación del círculo hermenéutico perono una movilidad irreflexiva sino la movilidad de una (verdadera y permanente) praxis. Para comprender la categoría pueblo, según Rebellato, la dimensión cultural es esencial. Si no tomamos en cuenta esta dimensión caemos en los enfoques objetivistas y deterministas que son propios del marxismo el cual encuentra un sujeto portador de la verdad universal y capaz de transformar la realidad en el proletariado pero lo hace desde la conformación a priori de un proyecto ético-político, es decir, desde la constatación de una situación objetiva y no desde el punto de vista de los oprimidos Este Sujeto es diverso, incluye una diversidad de identidades que articulan conjuntamente un proyecto liberador de acuerdo a sus intereses en contra del proyecto del bloque hegemónico. Este proyecto colectivo supone una profunda crítica al proyecto 
dominador y en él a las estructuras que permiten tal dominación, entre ellas la educación. La liberación de los oprimidos pasa también por la liberación de su saber, por el reconocimiento de su potencialidad creativa y su inteligencia que pueden generar un sistema-cultura alternativo y de resistencia al gran proyecto hegemónico.

Mediante el reconocimiento de la diversidad de identidades se genera también la posibilidad de nuevas opciones también en el terreno del conocimiento donde se ha privilegiado tanto por dominantes como por dominados algunas escuelas que son funcionales al proyecto hegemónico.

Sin embargo la elección del Sujeto Popular como protagonista de un proyecto liberador es una opción. He aquí la ruptura con los proyectos anteriores, se produce un corte, se toma conciencia que la extrema diversidad, los antagonismos internos, los obstáculos que oponen los mecanismos de subordinación y profundas contradicciones que enlentecen la capacidad de reflexión y pueden abrigar la idea de la imposibilidad de llevar a cabo este esfuerzo. Para ello debemos incluir un concepto que no precisamente corresponde al nivel epistemológico, ni forma parte del discurso de tipo descriptivo sobre el que se basa todo análisis en el campo cultural, es el concepto de "Esperanza". Del mismo tampoco se puede decir que pertenece al orden metafísico o teológico. En el orden teológico (en lo que compete a la estipulación de su discurso racional) la verdad es revelada por lo cual la esperanza no cuenta. La fe es la certeza de lo real de la palabra. En el orden metafísico tal concepto tampoco cuenta, la metafísica es la explicitación de las ideas mecanismos que funcionan más allá y como supuesto fundamento y consecuencia del orden empírico descriptivo. La metafísica adquiere su connotación esotérica solo por la aparición del racionalismo y del empirismo, sin ellos no tendría esa consideración. Entonces la esperanza surge como idea articuladora, como medio para la concreción de un proyecto que muchas veces parece inalcanzable según lo racional (es decir la secuenciación de estrategias en

Rebellato afirma: "De acuerdo a este enfoque el pueblo abarca también a todos aquellos sectores que son sus aliados en cuanto se identifican y han hecho una opción por y junto a los sectores explotados, dominados y excluidos. Se trata entonces del bloque ético-político alternativo, conformado en torno a un proyecto de liberación. Supone al pueblo entendido como sujeto protagónico y consciente, en cuanto gestor de una identidad nueva, madura y crítica.

Con lo cual la categoría pueblo no es una categoría encerrada en sí. Más bien se trata de algo que se construye, de un proceso marcado por las tensiones y contradicciones, de la articulación 
entre las dimensiones objetivas, económicas y sociales, por un lado y las dimensiones éticas, políticas y culturales, por el otro. (1995:169)función de los mecanismos lógicos: deducción, inducción y analogía). La esperanza involucra necesariamente un concepto propio del marxismo la Praxis. La misma como unidad teórica de la teoría y la práctica permite resolver las contradicciones que surgen el orden teórico funcionando como una afilada navaja de Occam y en el orden práctico funciona notablemente como guía para la acción. La praxis se convierte en síntesis particular y concreta de dichos órdenes y funciona en todo nivel del accionar humano.

Volviendo a la noción de "Esperanza" provista como adición a los proyectos concretos de resistencia la misma se entiende como confianza, como optimismo en las consecuencias de los posibles cambios tanto en el terreno epistemológico donde se da una ruptura como en el terreno cultural y por tanto ético. La confianza pone en juego otro de los conceptos claves para comprender nuestra época y que puede a la postre ser útil a la conformación de una praxis liberadora: la incertidumbre. Este concepto puede llevarnos a aceptar la realidad actual según los parámetros del pensamiento hegemónico. En función del reconocimiento de la instalación de la incertidumbre los portavoces del liberalismo pueden decir que eso deja todo como está confeccionando respuestas claras, elaboradas rigurosamente que genera la impresión en los colectivos de ser las únicas alternativas posibles de llevar a cabo.

La cultura de la desesperanza dominante archiva las grandes propuestas alternativas como ser el Socialismo, Teología y Filosofía de la liberación en momentos en que se acentúan los niveles de exclusión y la lucha por la supervivencia es la situación de vida normal para la mayor parte de la población mundial. La esperanza surge como articuladora una vez que se ha instalado la incertidumbre y se refuerza en la medida en que parecemos derrotados por los proyectos excluyentes de la diversidad.

El pueblo como Sujeto Histórico puede y debe jugar un papel decisivo en el proceso emancipador y depende de nosotros la posibilidad de tal. Corresponde ahora introducir un breve análisis de las actuales propuestas alternativas: las éticas comunicativas y la propuesta de Dussel asentada en la categoría del Otro como sustento para el logro de la liberación.

Rebellato focaliza su análisis en el pensamiento de Dussel quién se basa en el pensamiento de Marx. La intención de Dussel es encontrar el componente ético también en el pensamiento marxista . Se considera la teoría del valor como el fundamento de una ética puesto que "el capital 
no es tanto el análisis de la riqueza capitalista, sino de la miseria del trabajador" (1974:160) por lo tanto, las consecuencias del sistema: la pobreza, la miseria, la negación de la subjetividad y la diversidad son realidades anti éticas. Es fácil advertir que Dussel concluya que las enormes transferencias de valor desde América Latina a los países desarrollados constituyen una manifestación objetiva de la necesidad de la consideración de la relación con el Capital. Así toda nuestra filosofía pasará por un denodado esfuerzo por derribar o derrotar los discursos legitimantes de las relaciones establecidas por el Capital a efectos de asegurar la dominación. El blanco de los ataques debe ser el Capital.

Los enfoques de Dussel exageran en su exégesis el pensamiento escrito de Marx ya que estos enfoques se fundan en un fuerte reduccionismo economicista quedando relegados los aspectos culturales y éticos. Por supuesto, Marx explica y explicita las relaciones de dominación y explotación en el plano superestructural, pero desde una perspectiva económica y no ética.

Tanto para Rebellato como para Dussel, la ética ocupa un lugar central: la filosofía de la liberación es una opción ético-politica que consiste en la crítica a la "moral vigente" que justifica la dominación. Dussel desarrolla una crítica ética de la situación socioeconómica de los pueblos en los países subdesarrollados, de las relaciones sociales de dominación, de modo que la ética cumple la función de concienciar sobre estos problemas y sus posibles soluciones. Ética significa referencia al proyecto del Otro, en estado de apertura a la demanda, al deseo del otro y moralidad quiere decir el proyecto mismo, es decir, la praxis.

Rebellato apela a una noción de dialéctica abierta o en proceso de apertura que implica el conflicto de las fuerzas excluidas con las fuerzas dominantes y afirma que en tal sentido podría hablarse de una dialéctica abierta y no tanto de una síntesis dialéctica. (2000a:37) Afirma que filosofía de la liberación tiene que avanzar mucho en la rigurosidad del pensamiento: "El conflicto Norte-Sur no puede hacernos caer en la simplicidad de desechar el aporte de los pensadores del Norte. La lucha ideológica no se traduce en un rechazo sino en una recuperación dialéctica. Por otra parte, la liberación no es sólo una categoría histórica de los pueblos del Tercer Mundo, sino también de los pueblos y sectores del Norte que sufren la dominación y la exclusión"(1995:203). Se trata de una dialéctica abierta susceptible de ser vinculada a la analéctica de Dussel. 
En el pensamiento dusseliano la categoría central es el pobre. De allí la necesidad de una reflexión que instale la hermenéutica. Pero su exaltación de la sabiduría y la cultura popular le hace caer en el nacionalismo populista y en el culturalismo. La cultura se convierte así en la perspectiva única para la interpretación de los fenómenos sociales y aún en la elaboración de estrategias para su superación.

El reduccionismo culturalista, como sabemos, desconoce las diversidades subjetivas y promueve una visión ingenua, conservadora y apologética de la cultura. El ataque al sistema capitalista en su totalidad genera, claro está, un nosotros objetivo: no solo debemos hablar de un nosotros encerrado en sí mismo, sino de un nosotros que contenga aún a aquellos que no tienen la posibilidad de participar en el intercambio o negociación. Duro golpe a las éticas comunicativas del tipo habermasianas donde el énfasis en la pragmática política, al desplazar la condición económica concreta de las masas sociales, postula un nivel de intercambio discursivo idealizado puesto que objetivamente las condiciones de posibilidad para la participación impiden la participación. Si bien políticamente es posible un mínimo intercambio, lo político se niega a determinados grupos sociales. Así el otro se configura como condición de toda argumentación, aún los que no tienen nada, los pobres, los excluidos pueden poner en cuestión los resultados de las discusiones en las que no participaron. El acuerdo alcanzado por aquellos que están en condiciones de negociar puede contener un perfil dominador. Y el consenso se vuelve expresión de la hegemonía y el control político del bloque dominante y participante sobre los sectores excluidos e ignorados. Para poder transformar esta situación, ese Otro debe comenzar a ser reconocido: en política aquellos que se les niegan sus derechos, en economía aquellos que son explotados, en la erótica la mujer, en la pedagogía el alumno. Se da aquí una analéctica es decir una decidida irrupción del otro.

La distinción conceptual entre intención emancipadora e intención liberadora que aporta el mismo Dussel nos sirve para ubicar los análisis que refieren a una comunidad de comunicación pensada como espacio de argumentación racional. En la primera sería transformar la comunidad de comunicación real para irnos aproximando a la comunidad de participación ideal. El plano emancipatorio intenta siempre superarla alienación pero solo en el nivel cognitivo (1974:163). En cambio, la racionalidad liberadora pretende transformar radicalmente las estructuras y 
prácticas de dominación. Es una praxis que integra en una unidad los más distintos ámbitos: la racionalidad, la corporalidad, la política, la económica y la ética.

Dussel indica los límites de cualquier comunidad de comunicación y cualquier democracia de consenso porque éstas quedan atrapadas por la ideología liberal puesto que no cuestionan profundamente las estructuras de dominación. A su vez el liberalismo desde el punto de vista de las éticas comunicativas no desarrolla una crítica sobre los mecanismos que impiden la posibilidad de la libertad y la tolerancia que son sus valores clásicos. En consecuencia, la ideología liberal es superada por el neoliberalismo. La comunidad de comunicación acepta y debe aceptar la presencia de numerosos sectores excluidos, los valores burgueses de libertad, igualdad y fraternidad ni siquiera son posibles dentro de cultura que los generó, Rebellato se pregunta de qué tolerancia estamos hablando, si las sociedades capitalistas sostienen modelos neoliberales cada vez más excluyentes. Frente a ello no puede el análisis filosófico limitarse a predicar la comunicación puesto que las condiciones objetivas impiden que se dé tal comunicación.

Rebellato afirma: "A mi entender, corresponde nuevamente sostener que la comunidad se construye a través de acciones estratégicas orientadas a transformarlas estructuras de dominación. Para articular dichas estrategias se requiere de múltiples acciones comunicativas al interno del bloque social que lucha por la liberación. Pero no es posible una acción comunicativa con el dominador puesto que la dominación de por sí excluye toda comunicación." (1995:164)

Rebellato se plantea algunas dudas frente al pensamiento de Dussel. Una es sobre la categoría Otro como exterioridad. La presentación de esta categoría por parte de Dussel la hace ver como un más allá interpelante, como algo que no se encuentra en el sistema que habla desde la exterioridad absoluta cuando el proceso histórico concreto del sistema es el que produce al excluido. Ese excluido está aquí, entre nosotros y solo la transformación de ese sujeto puede producir cambios en la estructura del sistema. La razón por la cual Dussel esboza esta caracterización del Otro se puede encontrar en la filosofía de Levinas que a su vez parece asentarse en la filosofía de Heidegger. La segunda duda está relacionada a la primera. Hay una aceptación del imperativo: libera al otro, al pobre. Esta interpelación supone a alguien que puede ser liberado y a alguien que puede liberar. Así la liberación no es un proceso de interacción entre quienes tienen la capacidad de liberar y los oprimidos, más bien es una iniciativa de los 
intelectuales que son los filósofos de la liberación. Pero nadie libera a nadie sino que nos liberamos juntos si somos capaces de poner en cuestión el modelo identitario autoritario sobre el cual estamos construidos. Es obvio que esta nueva conceptualización pone en juego otros ámbitos de los que nos ocuparemos más adelante: la política y la pedagógica. El perfil del intelectual así se debe entender como el de alguien que se sabe influido en su ser por los procesos de transformación que a su vez marcan como punto de inicio un completo replanteo de la situación del saber y de la política. Una vez superada la dependencia en estos ámbitos de los discursos hegemónicos ya se puede hablar del comienzo de un recorrido hacia la liberación. 


\section{CRECIENDO Y HACIENDO CRECER MI MUNDO}

En este punto de la investigación vemos concretado la propuesta inicial del trabajo, pues los módulos me constru-yo se convierten en el punto de convergencia entre lo filosófico y lo pedagógico condensado en una sola herramienta que apunta a un mismo fin

Como primera medida los módulos están pensados y elaborados desde los lineamientos pedagógicos del constructivismo social planteados por Vigotsky donde el niño tiene dos fases de aprendizaje que parte desde la interacción individual con el entorno desde una problemática planteada y la segunda es la puesta en común con los miembros de su comunidad o grupo de trabajo sobre el aprendizaje obtenido en su interacción con el medio y es justo allí donde se logra un intercambio de experiencias exitosas y no exitosas y donde se genera tanto la auto-afirmación, el auto-reconocimiento y el auto- conocimiento del niño como sujeto dentro de un contexto, lo que le permite hacerse a su vez, a la noción misma de sujeto y proyectarla a otras como la de individuo, ciudadano y miembro activo de su entorno, generando así aprestamiento y afianzamiento de los postulados filosóficos traídos a colación en el capítulo anterior.

En su forma estructural, cada módulo está diseñado con un eje central, éste a su vez se subdivide en cuatro temáticas, que ofrecen actividades en dos sesiones, para así optimizar tiempos dentro de las mismas.

Como la cartilla está diseñada especialmente para el centro de proyección social de la universidad, ofrece algunos beneficios al trabajo en el interior de éste: el primero un trabajo que permita la reconstrucción desde su individualidad como sujeto y el aprendizaje de nuevas herramientas que puede extraer desde su entorno y el segundo permitir mayor orden en el refuerzo escolar, que ya es tradicional dentro de las actividades llevadas a cabo en el centro de proyección social.

Dichos módulos que se presentan a continuación pueden ser ejecutados con niños de diversas edades, tienen cada uno de los pasos claramente enunciados para evitar dificultades en su ejercicio mismo y se convierte en un trabajo que puede ser proyectado permitiendo involucrar 
a otras comunidades, pues los temas que allí se abordan van desde lo individual, hasta lo ecológico, pasando por las artes, la lúdica y el refuerzo escolar organizado.

\subsection{CARTILLA "ME CONSTRU-YO"}

La cartilla "Me Constru-Yo" son una herramienta para el docente, y diseñados específicamente para ser desarrollados con población vulnerable, ya que toman en cuenta los espacios, el tipo de estudiantes, la inconstancia en la asistencia de los mismos, y la contingencia de las personas que dirigen los procesos de aprendizaje en la zona.

Está pensada desde la pedagogía de Vigotsky en busca de la reconstrucción del sujeto, como táctica para preparar activamente a los niños y las niñas en los roles que enfrentarán en su juventud y madurez, mediante conceptos aprendidos de manera significativa.

Además, para facilitar más el trabajo del docente, los módulos explican la dinámica conceptual que se debe manejar, las actividades que se deben llevar a cabo, los materiales que se deben usar (con sugerencias sobre material alterno) y contiene algunos anexos para trabajar con los niños y las niñas.

\subsubsection{Cartilla de Trabajo Creciendo y haciendo crecer mi mundo}

\subsubsection{Modulo 1: Eje de Autoconstrucción: YO}

\subsection{Temática 1: Conozco y reconozco mi cuerpo}

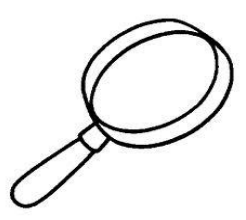

Queridos amiguitos: Si quieren dedicarse a la mayor aventura de su vida, recorriendo el mundo y sus historias, primero tenemos que conocer la maravilla de nuestro cuerpo, sus alcances, sus cualidades, sus cuidados, y todo lo que podríamos hacer con él. Hoy, aprenderás y transmitirás mucho sobre tu cuerpo y sus capacidades. 


\section{Justificación:}

Los niños y las niñas necesitan reconocerse como seres humanos para que puedan admitir los principios sociales que les esperan en años venideros.

Las siguientes actividades tienen el fin de facilitarle al infante esta posibilidad en cuatro etapas: Las dos primeras permiten que los niños y

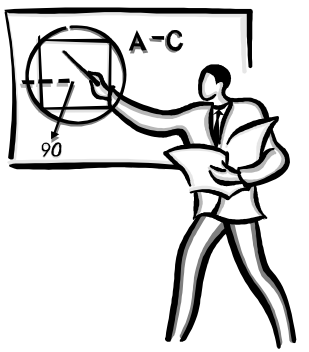
las niñas realicen una introspección, ejercitando su zona de desarrollo efectivo. Las dos siguientes buscan que los

niños y las niñas exterioricen lo aprendido, ejercitando su zona de desarrollo potencial, generando interacción, aprendizaje significativo y consciencia sobre la construcción del tejido social.

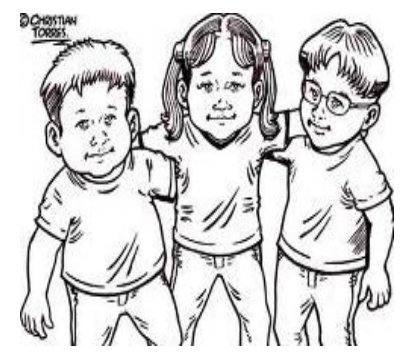

\section{ACTIVIDADES INDIVIDUALES Y GRUPALES}

\section{Primera sesión: Cómo me armo y me desarmo}

Materiales: Fotocopias del modelo del cuerpo (anexo 1), Colores (o cualquier material para pintar), Tijeras.

Docente: Explicar los nombres y las funciones de la cabeza, hombros, brazos, manos y pies.

1- Escucha con atención cuales son y donde se encuentran tres principales divisiones del cuerpo (Cabeza, hombros y extremidades) y sus dos terminaciones (manos y pies). Luego escucha para que sirve cada una de estas partes del cuerpo.

2- $\quad$ Toma el modelo del cuerpo que te han entregado y decóralo de la mejor manera con colores, crayolas, témperas, o con lo que tú quieras.

3- Una vez el material esté decorado, toma las tijeras y recorta el cuerpo en sus tres principales divisiones y sus dos terminaciones, formando así un rompecabezas.

4- Juega con este rompecabezas e intercambia las partes de tu cuerpo con las de los demás compañeros y diviértete a montón creando seres humanos de muchas diferencias pero de grandes similitudes. 


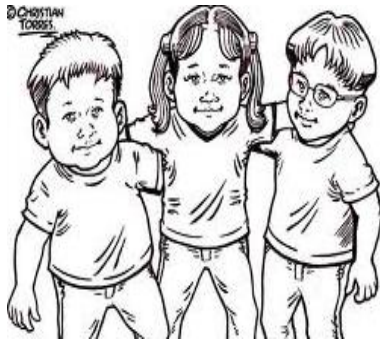

1- Escucha con atención cuales son las partes del rostro (Ojos, cejas, pestañas, mejillas, nariz, boca y orejas). Luego escucha para que sirve cada una de estas partes.

2- Dibuja tu rostro con el lápiz en el papel y luego decóralo de la mejor manera con los colores y materiales que trajiste.

3- Dibuja al lado de los ojos lo que más te gusta ver, al lado de la nariz lo que más te gusta oler, al lado de la boca lo que más te gusta saborear, y al lado de las orejas lo que más te gusta oír.

4- Junta todos los trabajos del curso y hagan un mural con las caras de todos y lo que más les gusta.

\subsection{Temática 2: Siento lo que siento}

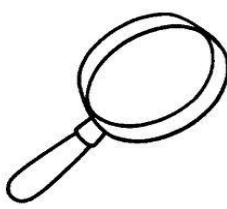

Queridos amiguitos: Si queríamos saber cómo expresar nuestros sentimientos, éste será nuestro espacio, en donde exploraremos lo que sentimos, en relación con lo que pensamos. Quédate con tu docente y disfruta de las maravillas de tener sentimientos.

\section{Justificación:}

Los niños y las niñas necesitan aprender a expresar sus sentimientos de una manera adecuada y moderada. De esto depende que los vínculos afectivos que el infante vaya a construir, resulten en relaciones exitosas, ya sea con su familia, colegio, trabajo o amigos.

Las siguientes actividades tienen el fin de facilitarle al infante esta posibilidad en cuatro etapas: Las dos primeras permiten que los niños y

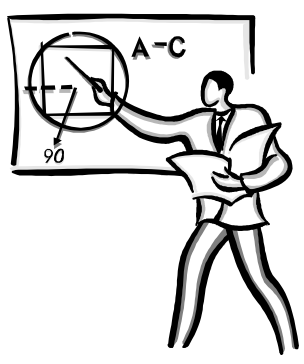
las niñas realicen una introspección, ejercitando su zona de desarrollo efectivo. Las dos 
siguientes buscan que los niños y las niñas exterioricen lo aprendido, ejercitando su zona de desarrollo potencial, generando interacción, aprendizaje significativo y consciencia sobre la construcción del tejido social.

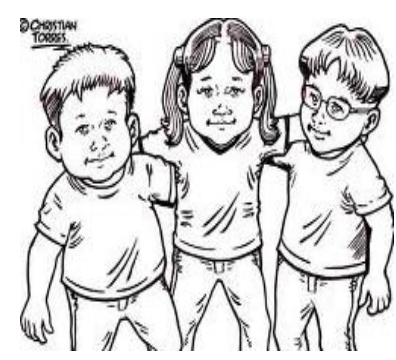

\section{ACTIVIDADES INDIVIDUALES Y GRUPALES}

\section{Primera sesión: Mis sentimientos crean}

Materiales: Cartulina, Colores (o cualquier material para pintar), Revistas, Pegante, Tijeras.

Docente: Explicar la importancia del afecto y los amigos para poder desarrollarnos en sociedad. Separar el grupo en parejas y ayudar con los dobleces de la cartulina.

1- Escucha con atención qué es el afecto y cuál es la importancia de este para mantener nuestras relaciones sociales. Todo el grupo debe trabajar en parejas de ahora en adelante.

2- Toma cartulina y divídela en dos. Así tendrás varias caras de la cartulina para hacer tu tarjeta. Dibuja a tu compañero de grupo en la primera cara y decóralo.

3- Luego con palabras y recortes exprésale por qué es bueno ser amigos. También puedes decorar el interior y el exterior de la tarjeta con bolitas de papel rasgado de las revistas que trajiste.

4- $\quad$ Cuando ya esté lista, regálale tu tarjeta a tu compañero y muéstrale a todos los del salón lo que te hicieron.

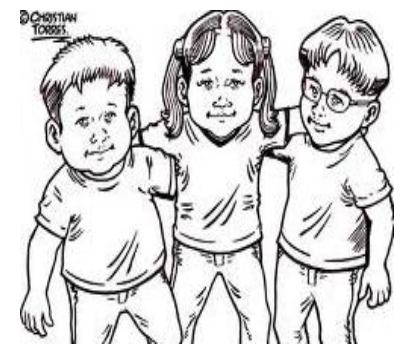

\section{Segunda sesión: Mis sentimientos ayudan}

Materiales: Un oso de peluche (o cualquier muñeco manejable y vistoso) Docente: Inventar una historia sobre la identidad del oso y la forma cómo llego al aula. Indagar a los niños acerca del porqué el oso está muy triste, permitiendo que los niños expresen sus propias tristezas sin querer. Al final es prudente hacer una actividad que saque a los niños de la tristeza.

1- $\quad$ Escucha con atención la explicación del porqué el osito está muy triste. 
2- Con ayuda de tu docente busca una solución para los problemas del oso. Dibuja en tu cuaderno la forma cómo vas a ayudar al oso a salir de sus problemas.

3- Entre todos construyan una lista que se llame "Los amiguitos del osito triste" en la cual se repartirán el orden en el que se llevarán el oso a su casa y lo cuidarán hasta la siguiente sesión.

4- Escucha a tu docente hablar sobre los momentos tristes que podríamos llegar a enfrentar en nuestra vida, y lo importantes que son para encontrar la felicidad.

\subsection{Temática 3: Me pongo en el espejo}

Queridos amiguitos: Es importante saber que todos tenemos virtudes y defectos.

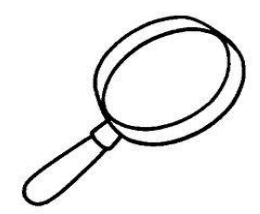

Además, no todos tenemos las mismas cualidades ni las mismas fallas, y eso es lo que hace que tú seas distinto de otras personas. No es lo alto, no es lo gordo, ni lo es el color de nuestra piel lo que nos diferencia. Es lo que hagamos por nuestra sociedad. Entonces niños, vamos a aprender como tener más virtudes y menos defectos día a día.

\section{Justificación:}

Los niños y las niñas necesitan crear su propio retrato ético y compararlo con el de los demás para hacerse conscientes de lo que son. Este diagnostico también es importante para corregir algunos hábitos perjudiciales para el desarrollo social del infante, mediante una herramienta que fomenta la autonomía.

Las siguientes actividades tienen el fin de facilitarle al infante esta

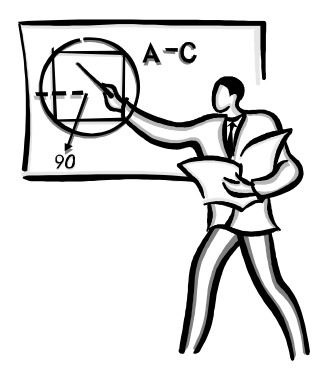
posibilidad en cuatro etapas: Las dos primeras permiten que los niños y las niñas realicen una introspección, ejercitando su zona de desarrollo efectivo. Las dos siguientes buscan que los niños y las niñas exterioricen lo aprendido, ejercitando su zona de desarrollo potencial, generando interacción, aprendizaje significativo y consciencia sobre la construcción del tejido social. 


\section{ACTIVIDADES INDIVIDUALES Y GRUPALES}

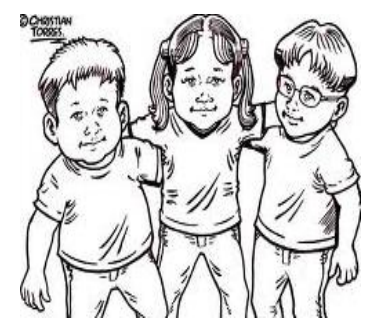

\section{Primera sesión: Sumemos nuestras cualidades.}

Docente: Separar los niños y las niñas en grupos de cinco. Luego proponga un concurso entre los grupos con algún aliciente. Dentro del grupo los niños se identificarán como: El más grande, el más pequeño, el más rápido y los de mediana estatura y jugarán de acuerdo a los parámetros del paso tres.

1- $\quad$ Construye grupos de mínimo cinco personas.

2- Encuentra en tu grupo las siguientes características: El más grande, el más pequeño, el más rápido y los de mediana estatura.

3- Los de mediana estatura deben hacer un túnel abriendo las piernas separándose un metro uno entre otro. El más pequeño pasará debajo de las piernas de los medianos llevando un objeto. Al final del túnel, el más rápido tomará el objeto y lo llevará hasta donde se encuentra el más fuerte, quien cargara a su compañero hasta la meta que fije el docente. El grupo que lo haga en menor tiempo gana el juego.

4- Escucha atentamente la reflexión sobre las cualidades de cada uno, y la necesidad de sumar nuestras cualidades para mejorar nuestra sociedad.

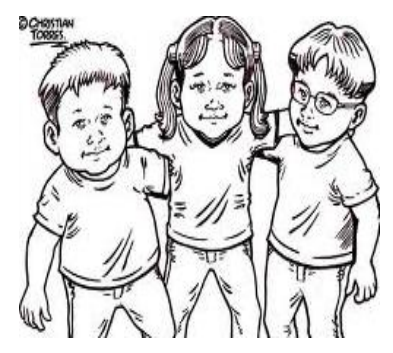

\section{Segunda sesión: Antes de ver a otro, me veo}

Materiales: Papel, Lápiz, Colores.

Docente: Hacer una reflexión sobre qué son las cualidades y los 1- Escucha con atención la explicación de los defectos y cualidades que todos tenemos.

2- Dibuja en tu papel el momento en el que viste como apareció tu mayor defecto.

3- Dibuja a tus compañeros de grupo y señala las cualidades y los defectos de cada uno.

4- Explícale a todo el salón que vas a hacer de ahora en adelante para corregir tus defectos y mejorar tus cualidades. 


\subsection{Temática 4: Estoy sano, vivo feliz}

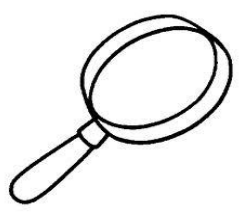

Queridos amiguitos: Si sabemos que es lo que nos enferma, lo más seguro es que podamos evitar estas cosas para no afectarse. Cuando estás enfermo no puedes jugar, ni estudiar, ni comer. Por eso hoy aprenderemos con nuestro docente cómo llevar una vida sana e higiénica para que disfrutemos al máximo el hecho de ser niños.

\section{Justificación:}

Los niños y las niñas deducir los vínculos entre la higiene y la salud, partiendo de la definición y creando hábitos que deben trascender del aula a los hogares, pues es allí donde los niños deben reflejar su conocimiento descubierto, transmitiendo algo de este a sus compañeros de hogar.

Las siguientes actividades tienen el fin de facilitarle al infante esta

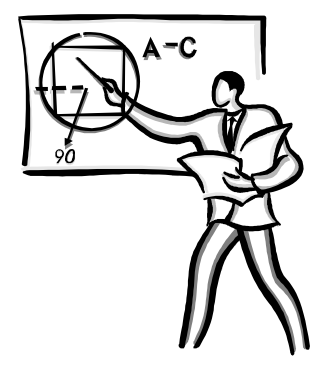
posibilidad en cuatro etapas: Las dos primeras permiten que los niños y las niñas realicen una introspección, ejercitando su zona de desarrollo efectivo. Las dos siguientes buscan que los niños y las niñas exterioricen lo aprendido, ejercitando su zona de desarrollo potencial, generando interacción, aprendizaje significativo y consciencia sobre la construcción del tejido social.

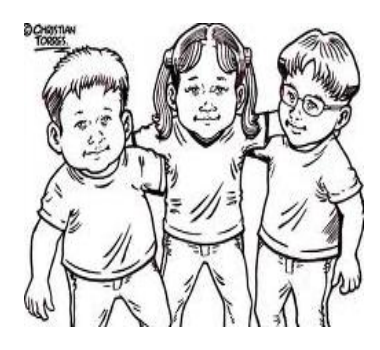

\section{ACTIVIDADES INDIVIDUALES Y GRUPALES}

\section{Primera sesión: Que haría sin mis dientes}

Materiales: Revistas, tijeras, pegante, cartulina.

Docente: Explicar la importancia de los dientes para nuestra vida y lo mucho que hay que cuidarlos. Muéstrele como todos dependemos de nuestros dientes y guíelos en la actividad.

1- Escucha con atención cómo deben ser tratados nuestros dientes y reflexiona sobre qué tendrías que hacer si no los tuvieras.

2- Comienza a revisar las revistas y recorta todas las sonrisas que veas.

3- Recorta la cartulina por la mitad. En una de estas mitades dibuja una sonrisa con lápiz y pega las sonrisas de las revistas en ella. 
4- Con la otra mitad construye una "cámara de fotos" con la que le tomarás muchas fotografías a tus compañeros posando con su gran sonrisa.

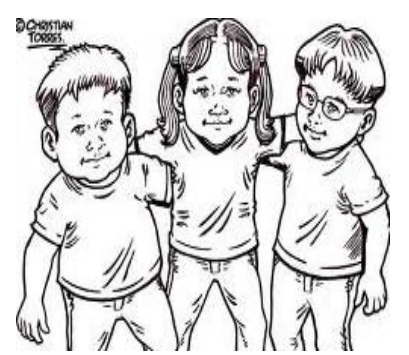

\section{Segunda sesión: Soy el que enseña sobre aseo}

Materiales: Materiales de aseo tales como cepillos, jabón, trapos, detergentes, escobas etc.

Docente: Formar grupos de cuatro estudiantes y explicar a los niños el correcto uso de cada uno de esos implementos.

1- Forma grupos de cuatro personas y escucha con atención la explicación del correcto uso de los productos de aseo.

2- Dentro del grupo los niños y niñas van a planear un comercial de televisión en donde promocionen uno o varios productos de aseo de los que trajeron al salón.

3- Cada grupo se irá presentando en orden mientras vas resaltando lo más importante de cada representación.

4- Coloca todos los elementos de aseo en el centro del salón, y luego el docente irá preguntando sobre el nombre y el uso del producto. Diviértete con el comercial.

\subsubsection{Modulo 2: Eje de Autoconstrucción: LA SOCIEDAD}

\subsubsection{Temática 1: mi familia, mi primera idea de sociedad}

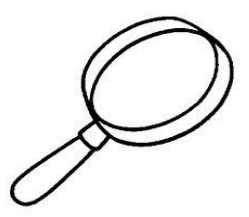

Queridos amiguitos: En esta nueva parte de nuestro viaje, emprenderemos una nueva aventura, haciendo un recorrido por nuestro entorno próximo para poder reconocernos como miembros activos de nuestra comunidad, nuestro docenteguía será el encargado de conducirnos en esta travesía, solo necesitamos de toda tu alegría y entusiasmo para el desarrollo de las actividades...Bienvenidos!

\section{Justificación:}

Los niños y las niñas están empezando a experimentar sus primeros vínculos con otras personas y para ello se ven abocados a una serie de

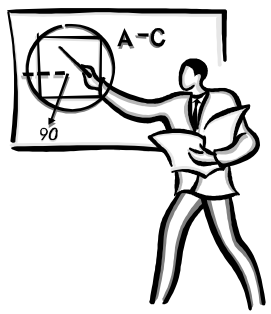


procesos donde logran formar su identidad, lazos de unión y cariño hacia un grupo determinado de personas y su sentido de pertenencia con el lugar que habitan. Para el refuerzo de este proceso en el presente modulo veremos 4 piezas claves del proceso socializador del niño, la familia, el barrio, la ciudad y el país, partiendo de la definición y creando hábitos que deben trascender del aula a los hogares, pues es allí donde los niños deben reflejar su conocimiento descubierto, transmitiendo algo de este a sus compañeros de hogar y viceversa.

ACTIVIDADES INDIVIDUALES Y GRUPALES

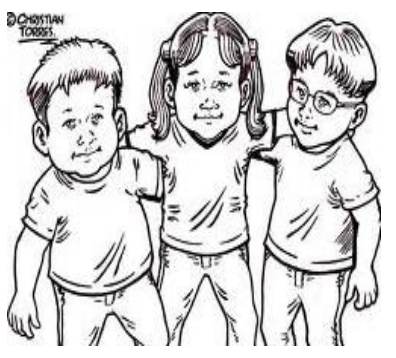
Primera sesión: La familia, mi primer núcleo social-juego de roles

Docente: Explicar la importancia del núcleo familiar sobretodo en contextos donde se ve amenazada la estructura familiar estándar y los niños en ocasiones sienten la ausencia bien sea de algunos de los padres o de otro de sus miembros, de igual manera resaltar la importancia de la buena convivencia en el hogar con cada uno de sus integrantes y los valores que se fundamentan en su interior.

1. Escucha con atención la explicación de nuestro guía sobre la idea de familia y quienes la conforman así como sus funciones

2. Organízate en grupos de 4 personas

3. Entre los integrantes del grupo la guía definirá quien va a ser el papá, quien la mamá, quien el hijo (a) mayor y el hijo(a) menor y les asignará una situación que deben recrear frente a sus compañeros

4. Luego de haber pasado todos los grupos deben compartir con sus compañeros y guía como se sientieron actuando de papá, mamá o hijo (a) y resaltar la importancia de la existencia de la familia en nuestra sociedad 


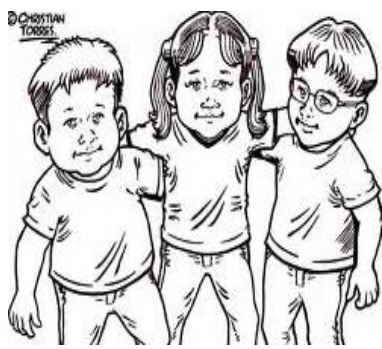

\section{Segunda sesión: Mi espacio dentro de mi familia}

Materiales: Cartulinas por octavos, temperas, pinceles, vasos plásticos.

Docente: Hablar con los niños sobre la importancia que tienen dentro de la familia y el amor que debe profesarse entre cada uno de sus miembros así como el cuidado de padres a hijos y entre hermanos, abuelos, tíos y primos

1. En el octavo de cartulina dibuja en primer lugar a lápiz a los miembros cercanos de tu familia (preferiblemente con quienes vives) incluyéndote

2. Luego pintar los dibujos con tempera de manera cuidadosa

3. Una vez seca la tempera, debajo de cada dibujo coloca de quien se trata y por qué es importante para la familia la presencia de esa persona

4. En tu autorretrato describe una experiencia positiva vivida en familia (una celebración, una salida etc).

5. Para finalizar cada uno de los niños expondrá su trabajo a sus compañeros y a su guía quien cerrará la sesión dando las conclusiones sobre la importancia de vivir en familia y como esta debe ser un mecanismo de apoyo para cada uno de sus miembros.

\subsubsection{Temática 2: mi barrio y sus habitantes}

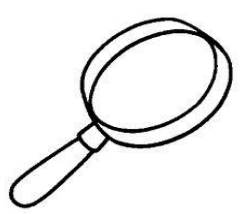

Queridos amiguitos: En esta nueva parte de nuestro viaje, emprenderemos una nueva aventura, haciendo un recorrido por nuestro entorno próximo para poder reconocernos como miembros activos de nuestra comunidad, nuestro docenteguía será el encargado de conducirnos en esta travesía, solo necesitamos de toda tu alegría y entusiasmo para el desarrollo de las actividades...Bienvenidos!

\section{Justificación:}

Los niños y las niñas están empezando a experimentar sus primeros vínculos con otras personas y para ello se ven abocados a una serie de procesos donde logran formar su identidad, lazos de unión y cariño hacia

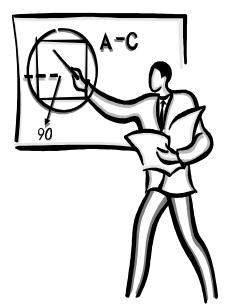


un grupo determinado de personas y su sentido de pertenencia con el lugar que habitan. Para el refuerzo de este proceso en el presente modulo veremos 4 piezas claves del proceso socializador del niño, la familia, el barrio, la ciudad y el país, partiendo de la definición y creando hábitos que deben trascender del aula a los hogares, pues es allí donde los niños deben reflejar su conocimiento descubierto, transmitiendo algo de este a sus compañeros de hogar y viceversa.

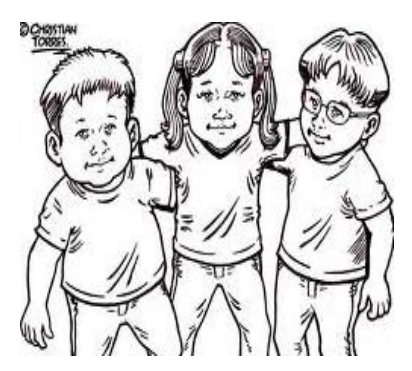

\section{ACTIVIDADES INDIVIDUALES Y GRUPALES}

Primera sesión: Ubicando quienes habitan mi barrio - mini entrevistas

Docente: el guía en esta oportunidad debe iniciar la sesión explicando que nuestro territorio se encuentra dividido por barrios, lo cual facilita la ubicación de la gente en la ciudad para efectos de beneficios y favorecimiento de la vida en comunidad.

1. Escucha con atención la explicación de nuestro guía sobre la idea de barrio y quienes conforman la comunidad así como el servicio que le prestan

2. Organízate en grupos de 4 personas

3. Entre los integrantes del grupo la guía definirá quien será el panadero, quien será el policía, quien será un habitante del barrio (entrevistador) y quien será el tendero

4. Luego de haber definido los roles, el entrevistador preguntará a manera de entrevista a sus compañeros cual es la importancia del servicio que le prestan a la comunidad una vez han pasado todos los grupos deben compartir con sus compañeros y guía como se sientieron actuando como personas activas en la comunidad y su importancia en el barrio

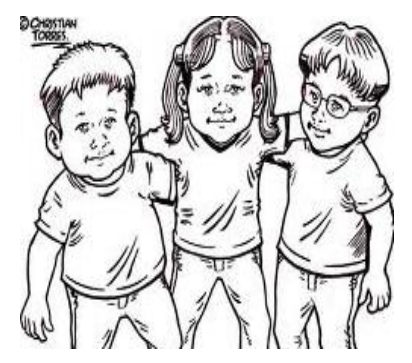

\section{Segunda sesión: Mi barrio, mi primer gran espacio}

Materiales: Hojas blancas, colores, lápices y plumones de colores

Docente: Explicar a los niños sobre la importancia de la vida en comunidad y los servicios que se prestan sus miembros entre sí (panadería, carnicería, el centro de salud etc) 
1. Divide la hoja en 4 partes, en la primera parte dibuja a tus amiguitos de barrio y el lugar favorito donde comparten juego

2. En la segunda parte dibuja la fachada de tu casa y el paisaje que la rodea (montañas, otras casas, etc.)

3. En la tercera parte dibuja un miembro de tu barrio que se destaque por prestar un servicio a la comunidad

4. En la última parte pregúntale a un compañerito que quiere ser cuando grande y dibújalo en tu hoja.

5. Para finalizar cada uno de los niños expondrá su trabajo a sus compañeros y a su guía quien cerrará la sesión dando las conclusiones sobre la importancia de vivir en un barrio armónico donde todos los miembros de la comunidad se colaboren entre sí.

\subsection{Temática 3: Mi ciudad territorio humano}

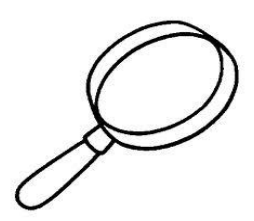

Queridos amiguitos: En esta nueva parte de nuestro viaje, emprenderemos una nueva aventura, haciendo un recorrido por nuestro entorno próximo para poder reconocernos como miembros activos de nuestra comunidad, nuestro docenteguía será el encargado de conducirnos en esta travesía, solo necesitamos de toda tu alegría y entusiasmo para el desarrollo de las actividades...Bienvenidos!

\section{Justificación:}

Los niños y las niñas están empezando a experimentar sus primeros vínculos con otras personas y para ello se ven abocados a una serie de procesos donde logran formar su identidad, lazos de unión y cariño hacia un grupo determinado de personas y su sentido de pertenencia con el lugar que habitan. Para el refuerzo de este proceso en el presente modulo veremos 4 piezas claves del proceso socializador del niño, la familia, el

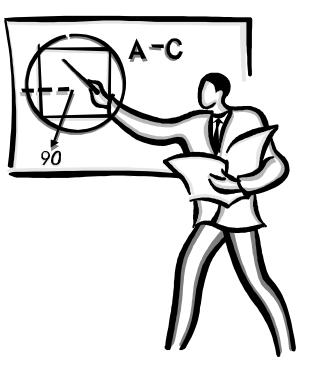


barrio, la ciudad y el país, partiendo de la definición y creando hábitos que deben trascender del aula a los hogares, pues es allí donde los niños deben reflejar su conocimiento descubierto, transmitiendo algo de este a sus compañeros de hogar y viceversa.

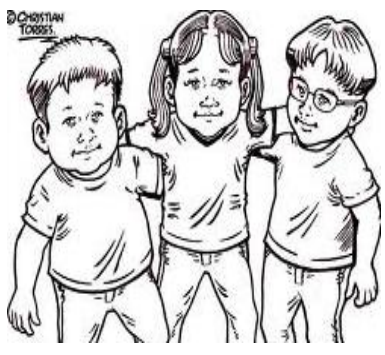

\section{ACTIVIDADES INDIVIDUALES Y GRUPALES}

\section{Primera sesión: La vida en la ciudad-cuento}

Materiales: Anexo 2 cuento "Ratón de campo/ratón de ciudad", bolsas

de papel, marcadores

Docente: el guía durante el desarrollo de esta sesión debe brindarle a los niños la idea de ciudad, sus diferencias con el campo y los principales lugares que concentra una ciudad, así como los diferentes roles de las personas que viven en la ciudad.

1. Escucha con atención la lectura del cuento "Ratón de campo/Ratón de ciudad" que realizará nuestro guía de grupo.

2. Busca un compañero para trabajar

3. Con las bolsas de papel uno de los dos elaborará un títere del ratoncito de ciudad y el otro el del ratoncito de campo

4. Por medio de una mini presentación plasmar las principales diferencias entre la vida el campo y la vida en la ciudad

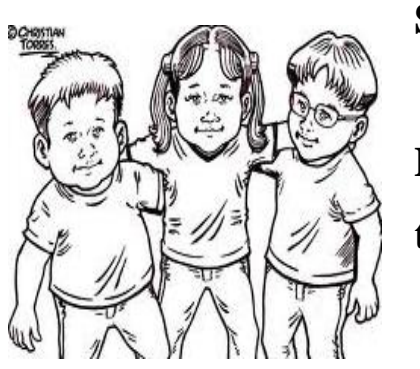

\section{Segunda sesión: Mi ciudad un lugar que se mueve}

Docente: Explicar a los niños sobre la importancia de la organización del tránsito en una ciudad, las normas de transito y las vías

1. Se divide el grupo en sub grupos de niños donde unos serán carros de servicio público, otros particulares, unos serán semáforo y otros agente de tránsito

2. El agente de tránsito con la ayuda del guía se encargará de guiar la circulación de los carros tanto de servicio público como particulares y el funcionamiento de los semáforos 
3. Luego se organiza la vía y se hacen circular los carros durante un tiempo de 10 a 15 minutos

4. Luego de circular durante el tiempo estimado el guía indicará el fin de la actividad y se hará una retroalimentación sobre lo que los niños lograron percibir sobre como funciona la movilidad en la ciudad.

\subsection{Temática 4: Soy Colombia}

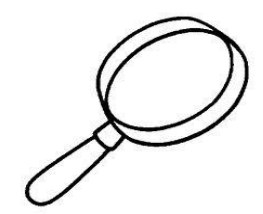

Queridos amiguitos: En esta nueva parte de nuestro viaje, emprenderemos una nueva aventura, haciendo un recorrido por nuestro entorno próximo para poder reconocernos como miembros activos de nuestra comunidad, nuestro docenteguía será el encargado de conducirnos en esta travesía, solo necesitamos de toda tu alegría y entusiasmo para el desarrollo de las actividades...Bienvenidos!

\section{Justificación:}

Los niños y las niñas están empezando a experimentar sus primeros vínculos con otras personas y para ello se ven abocados a una serie de procesos donde logran formar su identidad, lazos de unión y cariño hacia un grupo determinado de personas y su sentido de pertenencia con el lugar que habitan. Para el refuerzo de este proceso en el presente modulo veremos 4 piezas claves del proceso socializador del niño, la familia, el

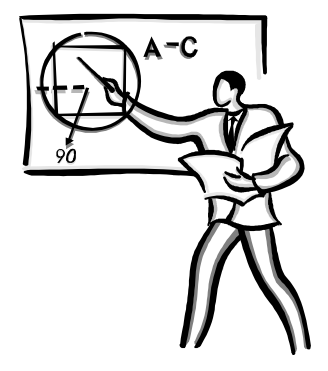
barrio, la ciudad y el país, partiendo de la definición y creando hábitos que deben trascender del aula a los hogares, pues es allí donde los niños deben reflejar su conocimiento descubierto, transmitiendo algo de este a sus compañeros de hogar y viceversa.

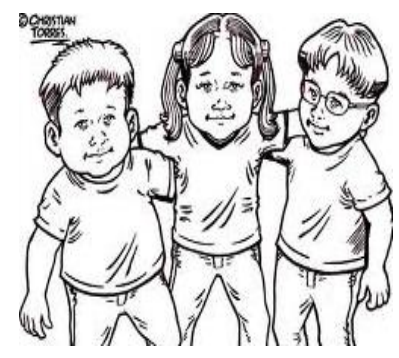

\section{ACTIVIDADES INDIVIDUALES Y GRUPALES}

\section{Primera sesión: Mi territorio, mi identidad}

Materiales: Cartulina, crayolas

Docente: el guía durante el desarrollo de esta sesión debe brindarle a los niños las nociones básicas de nuestra nacionalidad como Colombianos nuestros símbolos patrios y los acontecimientos más importantes de 
nuestra historia.

1. Escucha con atención la explicación que te da tu guía sobre nuestro país Colombia, sus riquezas naturales y nuestra cultura.

2. El guía debe dividir el grupo en 4 partes

3. A cada grupo debe indicarle pintar: grupo 1 la bandera de Colombia, grupo 2 el escudo, grupo 3la flor insignia (catleya) de nuestro país y el grupo 4 la palma de cera.

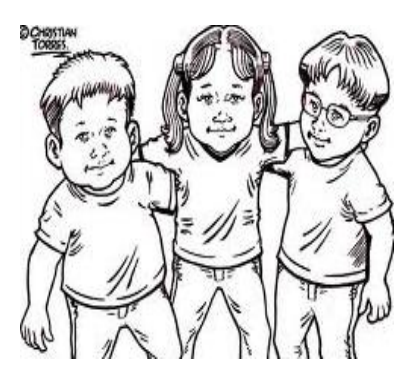

\section{Segunda sesión: Compartiendo experiencias}

Docente: Explicar a los niños sobre la importancia de los símbolos patrios y como éstos refuerzan nuestra identidad

4. Luego de tener los diferentes grupos con los símbolos patrios elaborados, reorganizar el grupo donde haya un niño con cada uno de los diferentes símbolos elaborados

1. para compartir con sus compañeros deben elaborar una mini trova donde expliquen de que se trata cada símbolo y por qué es importante en nuestra cultura.

2. El guía al final de la presentación de cada grupo debe hacer la respectiva retroalimentación

\subsubsection{Modulo 3: Eje de Autoconstrucción: MEDIO AMBIENTE}

\subsubsection{Temática 1: Yo soy parte de los recursos naturales}

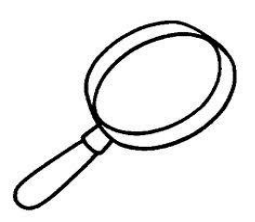

Queridos amiguitos: Es importante saber la importancia de los recursos naturales para los seres humanos y todo su entorno. Estos recursos son los materiales y espacios que el hombre aprovecha de la naturaleza para sobrevivir, sin embargo, estos recursos no son infinitos. Por eso necesitamos saber cuáles son, aprovecharlos al máximo y aprender a conservarlos. Si no conservamos estos recursos se acabaran, y la humanidad también lo hará. Si tu quieres ser el que salve a toda la humanidad de su autodestrucción, ayuda a la madre naturaleza conservándola de la mejor manera. 


\section{Justificación:}

Los niños y las niñas necesitan entender que son los recursos naturales en pro de la construcción de una mentalidad ecológica, que colabore con las políticas ambientalistas, y lo más importante, que genere consciencia sobre el estado actual del medio ambiente.

Las siguientes actividades tienen el fin de facilitarle al infante esta

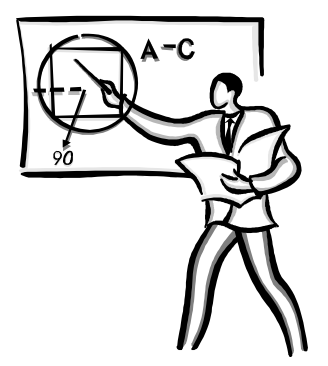
posibilidad en cuatro etapas: Las dos primeras permiten que los niños y las niñas realicen una introspección, ejercitando su zona de desarrollo efectivo. Las dos siguientes buscan que los niños y las niñas exterioricen lo aprendido, ejercitando su zona de desarrollo potencial, generando interacción, aprendizaje significativo y consciencia sobre la construcción del tejido social.

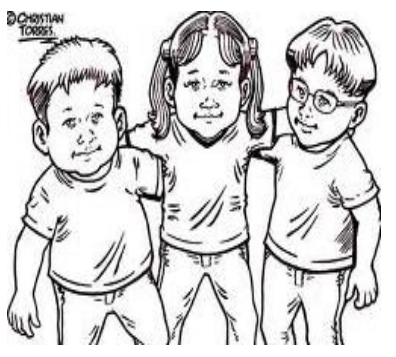

\section{ACTIVIDADES INDIVIDUALES Y GRUPALES}

\section{Primera sesión: Estoy rodeado de recursos naturales}

Materiales: Hojas de papel, pegante, material recogido de la calle (palitos, piedritas, tierra o arena, hojas de árbol caídas)

Docente: Explicar que son los recursos naturales y relacionarlos con todos los materiales que haya en el salón como lápices, papel, agua, piedras, vidrio, etc. Mostrar que nada viene del hombre sino que él solo transforma esta materia prima en lo que necesita.

1- Escucha con atención qué son los recursos naturales, de donde salen y para qué sirven.

2- Saca tu hoja de papel y comienza a construir bosques con el material recogido de la calle y el pegante.

3- Luego comparte el bosque con todo el curso haciendo un gran bosque sumando los trabajos de todos los niños y niñas del curso.

4- Escucha al docente hablar de todo lo que nos dan los bosques, lo difícil que es construirlos, y lo fácil que es conservarlos. 


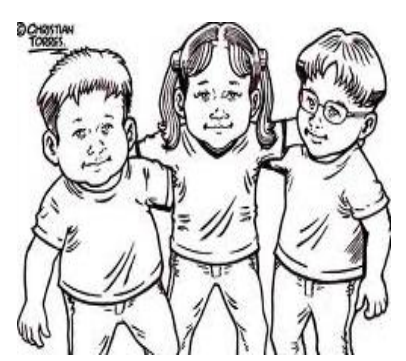

\section{Segunda sesión: Un recurso que mueve al mundo}

Docente: Explicar a los niños y las niñas las utilidades y el lugar de origen del petróleo. Dividir el salón en dos grupos. Uno de grandes y otro de pequeños. Hacer parejas entre un niño grande y uno pequeño para la actividad. Reunir las parejas en dos grupos del mismo número de parejas.

1- Escucha atentamente la explicación sobre el petróleo, sus usos y problemas.

2- Formar parejas de un niño grande y uno pequeño. Luego formar los dos equipos de parejas (jinetes y caballos) para una carrera de relevos.

3- En orden, una pareja de cada equipo sale al frente y compiten en velocidad, yendo y viniendo. Al llegar la primera pareja del equipo, la segunde pareja parte, repitiendo la operación hasta que ya no queden parejas.

4- Ya que estas cansado pregúntate que pasaría si en vez de vehículos impulsados con petróleo, nosotros tuviéramos que trasportar todo, sin ayuda del petróleo. Pregúntale al docente.

\subsubsection{Temática 2: Si cuidas el ambiente te cuidas}

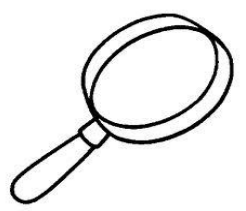

Queridos amiguitos: Es importante saber la importancia de los recursos naturales para los seres humanos y todo su entorno. Estos recursos son los materiales y espacios que el hombre aprovecha de la naturaleza para sobrevivir, sin embargo, estos recursos no son infinitos. Por eso necesitamos saber cuáles son, aprovecharlos al máximo y aprender a conservarlos. Si no conservamos estos recursos se acabaran, y la humanidad también lo hará. Si tu quieres ser el que salve a toda la humanidad de su autodestrucción, ayuda a la madre naturaleza conservándola de la mejor manera.

\section{Justificación:}

Los niños y las niñas necesitan entender que son los recursos naturales en pro de la construcción de una mentalidad ecológica, que

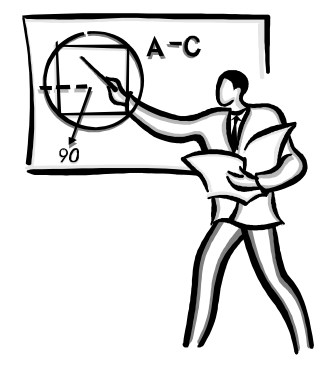


colabore con las políticas ambientalistas, y lo más importante, que genere consciencia sobre el estado actual del medio ambiente.

Las siguientes actividades tienen el fin de facilitarle al infante esta posibilidad en cuatro etapas: Las dos primeras permiten que los niños y las niñas realicen una introspección, ejercitando su zona de desarrollo efectivo. Las dos siguientes buscan que los niños y las niñas exterioricen lo aprendido, ejercitando su zona de desarrollo potencial, generando interacción, aprendizaje significativo y consciencia sobre la construcción del tejido social.

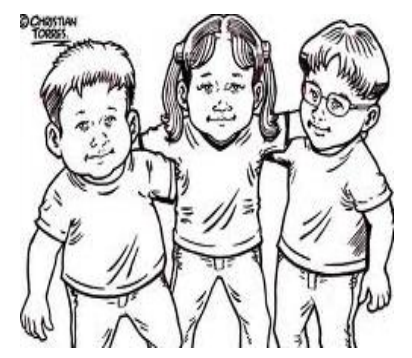

\section{ACTIVIDADES INDIVIDUALES Y GRUPALES}

\section{Primera sesión: Soy de agua}

Docente: Explicar qué es el agua dulce y salada. Muéstreles a los niños y a las niñas lo mucho que necesitamos el agua, y lo fácil que es contaminarla. Luego explique el ciclo del agua y guie a los niños y niñas en la actividad. Reúnalos en grupos de cinco personas.

1- Escucha con atención qué es el ciclo del agua y la importancia de este mineral para nuestra vida.

2- Reúnete con tu grupo y crea una ronda infantil que hable del agua.

3- Hagamos un concurso donde todos los grupos cantan y muestran quien compuso la mejor ronda infantil.

4- Todos los del salón le van a contar al docente en que momentos de sus vidas han desperdiciado el agua.

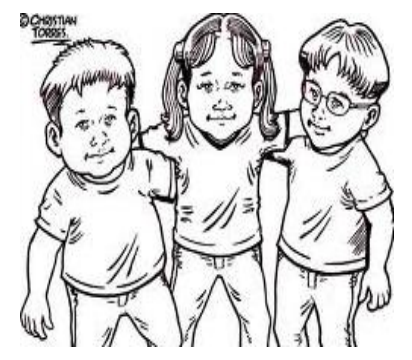

Segundasesión: Soy de aire

Materiales: Cuaderno, lápiz y colores

Docente: Explicar a los niños y las niñas importancia de un aire limpio para respirar. También explicar cómo se da la contaminación de este y las posibles formas de evitar esta terrible situación. Dar lectura al cuento sobre el aire y pedirle a los niños hacer un dibujo (Anexo 3). 
1- Escuchar atentamente al docente cuando explique la importancia del aire limpio y la forma de descontaminarlo.

2- Poner atención al cuento sobre el aire (anexo 3).

3- Haz un dibujo de un paisaje donde haya un medio ambiente hermoso, con agua, aire limpio, animales libres y hombres felices.

4- Explícale al docente cuando haz contaminado el aire y dile cómo vas a hacer para descontaminar de ahora en adelante.

\subsubsection{Temática 3: Ecología}

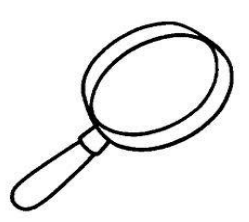

Queridos amiguitos: Es importante saber la importancia de los recursos naturales para los seres humanos y todo su entorno. Estos recursos son los materiales y espacios que el hombre aprovecha de la naturaleza para sobrevivir, sin embargo, estos recursos no son infinitos. Por eso necesitamos saber cuáles son, aprovecharlos al máximo y aprender a conservarlos. Si no conservamos estos recursos se acabaran, y la humanidad también lo hará. Si tú quieres ser el que salve a toda la humanidad de su autodestrucción, ayuda a la madre naturaleza conservándola de la mejor manera.

\section{Justificación:}

Los niños y las niñas necesitan entender que son los recursos naturales en pro de la construcción de una mentalidad ecológica, que colabore con las políticas ambientalistas, y lo más importante, que genere consciencia sobre el estado actual del medio ambiente.

Las siguientes actividades tienen el fin de facilitarle al infante esta posibilidad en cuatro etapas: Las dos primeras permiten que los niños y

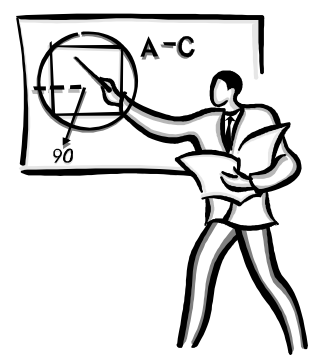
las niñas realicen una introspección, ejercitando su zona de desarrollo efectivo. Las dos siguientes buscan que los niños y las niñas exterioricen lo aprendido, ejercitando su zona de desarrollo potencial, generando interacción, aprendizaje significativo y consciencia sobre la construcción del tejido social.

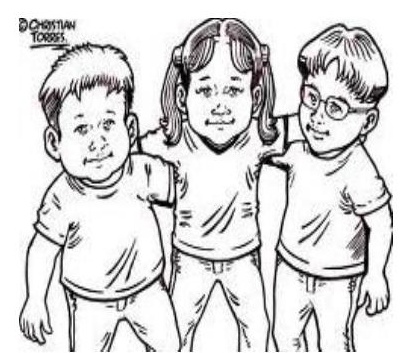

ACTIVIDADES INDIVIDUALES Y GRUPALES 


\section{Primera sesión: Mi amigo el sol, fuente de energía}

Docente: Explicación a los niños sobre el sol, sus características, así como los beneficios que representa para el ser humano, breve contextualización sobre el calentamiento global y sus consecuencias para el planeta a mediano y corto plazo.

Luego de la contextualización sobre el calentamiento global, enseñar a los niños el concepto de:

1. Energía solar

2. Fuentes de energía

3. Uso cotidiano de la energía solar en casa

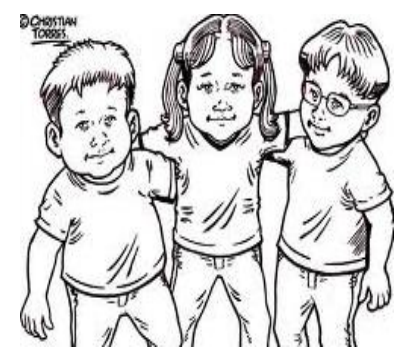

\section{Segunda sesión: Construyendo planetas de papel} Materiales

un globo de goma; papel de periódico usado; un balde; agua; linterna; palillos de madera; plastilina o arcilla esta actividad se realiza de manera individual

\section{Construyendo planetas de papel}

\section{Desmenuzar el periódico en tiras}

2.Prepare un balde lleno con una mezcla de aguay harina. Esta debería tener la consistencia de pasta líquida. La cantidad de harina varia con el tamaño del balde y el agua.

3. Remoje las tiras de papel en la pasta durante la noche.

4. Cubra el globo, parcialmente inflado, con las tiras de papel remojado colocándolas en forma de cruces para hacer un globo de papel mache. Recuerde no inflar el globo al máximo

5. Cuando el globo se haya desinflado (o reventado) queda un globo de papel. Este puede ser instalado sobre un escenario usando plastilina y un soporte de madera. El soporte es, simplemente, enterrado en la plastilina y el globo se baja sobre él. 
6. Los continentes se pueden dibujar sobre el globo; también se pueden construir "planetas" de diferentes tamaños. Utilice globos de distintos tamaños y observe el efecto de formas diferentes.

7. Coloque el globo en el centro de una sala oscura y encienda una linterna sobre él. Observe el área del globo que le llega la luz (para generar un haz definido de luz cubra la linterna con papel de diferentes colores que reflejen la luz.

8.Puede sujetar la linterna con una prensa de turnillo para experimentar diferentes ángulos o rotar el globo alrededor y preguntar a los chicos.

¿Existe un área en el globo que siempre recibe luz?,

¿Qué partes del globo reciben menos energía luminosa?, ¿por qué?

¿Qué ocurre cuando el ángulo de inclinación se incrementa?

Dejar las ideas consignadas en hojas.

\subsubsection{Temática 4: Mi tierra, mi identidad.}

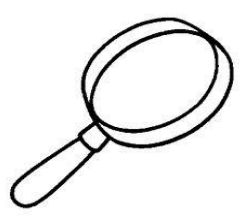

Queridos amiguitos: Es importante saber la importancia de los recursos naturales para los seres humanos y todo su entorno. Estos recursos son los materiales y espacios que el hombre aprovecha de la naturaleza para sobrevivir, sin embargo, estos recursos no son infinitos. Por eso necesitamos saber cuáles son, aprovecharlos al máximo y aprender a conservarlos. Si no conservamos estos recursos se acabaran, y la humanidad también lo hará. Si tu quieres ser el que salve a toda la humanidad de su autodestrucción, ayuda a la madre naturaleza conservándola de la mejor manera.

\section{Justificación:}

Los niños y las niñas necesitan entender que son los recursos naturales en pro de la construcción de una mentalidad ecológica, que

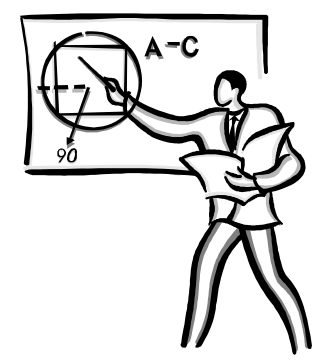


colabore con las políticas ambientalistas, y lo más importante, que genere consciencia sobre el estado actual del medio ambiente.

Las siguientes actividades tienen el fin de facilitarle al infante esta posibilidad en cuatro etapas: Las dos primeras permiten que los niños y las niñas realicen una introspección, ejercitando su zona de desarrollo efectivo. Las dos siguientes buscan que los niños y las niñas exterioricen lo aprendido, ejercitando su zona de desarrollo potencial, generando interacción, aprendizaje significativo y consciencia sobre la construcción del tejido social.

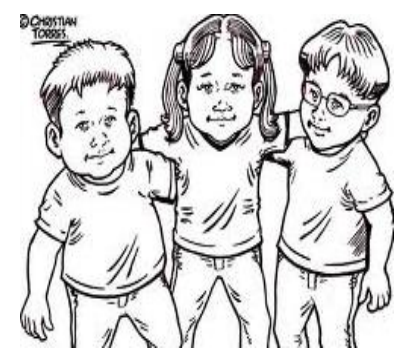

\section{ACTIVIDADES INDIVIDUALES Y GRUPALES}

\section{Primera sesión: gusanos embotellados}

Docente: Debe explicar a los niños y niñas las funciones de los cultivos hechos en invernadero y su utilidad para la agricultura, así mismo debe

resaltar la función de los campesinos dentro de nuestro sistema social ya que de ellos depende, en buena parte, la producción de alimentos que consumimos; de igual manera se debe hacer énfasis en la conservación de los suelos y la explotación de los mismos así como en la producción en masa desde la tecnificación de la agricultura.

Actividad: Gusanos embotellados

Materiales: Botella de plástico, cartulina o periódicos, hojas de plantas, arena, arcilla, muestra de tierra, lombrices, elásticos de goma.

Procedimiento: 1. Corte el extremo superior, con forma de embudo de una botella de plástico.

2. Llene la botella con capas de diferentes tipos de suelos(evite las piedras y los suelos duros y aterronados), 3. Humedezca los suelos en la botella, pero no los moje en exceso. Luego, coloque ó 4 hojas (preferiblemente algunas que hayan comenzado a descomponerse) sobre la superficie e Introduzca unas pocas lombrices.4. Cubra la botella con una cubierta hecha de una bolsa de

Plástico y perfórela con una serie de orificios para permitir que la mezcla de suelo "respire".

5. Mantenga su gusanera en un lugar frio y oscuro; un tubo o manga hecho con papel de 
Periódico colocada alrededor dela botella o gusanera estimulará a las lombrices a hacer cuevas cerca del borde de la botella.

Después de una semana revise la superficie del suelo levantando hacia arriba el tubo hecho con papel periódico y respondan ¿qué le han sucedido a las hojas?, ¿los estratos del suelo son aun Visibles?, ¿hay algún deposito de lombrices? ¿De ser así, de qué están hechos?

El aire se introduce en el suelo mediante esta mezcla y la formación de laberintos hechos por las lombrices, lo cual es muy parecido a excavar. Trate de cavar un orificio en el suelo, colocando todo el suelo extraído sobre un pedazo de plástico. Luego reponga cuidadosamente el suelo. ¿Cabe todo el suelo cuando se vuelve al orificio?, ¿Qué cosa ocupa el espacio extra?, ¿por qué ello es importante?

Dejar las ideas centrales consignadas en hojas.

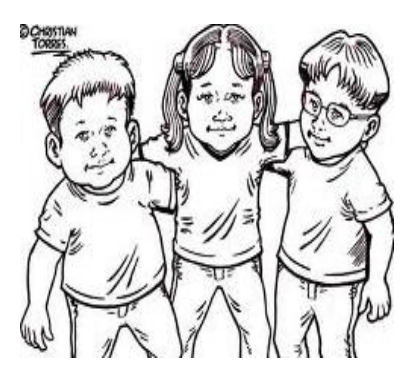

\section{Segunda sesión: el juego de la fotosíntesis}

Materiales: Cartulina, cordeles lápices linternas o candela

Docente: Explicar a los niños y las niñas el proceso de fotosíntesis de las plantas, así como las diferentes partes que la componen, luego de esto procederemos a realizar la siguiente actividad

1. Necesitará confeccionar algunos carteles, pedazos de cartulina que puedan colgarse al cuello mediante un pedazo de cordel. Se fabrican fácilmente, antes de colocar el cordel es necesario reforzar el orificio del cartel con cinta pegante, amarrando el cordel como se indica permite que los carteles duren más tiempo. Cada

2. Sobre la mitad de los carteles escriba: "dióxido de carbono" o invente un símbolo para representarlo, en la otra mitad escriba "agua" o invente un símbolo para representarlo.

3. Ahora prepare un numero de carteles pintados de color verde para representar la clorofila en la hoja (cada cartel necesita ser lo suficientemente grande para que dos personas se paren sobre él) los carteles pueden ser luego distribuidos por el suelo.

4. Oscurezca la sala y coloque en una esquina la fuente luminosa, la cual representará al sol.

5. Cuando los estudiantes entren en la sala entregue a cada uno de ellos un cartel, el cual deberán colocárselo en el cuello con las palabras o símbolos hacia su pecho 
6. Explíqueles a ellos que la pieza que tienen en su pecho representa una fábrica de alimento, cuando el sol aparece, la fábrica es capaz de combinar agua, dióxido de carbono, para formar azúcar (un alimento) siendo el oxigeno producido como un subproducto.

7. Los niños y niñas dan vuelta a los carteles que tienen en su poder para ver si son dióxido de carbono o agua, luego deben encontrar un socio y pararse sobre un cartel de color verde que captura la luz solar y potencia la reacción. Solo una pareja puede pararse sobre una clorofila verde por vez, y todo se detiene cuando el sol se pone.

8. Cuando el sol aparece de nuevo las moléculas que se combinan puede reportarse a una salida (una esquina de la sala que ha sido designada antes de que se inicie el juego)

\subsubsection{Modulo : Eje de Autoconstrucción: YO, SOCIEDAD, MEDIO AMBIENTE}

\subsubsection{Temática 1: Pintando y moldeando el mundo}

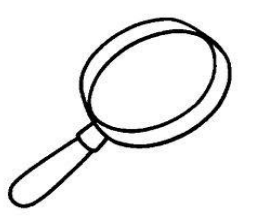

Queridos amiguitos: Es importante saber la importancia de las artes plásticas para el desarrollo de la humanidad. Estas decoran gran parte de nuestro mundo, pero lo mejor es darse cuenta que estas no solo sirven para embellecer, sino que también se encargan de servir como medio de expresión del artista.

\section{Justificación:}

Los niños y las niñas necesitan entender como las artes sirven para expresar toda la significación de la cultura de un pueblo, como también, para permitir que el artista deje una evidencia material de su pensamiento y forma de ver el mundo.

Las siguientes actividades tienen el fin de facilitarle al infante esta posibilidad en cuatro etapas: Las dos primeras permiten que los niños y

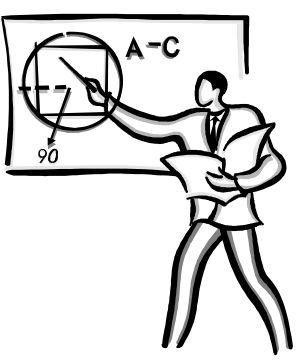
las niñas realicen una introspección, ejercitando su zona de desarrollo efectivo. Las dos siguientes buscan que los niños y las niñas exterioricen lo aprendido, ejercitando su zona de desarrollo potencial, generando interacción, aprendizaje significativo y consciencia sobre la construcción del tejido social. 


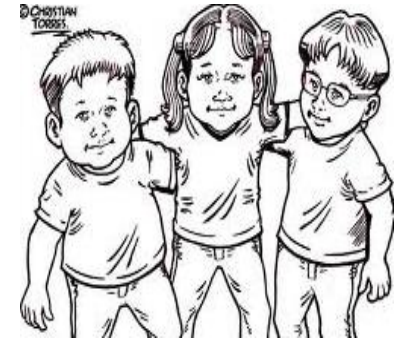

\section{ACTIVIDADES INDIVIDUALES Y GRUPALES}

\section{Primera sesión: Pinto todo lo que tenga color}

Materiales: Pintura, pinceles, papel y/o cartulina.

Docente: Explicar el tema sobre el cual se va a pintar como: la familia, el medio ambiente, el animal favorito, la naturaleza, etc. Luego guiar la pintura aseadamente para que no sucedan accidentes que dañen el trabajo de los niños y niñas.

1. Escucha con atención cual es el tema que rodeará nuestra obra de arte.

2. Escoge un color de pintura, un pincel, y comienza a hacer el modelo de lo que vas a pintar.

3. De manera muy aseada debes pintar los objetos que comprenden la temática que el profesor nos explicó.

4. Construye un gran mural con los trabajos pictóricos de todos tus compañeros.

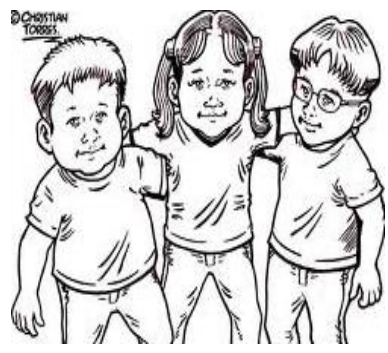

Segunda sesión: Hacen falta más flores en el mundo. Materiales: 1 lata de gaseosa o cerveza vacía. Tijeras.

Docente: Explicar a los niños y las niñas el papel de las flores en el mundo. Dividir el salón en dos grupos. Seguir paso a paso cada una de las instrucciones propuestas para poder hacer una flor de papel. Crear un jardín con las flores de los niños.

1. Escucha atentamente la explicación sobre el papel de las flores en nuestro planeta.

2. Toma tus tijeras corta la lata por la mitad, quedando así un cilindro partido en dos recipientes iguales.

3. Tomo una tira de aluminio que recortaste de una de las partes de la lata, y enróllalo para hacer el tallo.

4. A la otra mitad córtale flecos y dóblalos de forma que parezcan pétalos.

5. Cuando ya esté todo, une las tres partes: Las dos mitades de la lata y el tallo.

6. Construye un jardín de latas con tus compañeros. 


\subsubsection{Temática 2: Construyo herramientas para romper el silencio}

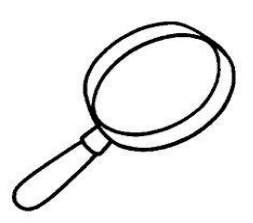

Queridos amiguitos: Es importante saber la importancia de las artes musicales para el desarrollo de la humanidad. Estas expresan al artista desde sus cualidades auditivas, creativas, formas matemáticas y memorísticas.

\section{Justificación:}

Los niños y las niñas necesitan entender como las artes sirven para expresar toda la significación de la cultura de un pueblo, como también, para permitir que el artista deje una evidencia material de su pensamiento y forma de ver el mundo.

Las siguientes actividades tienen el fin de facilitarle al infante esta posibilidad en cuatro etapas: Las dos primeras permiten que los niños y las

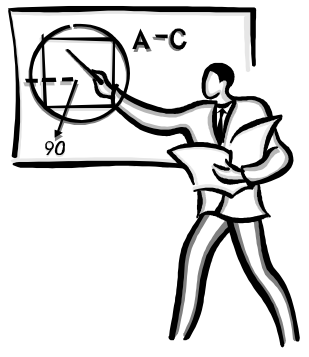
niñas realicen una introspección, ejercitando su zona de desarrollo efectivo. Las dos siguientes buscan que los niños y las niñas exterioricen lo aprendido, ejercitando su zona de desarrollo potencial, generando interacción, aprendizaje significativo y consciencia sobre la construcción del tejido social.

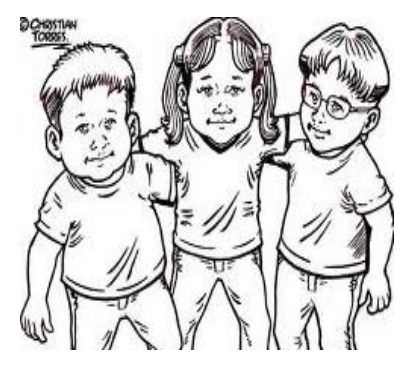

\section{ACTIVIDADES INDIVIDUALES Y GRUPALES}

\section{Primera sesión: Construyendo las máquinas del sonido}

Materiales: Tubos PVC, Herramienta para abrir huecos, cortar y martillar, canecas, alambre y tapas de gaseosa, puntillas, palos.

Docente: Hablar sobre la importancia de la música y manipular todas las herramientas con las que se puedan lastimar los niños.

1- Escucha con atención cual es el tema que rodeará nuestra obra de arte.

2- Cortar los tubos a $30 \mathrm{~cm}$. Y tapar con cinta o con un tapón uno de los extremos.

3- Hacer un hueco a $5 \mathrm{~cm}$ del tapón. A $15 \mathrm{~cm}$ del hueco comenzar a hacer huecos separados por $1.5 \mathrm{~cm}$ hasta terminar con el espacio del tubo.

4- Aplasta las latas de gaseosa y hazles un hueco en la mitad con una puntilla. Insértalas en el alambre y ciérralo en un círculo. 
5- Ya tenemos la flauta, el pandero, y el tambor que se hace con la caneca y los palos.

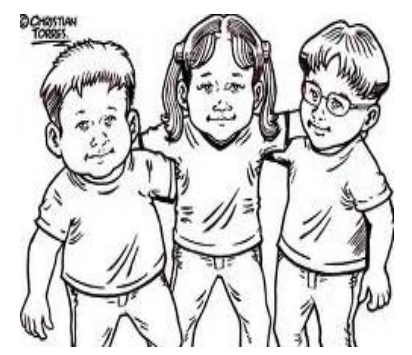

\section{Segunda sesión: aprendamos música y hagamos una canción.} Materiales: instrumentos de material reciclado.

Docente: Explicar a los niños y las niñas la mecánica de los tiempos musicales, y aprovechando que sólo hay un instrumento melódico (la flauta) acompañar usando el pandero y el tambor.

1- $\quad$ Aprende de música con tu profesor pues te hablará de los tiempos musicales

2- Escucha como suena el tambor de tu compañero.

3- Acompaña con el pandero.

4- Construye una armonía con la flauta.

5- Todos los que no tengan instrumento a componer una letra y cantar la canción.

\subsubsection{Temática 3: Mi mundo es del tamaño de mis palabras}

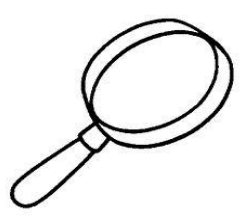

Queridos amiguitos: Es importante saber la importancia de las artes literarias para el desarrollo de la humanidad. Estas han expresado a las culturas mediante ralatos y ensueños que una vez un hombre uso para divertir, y termino configurando uno de los caminos para entender a la humanidad.

\section{Justificación:}

Los niños y las niñas necesitan entender como las artes sirven para expresar toda la significación de la cultura de un pueblo, como también, para permitir que el artista deje una evidencia material de su pensamiento y forma de ver el mundo.

Las siguientes actividades tienen el fin de facilitarle al infante esta posibilidad en cuatro etapas: Las dos primeras permiten que los niños y

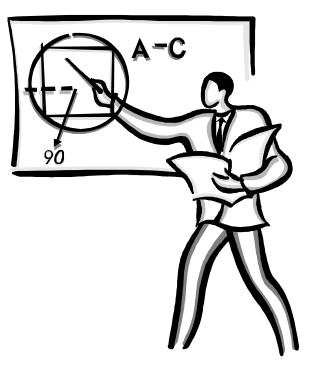
las niñas realicen una introspección, ejercitando su zona de desarrollo efectivo. Las dos siguientes buscan que los niños y las niñas exterioricen lo aprendido, ejercitando su zona de desarrollo potencial, generando interacción, aprendizaje significativo y consciencia sobre la construcción del tejido social. 


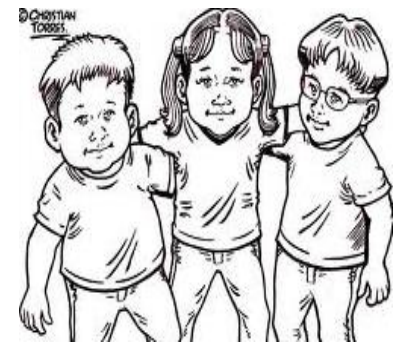

\section{ACTIVIDADES INDIVIDUALES Y GRUPALES}

\section{Primera sesión: Concurso de ortografía}

Materiales: Diccionarios, hojas de papel y Lápiz

Docente: La manera de cómo se usa el diccionario y proponer la cantidad de palabras suficientes para la actividad.

1- Escucha con atención el cómo se usa el diccionario.

2- Espera a que el profesor diga una palabra para comenzar a buscarla con tu compañero en su diccionario.

3- La primera etapa del juego la ganará la persona o equipo que encuentre la mayor cantidad de palabras en el menor tiempo posible.

4- Construye un cuento usando cada una de las palabras que buscaste en el diccionario.

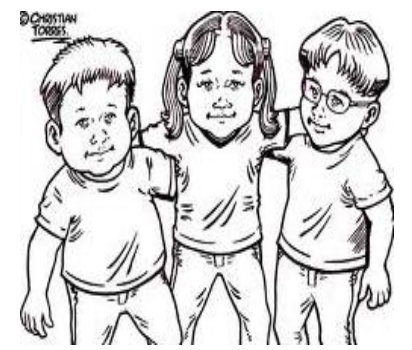

Segunda sesión: A llenar todo de expresión. Materiales: Colores, marcadores, papel, cinta

Docente: Explicar a los niños y las niñas que es un grafiti, que elementos contiene, donde se encuentra y cómo podemos hacer uno en clase.

1- Escucha atentamente la explicación sobre los grafitis.

2- Escribe un mensaje que quieras darle a todos las personas y plásmalo en una hoja de papel.

3- Decóralo con todo lo que tengas y dibújale cosas alusivas a tu mensaje.

4- Toma todos los grafitis de tus compañeros y haz un mural que exprese que quieren los niños y las niñas del centro de proyección.

\subsubsection{Temática 4: Actúo, represento y soy}

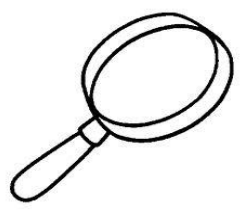

Queridos amiguitos: Es importante saber la importancia de las artes escénicas para el desarrollo de la humanidad. Estas le permiten al ser humano representar todos los roles de los que depende la sociedad. El teatro es la versión en vivo de la literatura, estructurando dos artes en una sola. 


\section{Justificación:}

Los niños y las niñas necesitan entender como las artes sirven para expresar toda la significación de la cultura de un pueblo, como también, para permitir que el artista deje una evidencia material de su pensamiento y forma de ver el mundo.

Las siguientes actividades tienen el fin de facilitarle al infante esta posibilidad en cuatro etapas: Las dos primeras permiten que los niños y las niñas realicen una introspección, ejercitando su zona de desarrollo

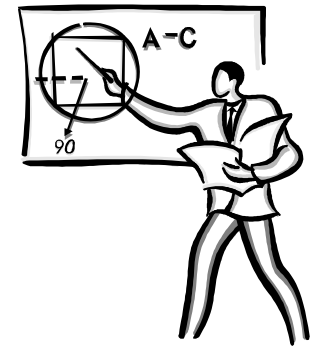
efectivo. Las dos siguientes buscan que los niños y las niñas exterioricen lo aprendido, ejercitando su zona de desarrollo potencial, generando interacción, aprendizaje significativo y consciencia sobre la construcción del tejido social.

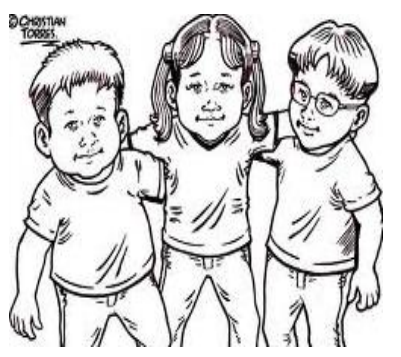

\section{ACTIVIDADES INDIVIDUALES Y GRUPALES}

\section{Primera sesión: Mi mano es una actriz}

Materiales: Pintura, pinceles, medias, botones, conos de cartón, telas, papel, marcadores, pegante, y todo el material reciclable que se pueda usar para construir un títere.

Docente: Explicar la importancia del teatro y motivar a los niños y las niñas para idear la manera de crear nuestro títere.

1- Escucha con atención cual es la importancia del teatro.

2- Escoge material para crear tu títere.

3- Decóralo y ponle nombre a tu títere para crear tu personaje.

4- Comienza a idear un cuento de hadas en el que tu títere sea el personaje principal.

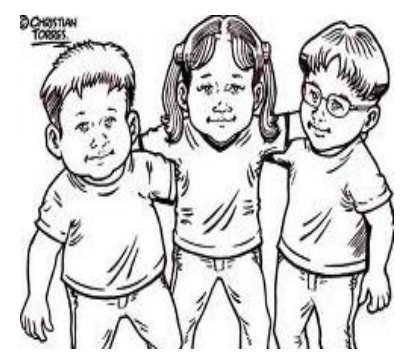

Segunda sesión: Manos a las tablas.

Materiales: 1 caja de cartón, pinturas, telas, marcadores, papel

Docente: Ayudar a los niños y niñas a decorar el escenario para los títeres que estará hecho de una caja de cartón grande. También dejar listo el guion para la obra de teatro con los títeres.

1- $\quad$ Ayuda a decorar la caja que servirá como escenario para las obras de teatro. 
2- $\quad$ Construye el guion de la obra de teatro en la cual está actuando tu títere.

3- Reúnete en grupos y planea como van a actuar.

4- $\quad$ Ahora viene una obra de teatro que tiene cuentos de hadas e improvisa todo cuanto quieras.

\subsubsection{Modulo 5: Eje de Autoconstrucción: REFUERZO ACADÉMICO TEÓRICO}

\subsubsection{Temática 1: Matemáticas}

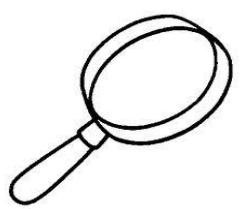

Queridos amiguitos: Si quieren dedicarse a la mayor aventura de su vida, recorriendo el mundo y sus historias, primero tenemos que conocer la maravilla de nuestra mente, sus alcances, cualidades, sus cuidados, y todo lo que podríamos hacer con ella. Hoy, aprenderás mucho sobre el uso de nuestra mente a través de diferentes campos de conocimiento.

\section{Justificación:}

Los niños y las niñas necesitan reconocerse como seres humanos para que puedan admitir los principios sociales que les esperan en años venideros.

Las siguientes actividades tienen el fin de facilitarle al infante esta posibilidad en cuatro etapas: Las dos primeras permiten que los niños y

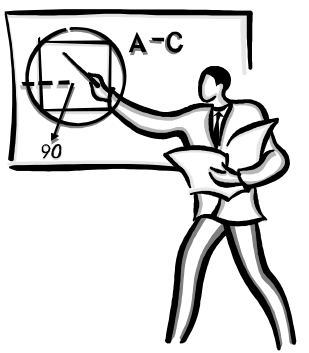
las niñas realicen una introspección, ejercitando su zona de desarrollo efectivo. Las dos siguientes buscan que los niños y las niñas exterioricen lo aprendido, ejercitando su zona de desarrollo potencial, generando interacción, aprendizaje significativo y consciencia sobre la construcción del tejido social.

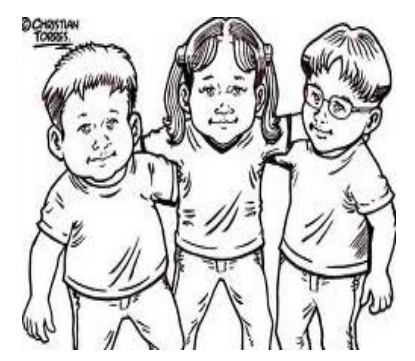

ACTIVIDADES INDIVIDUALES Y GRUPALES

\section{Primera sesión: Añadiendo y prestando}

Materiales: hojas, lápices, borrador, tijeras, pegante, revistas.

Docente: Explicar a los estudiantes el proceso de suma y resta simple, llevando y con decimales.

1. Escucha con atención en qué consiste el procedimiento para llevar a 
cabo correctamente sumas y restas y de que manera éstos procesos resultan útiles dentro de la vida diaria.

2. Tu docente deberá ejemplificar con problemas de la vida diaria (10 de suma y 10 de resta) como se llevan a cabo dichos procesos.

3. Una vez resueltos los problemas, debes crear cinco problemas de suma y cinco de resta utilizando ti propia imaginación y realizando el respectivo dibujo de cada uno.

4. Para finalizar, recorta elementos y arma sumas y restas con ellos, por ejemplo, recorta manzanas, peras, rostros, súmalos y réstalos a tu antojo, pero demostrando siempre que haz comprendido los procesos.

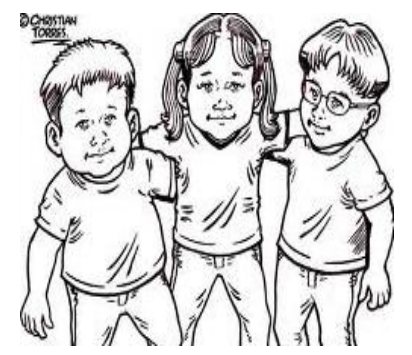

\section{Segunda sesión: El mini mercado}

Materiales: dinero didáctico, frijoles, tapas de gaseosa, lentejas, peluches, juguetes.

Docente: debe dividir el grupo en dos partes, una más grande que la otra y la idea es que el grupo pequeño cumpla con el rol de vendedores y el grupo grande con el de compradores.

1. Si tienes el papel de vendedor, debes tomar un grupo de elementos para vender y asignarles un precio, por supuesto una buena publicidad para promocionar tus

2. Si tienes el papel de comprador, debes tener muy en cuenta que tu guía te de igual cantidad de dinero que a tus compañeros.

3. Ahora organicen tanto a los vendedores como a los compradores, para que adquieran productos aq buenos previos, al final, deben explicar a sus compañeros como hicieron para adquirir los productos más baratos utilizando la suma y la resta.

\subsubsection{Temática 2:Lenguaje}

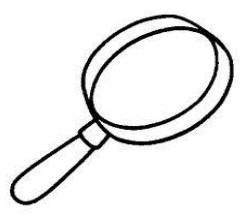

Queridos amiguitos: Si quieren dedicarse a la mayor aventura de su vida, recorriendo el mundo y sus historias, primero tenemos que conocer la maravilla de nuestra mente, sus alcances, cualidades, sus cuidados, y todo lo que 
podríamos hacer con ella. Hoy, aprenderás mucho sobre el uso de nuestra mente a través de diferentes campos de conocimiento.

\section{Justificación:}

Los niños y las niñas necesitan reconocerse como seres humanos para que puedan admitir los principios sociales que les esperan en años venideros.

Las siguientes actividades tienen el fin de facilitarle al infante esta posibilidad en cuatro etapas: Las dos primeras permiten que los niños y

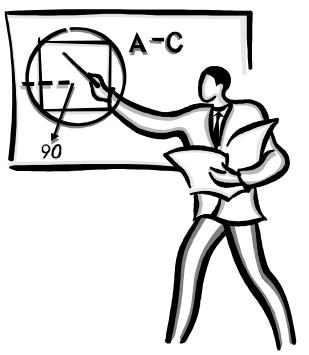
las niñas realicen una introspección, ejercitando su zona de desarrollo efectivo. Las dos siguientes buscan que los niños y las niñas exterioricen lo aprendido, ejercitando su zona de desarrollo potencial, generando interacción, aprendizaje significativo y consciencia sobre la construcción del tejido social.

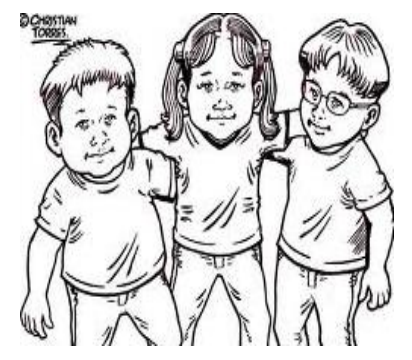

\section{ACTIVIDADES INDIVIDUALES Y GRUPALES}

\section{Primera sesión: Lecto-escritura}

Materiales: hojas, lápices

Docente:Debe realizar una pequeña charla sobre que es el lenguaje la importancia de la lectura y de un buen escribir para el desarrollo de nuestras habilidades, también se hace pertinente que haga la lectura de un cuento corto, y hacerle ver al estudiante que la literatura le permite a la imaginación la creación de personajes, mundos y situaciones maravillosas.

1. Escucha con atención la explicación que da tu guía sobre los procesos de lectura y escritura.

2. En las hojas proporcionadas por tu guía, dibuja en cada cara de la hoja 4 letras del abecedario y un dibujo que las represente, por ejemplo si tienes la letra E puedes dibujar un elefante, luego de que termines de dibujar todo el abecedario, tu dibujo hará parte de una exposición que se colgará en las paredes.

3. Luego de haber escuchado que los cuentos son una de las formas más hermosas para usar nuestro lenguaje, debemos crear un cuento con elementos fantásticos mezclados de las

4. narraciones originales de: blanca nieves y los siete enanitos, la bella durmiente y los tres cerditos y el lobo.

5. Lee de manera graciosa y entusiasta tu creación a tus compañeros. 


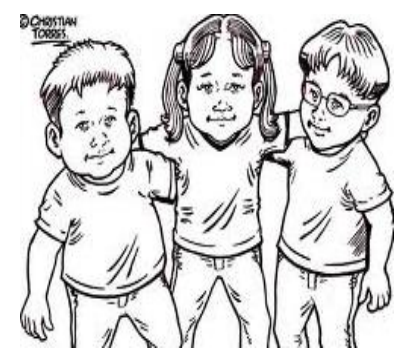

\section{Segunda sesión: Creando ando}

Materiales: Un cuento, cartulinas hojas y colores

Docente: debe leer atentamente a los niños el cuento que eligió para ellos.

1. Con ayuda de tu docente dibuja a los personajes principales del cuento y describe sus características emocionales (bueno, malo, compasivo etc).

2. En una de las hojas que te dio tu guía debes re escribir un final diferente para el cuento y debes leerlo a tus compañeros

3. Para finalizar, deben reunirse en grupos de 4 personas y representar el final del cuento que más les agradó

\subsubsection{Temática 3: Ciencias Naturales}

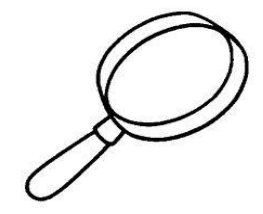

Queridos amiguitos: Si quieren dedicarse a la mayor aventura de su vida, recorriendo el mundo y sus historias, primero tenemos que conocer la maravilla de nuestra mente, sus alcances, cualidades, sus cuidados, y todo lo que podríamos hacer con ella. Hoy, aprenderás mucho sobre el uso de nuestra mente a través de diferentes campos de conocimiento.

\section{Justificación:}

Los niños y las niñas necesitan crear su propio retrato ético y compararlo con el de los demás para hacerse conscientes de lo que son. Este diagnostico también es importante para corregir algunos hábitos perjudiciales para el desarrollo social del infante, mediante una herramienta que fomenta la autonomía.

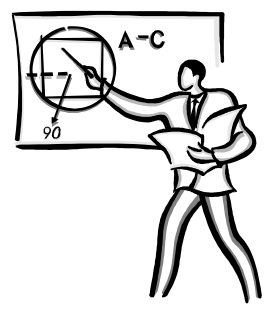

Las siguientes actividades tienen el fin de facilitarle al infante esta posibilidad en cuatro etapas: Las dos primeras permiten que los niños y las niñas realicen una introspección, 
ejercitando su zona de desarrollo efectivo. Las dos siguientes buscan que los niños y las niñas exterioricen lo aprendido, ejercitando su zona de desarrollo potencial, generando interacción, aprendizaje significativo y consciencia sobre la construcción del tejido social.

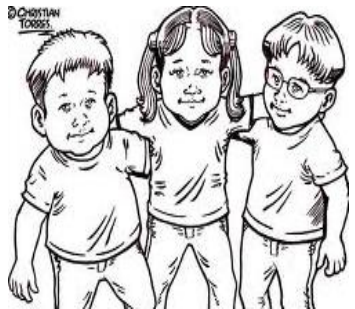

Imagina un lugar:

Imagina un lugar que te guste, donde tú pasas tus vacaciones o tus fines de semana, o donde te gustaría pasarlos (tu pueblo, tu casa de campo, una casa en la playa, un lugar en la selva, un poblado en un desierto...). Rellena esta ficha con tu imaginación y lo que conoces de geografía: Lugar geográfico:

Paisaje dominante:

Temperaturas medias en verano:

Temperaturas medias en invierno:

Lluvias a lo largo del año:

Cursos o zonas de agua (lagos, ríos, playas, arroyos...):

Relieve (montañoso, llano, valle, acantilado, alta montaña):

Estado del agua en invierno:

Tipo de suelo (arcilloso, arenoso, arena suelta, rocas duras, abonado...):

Horas de luz al día (sombría, soleada, expuesta....):

Poblaciones cercanas, si o no:

Zonas industriales cercanas, si o no:

Agricultura y ganadería frecuentes en la zona, si o no:

Luego de completar la ficha debemos socializarla con nuestros compañeros 


\section{Segunda sesión: El amplio reino de la naturaleza Materiales sopa de letras, colores}

Docente: Hacer una breve explicación sobre los diferentes reinos de la naturaleza, en qué consiste cada uno y como todos forman parte de la inmensa mecánica natural, asi no los podamos ver a simple vista.

A continuación resuelve las siguientes actividades

Describe los siguientes organismos teniendo en cuenta las características anteriores y escribe al reino al que pertenecen.
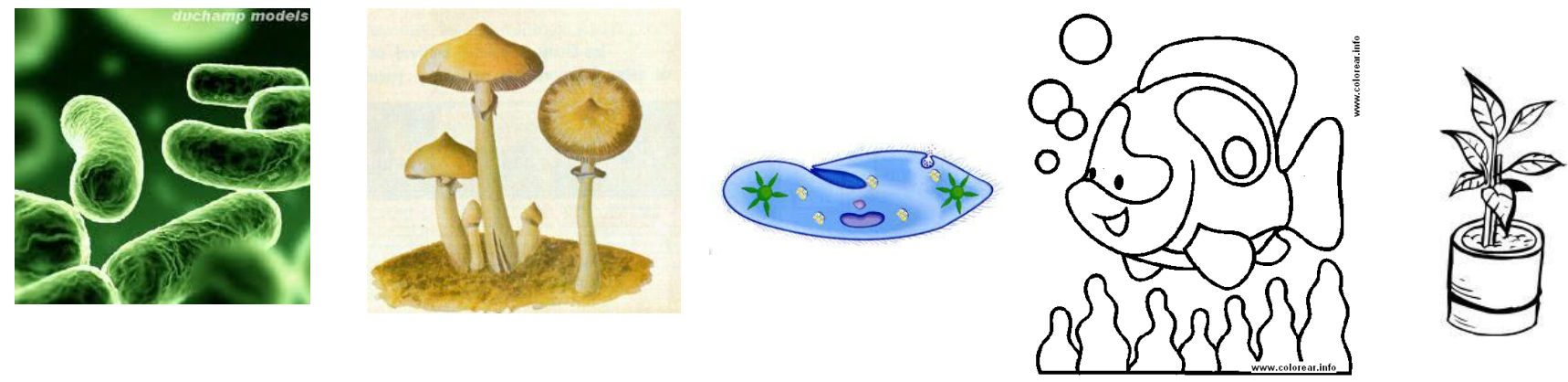

Completa correctamente el siguiente cuadro

\begin{tabular}{|l|l|l|l|l|l|l|l|}
\hline ORGANISMO & REINO & UNIC. & PLURI. & PROC. & EUCAR. & AUTOT. & HETER. \\
\hline LOMBRIZ & & & & & & & \\
\hline PASTO & & & & & & & \\
\hline AMEBA & & & & & & & \\
\hline CHAMPIÑON & & & & & & & \\
\hline BACTERIAS & & & & & & & \\
\hline
\end{tabular}




\subsubsection{Temática 4: Ciencias sociales}

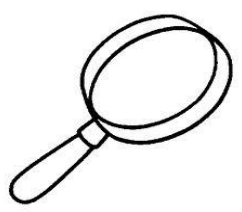

Queridos amiguitos: Si quieren dedicarse a la mayor aventura de su vida, recorriendo el mundo y sus historias, primero tenemos que conocer la maravilla de nuestra mente, sus alcances, cualidades, sus cuidados, y todo lo que podríamos hacer con ella. Hoy, aprenderás mucho sobre el uso de nuestra mente a través de diferentes campos de conocimiento.

\section{Justificación:}

Los niños y las niñas deducir los vínculos entre la higiene y la salud, partiendo de la definición y creando hábitos que deben trascender del aula a los hogares, pues es allí donde los niños deben reflejar su conocimiento descubierto, transmitiendo algo de este a sus compañeros de hogar.

Las siguientes actividades tienen el fin de facilitarle al infante esta

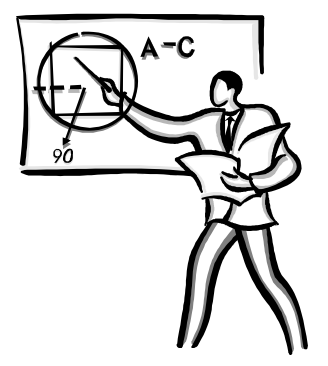
posibilidad en cuatro etapas: Las dos primeras permiten que los niños y las niñas realicen una introspección, ejercitando su zona de desarrollo efectivo. Las dos siguientes buscan que los niños y las niñas exterioricen lo aprendido, ejercitando su zona de desarrollo potencial, generando interacción, aprendizaje significativo y consciencia sobre la construcción del tejido social.

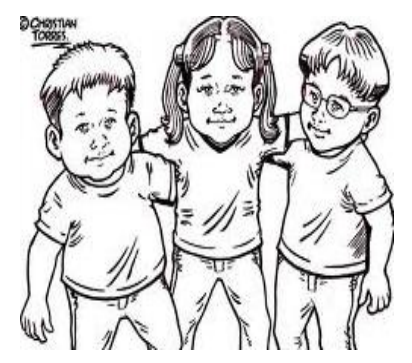

\section{ACTIVIDADES INDIVIDUALES Y GRUPALES}

\section{Primera sesión: La historia sin fin}

Materiales: Hojas, regla, lápices

Docente: Comunicar a los estudiantes quela historia comprende todo aquello que vivimos en el día a día y que se construye con el tiempo, y que a la vez que hablamos de las historias que nos suceden en el diario vivir, también hablamos de la historia de los grandes sucesos del mundo a lo largo del tiempo, por lo conocemos como, así como la geografía sirve para ubicar el lugar en donde nos encontramos y hacia donde nos podemos orientar, de igual manera nos es útil para conocer las características esenciales de nuestros paisajes. 
A continuación realiza las siguientes actividades

1. LAS EDADES DE LA HISTORIA

Señala cuáles de estos acontecimientos ocurren Antes de Cristo (VARIAS RESPUESTAS CORRECTAS)

[ ]Aparición del Hombre

[ ]Aparición de la escritura

[ ]Aparición de la Agricultura y la Ganadería

[ ]Caída del Imperio Romano

[ ]Conquista de Constantinopla por los turcos [ ]Revolución Francesa

[ ]Descubrimiento de América

2. Asocia cada Edad con sus acontecimientos

EDADRESPUESTAACONTECIMIENTOS

PREHISTORIA

EDAD ANTIGUA

EDAD MEDIA

EDAD MODERNA

EDAD CONTEMPORÁNEA

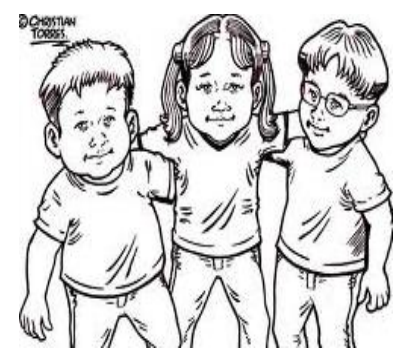

\section{Segunda sesión: En busca del tesoro perdido}

Materiales: un peluche o dulces que servirán de tesoro

Docente: debe formar grupos de cuatro personas, esconder el tesoro en algún lugar del recinto y diseñar previamente una serie de pistas relacionadas con ubicación geográfica (norte-sur-oriente-occidente) del tesoro.

1. Cada grupo de los grupos debe leer atentamente cada una de las pistas

2. Para encontrar el tesoro es esencial el trabajo en equipo y deben comenzar a resolver las pistas en orden estricto 
3. El grupo que primero encuentre el tesoro será el ganador y deberá socializar a sus demás compañeros que estrategia utilizó para poder encontrar de manera eficaz el tesoro.

\subsubsection{Modulo 6: Eje de Autoconstrucción: RESPONSABILIDAD SOCIAL}

\subsubsection{Temática 1: derechos de los niños y las niñas}

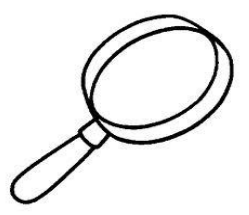

Queridos amiguitos: Si quieren dedicarse a la mayor aventura de su vida, recorriendo el mundo y sus historias, primero tenemos que conocer la maravilla de nuestro cuerpo, sus alcances, sus cualidades, sus cuidados, y todo lo que podríamos hacer con él. Hoy, aprenderás y transmitirás mucho sobre tus derechos y deberes como personita.

\section{Justificación:}

Los niños y las niñas necesitan reconocerse como seres humanos para que puedan admitir los principios sociales que les esperan en años venideros.

Las siguientes actividades tienen el fin de facilitarle al infante esta posibilidad en cuatro etapas: Las dos primeras permiten que los niños y

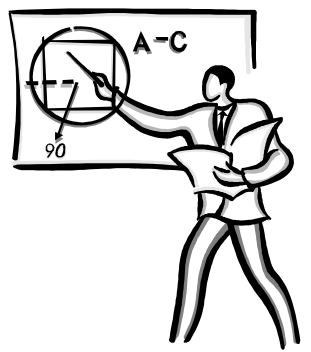
las niñas realicen una introspección, ejercitando su zona de desarrollo efectivo. Las dos siguientes buscan que los niños y las niñas exterioricen lo aprendido, ejercitando su zona de desarrollo potencial, generando interacción, aprendizaje significativo y consciencia sobre la construcción del tejido social.

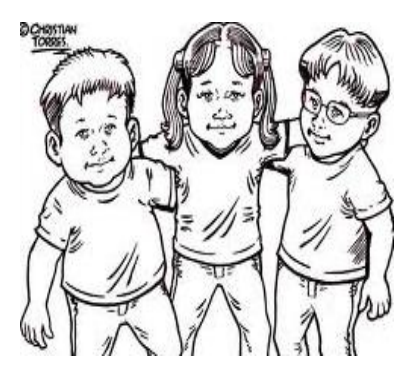

\section{ACTIVIDADES INDIVIDUALES Y GRUPALES} Primera sesión:"YO SOY YO, IGUAL Y DIFERENTE"

La identidad se construye dentro de una familia, una comunidad y una nación. Tiene aspectos singulares que nos permiten diferenciarnos de los otros y aspectos comunes que hacen posible nuestra identificación y nuestra comunicación con los demás. Además de estimular el conocimiento y la autoestima de los niños y las niñas mediante la identificación y el respeto por las diferencias entre las personas y los grupos, desarrollar sentimientos de solidaridad, valorar las 
diferencias como punto de partida para el desarrollo de las potencialidades individuales y de los vínculos sociales.

\section{Principio a trabajar: IDENTIDAD}

"El niño tiene derecho desde su nacimiento a un nombre y a una nacionalidad."

\section{ACTIVIDADES:}

1 Jugamos con nuestros nombres. Estarán escondidos en la sala y trataremos de encontrarlos e identificarlos.

2 Inventamos rimas con nuestro nombre.

3 Realizamos una poesía con nuestros nombre.

4 Averiguamos en casa porque tenemos el nombre que tenemos.

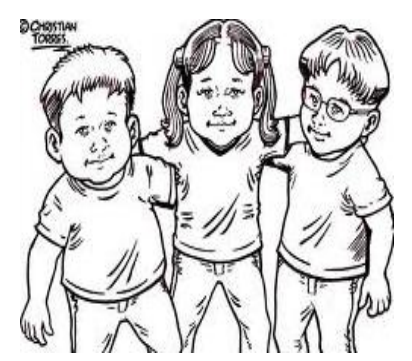

\section{Segunda sesión: "El niño debe ser protegido contra las prácticas} que puedan fomentar la discriminación racial, religiosa o de cualquier otra índole".

Materiales: Pañoleta para jugar al gallito ciego, objetos como lápices, borradores, muñecos, etc, sonaja, fotocopia de una foto de ellos, cartulinas, caja mediana.

\section{ACTIVIDADES}

1 Jugar con los sentidos. Conversar sobre como se sienten los que no lo poseen.

2. Jugar al Gallito Ciego.

3 Reconocer objetos sin mirar

4 Reconocer ¿quién tiene el sonido escondido? (una sonaja a alguien del lugarb que la haga sonar a escondidas)

5 Dibujar a un amigo (frente a frente) y buscar semejanzas y diferencias.

6 Pedirles una foto o fotocopia color de la cara de ellos, recortarla, mezclarlas en una caja y cada niño sacara una y tendrá que dibujar el cuerpo del amigo que le toque.

\subsubsection{Temática 2:Derechos e infancia}

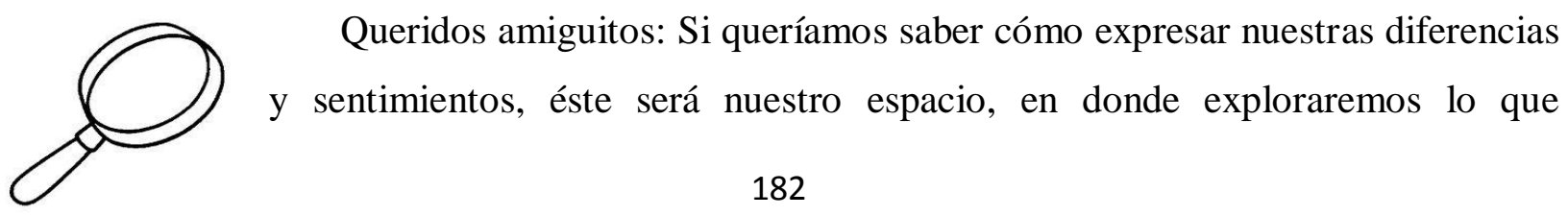


sentimos, en relación con lo que pensamos. Quédate con tu docente y disfruta de las maravillas de tener derechos.

\section{Justificación:}

Los niños y las niñas necesitan reconocerse como seres humanos para que puedan admitir los principios sociales que les esperan en años venideros.

Las siguientes actividades tienen el fin de facilitarle al infante esta

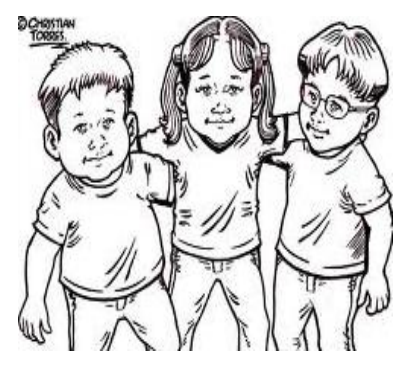
posibilidad en cuatro etapas: Las dos primeras permiten que los niños y las niñas realicen una

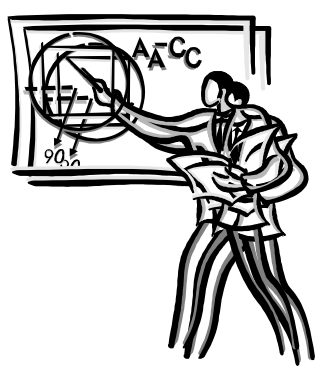
introspección, ejercitando su zona de desarrollo efectivo. Las dos siguientes buscan que los niños y las niñas exterioricen lo aprendido, ejercitando su zona de desarrollo potencial, generando interacción, aprendizaje significativo y consciencia sobre la construcción del tejido social.

Primera sesión: Mandaremos una nota informativa a las casas contando acerca del proyecto que estamos trabajando y pediremos la colaboración enviándonos recortes de diarios o revistas en alusión al tema.

Materiales: textos donde se encuentren los derechos del niño, cartulinas, tijeras, pegante, marcadores, hojas.

Enviaremos encuestas a las casas:

* ¿Qué son los derechos del niño?

* ¿Por qué creen ustedes que son importantes?

¿ ¿Uds. Creen que se respetan?

Realizaremos un afiche escribiendo los derechos y los dibujaremos para colocar en la galería para informar.

Promover la difusión de la actividad: preparación de afiches, creación de textos con los derechos del niño, registro de opiniones, intercambio de información con los chicos, nos leeremos mutuamente las normas del grupo y marcaremos las semejanzas y diferencias. 
Realizaremos BOLETINES INFORMATIVOS para colocar en todos los cuadernos para informar a la comunidad educativa.

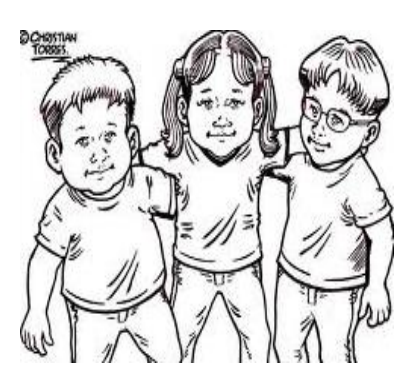

Segunda sesión: El respeto por la dignidad humana y las normas equitativas Valor moral: El respeto por la dignidad humana ¿qué es ser humano?

\section{Materiales:}

Una planta u otro ser vivo que todos puedan verel Preámbulo de la Declaración Universal de los Derechos humanos.

Paso 1. Utiliza el juego tingo tingo, tango con la que se logra que cada participante se presente a los otros de manera individual.

Paso 2. Forma una rueda de charla, al mismo tiempo explique que esta es una forma de debatir asuntos importantes. Aunque ya todos se habían presentado en el Paso 1, recorre el círculo y haz que todos digan el nombre en voz alta y con firmeza para que cada persona vuelva a presentarse ante el grupo completo. Hablar de modo fuerte y positivo se conoce como “afirmación”. Por regla general, un sentimiento de timidez se apodera del grupo, por lo que debe dejar claro que todos en el círculo dirán sus nombres en voz alta y esta vez lo acompañarán con un gesto significativo, tal como un brazo en alto o un golpe con el puño. El grupo aplaude cada vez que alguien lo haga.

Paso 3. Invita a cada participante a que piense en silencio durante un minuto y escoja una cualidad de sí mismo que le parezca su mejor cualidad y la diga en pocas palabras:

soy generoso, un padre amoroso, trabajo duro, comparto con los que tienen menos, etc.

Se trata de que se den cuenta que todos tenemos buenas cualidades. Invita a los participantes que manifiesten si la cualidad propia que han identificado es una cualidad que respetan en otros. ¿Qué significa la expresión "para poder respetar a los otros hay que respetarse a sí mismo”? ¿Si las buenas cualidades de los otros son diferentes a las tuyas, debes respetarlas igualmente? ¿Es todo ser humano merecedor de respeto? ¿Por qué? 
Paso 4. (Es opcional y depende del tiempo disponible y de la receptividad de los participantes.) Pregunta si alguno de los participantes puede recordar alguna ocasión en que alguien lo haya hecho sentir mal porque parecía faltarle al respeto. En este tipo de situaciones se incluye lo que la gente nos dice para hacernos sentir estúpidos o tontos, como "no perdamos el tiempo hablándole porque no sabe ni donde está parado". Se trata de recordar una o dos frases ofensivas como ésta. ¿Por qué las personas se ofenden mutuamente? ¿Lo hacen porque lo que dicen es cierto, o será que no se respetan mutuamente? ¿Serán ambas cosas o ninguna? ¿Hieren tu amor propio cuando no te respetan? ¿Cómo te hace sentir ese hecho? ¿Qué entiendes por dignidad?

Paso 5. Destaca a los participantes que todos los presentes son seres humanos y pregunta si pueden nombrar otros seres vivos. Pregunta por la forma en que los seres humanos se diferencian de dichos seres vivos. En los grupos en los que haya practicantes de alguna religión o creencia, se pueden incluir en la discusión las consideraciones éticas y espirituales que sobre los seres humanos tienen sus respectivas creencias. El facilitador debe realizar un resumen con las diferencias encontradas y hacer énfasis en que los seres humanos se comunican entre sí con palabras, no con sonidos restringidos, como ocurre con muchos animales. En segundo término, los humanos tienen la facultad de elegir, ya que pueden decidir sobre gran cantidad de situaciones en la vida, a diferencia de muchos animales. ¿Cuál es el significado de esto para nuestra vida diaria? Pregunte a los participantes si están de acuerdo en que esta forma de ver al ser humano significa que tenemos que aprender el modo de manejar bien las palabras y la forma de realizar elecciones óptimas.

Paso 6. Si utilizamos las palabras con cuidado y si decimos que todos los seres humanos merecen respeto debido a que compartimos la dignidad humana, ¿qué significa esto? Explica que en 1948, después de una guerra terrible (la atroz Segunda Guerra Mundial) todos los países del mundo se pusieron de acuerdo en unas palabras que dicen que éste sería un mundo más pacífico si todos los seres humanos respetaran la dignidad de los otros. Explica que hoy, su país, como otros países, está de acuerdo con dichas palabras. ¿Qué es lo que dichas palabras (de la Declaración Universal de los Derechos humanos) quieren decir cuando expresan: “... la libertad, la justicia y la paz en el mundo tienen por base el reconocimiento de la dignidad inherente a 
todos los miembros de la familia humana...". Dales a conocer el texto del Preámbulo de la Declaración Universal.

Por medio del método de la vuelta completa invite a los participantes a encontrar un ejemplo de la vida cotidiana en su comunidad en el que se muestre que la vida puede ser más llevadera si las personas muestran mayor respeto mutuo.

\subsubsection{Temática 3: Dignidad humana}

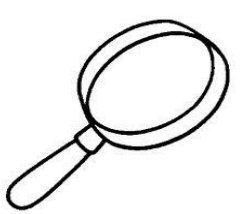

Queridos amiguitos: Si queríamos saber cómo expresar nuestras diferencias y sentimientos, éste será nuestro espacio, en donde exploraremos lo que sentimos, en relación con lo que pensamos. Quédate con tu docente y disfruta de las maravillas de tener derechos.

\section{Justificación:}

Los niños y las niñas necesitan crear su propio retrato ético y compararlo con el de los demás para hacerse conscientes de lo que son. Este diagnostico también es importante para corregir algunos hábitos perjudiciales para el desarrollo social del infante, mediante una herramienta que fomenta la autonomía.

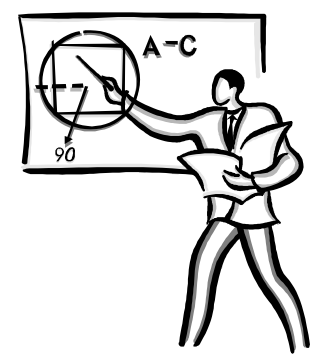

Las siguientes actividades tienen el fin de facilitarle al infante esta posibilidad en cuatro etapas: Las dos primeras permiten que los niños y las niñas realicen una introspección, ejercitando su zona de desarrollo efectivo. Las dos siguientes buscan que los niños y las niñas exterioricen lo aprendido, ejercitando su zona de desarrollo potencial, generando interacción, aprendizaje significativo y consciencia sobre la construcción del tejido social.

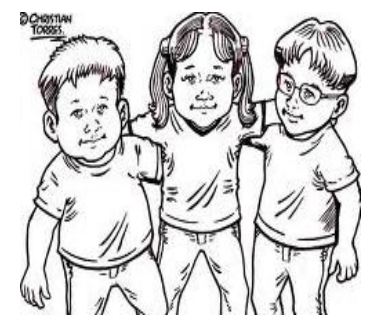

\section{ACTIVIDADES INDIVIDUALES Y GRUPALES}

\section{Primera sesión: Las necesidades, los derechos y la dignidad} humana

Docente: Para lograr que el concepto de derechos humanos se comprenda y acepte es muy importante establecer un vínculo entre las necesidades humanas básicas y los derechos humanos. La Declaración 
Universal de los Derechos humanos se debe presentar inicialmente en un lenguaje accesible. Para lograr una pronta aceptación de la noción de que los derechos humanos son importantes y pueden ser de utilidad, se deben plantear preguntas sencillas sobre la diversidad de las necesidades humanas y mostrar a los participantes que en general a cada derecho le corresponde una necesidad.

Materiales: La "Versión Simplificada de la Declaración Universal de los Derechos humanos". (anexo)

Paso 1. Invita a los participantes a que te ayuden a elaborar una lista de todas las necesidades básicas inherentes al ser humano. La discusión se puede hacer a partir de la actividad anterior, en la cual se estableció la diferencia entre los seres humanos y otros seres vivos con base en características propias.

Paso 2. Utiliza la técnica de los grupos de murmullos (ver las Definiciones) o divide a los participantes en equipos, uno para cada necesidad. Pídeles que elaboren un informen el que cuenten si consideran que la necesidad que les asignaron ha sido en realidad satisfecha por la sociedad. Invítalos a que respondan la siguiente pregunta: ¿permite nuestra sociedad que las personas satisfagan sus necesidades, utilicen sus posibilidades les ayuda a que desarrollen sus cualidades como seres humanos?

Paso 3. Invita a cada equipo a que visualice y describa las metas de una sociedad ideal que permita el disfrute, satisfaga las necesidades básicas y posibilite el desarrollo de las potencialidades del ser humano.

Paso 4. Invita a cada equipo a elaborar un breve informe de la discusión. Mientras escucha los informes, el facilitador debe elaborar una tabla de tres columnas: 1)necesidades básicas típicas de un ser humano; 2) características de la sociedad actual y si satisface a la mayoría de las personas las necesidades identificadas; y 3) características de las metas a las que aspira una sociedad.

\section{NECESIDADES 2. HECHOS 3. METAS 4. DERECHOS}

Paso 5. El facilitador elabora otra columna (4)para mostrar los distintos derechos humanos esenciales para disfrutar, proteger y enriquecer nuestra dignidad. Explique que cada necesidad 
básica trae aparejado un derecho humano, como se mostró en la actividad anterior. Los derechos humanos correspondientes pueden ser escogidos de

la versión simplificada de la Declaración Universal de los Derechos humanos que se presenta en el Anexo de esta actividad.

Paso 6. Inicia una discusión acerca del contenido de la columna 2, en la que se podrían identificar violaciones de los derechos humanos, y la columna 3 , que ofrece una perspectiva de la situación cuando por fin los derechos humanos se respeten, protejan y promuevan. Invite a los equipos que se formaron anteriormente a examinar las necesidades y responder a la pregunta sobre qué se puede hacer en nuestra sociedad para satisfacer las necesidades humanas básicas, tales como alimentación, salud y vivienda; y para proteger los respectivos derechos humanos.

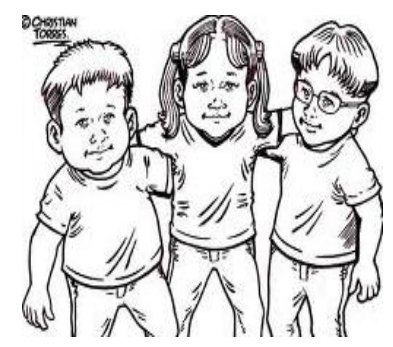

\section{Segunda sesión: La confección de las propias normas}

Las personas, sin esfuerzo, logran comprender la pertinencia de los límites sociales que las leyes y las normas fijan. En la medida en que la conducta madura y los valores se vuelven más complejos, las personas esperan que las normas sean imparciales y protectoras, además de que quieren participar en su formulación. Las normas de los derechos humanos por lo general se encuentran en constituciones, cartas, convenios y pactos. Dichas normas se dictan con la intervención de personas que llegaron a un acuerdo sobre las reglas que se les podían aplicar y, como tal, constituyen un "contrato

social".

\section{Materiales:}

Una serie de reglas que faciliten la realización de sesiones organizadas y dignas, las cuales serán seleccionadas inicialmente por el facilitador, y los Artículos 32 y 34 de la Convención sobre los Derechos del Niño

\section{Actividad:}

Paso 1. El facilitador propone una lista de normas para el grupo la que podría incluir los siguientes compromisos: 1) las sesiones tendrán una duración de (tiempo) y no se trabajará tiempo extra; 2) no vamos a enfrascarnos en altercados; sin embargo, trataremos de 
tener en cuenta todas las opiniones; 3) todos los participantes serán tratados con respeto, aún si no estamos de acuerdo con ellos; 4) no se interrumpirá a quien esté hablando; 5) si consideramos que algunas normas están parcializadas, las cambiaremos; etc. Léale la propuesta de normas a los participantes e invítelos a que decidan la que les parezca más importante.

Paso 2. Forma grupos con los participantes de acuerdo con la norma que cada uno haya elegido como la más importante. En lo posible, que a cada norma le corresponda un grupo. En primer lugar, los integrantes de los grupos deben conversar entre sí sobre las razones por las cuales creen que la norma es necesaria. El facilitador debe comportarse como un flotador entre los grupos. Cada grupo escoge a un representante para que prepare el informe. Permita que los participantes propongan normas propias, las cuales se someterán a votación.

Paso 3. Tan pronto como se hayan reconocido y aceptado las normas, informa a los participantes que las normas son un tipo de promesa que los integrantes de la clase realizaron para ser equitativos y correctos, con el fin de mostrar consideración por nosotros. Cuéntales que a tales promesas en ocasiones se les da el nombre de "acuerdos", "convenios" o "pactos". Explique que cuando las naciones hacen promesas sobre los derechos que van a respetar, están aceptando el compromiso de ceñirse a una norma que reconocerán y harán cumplir.

Paso 4. Intervención del facilitador: explica que la mayoría de los países del mundo se han puesto de acuerdo en lo que dispone la Convención sobre los Derechos del Niño, que es una larga lista de promesas, la cual contiene 54 artículos o secciones que se aplican a los jóvenes menores de 18 años. Por ejemplo, en el Artículo 32, el Estado se compromete a promover y acatar: "El derecho del niño a la protección contra prácticas peligrosas de trabajo y contra la explotación". El Artículo 34 se compromete a "proteger al niño de la explotación sexual, incluso la prostitución y el uso de niños en materiales pornográficos”. Todas estas promesas se hacen para cumplir normas concebidas para proteger a los niños.

Paso 5. Reconozca que las promesas no siempre se cumplen e invite al grupo a que dedique una lluvia de ideas a elaborar una lista de las formas en que se viola el Artículo32 en sus comunidades, lo que conlleva a que la promesa de la nación no se cumpla.

Divide el salón en grupos y haga que cada grupo se centre en una violación del 
compromiso de proteger a los niños. El grupo debe discutir cuáles son las causas que explican la explotación laboral de los niños y quién es responsable. Además, deben identificar una acción que se puede realizar para corregir esta situación.

Paso 6. Repite el proceso para los Artículos 32 o 34 y si el tiempo lo permite, en lugar de discutir las razones por las que se violan los derechos humanos, utilice el ejercicio de solución de problemas que se describen en la sección de Ejercicios de este libro. Los tratados de derechos humanos entre Estados son ejemplo del tipo de

acuerdo que se ciñe a reglas específicas. Por ejemplo, repítales el Artículo 31 de la Convención sobre los Derechos del Niño en el que se reconoce el derecho del niño al juego. Lea el artículo32 que dice que los Estados reconocen el derecho del niño a

la protección contra trabajos que "puedan ser peligrosos o entorpezcan su educación, o que sean nocivos para su saludo para su desarrollo físico, mental, espiritual, moral o social”.

Pregúntales si saben de alguna situación en la que los juegos o el trabajo de los niños los pongan en peligro e ínstelos a que discutan este tipo de problemas en la comunidad.

Advierta a los participantes que la aplicación de este derecho le compete no sólo al Estado sino a la comunidad entera. El facilitador pregunta que a quién le corresponde la

protección de los niños y favorece una discusión a fondo trazando "círculos de responsables", como demuestra aquí. Los participantes se ponen de acuerdo en el tipo de círculo de responsables que les gustaría tratar. Su elección debería reflejar el dicho popular "se necesita de toda una aldea para criar a un niño". Con este enfoque, los participantes finalmente se dedican

al desarrollo de un "plan de acción" para proteger a los niños de los maltratos que violan los Artículos 31, 32 o 33.

Paso 7. El facilitador entonces "da la puntada final” a la sesión recordando a los

participantes del compromiso que han adquirido de ayudar a la puesta en práctica de la Convención sobre los Derechos del Niño. El plan de acción puede incluir reuniones periódicas entre los miembros de la familia para comparar la información sobre las condiciones de riesgo en los juegos de los niños; por ejemplo, en el caso de la cercanía de un vertedero de depósitos tóxicos, ésta se realiza por medio del intercambio de información sobre las señas y síntomas tempranos de deterioro de la salud debido a envenenamiento por jugar en ese sitio. El plan de 
acción debe incluir información sobre salud pública y la forma de ponerse en contacto con otros funcionarios cuando se detecten riesgos para los niños en el juego o el trabajo.

Paso 8. El facilitador finaliza realizando un resumen completo. Repasa la idea de quelas normas bien diseñadas sirven al propósito de proteger a las personas como los niños, que las normas son mejores cuando las personas tienen la oportunidad de contribuir a su elaboración y que todos tenemos el mismo grado de responsabilidad en lograr que se cumplan. Pregunte si alguien no está de acuerdo con el repaso y pídeles que añadan cualquier comentario sobre lo que haya olvidado mencionar.

\subsubsection{Temática 4}

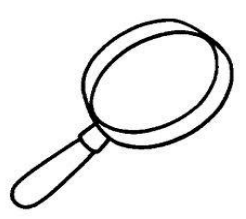

Queridos amiguitos: Si quieren dedicarse a la mayor aventura de su vida, recorriendo el mundo y sus historias, primero tenemos que conocer la maravilla de nuestro cuerpo, sus alcances, sus cualidades, sus cuidados, y todo lo que podríamos hacer con él. Hoy, aprenderás y transmitirás mucho sobre tus derechos y deberes como personita.

\section{Justificación:}

Los niños y las niñas deducir los vínculos entre la higiene y la salud, partiendo de la definición y creando hábitos que deben trascender del aula a los hogares, pues es allí donde los niños deben reflejar su conocimiento descubierto, transmitiendo algo de este a sus compañeros de hogar.

Las siguientes actividades tienen el fin de facilitarle al infante esta

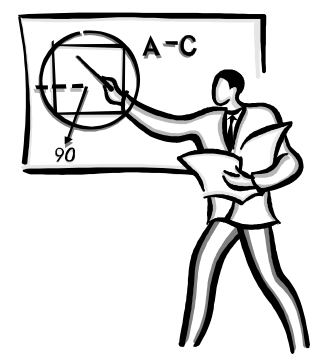
posibilidad en cuatro etapas: Las dos primeras permiten que los niños y las niñas realicen una introspección, ejercitando su zona de desarrollo efectivo. Las dos siguientes buscan que los niños y las niñas exterioricen lo aprendido, ejercitando su zona de desarrollo potencial, generando interacción, aprendizaje significativo y consciencia sobre la construcción del tejido social. 


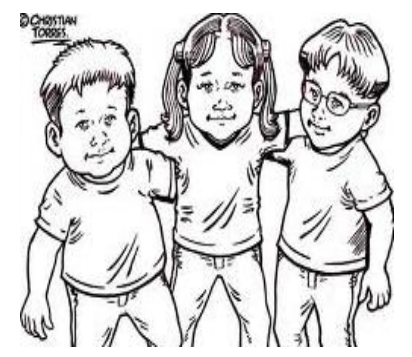

\section{ACTIVIDADES INDIVIDUALES Y GRUPALES}

\section{Primera sesión: El juego del bolígrafo}

Docente: Los ciudadanos deben formar parte de todos los niveles en los procesos en los que se tomen decisiones que afecten sus vidas. Esto, sin embargo, ocurre más en la teoría que en la práctica. De modo similar, las leyes se deben elaborar por y para la gente, no para unos pocos privilegiados y clases dominantes. El propósito de esta actividad es mostrar cómo las leyes sancionadas sin tener en cuenta a todas las personas pueden producir decisiones parcializadas y arbitrarias y, como resultado, generar injusticias. Además, la aplicación arbitraria de las normas produce actitudes escépticas hacia las reglas en general, socava las bases del consenso en que se basan las normas bien diseñadas y aumenta la probabilidad de la imposición coercitiva. Bajo tales circunstancias, la legitimidad de quien elabora las normas se erosiona.

Materiales: Un lápiz, un bolígrafo o algo similar.

\section{Actividad:}

Los participantes deben sentarse en dos filas frente a frente. Únicamente les dirá que van a jugar "El Juego del Bolígrafo" y no les dará explicaciones sobre las normas del juego. El paso 1 no debe durar más de 5 minutos, sin embargo, los pasos 2 y 3 requieren por lo menos 15 minutos cada uno. Para el paso 4 se debe disponer de suficiente tiempo para que haya una discusión crítica amplia y los participantes compartan sus impresiones.

Paso 1. El facilitador se comportará de forma poco común ya que actuará de modo arbitrario y dictatorial. Dividirá el grupo en dos equipos de igual número. Tal vez tenga que reprender a alguien por hacerse en el lado equivocado, sin explicar el porqué de "lo equivocado". Comience el juego entregándole el bolígrafo a uno de los participantes. Señalando y con movimientos de la cabeza, aliente a la primera persona para que entregue el bolígrafo a otro participante. En ese mismo momento, de repente dígale a quien recibe el bolígrafo que ha cometido un error y que el bolígrafo debe ser entregado al otro equipo. El facilitador debe estar muy atento de cómo, a quién y en qué dirección el jugador inicial entrega el bolígrafo. El error que identificará puede ser que el primer jugador usó la mano derecha en lugar de la izquierda para entregarlo a la persona a su derecha en lugar de la izquierda, o entregó el bolígrafo sin la tapa o cualquier otra rareza que pueda observar. De nuevo, sin explicación, debe pedirle a la persona a la que se le 
entregó el bolígrafo que continúe el juego. Después de la segunda o tercera ronda, anunciará del mismo modo que se ha cometido otro error; el cuál puede ser que el bolígrafo se entregó a una persona del sexo contrario, o a una persona que tenía un anillo a alguien que tenía el pelo canoso, y así sucesivamente. De esta forma el juego puede continuar hasta que el bolígrafo finalmente haya pasado por los integrantes de los dos equipos. En el transcurso, muchas personas habrán cometido faltas.

Paso 2. El facilitador abruptamente anuncia que el juego ha finalizado, y dice que uno de los equipos ganó y el otro perdió. Después le pregunta a cada equipo por separado si les gustó o no el juego. El equipo ganador generalmente dice que le gustó, mientras que el equipo perdedor se queja.

Paso 3. Después de que el juego haya terminado del modo que se describe arriba, el facilitador invita a:

- Los participantes, a que identifiquen los errores atribuidos a las personas que cometieron faltas.

- Los jugadores acusados de cometer falta, que si ellos las aceptan y por qué.

- Los participantes, a que digan todo lo que piensen que haga falta, esté mal, fuera de lugar o sea parcializado en el juego.

- Los participantes, a que decidan quién cometió las presuntas faltas, si el facilitador o los jugadores a los que se atribuyen y ¿por qué?

Paso 4. Pregunte a los participantes cuáles serían las medidas que se deben tomar para lograr que el juego sea equitativo y justo.

Paso 5. El facilitador lee este aparte de Chinua Achebe, un famoso escritor africano que en su libro Anthills of the Savannah (página 45), dice:

"Rendirle culto a un dictador es una molestia, y no sería tan malo si sólo se tratara de bailar parado en la cabeza, porque cualquiera puedo hacerlo si practica lo suficiente. El verdadero problema es que no hay forma, en ningún momento, de saber dónde queda arriba y dónde abajo”.

Por medio de la técnica la vuelta completa, pídale a los participantes su opinión sobre las palabras de ChinuaAchebe. ¿Les traen estas palabras algún recuerdo de sus propias vivencias? Explique que cuando la ley impera en un país, todos deben tener la posibilidad de conocerla y aprenderla, y que se debe aplicar sin intervenciones arbitrarias. 


\section{CONCLUSIONES}

En el desarrollo de la presente investigación, en primer lugar se trazó como objetivo, la elaboración de una herramienta que pudiera solventar algunas de las necesidades de corte educativo que pudiesen tener los niños y niñas en condiciones de vulnerabilidad, que a la vez permitiera retomar la categoría de sujeto de la que tanto hemos hablado desde América Latina y su pensamiento.

Para el progreso de la misma, se tuvieron en cuenta los planteamientos de Lev Vigotsky quien desde el constructivismo social nos aportaría los lineamientos bajo los cuales se regirían tanto las temáticas como la estructura misma de nuestra herramienta, a la cual titulamos “módulos me constru-yo", que fueron aplicados en niños y niñas asistentes al centro de proyección social de altos de Cazucá en el barrio minuto de Dios.

En segundo lugar debemos mencionar que para abordar las temáticas y plasmarlas en la cartilla, se tuvieron en cuenta temas de interés como la idea del yo, la sociedad, el medio ambiente, y los refuerzos académicos escolares, que fueron identificadas como las de mayor acogida dentro de la población infantil en altos de Cazucá, en el centro de proyección social.

El principal aporte de Vigotsky se evidencia en la estructura de los módulos, donde los niños tuvieron la posibilidad de generar un aprendizaje independiente, en la que se recalca la condición de sujeto como ser que conoce, dentro de un contexto específico y que éste a su vez, se convierte en su primera fuente de aprendizaje, para luego, en interacción con sus compañeros, dejar claro que el conocimiento surge de tres factores básicos: la interacción entre mis conocimientos con los de mis compañeros y los que me puede brindar el entorno.

En tercer lugar, se puede decir, que la interacción con el medio es una de las piedras angulares del constructivismo social de Vigotsky y es hacia esa interacción hacia donde apuntan los módulos diseñados en la presente investigación, y que constituyentes humanos como el lenguaje (que se convierte en una forma sistematizada de expresar la realidad) ayudan a que el niño logre a partir de conocimientos previos producir conocimientos nuevos, pues las temáticas contenidas hablan sobre elementos con los cuales los niños han tenido acercamiento previo o en su defecto hacen parte de su diario vivir. 
En cuarto lugar, el trabajo realizado con los niños del centro de proyección social, mostraron como éstos, a pesar de que muchos de ellos asisten al colegio, si mostraban interés por el conocimiento nuevo que les podía brindar el tema tratado en el modulo, asi como la reafirmación de sus conocimientos previos, por ejemplo, en el caso del cuerpo humano, fue evidente el conocimiento tanto interno como externo del mismo, así como las funciones vitales del ser humano.

Por otro lado, el conocimiento de la sociedad a gran y pequeña escala, dejo ver como los niños construyen desde sus primeros años de vida ( y desde el egocentrismo característico de esta época) pequeños lazos sociales, que nacen desde la familia y se proyectan hacia el grupo de amigos, el núcleo escolar dejando ver que son capaces tanto se asignar como de asumir roles dentro de los mismos, lo que los módulos pretendían era hacer evidente estos procesos, lo que se logró de manera satisfactoria, al ver como ellos mismos formaron grupos de trabajo donde se distinguía un líder y otros que aportaban a sus direccionamientos.

En quinto lugar, como bien se sabe, el constructivismo social, no es otra cosa que una teoría que pretende explicar la naturaleza del conocimiento humano en la medida en que el sujeto que conoce, interactúa con el contexto que le rodea, por esta razón nuestro trabajo se ve enfocado a una población específica que además de buscar un refuerzo escolar cotidiano, tenga la posibilidad de experimentar nuevas formas de producción de conocimiento, ya que solo en un contexto social se logra el aprendizaje significativo. A continuación algunos de los elementos que merecen especial trato dentro de las conclusiones arrojadas por la investigación son:

\section{Poseer conciencia sobre las operaciones mentales}

Cada uno de los módulos "Me Constru-yo" procura la formación en las operaciones mentales mediante todas las herramientas que puede dar el entorno en el cual los niños de Altos de Cazucá están inmersos. Para lograr esto se tuvieron en cuenta las siguientes actividades respecto de la operación mental a potenciar.

Para lograr la identificación se hizo observación de gráficas, señalamiento de palabras en un texto, identificación de elementos en un conjunto, palabras, ubicación de lugares en un mapa. Para la diferenciación se trabajó con hallar diferencias entre figuras, objetos, personas. La representación mental se pretendió con características de los seres vivos, inertes y figuras 
geométricas. Realizar mapas conceptuales, cuadros sinópticos, diagramas de flujo. Para fomentar la transformación mental hicimos construcción de sólidos geométricos, al igual que la elaboración de conceptos, definiciones, composiciones con dibujos, figuras, palabras. La evocación se persiguió memorizando una definición, un hecho, un poema, un texto, para luego recordar un momento significativo, cerrar los ojos y nombrar cosas que están a la derecha, izquierda, al frente, atrás, salir del salón y escribir lo que vieron, mirar una figura y luego dibujarla. La comparación se alcanzó con mediciones y superposiciones al encontrar diferencias y semejanzas entre figuras, objetos, personas, palabras. Para lograr la clasificación se establecieron semejanzas, diferencias, pertenencias e inclusiones entre objetos. Se reunieron grupos, y se plantearon actividades de separar por cualidad, color, forma, tamaño. En cuanto la seriación se pretendió con ejercicios de formar parejas y tríos. Escaleras con objetos, números, letras, palabras. Organizar series ascendente y descendente. Organizar palabras alfabéticamente, datos y fechas. La codificación descodificación se ejercitó con el reconocimiento de letras, palabras, sílabas, sopa de letras, crucigramas y la búsqueda de palabras en el diccionario. En cuanto al análisis-síntesis se propuso organizar rompecabezas, sopas de letras, juegos de encontrar la palabra desconocida cómo "el ahorcado". Toma de apuntes, consulta de información, lecturas, preguntas, presentación de problemas.

\section{Producción de generalizaciones y conceptos}

En cuanto a la producción conceptual, los estudiantes de altos de Cazucá respondieron óptimamente, ya que las relaciones que se crean entre el conocimiento y el mundo de los niños son muy estrechas. Luego del reconocimiento estructural de algún fenómeno de la comunidad se orienta una visión generalizada que le permite proyectar su saber a otros rincones del conocimiento, gracias a que se construye un gran cimiento teórico-práctico en pro de la aprehensión de nuevos saberes.

Desafortunadamente para los objetivos de nuestro proyecto, no todos los niños tienen el nivel educativo para trabajar con las herramientas educativas que diseñamos pues algunos no saben leer ni escribir, sin embargo, el docente que desarrolle las guías tendrá que adaptar algunas formas de evaluación de la actividad para que este ejercicio sea ejecutable, a pesar de que la aplicabilidad de las actividades no depende de una evaluación en sí. 
3. Hipótesis sobre la evolución mental de los niños

Después de haber interactuado y evaluado cada uno de los procesos de los participantes de la primera etapa de este proyecto, afirmamos que es posible potenciar las relaciones socioculturales en pro de su entorno con actividades de fondo académico, fomentando así que el niño de población vulnerable sea un sujeto con alto grado de conciencia social mediante la vía educativa, mejorando también sus oportunidades académicas, y por lo tanto, las laborales en un futuro.

Sin embargo, hay que tener en cuenta que el progreso mental de los niños depende de la continuidad de la aplicación de estas herramientas, pues hay que recordar que las condiciones de vida son adversas, constituyendo factores que entorpecen el ideal del resultado que se tenía. Es notable que, a pesar de todo esto, el progreso de los estudiantes tras tres o cuatro clases ya se veía reflejado en las maneras de interactuar con los demás, en la puntualidad, y en todos los convenios sociales que se habían planteado para el aula, al igual que la visión de sí mismo.

4. El pensamiento verbal que forma los niños sobre la realidad

Básicamente, es la realidad la que permite que el niño alimente cada vez más su pensamiento verbal, y al incentivar las relaciones sociales, el potencial lingüístico incrementa. Acercar a los niños a grandes glosarios no tiene sentido si estas palabras no tienen que ver con su realidad socio afectiva, ya que no tendrán un referente y por lo tanto, será conocimiento olvidado, además, hay que tener en cuenta que los problemas económicos que tendrán que sortear estos niños los acercarán más a un estilo de vida laboral que académico, por eso la importancia de la relación entre lo conceptual académico y lo sociocultural.

\section{Cómo pasa de memoria mecánica a una memoria logística}

Ya que los ejercicios planteados en los módulos "Me Constru-yo" plantean relaciones entre el mundo académico y el mundo social, se permite claramente que se dé conocimiento significativo y no memorístico. Aunque el conocimiento memorístico se logre, no es el objetivo del proceso, pues aparece gracias a que el niño crea vínculos entre el concepto y su 
realidad logrando que cada significado se adopte por medio de imágenes que él ya sabe, creando un enlace y no una imposición del docente que terminará aislada de los otros saberes y prontamente olvidada.

\section{Cómo se lleva a cabo el control intelectual y volitivo}

Por cada sesión se hacía una evaluación de tipo teórico sobre lo aprehendido en clase, oral o escrita dependiendo de la viabilidad del caso. También se hicieron heteroevaluaciones que buscaban potenciar las relaciones socioafectivas al igual que los valores, y finalmente se hizo una auto evaluación que buscaba la reflexión sobre sí mismo, incentivando el desarrollo de la conciencia.

El proceso del factor volitivo se hace notable en el incremento de la asistencia, permanencia y cumplimiento sobre el trabajo en clase, resultados que se lograron por la no convencionalidad de las sesiones y por el gusto que los estudiantes generaron hacia ellas. La voluntad en este sentido empieza a tomar forma de autonomía con responsabilidad social, tema y ejercicio de cada uno de los módulos "Me Constru-yo"

\section{Cómo aprende del más experto}

En este tipo de aprendizaje se da un acompañamiento y no una cátedra. "El más experto" tan solo plantea una vía por la cual comenzar a saciar la curiosidad intelectual del infante, encausando frecuentemente para no perderse en un mar de preguntas planteadas, es decir, teniendo claro el objetivo al cual el estudiante debe apuntar.

En el caso del contexto de Altos de Cazucá creemos que en muchos momentos no se puede hablar de "el más experto", pues hay muchas cosas y situaciones que los profesores que asisten jamás han vivido, por lo tanto es muy frecuente que el más experto no sea la persona que se supone deba ser. Incluso este tipo de experiencias que proponen los niños tienen una carga problemática tan grande que se pueden poner como hilo conductor de las sesiones con un poco de adecuación metodológica. 
8. Cómo logra el jalonamiento del conocimiento.

Teniendo en cuenta las estrategias que se llevaron a cabo en el proyecto, donde los estudiantes aprenden de acuerdo con sus características y contextos, de la misma manera que se instruyen con sus compañeros en el momento del desarrollo de diferentes actividades, es claro que estas relaciones se establecen y fortalecen el jalonamiento de conocimiento, tal y como se fortifican en la resolución de problemas, tema que debe ser esencial en el ser humano debido a que se puede encontrar en situaciones que tendrá que asumir constantemente.

\section{Cómo percibe sus procesos psíquicos}

Es necesario evaluar cada uno de los procesos psíquicos por aparte:

Procesos Cognitivos: Los niños mejoraron las formas para acercarse a su entorno, haciéndose más conscientes de sus herramientas sensitivas, ampliando su nivel de percepción y crítica gracias a que la cantidad de información asimilada ahora es mayor, incentivando así a crear una personalidad comprometida con su entorno en el sentido práctico.

Procesos Afectivos: Los niños aprendieron nuevos valores para la convivencia y los aplicaron tanto en clase como en los ejercicios que quedaban como trabajo independiente. Mediante estos ejercicios se pretende que todos controlen sus emociones ubicándolas en un momento y un lugar adecuado, pues no se trata de reprimir sentimientos sino de canalizarlos.

Procesos Motivacionales: Aunque los niños de Altos de Cazucá responden con gran interés a todas las actividades, hay que recordar que ellos asisten gracias a que les gusta lo que van a hacer, es decir que estamos formando hábitos de constructor de conocimiento, por ello la tendencia lúdica y teórico-práctica debe continuar para incrementar aún más el gusto por aprender y preguntarse.

10. Cómo transfiere y aplica conocimiento.

Los ejercicios individuales y grupales en cada uno de los módulos sugieren una interacción del niño con el conocimiento previo como con el adquirido por medio de actividades que potencian sus habilidades intelectuales y sociales simultáneamente, siendo imposible aprender sin aplicar, atendiendo así a los postulados del constructivismo social de Vigotsky. 
11. Cómo desarrolla destrezas específicas.

Las destrezas referentes a la sociabilidad son potenciadas al igual que las cognitivas, sin embargo, los módulos no contemplan las habilidades motoras por varias razones: En primer lugar no hay un espacio apto para las actividades, y los escenarios deportivos quedan muy alejados del centro de proyección social, lo cual significa un gran riesgo para los niños y los docentes que trabajan allí. En segundo lugar se está trabajando con grupos que no son de edades homogéneas, problema que se solucionaría con un plan de desarrollo corporal adecuado con la edad y las capacidades de cada uno de los participantes del proceso de construcción de conocimiento. En tercer lugar es necesario que el guía que esté con los niños tenga el mínimo de conocimiento sobre la motricidad y la armonía del movimiento humano, por ello es necesario ampliar esta parte del proyecto para lograr mejores resultados que los que hasta ahora se han tenido.

Otro de los pilares de la investigación tiene como referencia es la recepción del concepto de sujeto en el pensamiento latinoamericano y como este puede en cierta medida, ayudar en nuestros módulos con la reconstrucción del tejido social, pues con los módulos de trabajo se logra una auto afirmación del niño y su condición humana como sujeto que conoce y se reconoce con su entorno y su realidad y a partir de ella, logra generar tanto procesos de conocimiento como de mejoramiento (en la medida de sus posibilidades) de sus condiciones, que va desde el cuidado de sí mismo, hasta el cuidado del medio ambiente desde su entorno inmediato.

De igual forma, el resultante de nuestro trabajo permite que los niños de la población en la cual sea aplicada se auto conozcan y auto reconozcan como sujetos activos dentro de una comunidad que en primera instancia se encarga de formarlos, pero que a fututo verá en ellos sujetos activos, constructores de sociedad.

Como ya se ha expuesto de manera detallada, el sujeto dentro del pensamiento latinoamericano, es visto como un ser racional que hace parte del gran andamiaje de la sociedad y los sistemas, pero también debemos concebirlo como un sujeto que puede conocer su realidad y transformarla, primero desde sí mismo y luego en interacción con los demás, que parte de nuestros modelos educativos se ven truncados, en gran medida porque aun tenemos la visión de ser un sujeto meramente sustancial y no contemplamos que también somos sujetos epistemológicos, históricos, ontológicos y estructurales, y que justamente, en la medida en que 
esa integralidad sea tenida en cuenta, veremos al sujeto latinoamericano como el responsable directo de su edificación sin desconocer, claro está su historia.

Es así como desde Vigotsky y la recepción de los diversos autores expuestos desde el pensamiento latinoamericano, logramos ver un sujeto actuante dentro de sus historia y justamente, los niños y niñas en condiciones de vulnerabilidad son los mejores testigos de una América latina que se levanta en medio de condiciones cada vez más adversas, pero que a pesar de esto, el ejercicio del pensamiento es una parte inherente al ser humano, y que los grandes cambios de la sociedad se ven en la medida en que seamos capaces de conocer, interactuar y transformar nuestros contextos cotidianos, tal y como fue el objetivo de la presente investigación, que a su vez, deja claro que los niños y niñas también son sujetos actuantes autoreconocidos que pueden abarcar diferentes temas del conocimiento.

12. Resultados y hallazgos: el sujeto latinoamericano observación, talleres, contacto humano y la pedagogía de la liberación

El acercamiento a los niños asistentes al centro de proyección social dejó varios puntos para analizar, el primero de ellos, es la calidez con la que se reciben proyectos como éste, en el que se brindan nuevos horizontes de conocimiento a la vez que se presta un servicio como el de asesoría de tareas, el segundo es la compatibilidad generada entre los niños y los guías del trabajo, pues fácilmente acatan ordenes, se mostraron dispuestos al trabajo y se generaron lazos afectivos entre las partes implicadas, lo que posibilitó la construcción de conocimiento y de tejido social y humano.

En tercer lugar el interés por el conocimiento nuevo y el refuerzo por el conocimiento adquirido marcó la pauta en el desarrollo del proyecto, pues los temas tratados en los módulos corresponden a temáticas tratadas en la escuela dentro de la enseñanza de la básica primaria, como la sociedad, la familia, entre otros; la novedad y atracción radicó en las actividades y la manera de transmitir la información, jugando, creando e interactuando también se aprende, haciendo alusión a su contexto inmediato, la observación detallada de sus propias condiciones y la reflexión sobre su entorno por medio de la creación de cuentos donde el personaje central fuera un ser imaginario que viviera dentro de una situación que ellos hayan vivido y en su zona de desarrollo, generó no solo identificación de los niños con sí mismos sino con la realidad en la que viven y las posibles maneras de mejorarla. 
En cuarto lugar para el desarrollo eficaz de nuestro proyecto y de otros que vengan a futuro debemos deshacernos del falso paradigma de creer que los niños de altos de Cazucá viven en una especie de "universo paralelo" respecto de niños de otras condiciones, lo cual resulta falso, los niños de altos de Cazucá tienen acceso a las mismas cosas que niños de otras condiciones pero en menor medida, son chicos que practican deportes, juegan videojuegos, ven dibujos animados, disfrutan del juego, saben trabajar en equipo e incluso son rebeldes frente a lo que no les genera conformidad.

La creatividad es otro factor fundamental, son niños recursivos y toman de elementos cercanos como materiales reciclables, botellas, palos y plásticos recursos para la creación de instrumentos musicales, funcionales y decorativos, así como educativos tales como títeres y carteleras.

En quinto lugar y haciendo referencia al sujeto situacional, el niño del centro de proyección de altos de Cazucá no siente vergüenza de su condición él no se sabe ni pobre ni oprimido, no discrimina a otros niños ni adultos, por el contrario experimenta sentido de pertenencia y aprecio por el lugar y el suelo que habita, por su núcleo familiar, por su ciudad y su país, reconoce figuras de poder dentro de nuestro país así como el funcionamiento del estado y experimenta sentimientos de nacionalismo al sentirse Colombiano.

Ahora bien, si miramos todos los factores expuestos a la luz de los planteamientos de la pedagogía de la liberación expuesta por Paulo Freire tendremos varias anotaciones al respecto.

En primera medida, el proyecto sugiere un modelo de educación activa, dialogal, donde no hay quien transmite un conocimiento que otros reciben sino es una construcción mutua donde todos obtienen aprendizajes de diversos niveles dejando semillas de espíritu crítico, pues no basta con conocer el mundo en el que se vive, sino también en qué medida podemos transformarlo para hacerlo un lugar mejor.

Como un segundo aspecto contemplemos entonces, los tipos de conciencia que sugiere Freire; ¿será acaso que los niños de altos de Cazucá poseen una conciencia ingenua donde se tiene una falsa concepción de "posesión de la verdad absoluta" que los libera para poder juzgar de manera arbitraria todo lo que se sucede en el mundo y en su contexto sin ningún afán de mejorar las cosas?, sin duda alguna no, pues aunque no se quiere enmarcar a estos niños y niñas dentro de un nivel de conformismo tampoco son seres crítico-destructivos del medio en el que viven, la condición propia de su edad y su desarrollo mental y cognoscitivo los libera de cierta manera 
paradójica de este tipo de conciencia, luego entonces ¿será que los niños y niñas de altos de Cazucá tienen la concepción de que su realidad los sobrepasa y los absorbe y los sumerge en una mentalidad oprimida, donde solo les resta operar como observadores pasivos? Según Freire, ésta forma de conciencia es "mágica" pues desposee a los sujetos del poder de transformar su entorno permitiendo así el mejoramiento de sus condiciones su posibilidad misma de ser, así como su calidad de vida.

Sin duda alguna, los niños y niñas de esta zona están por encima de esa vulnerabilidad que la misma sociedad les ha impuesto, no se consideran ni superiores ni inferiores al momento histórico que les ha correspondido vivir, basta ver la recursividad para desarrollar trabajos en equipo, el amor propio y hacia el otro manifestado en la disposición para asumir cada una de las actividades propuestas en los módulos aplicados, la confianza en que la educación es la puerta abierta para librarse de la "opresión" impuesta por diversos factores como el conflicto armado, los sistemas de gobierno y la realidad a la que no son ajenos, ante una pobreza material inminente pero que no es un obstáculo para el enriquecimiento mental y espiritual y es allí mismo donde germinan las semillas de una conciencia crítica "freiriana" donde el sujeto propio de un contexto como el de altos de Cazucá tiene aprehendida la noción de su lugar en la sociedad y la relación entre ésta y los hechos que componen su diario vivir, tales como ir a la escuela, reconocer al otro como compañía y fuente de conocimiento construido y por construir, así como la influencia de agentes externos como las diferentes ONG que se encuentran en el lugar y los espacios brindados incluso por entidades como la Universidad Santo Tomás.

La pedagogía de la liberación sugiere a la educación como un medio de cambio para los sujetos y por consiguiente la sociedad en la que se encuentran inmersos, la educación es el agente liberador que le permite al hombre un actuar libre y consiente sobre el mundo, la escuela (no el aula) es entonces el mecanismo de inclusión y el conocimiento la base de un nuevo tipo de sociedad y estos postulados son "el inicio de un caminar distinto" ese es uno de los valores agregados a esta investigación y que se deja explícito en la aplicación de módulos que ofrezcan nuevas visiones de la educación dentro de contextos determinados tal y como sucede en altos de Cazucá amparados en modelos pedagógicos de amplio reconocimiento como Vigotsky y Freire. 
13. Detalles de muestras estadísticas: impacto del proyecto y evaluación de materiales por edades desde un enfoque cuantitativo y cualitativo

Análisis Cuantitativo donde se contemplan algunas variables que se tuvieron en cuanta para el desarrollo del proyecto.

\begin{tabular}{|ll|l|}
\hline \multicolumn{3}{|c|}{ Género } \\
\hline Niños & Niñas \\
\hline & 10 & \\
\hline
\end{tabular}

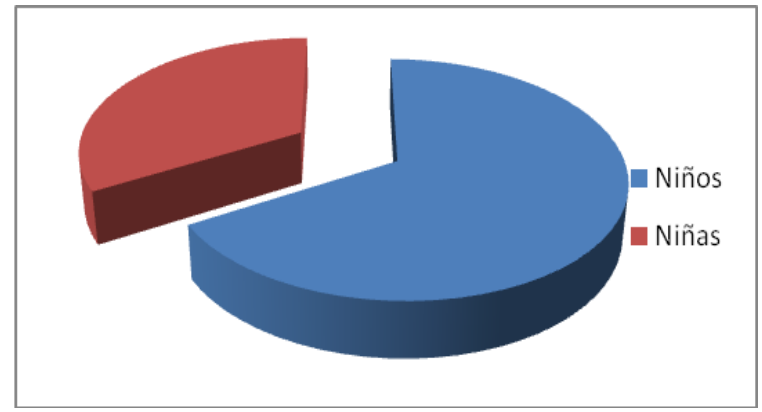

\begin{tabular}{|l|r|r|}
\hline \multicolumn{3}{|c|}{ Edad } \\
\hline & Niños & Niñas \\
\hline de 5 a 7 & 5 & 0 \\
\hline de 8 a 10 & 5 & 2 \\
\hline de 11 a 13 & 0 & 3 \\
\hline
\end{tabular}

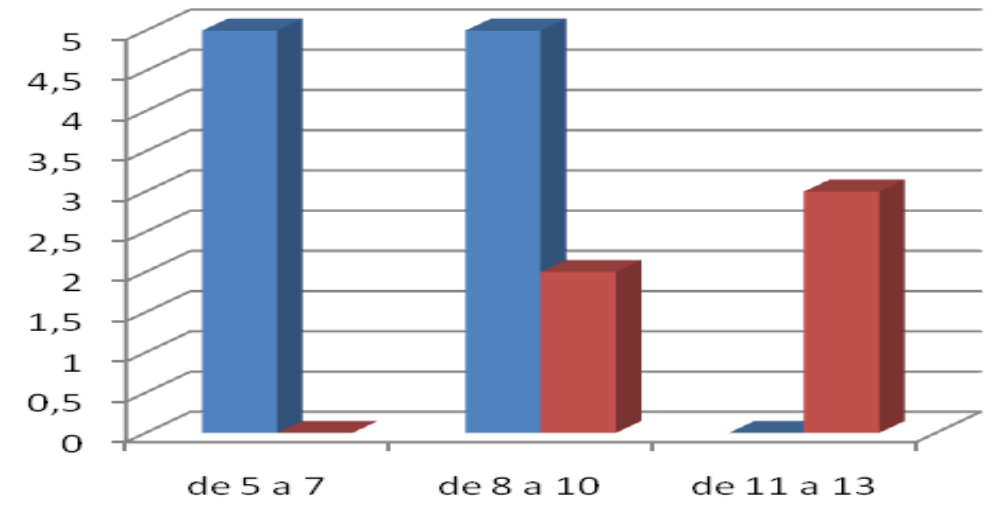

- Niños

- Niñas 


\begin{tabular}{|r|r|r|}
\hline \multicolumn{3}{|c|}{ Escolaridad } \\
\hline & Niños & \multicolumn{1}{l|}{ Niñas } \\
\hline No estudia & 1 & 1 \\
\hline 2 & 2 & 0 \\
\hline 3 & 4 & 1 \\
\hline 4 & 3 & 0 \\
\hline 5 & 0 & 1 \\
\hline 6 & 0 & 2 \\
\hline
\end{tabular}

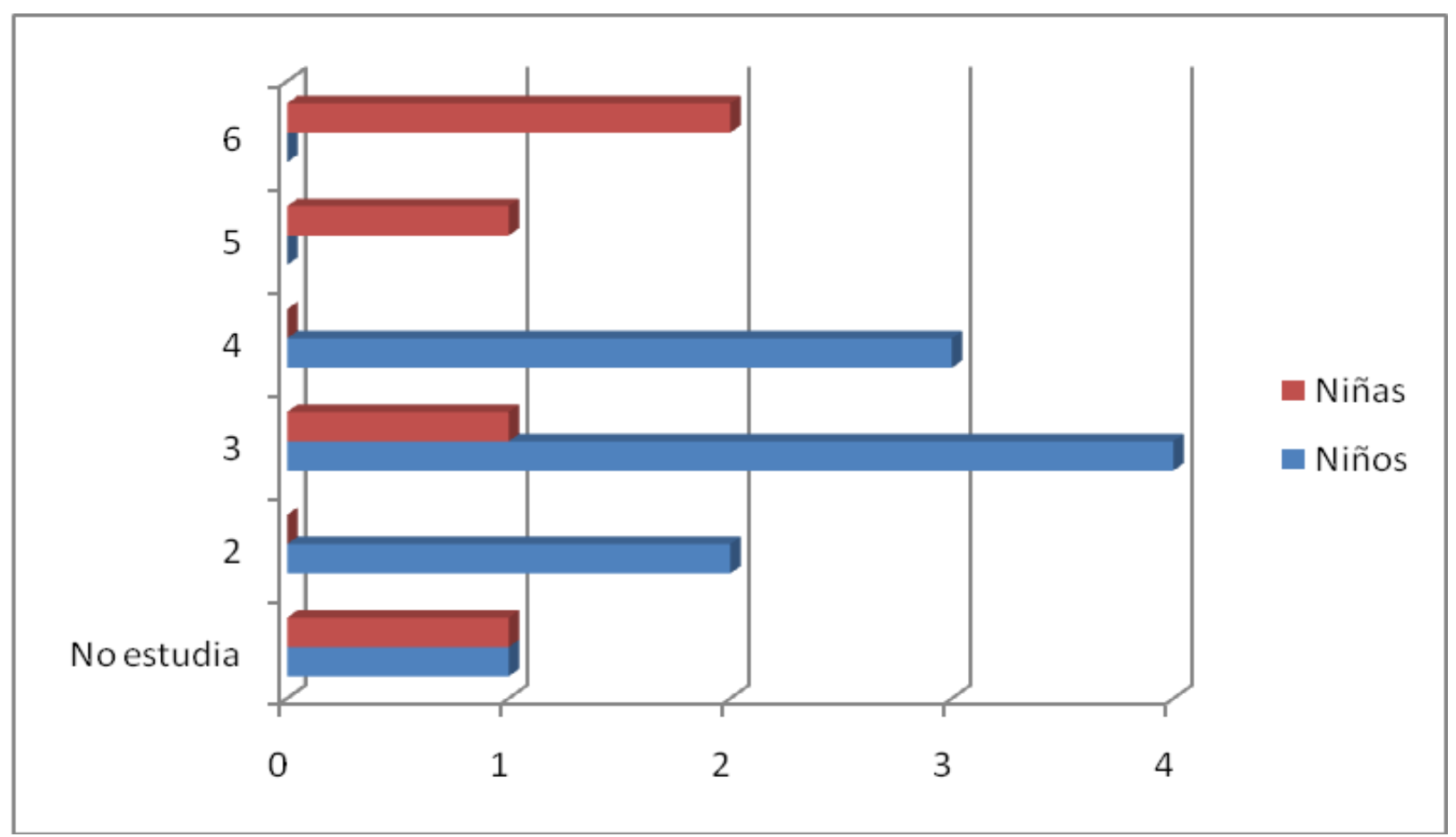




\begin{tabular}{|l|r|r|}
\hline \multicolumn{3}{|c|}{ Habilidades } \\
\hline & Niños & Niñas \\
\hline No maneja & 2 & 1 \\
\hline Leer- Escribir & 8 & 4 \\
\hline Sumar- Restar & 7 & 4 \\
& & \\
\hline
\end{tabular}

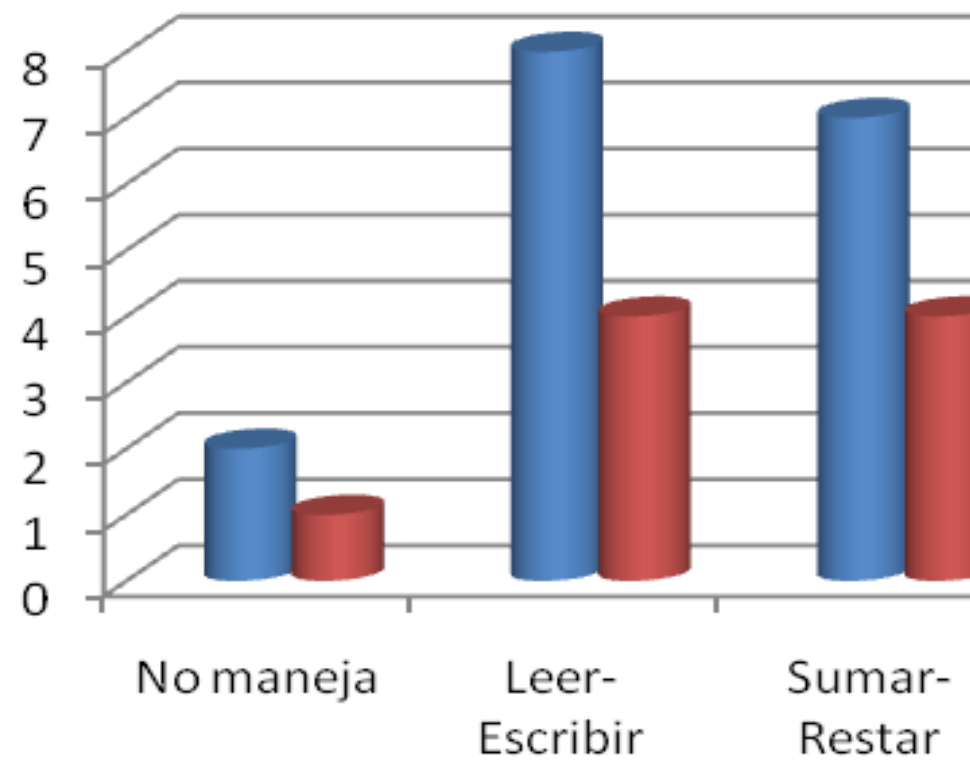

\begin{tabular}{|l|r|}
\hline \multicolumn{2}{|c|}{ Total Estudiantes } \\
\hline & Asistencia \\
\hline Primera Sesión & 7 \\
\hline Segunda Sesión & 9 \\
\hline Tercera Sesión & 8 \\
\hline Cuarta Sesión & 12 \\
\hline Quinta Sesión & 1 \\
\hline Sexta Sesión & 10 \\
\hline Septima Sesión & 13 \\
\hline Octava Sesión & 15 \\
\hline Novena Sesión & 14 \\
\hline Décima Sesión & 15 \\
\hline
\end{tabular}

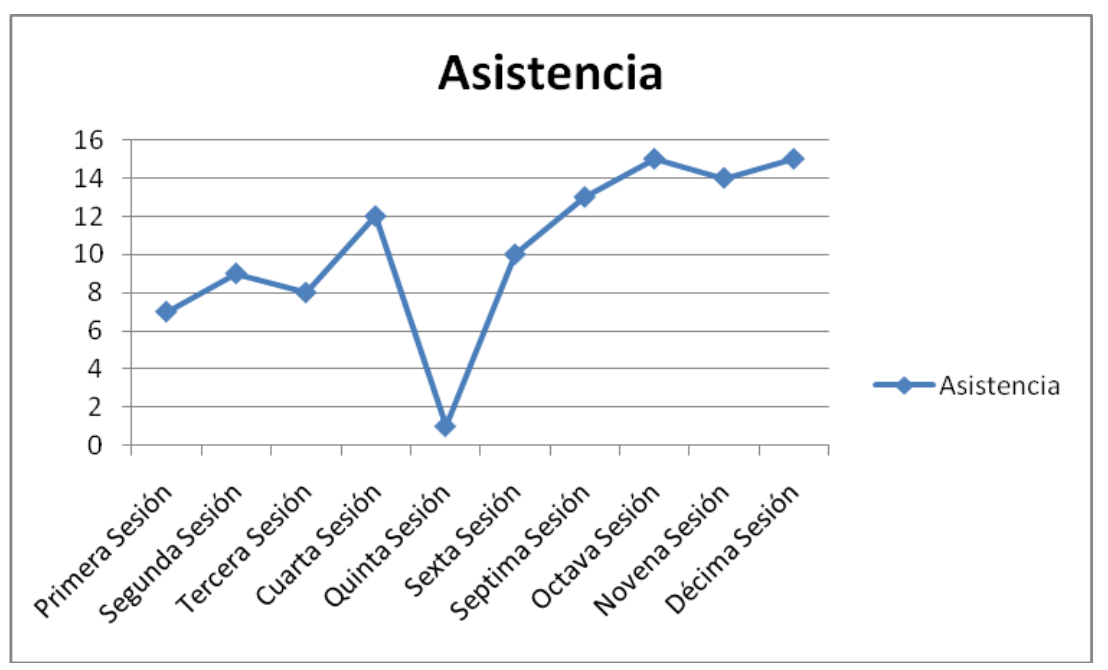


Para realizar una evaluación al proceso realizado tendremos en cuenta los siguientes aspectos:

- Replanteamiento de los módulos frente a la experiencia

- Aceptación y rechazo

- Metodología

- Impacto

- Uso de espacios/recursos

- Asistencia

- Habilidades de investigación

- Conocimiento reforzado

- Conocimiento adquirido

Replanteamiento: Los módulos educativos que se plantearon presentaron aciertos en la mayoría de los retos trazados, como punto para replantear sería importante incluir actividades de mayor nivel cognitivo (cine-foro para niños por ejemplo), pues la mayoría de los niños asisten al colegio y tienen grandes capacidades por explotar, también se hacer pertinente incluir actividades para niños y niñas que no sepan leer y escribir, pues ellos también asisten al centro de proyección social y deben contar con actividades específicas para su edad y nivel de desarrollo cognitivo.

Aceptación y Rechazo: los módulos que contaron con mayor aceptación fueron aquellos que incluyeron actividades lúdicas propiamente, pues los niños mostraron mayor interés y disposición para el desarrollo de éstos, sin duda, los que no contaron con mayor respaldo fueron aquellos en los que se hacía refuerzo de temas como matemáticas o lenguaje, pero se lograron avances que enunciaremos más adelante.

Metodología: Los niños y niñas asistentes se mostraron complacidos con la forma en la cual se desarrolló el trabajo, pues a la vez que se les permitió trabajar de manera autónoma, también tuvieron la oportunidad de desempeñar varios roles como el de líderes, artistas, jugar y sentirse cómodos tanto consigo mismos, como con sus acompañantes y compañeros, lo que prueba que el autor y la metodología implantadas fueron acertadas.

Impacto: sin duda alguna el gran aporte de nuestro proyecto al trabajo que se viene realizando en el centro de proyección social consiste en brindar espacios especializados y de orden al espacio 
que se tiene con los niños asistentes, lo que favorece la permanencia de los mismos en el programa, pues a nuestra llegada encontramos varios practicantes de la licenciatura y estudiantes de varias facultades, todos con el mejor de los ánimos y disposiciones pero sin un plan de trabajo específico, pues solamente se hacían guías que cada joven llevaba a los niños por su cuenta pero no se veía un trabajo unificado que permitiera algún tipo de avance, así mismo, la colaboración con las tareas era lo único que atraía a los niños para que asistieran, con la ejecución de los módulos se implantó un trabajo orientado apuntando a un mismo horizonte, construir en lo intelectual y lo humano, generando gran satisfacción el poder dejar esta herramienta para que sea ejecutada y por qué no, enriquecida por las personas que asuman los procesos en el centro de proyección social.

Uso de espacios/recursos: Si bien el contexto ya es bastante fuerte para trabajar, en el centro de proyección social se encontraron espacios que albergan a los niños de la mejor manera posible, por iniciativa de todas las personas que de una u otra manera colaboran con el centro se cuentan con recursos como lápices, colores, pegante, hojas etc, así como una sala específica para ver películas y brindar espacios de juego a los niños con peluches entre otros juguetes.

Lo que mencionaríamos como mejoría, sería la oportunidad de contar con otros espacios como parques cercanos e incluso, la salida a ciertos lugares de la capital como el parques públicos y centros históricos, aunque para ello hayan que preparar actividades alternas para subsidiar los recursos necesarios para llevar a feliz término las mismas.

Una de las amenazas que detectamos a la hora de trabajar con material reutilizable como botellas, alambre entre otros, es la recolección con suficiente tiempo anticipado para no presentar retrasos en la ejecución correcta de las actividades.

Asistencia: Este factor, se constituye como la amenaza más fuerte para el desarrollo de cualquier proyecto en el centro de proyección social, pues si bien contamos con un foro promedio de 15 niños durante todo el desarrollo del trabajo, muchos de los niños y niñas asistentes no asistían de manera constante debido a diversas causas que van desde la falta de entusiasmo hasta la falta de recursos o tiempo para desplazarse.

Uno de los acontecimientos que marcaron inasistencia total dentro de los días establecidos de trabajo fue el día en que los carro tanques del acueducto de acercaban a repartir el agua y algunas instituciones hacía simultáneamente la entrega de mercados, en esos días es sabido que los niños 
no asisten al centro de proyección por encontrarse ayudando en sus casas con la recolección del agua y la recepción de mercados.

Una vez se dejó en claro la forma y los objetivos de nuestro trabajo con ellos, los niños (15) fueron puntuales y disciplinados en la asistencia, compromiso y cumplimiento con las responsabilidades adquiridas.

Habilidades de investigación: uno de los hallazgos más importantes durante el desarrollo de los módulos, fueron las habilidades de investigación de los niños y niñas asistentes, su intensa curiosidad frente a los temas planteados, la consulta de algunos de los temas en fuentes físicas, la capacidad de seleccionar información pertinente, decodificación de la misma, aportes a los compañeros de equipo o la socialización al grupo de sus hallazgos individuales y la aplicación de la información al medio dejan ver claramente habilidades investigación, aspecto relevante dentro de sus desarrollo como sujeto activo constructor de conocimiento.

Conocimiento reforzado: los conocimientos en habilidades como lecto-escritura, operaciones básicas, funcionamiento del cuerpo, el orden social, derechos y deberes, entre otros son los conocimientos reforzados con mayor relevancia dentro del trabajo realizado, lo que comprobó que los niños y las niñas asistentes gozan de un nivel promedio de escolaridad dentro de lo que su situación les puede ofrecer y a su vez, le brinda un horizonte más claro a los módulos planteados.

Conocimiento adquirido: podemos enmarcar dentro de esta categoría lo relacionado con el manejo de material reciclable y su re uso útil en instrumentos musicales o experimentos de ciencias naturales, así mismo, el acercamiento a la música, al teatro, a los títeres se manifestó como unos de los conocimientos adquiridos que más impacto causan dentro de los niños y niñas. La conciencia sobre lo social, lo ambiental, lo artístico y lo humano influye naturalmente en la construcción de lo que hemos denominado el sujeto situacional de altos de Cazucá, seres que se forman desde todos los ámbitos y dimensiones acogidos por el contexto en el que viven procurando mejorarlo para sí mismos y para los demás.

14. Cómo se percibe el sujeto de Cazucá desde la óptica Vigotskiana y funcionalidad del discurso. 
Una vez entablado el contacto con los niños del centro de proyección de altos de Cazucá, vemos como todos cuentan con un nivel básico de escolaridad, y su diario vivir a pesar de los factores que los rodean permite que su infancia se desarrolle dentro de los límites de lo normal.

Las funciones mentales Vigotskianas de corte inferior son manifestadas de manera clara, ninguno de los niños padece ninguna deficiencia física ni cognitiva y han adquirido funciones mentales superiores de manera eficaz, leer y escribir en los niños de más de 5 años de edad y los trazos, manejo del papel y el lápiz en los menores de cinco años, todos manifiestan de manera acertada necesidades básicas mediante la expresión verbal, atienden a comandos básicos generando procesos de comunicación efectiva, nacida claro está dentro de diversos contextos como el familiar, el social y el cultural atendiendo a los elementos que éstos les brindan.

Mirando desde la óptica social, los niños tienden en ocasiones a generar pequeñas disputas por el liderazgo dentro del trabajo en equipo, lo cual podemos considerar como típico de la edad, en el trabajo individual se deja ver la independencia con la cual manejan las herramientas brindadas, tales como hojas, colores, pinturas entre otros, como mencionamos anteriormente, gracias a una comunicación efectiva pueden compartir materiales de manera ordenada pidiéndolos prestados.

Ahora bien la ley genética de desarrollo se resume del siguiente modo:

Toda función psicológica superior existe en dos planos, el primero es el interpsicológico o entre mentes, y el segundo es el plano intrapsicológico o psicológico individual. Tal definición de los planos interpsicológicos e intrapsicológicos nos conduce a recalcar la existencia de un mecanismo de internalización como responsable del tránsito de las acciones materiales que se realizan en el plano de las relaciones intrapsicológicas.

Con ello Vigotsky nos dice que si bien nuestras capacidades cognitivas como el lenguaje, la memoria etc. se desarrollan de manera natural, llega un momento en que este desarrollo se estanca gracias a la mediación social que pueden desarrollar potencialmente. Aquí atendemos a un cuestionamiento: ¿será acaso que el medio social en el que crecen los niños de altos de Cazucá impide de alguna manera la construcción de conocimiento?

Para explicar este paso de un nivel natural a un nivel potencial, Vigotsky plantea el concepto de desarrollo próximo. La zona de desarrollo próximo se define como la distancia que existe entre el nivel de desarrollo real y el nivel de desarrollo potencial de cada sujeto, es decir como la 
distancia que existe entre lo que el sujeto puede hacer solo y lo que podría hacer con la colaboración de otros.

Bajo esta medida, los módulos diseñados y ejecutados tenían dos etapas para su desarrollo, una de trabajo individual en el que los niños tienen la oportunidad de reforzar un concepto, y expresarlo de manera autónoma y la otra consistía en la interacción con sus compañeros por ello la distancia entre el nivel real de desarrollo, determinado por la capacidad de resolver independientemente un problema y el nivel de desarrollo potencial, determinado a través de la solución de un problema bajo la guía de un adulto o con la colaboración de un compañero más capaz.

Se presenta así innumerables posibilidades de desarrollo y aprendizaje en los sujetos (en nuestro caso los niños del centro de proyección social de altos de Cazucá), gracias a los procesos de mediación que se efectúan en la zona de desarrollo próximo. Una de las aplicaciones más generalizadas que se ha realizado en esta teoría en el proceso de enseñanza aprendizaje es el trabajo cooperativo, explicado dentro de los módulos realizados.

Siendo fieles a Vigotsky se afirma que la actividad mental es exclusivamente humana. Es el resultado del aprendizaje social, de la interiorización de los signos sociales y de la internalización de la cultura y de las relaciones sociales. El desarrollo psicológico es, en esencia, un proceso sociogenético, los niños de altos de Cazucá además de ser habitantes de un tiempoespacio, que inician su proceso de formación desde su propio yo, para más tarde reconocerse en el otro, donde acogen diversos elementos siendo sujetos activos dentro del aprendizaje y la construcción de cultura y tejido social en la medida en que el conocimiento adquirido sea una herramienta que tenga vigencia en todos los ámbitos en los que se desempeñen.

Por otro lado veamos que tanto funciona el discurso de Vigotsky en Altos de Cazucá, aquí tengamos en cuenta algunas variables:

- Se trabajó con niños en condiciones de vulnerabilidad

- El contexto propio es el latinoamericano Colombiano

- La educación es solo una de las necesidades básicas dentro de esta población, contar con fuentes hídricas, servicios públicos, pavimentación de vías, fuentes de trabajo y conflicto armado son las más sobresalientes. 
Siendo estos aparentes puntos de divergencia que ponen en tela de juicio la teoría de Vigotsky vemos también como para él, la educación formal era un instrumento esencial de enculturación. Dentro del contexto de una interacción activa y sistemática entre los niños y el maestro, a los primeros se les van proporcionando, de manera organizada, las herramientas psicológicas que determinarán la reorganización de sus funciones mentales.

El aprendizaje consiste así en la internalización progresiva de los instrumentos mediadores. Esto es una aplicación del principio antes señalado: todo proceso psicológico superior va de lo externo a lo interno, de las interacciones sociales a las acciones internas, adaptables naturalmente, al contexto dentro del cual se trabaje.

El aporte más importante de Vigotsky fue reconocer a los niños como agentes activos del proceso educativo, como elaboradores de los contenidos que se les presentan. Es decir que la internalización a la que hacíamos referencia antes, implica una transformación, una reorganización individual. No hay una transmisión automática de los instrumentos que la cultura suministra, vemos pues por cultura podemos tratarlo dentro de la nuestra, la latinoamericana, específicamente Colombiana, lo que evidencia un acierto a la hora de la selección del autor en pedagogía a tratar en el presente trabajo.

A pesar de que algunos autores han visto en la concepción de Vigotsky una postura “adultocéntrica", en realidad Vigotsky nos ha dejado una pedagogía centrada en el niño, en el análisis de sus intereses y motivaciones, en el conocimiento de sus rasgos característicos, niños de cualquier condición social.

Para Vigotsky el proceso de desarrollo debe ser visto de manera prospectiva, es decir referido más allá del momento actual, a lo que va a suceder en la vida del sujeto. Se trata entonces de comprender en el curso del desarrollo el surgimiento de lo nuevo en la trayectoria del individuo. El concepto de zona de desarrollo próximo guarda relación con esta mirada prospectiva del desarrollo. Marca la importancia de la intervención docente para provocar avances en los alumnos que no se producirían espontáneamente sino a través de esta interferencia en la zona de desarrollo próximo.

La educación crea procesos de aprendizaje que guían el desarrollo y esta secuencia da como resultado zonas de desarrollo próximo (ZDP). Dentro de la ZDP el niño no es un simple receptor pasivo de las enseñanzas del adulto, ni el adulto es sencillamente un modelo de conducta exitosa, 
experimentada. En lugar de ello, el niño y el adulto emprenden una actividad conjunta de resolución de un problema en el que ambos comparten conocimientos y responsabilidades por la tarea. Una vez que el niño comparte los objetivos del adulto y la definición de la situación problemática, el adulto debe transferir al niño, de manera gradual y creciente, la responsabilidad de la misma. El proceso va de la regulación de la tarea por parte de otro a la autorregulación, esto es, de la resolución conjunta a la resolución independiente de un problema. Los soportes o asistencia que se brinda deben replegarse gradual pero inexorablemente ya que si no se perpetuaría la necesidad de una asistencia externa para el desempeño del sujeto. Gradualmente, con el tiempo, el niño necesita cada vez menos ayuda porque su capacidad de autorregulación aumenta. Además la asistencia debe ser visible. Esto significa que el sujeto que es auxiliado perciba la naturaleza y tipo de ayuda que están siendo suministrados para poder monitorear el propio proceso de aprendizaje y tomar conciencia de los aspectos que aún no se dominan en forma autónoma.

El progreso por la ZDP con los niños de altos de Cazucá se presentó en cuatro etapas:

- Cuando otros más capaces ayudan al desempeño

- Cuando el yo ayuda al aprendizaje. Si bien el niño lleva a cabo una tarea sin ayuda ajena permanece un discurso auto dirigido: el niño dirige o guía su conducta con su habla propia.

- Cuando el desempeño se desarrolla y automatiza. La realización de la tarea es fluida e integral. La ayuda del adulto o del yo no es necesaria

- Donde la desautomatización del desempeño lleva a la recurrencia a través de la ZDP. Para enriquecer o mantener los logros se recurre a la ayuda de otros.

El conocimiento, como producto social, se construye a través de la interacción en la ZDP.

La colaboración con otra persona (adulto o par más capacitado) en la ZDP conduce a un desarrollo en forma culturalmente apropiada.

Si bien Vigotsky privilegia, en relación con la ZDP, las prácticas escolares, como interacciones susceptibles de provocar la internalización de los productos culturales, también el juego y los procesos de trabajo poseen un efecto similar.

Es fundamental entonces tener en cuenta que para Vigotsky son los procesos de aprendizaje los que ponen en marcha los procesos de desarrollo. A diferencia entonces de otros psicólogos, 
como Piaget, Vigotsky sostiene que el proceso evolutivo es guiado por el proceso de aprendizaje y no a la inversa.

El propósito de la escolarización es, en términos vigotskianos, enseñar a los estudiantes a ser alfabetizados en el sentido más amplio de la palabra: capaces de leer, escribir, hablar, computar, razonar y manipular símbolos y conceptos visuales y verbales.

La alfabetización se obtiene creando oportunidades para que los alumnos sean ayudados en el uso de los significados de las palabras, las estructuras conceptuales y el discurso mismo, de manera que los signos y símbolos cobren nuevos significados compartidos a medida que son consagrados por el uso durante la actividad productiva conjunta y conducidos abajo de la superficie para ser desnudados a la luz del pensamiento. Nuestros módulos refuerzan dichos procesos.

Directamente relacionada con el énfasis puesto por Vigotsky en la dimensión sociohistórica del funcionamiento psicológico humano se encuentra su concepción del aprendizaje como un proceso que siempre incluye relaciones entre individuos. Del mismo modo que el desarrollo no es un proceso espontáneo de maduración, el aprendizaje no es sólo fruto de una interacción entre el individuo y el medio; la relación que se da en el aprendizaje es esencial para la definición de ese proceso, que nunca tiene lugar en el individuo aislado. Es interesante mencionar que él siempre incluye al que aprende, al que enseña y la relación entre ambos. El proceso de enseñanza-aprendizaje es así considerado como un proceso global de relación interpersonal que a un tiempo incluye los elementos mencionados en todo único e indisociable.

El individuo no posee instrumentos endógenos para recorrer solo el camino hacia el pleno desarrollo. El mero contacto con los objetos de conocimiento no garantiza el aprendizaje. La intervención deliberada de los miembros más maduros de la cultura en el aprendizaje de los niños es esencial para el proceso de desarrollo infantil. En la escuela, por lo tanto, donde el aprendizaje es el objetivo de un proceso que se propone guiar hacia un determinado tipo de desarrollo, se privilegia la intervención deliberada. La intervención del docente desempeña un papel central en la trayectoria de los individuos que pasan por la escuela. De este modo, el marco de referencia teórico vigotskiano caracteriza los procesos pedagógicos como intencionales, deliberados, dirigidos a la construcción de seres psicológicos que sean miembros de una cultura específica, cuyo perfil, por lo tanto esté modelado por parámetros definidos culturalmente. 
Como podemos observar el discurso Vigotskyano tiene completa validez dentro del contexto de altos de Cazucá, ya que el modelo educativo planteado por el autor parte de conceptos como cultura, contexto y sociedad, lo que permite que el contexto Colombiano, específicamente el de Altos de Cazucá no sea la excepción, ya que los directos responsables del proceso educativo son los niños implicados y los docentes y las fuentes del conocimiento son los lugares donde habitan y las herramientas son dadas por la sociedad, el propio yo, y los otros con los que se comparte el proceso.

\section{Conceptos nuevos que nacen de la realidad de Cazucá}

Diríamos, que más que generar nuevos conceptos, sería más pertinente replantear algunas categorías a partir del trabajo realizado, dichos replanteamientos nacen a partir de la experiencia misma, y de los resultados que hemos descrito detalladamente.

El primero de los conceptos es el de sujeto. Como bien lo analizamos en el capítulo segundo de la investigación visto desde la perspectiva latinoamericana, el sujeto es parte del proceso de conocimiento y desde la filosofía en América latina es quien está llamado al "deber de conocer". Ahora bien, luego de la experiencia obtenida con la ejecución de nuestro trabajo, entendemos por sujeto como el agente principal de la construcción no solo de conocimiento, sino del contexto histórico que le corresponde vivir, el niño habitante de altos de Cazucá busca inquietamente el conocimiento nuevo, la interacción con el otro, no se victimiza por las circunstancias en las que vive, sino que por el contrario trabaja constantemente por cambiar su modo de vida.

El sujeto de dicho contexto conoce perfectamente los pro y los contra de su situación, así como las diferentes entidades que intervienen en la zona, incluso, aunque suene fuerte, sacan provecho de ello; pues incluso cobran por entrevistas y censos realizados por dichas instituciones en una tierra de todos y de nadie.

El sujeto de altos de Cazucá vive de manera situacional, pues es presa de muchas circunstancias que van desde el orden público hasta los estragos del clima que muchas veces ocasionan abandono de los territorios de manera intempestiva, lo que dificulta un seguimiento estricto a varios de los procesos que se generan con dicha población lo que se convierte en un limitante.

Vivir, como lo dijimos anteriormente, en tierra de todos y de nadie, hace que no halla un arraigo fuerte entre el sujeto que habita en este lugar y la tierra, muchas veces no hay líderes 
comunitarios interesados en sacar a flote los problemas de la comunidad para darles solución y mejorar las condiciones de vida.

Los niños-sujeto con los que se tuvo la oportunidad de trabajar son sujetos en construcción, activos, dinámicos, que dentro de su misma infancia no carecen de limitantes para ser ellos mismos y aportar algo de eso a los demás, lo que incluye a los adultos que los rodeamos temporalmente, son sujetos abiertos incluso, a la entrega de afecto y acogen a extraños como propios en un plazo corto, y eso es justamente interfiere con dos fuentes directas de nuestro trabajo, un niño-sujeto que tal y como lo pensó Vigotsky se comunica e interactúa construyendo por sí mismo y para sí mismo conocimientos y un sujeto situacional latinoamericano, que se siente habitante circunstancial y por ello tiene características tan especiales como la afectividad sin discriminación toque fundamental del latinoamericanismo que nos distingue, estos niñossujeto tienen un alto potencial intelectual, que enfocado y trabajado de la manera correcta se convertiría en la clave en la construcción de nuevos senderos del conocimiento, no sólo filosófico, sino de cualquier campo del saber.

El segundo concepto a analizar, es el de la realidad, pues si bien las altas proyecciones intelectuales de los sujetos son parte vital del desarrollo y progreso de un pueblo, lo que denominamos la realidad de altos de Cazucá la podemos describir de la siguiente manera: las necesidades tienen que ver, prioritariamente, con la vivienda, la alimentación, la educación y el acceso al empleo. Así mismo, algunos señalan como necesidad sentida la seguridad para los líderes, los jóvenes y en general para el conjunto de la población residente en el sector, lo cual es entendible si se tiene en cuenta la inseguridad que ha tomado diversas manifestaciones especialmente en los últimos años.

La educación y el empleo son también otras de las necesidades más apremiantes de esta población, las cuales se hallan directamente interrelacionadas. Esta interrelación, lo mismo que las ventajas derivadas del acceso a la educación, siendo ésta un medio de socialización, facilita la participación en el mercado laboral y es una variable determinante del nivel de ingreso. La ausencia de educación y calificaciones traduce en subempleo o empleo precario y es una mayor exposición a las fluctuaciones económicas.

La población adulta, de manera especial los jefes de hogar, tienen la necesidad de un empleo que les permita hacer frente a su supervivencia, los mismo que a la de los suyos, pero se 
encuentra con que las habilidades aprendidas en sus sitios de procedencia, muy poco cuentan en el sector urbano.

Ante estas y otras dificultades, la educación, que tenía poca importancia en el sector rural, comienza ahora a ser valorada como uno de los mecanismos de inserción en el mundo laboral. Se trata tanto de la educación formal como la informal. En el primer caso, de manera especial, son las mujeres las que sienten la necesidad de terminar sus estudios de primaria o secundaria, al mismo tiempo que esperan que sus hijos tengan la oportunidad de alcanzar aún mayores metas. En cuanto a la educación informal, las personas han comenzado a comprender que el proceso adaptación al nuevo entorno, les exige el dominio de ciertos conocimientos, como por ejemplo, el manejo adecuado de las finanzas, la manera de redactar un documento, como interponen una acción de tutela, o los requerimientos mínimos para la gestión de proyectos productivos.

Además existe la creencia de que, a través de la educación, resulta más fácil integrarse a la nueva dinámica urbana, en la medida en que se adquieren unos conocimientos que hacen que las personas se desenvuelvan de la mejor manera posible e incluso lleguen a cooperar más exitosamente en los procesos comunitarios del entorno inmediato.

Lastimosamente estos anhelos chocan con una serie de dificultades, algunas propias del lugar de asentamiento y otras asociadas con el proceso de adaptación de las personas. Algunas de estas dificultades que, con frecuencia las personas expresan, son:

- Se aprecia que en aras de la supervivencia lo primero que las familias sacrifican es la educación tanto de los niños como de los jóvenes. Las hijas mayores deben trabajar como empleadas domésticas o al menos dedicársela cuidado de los hermanos menores, mientras que la madre sale a trabajar en cualquier oficio que le resulte. En este sentido, la esperanza de hacer de la educación un mecanismo para aspirar al disfrute de mejores condiciones pareciera esfumarse y, por el contrario, al pobreza en toda sus dimensión, tiende a reproducirse indefinidamente.

- La limitada oferta de cupos en los centros educativos del sector, se opone de manera significativa a las aspiraciones educativas de la familia.

- Cuando los niños o jóvenes pueden acceder a un cupo en los establecimientos educativos públicos del sector, los padres encuentran que no resulta factible el sostenimiento de los hijos en los planteles por los altos costos de los implementos de estudio exigidos por los 
docentes, los uniformes (diario y deportivo), la cuota semanal de alimentación en los restaurantes escolares - donde los hay-, la salidas pedagógicas etc.

- Los niños y, de manera especial los jóvenes, perciben un desfase entre el contexto cultural de las instituciones educativas del lugar de asentamiento, y las prácticas educativas y culturales de los lugares de origen. Esta situación, genera desgano, apatía o resistencia y con frecuencia conduce a la deserción escolar.

- Los padres, que provienen, en su gran mayoría, del campo donde se respira un ambiente sano, temen las malas influencias del ambiente escolar; lo mismo que hay temor por los riesgos que puede correr la vida de los hijos, pero también hay malestar por el estigma de que son objeto los niños y jóvenes por parte de los maestros y compañeros por el hecho de ser desplazados.

- Las personas que acceden a la educación informal les queda la sensación de que ésta no garantiza su inserción en el mundo laboral

Ante las necesidades más apremiantes, las personas presentan diversas alternativas, entre las cuales se destacan el desarrollo de proyectos productivos, el fortalecimiento del trabajo comunitario y desde luego la formación necesaria para la inserción en el mercado laboral. Pero falta muchísimo apoyo de las entidades públicas y privadas para responder a los retos que se les plantean a las familias en situación de desplazamiento o vulnerabilidad.

Como hemos visto, hablar de realidad en altos de Cazucá, es hacer alusión a una amalgama de "microrealidades" donde se mezcla la violencia, la falta de oportunidades, los avatares económicos, climáticos, políticos, los malestares arquitectónicos y el aislamiento del territorio, así como los factores de inaccesibilidad. Muchas personas verían esta realidad como una serie de dificultades para el desarrollo de un individuo productivo para el resto, sin embargo, los sujetos partícipes ven en cada uno de estos factores oportunidades para construir su conocimiento y su entorno, e incluso, desarrollan un nivel altísimo de recursividad y economía.

Para finalizar, queremos dejar en claro que damos por cumplido en gran medida nuestro objetivo, ya que logramos conectar herramientas y teorías de corte pedagógico y filosófico a través de la concretización de un producto útil tanto para nosotros, los niños y niñas del centro de proyección de la universidad como para los futuros licenciados y magíster en filosofía así como para niños y niñas de diferentes poblaciones y contextos en tiempos venideros. 


\section{REFERENCIAS BIBLIOGRÁFICAS}

Aisenstein, A. (1996), El contenido de la educación física y la formación del ciudadano. En: Lecturas: Educación Física y Deportes, Año 1, N¹. Argentina 1880-1930.

Altimir, O. (1997), Desigualdad, empleo y pobreza en América Latina: efectos del ajuste y del cambio en el estilo de desarrollo. En: Desarrollo Económico. ( ${ }^{\circ} 145$, vol. 37). Buenos Aires: Instituto de Desarrollo Económico y Social.

Araujo y Oliveira (1994). La nueva empresa: el aprendizaje como parte del negocio. Montevideo: CINTERFOR

Ardao A. (1963). Logos foráneo, pero pathos y ethos personalísimos; Filosofía de lengua española. Montevideo: Alfa. pp 79-82

Ariño, Africa (2005). Tendencias en alianzas estratégicas. Center for Globalization and Strategy. Navarra: IESE.

Bonfil (1986). Implicaciones éticas del sistema de control cultural. México: Fondo de Cultura Económica.

Braslavsky, C. (1987). La juventud argentina: informe de situación. Buenos Aires: CEAL (1993). Una función para la escuela: Formar sujetos activos en la educación latinoamericana. Buenos Aires: Santillana/Convenio Andrés Bello

. (1993). Una función para la escuela: Formar sujetos activos en la construcción de su identidad y de la identidad nacional. En:Filmus, D., Para que sirve la escuela. Buenos Aires: Tesis-Norma.

- (1995). La educación secundaria en el contexto de los cambios en los sistemas educativos latinoamericanos. En: Revista Iberoamericana de Educación. (Nº9). Madrid:OEI.

- (1999).Re-haciendo escuelas: Hacia un nuevo paradigma en la educación latinoamericana. Buenos Aires: Santillana/Convenio Andrés Bello.

Calderón, F. y M. Dos Santos (1995). Sociedades sin atajos, Cultura, Política y reestructuración económica en América Latina: Buenos Aires:Paidós.

Carnoy, M. y C. de Moura Castro (1997). Qué rumbo debe tomar el mejoramiento de la educación en América Latina? En: Propuesta Educativa $\mathrm{N}^{\circ} 17$. Buenos Aires:

Carretero, M. (1997). Desarrollo cognitivo y Aprendizaje. Constructivismo y educación. México. Progreso II. 
Casanueva, Héctor (2007). Globalización y Gestión del Futuro. Ciencia y Tecnología. Vol. 24 No. 1-2 de 2006. Bogotá, Colombia: Colciencias

Cerutti Guldberg, Horacio (1992). Filosofía de la liberación latinoamericana. México: Fondo de Cultura Económica.

De Kerckhove, D. (1997). Connected intelligence. The arrival of the web society, Somerville Toronto: House Publishing.

De Moura Castro, C. (1984). Educación vocacional y productividad: alguna luz en la caja negra, Centro nacional de Recursos Humanos. Brasilia: IPEA,

Dorado Perea, Carles(2006). El trabajo en red como fuente de aprendizaje: posibilidades y límites para la creación de conocimiento. Una visión crítica. Barcelona: Universidad Autónoma.

Dussel, Enrique. (1974). Método para una filosofía de la liberación. Salamanca: Sigueme.

Dussel, I. y P. Pineau (1995). De cuando la clase obrera entró al paraíso: la educación técnica estatal en el primer peronismo. En: Puiggrós, A. (dir.).Discursos pedagógicos e imaginario social en el peronismo (1945-1955). Buenos Aires:Ed. Galerna

Fals Borda (1968). Las revoluciones inconclusas de América Latina. México: Siglo XXI.

Febles Elejalde, M. (1994): El humanismo en la "Psicología del Arte"de L.S. Vigotsky". (manuscrito).

Flavell, J. H. (1985). El Desarrollo Cognitivo. (Nueva Edición Revisada). Madrid: Visor.

Frank, Gunder. (1973). Capitalismo y Subdesarrollo en América Latina. Buenos Aires: Siglo XXI

Fullan, M. (1991). The meaning of educational change. Londres, Inglaterra.. 2007. Revista Blank. No. 68, octubre de 2007. Londes, Inglaterra: Cassell."Futurología"

González, Alejandro (2005). Segundo Seminario Regional. Desarrollo de la Competitividad con base en el Conocimiento. Foro consultivo, científico y tecnológico. México: Guanajuato.

González, F.; H. Valdés (1984). Psicología Humanista: actualidad y desarrollo. C. Habana: Editorial Ciencias Sociales.

Gutiérrez, Gustavo. (2000). Labor y contenido de la teología de la liberación. En: Christopher Rowland (ed.), La teología de la liberación, Madrid: Cambridge. pp. 41-63. 
Hinkelammert, Franz. (1970). Ideología del Desarrollo y Dialéctica de la Historia. Buenos Aires: Universidad Católica de Chile.

Mayer (1981). Diseño Curricular Base. Madrid: Servicio de Publicaciones. VV. AA. Construir los aprendizajes. Reforma, currículum y Constructivismo. Cuadernos de Pedagogía.

(1981). El Futuro de la Psicología Cognitiva. Madrid: Alianza. MEC

- (1981). Construir los aprendizajes. Reforma, currículum y Constructivismo. Cuadernos de Pedagogía.

McKeown, Rosalyn, Ph. D. (2002). Manual de Educación para el Desarrollo Sostenible. Versión.

MEC. (1989). Diseño Curricular Base. Madrid: Servicio de Publicaciones.

Medina, Javier (2006). Prospectivas en la escena colombiana. Ciencia y Tecnología. Vol. 24 No. 1-2 de 2006. Bogotá, Colombia: Colciencias.

Mejía, Jorge Julio, S.J. (2007). Recuperar el Sujeto. II Congreso Internacional de Educación y VII Congreso Nacional de Educación. Bogotá, Colombia.

Minidiccionario de Términos de Prospectiva. La Vanguardia. España.

Ministerio de Educación Nacional (2005). Bases para una nación bilingüe y competitiva". (No. 37 Diciembre). Bogotá, Colombia: Altablero.

Ministerio de Educación Nacional(2005). Tendencias mundiales. (No. 37, Diciembre). Bogotá, Colombia: Altablero

Oficina Internacional de Educación (2003). Cambios curriculares: una perspectiva global". Perspectivas Dossier. Vol. XXXIII, No. 1, marzo.

Pérez Bonet, Gregorio (2006). Sintaxis para una aproximación a los escenarios multiculturales. Viaje hacia la interculturalidad. Coordenadas básicas desde los bosques culturales. Revista Educación y Futuro. (No. 20). Madrid, España.

Proyecto Millenium (2007). Estado del futuro. Situación y desafíos globales del futuro. $11^{\circ}$ edición.

Rebellato, José Luis. (1995). La encrucijada de la ética. Neoliberalismo, conflicto Norte-Sur, liberación. Montevideo: Nordan.

Ricoeur, Paul (196). Sí mismo como otro. México: Siglo XXI. 
Roig, A.A. (1993). Ética del poder y moralidad de la protesta: La moral latinoamericana de la emergencia. En: “ Rostro y filosofía de América Latina”. Mendoza, Argentina: EDIUNC . (1973). Apuntes sobre la cultura de nuestra América. Buenos Aires: La Pléyade. . (1998). Posmodernismo, paradoja e hipérbole, Revista Hechos Ideas, Casa de las Américas, diciembre de 1998.

Shuare, M. (1990). La psicología soviética tal como yo la veo. Moscú: Editorial Progreso.

Social Watch (2006). El desafío de la Universalidad". España:Equipo investigador en Ciencias Sociales.

Steiner, George (1992). Presencias Reales. Barcelona: Destino.

UNESCO. 2003. "Cambios Curriculares: Una perspectiva global". Perspectivas. Vol. XXXIII, $\mathrm{N}^{\circ} 1$, marzo.

UNESCO. 2004. Conferencia Internacional de Educación. $47^{\circ}$ reunión. Ginebra, Suiza.

UNESCO. 2005. Informe Mundial. Hacia las sociedades del conocimiento. París, Francia.

UNESCO. 2007. Informe de seguimiento de la EPT (Educación para Todos) en el mundo. Atención y educación de la primera infancia. París, Francia.

Universidad Torcuato Di Tella y la Asociación Conciencia (2000). Seminario Educación del Ciudadano en la Escuela del Siglo XXI. Roma, Italy.

Vigotsky, L.S. (1981).Pensamiento y Lenguaje. Pueblo y Educación. La Habana: Batalla . (1987). Historia del Desarrollo de las Funciones Psíquicas Superiores. La Habana: Científico-Técnica. . (1982). Obras Escogidas. Tomo I y IV. Editorial Pedagógica. . (1985). Pensamiento y Lenguaje, Buenos Aires: Pléyade

Zea, Leopoldo (1976). El pensamiento latinoamericano. Barcelona: Ariel. 


\section{INFOGRAFÍA}

Braslavsky, Cecilia (2006). Diez Factores para una educación de calidad para todos en el Siglo XXI". Revista Electrónica Iberoamericana sobre Calidad, Eficacia y Cambio en Educación. (2e). Disponible en. http://www.rinace.net/arts/vol4num2e/art5.pdf. Consultado en marzo de 2007

Díaz, Hugo (s.f.). Perspectivas y desafíos de la educación en el mundo. Disponible en $<$ http://www.educared.edu.pe/directivos/index.asp?id_articulo=1013>. Consultado en abril de 2007.

Dickinson, Dee (s.f.). Tendencias Positivas: Cómo satisfacer las necesidades de un mundo rápidamente cambiante. Disponible en http://www.newhorizons.org/. Consultado en octubre de 2007

González, Federico (s.f.). Tendencias en e-learning - modalidades, barreras y futuro. Disponible en http://www.conocimientosweb.net/portal/article906.html. Consultado en noviembre de 2007.

Instituto Tercer Mundo (s.f.). Priorizar la Alfabetización. Disponible en. www.choike.org/nuevo/informes/1287.html. Consultado en octubre de 2007.

López Rayón, Ana Emilia (s.f.). Ambientes Innovadores de Aprendizaje. Disponible en www.somece.org.mx/memorias/2001/docs/82.doc. Consultado en noviembre de 2007.

Papert, Seymour y Cavallo, David. (s.f.). Los Centros de Aprendizaje. Punto de partida para el aprendizaje en el siglo XXI. Disponible en http://www.eduteka.org/tema_mes.php3?TemaID=0004. Consultado en noviembre de 2007.

Perales, Iosu. Redes y alianzas de ONGD en la globalización. (s.f.). Disponible en http://www.gruposur.eu.org/Redes-y-alianzas-de-ONGD-en-la.html. Consultado en octubre de 2007.

Pérez Edgardo. (s.f.). Aportes a la reflexión sobre el sujeto popular latinoamericano. A Parte Rei 25. Disponible en http://aparterei.com 15

Ruesga, S. y Fujii, G. El comportamiento del mercado de trabajo en América Latina en el contexto de la globalización económica. Center for U.S.-Mexican Studies. Disponible en http://repositories.cdlib.org/usmex/ruesga_fujii. Consultado en octubre de 2007. 


\section{WEBGRAFÍA}

Méndez (2002). http://www.cca.org.mx/dds/cursos/cep21/modulo_1/main0_35.htm>. (Abbott, 1999):http://www.cca.org.mx/dds/cursos/cep21/modulo_1/main0_35.htm http://www.educar.org/articulos/Vygotsky.asp http://www.ulsa.edu.mx/ estrategias/constructivismo_educacion.doc http://campus.uab.es/ 2133542/biografiav.html http://www.educar.org/articulos/Vygotsky.asp http://www.ulsa.edu.mx/ estrategias/constructivismo_educacion.doc http://www.google.com/search?q=cache:DjbPsgh2FmkJ:www.ulsa.edu.mx/ estrategias/construc tivismo

http://www.cca.org.mx/dds/cursos/cep21/modulo_1/main0_35.htm 


\section{ANEXOS A \\ FORMATO DE EVALUACIÓN Y PROYECCIÓN}

Primera parte: Evalué el desempeño de los estudiantes durante las actividades. Califique de uno (1) a cinco (5) los siguientes aspectos siendo uno el más bajo y cinco el más alto. En el caso de calificar algún aspecto con uno (1) o dos (2) justifique su respuesta bajo la tabla.

\begin{tabular}{|c|c|c|c|c|c|}
\hline ASPECTOS A EVALUAR & 1 & 2 & 3 & 4 & 5 \\
\hline $\begin{array}{l}\text { 1. ¿El estudiante expone sus razones y tiene en cuenta la de los } \\
\text { demás para llegar a acuerdos? }\end{array}$ & & & & & \\
\hline $\begin{array}{l}\text { 2. ¿Realiza de manera responsable y autónoma las actividades de los } \\
\text { módulos? }\end{array}$ & & & & & \\
\hline $\begin{array}{l}\text { 3. ¿Sustenta lo que comprende mediante la ayuda de las relaciones } \\
\text { con sus conceptos previos? }\end{array}$ & & & & & \\
\hline $\begin{array}{l}\text { 4. ¿Desarrolla su trabajo con interés y gusto contribuyendo a la } \\
\text { realización de las actividades de los módulos? }\end{array}$ & & & & & \\
\hline $\begin{array}{l}\text { 5. ¿Comienza y termina las actividades de acuerdo al tiempo } \\
\text { establecido para cada actividad? }\end{array}$ & & & & & \\
\hline
\end{tabular}

\section{Espacio para sustentar}

Segunda parte: Evalué el contenido de los módulos. Califique de uno (1) a cinco (5) los siguientes aspectos siendo uno el más bajo y cinco el más alto. En el caso de calificar algún aspecto con uno (1) o dos (2) justifique su respuesta bajo la tabla.

\begin{tabular}{|c|c|c|c|c|c|}
\hline ASPECTOS A EVALUAR & 1 & 2 & 3 & 4 & 5 \\
\hline $\begin{array}{l}\text { 1. ¿El módulo presenta claramente actividades de fácil aplicación y } \\
\text { desarrollo? }\end{array}$ & & & & & \\
\hline $\begin{array}{l}\text { 2. ¿El módulo presenta temáticas acordes con el tipo de población } \\
\text { para el que fue diseñado? }\end{array}$ & & & & & \\
\hline $\begin{array}{l}\text { 3. ¿El módulo genera proceso de construcción de conocimiento tanto } \\
\text { para el docente como para el estudiante? }\end{array}$ & & & & & \\
\hline $\begin{array}{l}\text { 4. ¿Los temas y los objetivos de los módulos son claros y aplicables a } \\
\text { la población programada? }\end{array}$ & & & & & \\
\hline 5. ¿Los módulos ME CONSTRU-YO son una herramienta auto & & & & & \\
\hline
\end{tabular}


sostenible a corto y largo plazo?

Espacio para sustentar

Tercera parte: Haga las propuestas necesarias para permitir mejorar esta herramienta a partir de las dificultades y aciertos que encuentre en los módulos ME CONSTRU-YO. 


\section{ANEXO 2 RATÓN DE CAMPO/RATÓN DE CIUDAD}

Érase una vez un ratón que vivía en una humilde madriguera en el campo. Allí, no le hacía falta nada. Tenía una cama de hojas, un cómodo sillón, y flores por todos los lados.

Cuando sentía hambre, el ratón buscaba frutas silvestres, frutos secos y setas, para comer. Además, el ratón tenía una salud de hierro. Por las mañanas, paseaba y corría entre los árboles, y por las tardes, se tumbaba a la sombra de algún árbol, para descansar, o simplemente respirar aire puro. Llevaba una vida muy tranquila y feliz.

Un día, su primo ratón que vivía en la ciudad, vino a visitarle. El ratón de campo le invitó a comer sopa de hierbas. Pero al ratón de la ciudad, acostumbrado a comer comidas más refinadas, no le gustó.

Y además, no se habituó a la vida de campo. Decía que la vida en el campo era demasiado aburrida y que la vida en la ciudad era más emocionante.

Acabó invitando a su primo a viajar con él a la ciudad para comprobar que allí se vive mejor. El ratón de campo no tenía muchas ganas de ir, pero acabó cediendo ante la insistencia del otro ratón.

Nada más llegar a la ciudad, el ratón de campo pudo sentir que su tranquilidad se acababa. El ajetreo de la gran ciudad le asustaba. Había peligros por todas partes.

Había ruidos de coches, humos, mucho polvo, y un ir y venir intenso de las personas. La madriguera de su primo era muy distinta de la suya, y estaba en el sótano de un gran hotel.

Era muy elegante: había camas con colchones de lana, sillones, finas alfombras, y las paredes eran revestidas. Los armarios rebosaban de quesos, y otras cosas ricas.

En el techo colgaba un oloroso jamón. Cuando los dos ratones se disponían a darse un buen banquete, vieron a un gato que se asomaba husmeando a la puerta de la madriguera.

Los ratones huyeron disparados por un agujerillo. Mientras huía, el ratón de campo pensaba en el campo cuando, de repente, oyó gritos de una mujer que, con una escoba en la mano, intentaba darle en la cabeza con el palo, para matarle.

El ratón, más que asustado y hambriento, volvió a la madriguera, dijo adiós a su primo y decidió volver al campo lo antes que pudo. Los dos se abrazaron y el ratón de campo emprendió el camino de vuelta.

Desde lejos el aroma de queso recién hecho, hizo que se le saltaran las lágrimas, pero eran lágrimas de alegría porque poco faltaba para llegar a su casita. De vuelta a su casa el ratón de campo pensó que jamás cambiaría su paz por un montón de cosas materiales. 


\section{ANEXO 3 \\ Preámbulo de la Declaración Universal de los Derechos humanos (1948)}

Considerando que la libertad, la justicia y la paz en el mundo tienen por base elreconocimiento de la dignidad intrínseca y de los derechos iguales e inalienablesde todos los miembros de la familia humana;Considerando que el desconocimiento y el menosprecio de los derechoshumanos han originado actos de barbarie ultrajantes para la conciencia de lahumanidad, y que se ha proclamado, como la aspiración más elevada del hombre,el advenimiento de un mundo en que los seres humanos, liberados del temor y de lamiseria, disfruten de la libertad de palabra y de la libertad de creencias;Considerando que los pueblos de las Naciones Unidas han reafirmado en laCarta su fe en los derechos fundamentales del hombre y en la dignidad y el valorde la persona humana, y que han decidido promover el progreso social y elevar elnivel de vida dentro de un concepto más amplio de la libertad;Considerando que los Estados Miembros se han comprometido a asegurar, encooperación con la Organización de las Naciones Unidas, el respeto universal yefectivo a los derechos y libertades fundamentales del hombre, yConsiderando que una concepción común de estos derechos y libertades es dela mayor importancia para el pleno cumplimiento de dicho compromiso;La Asamblea General proclama la presente Declaración Universal de DerechosHumanos como ideal común por el que todos los pueblos y naciones debenesforzarse, a fin de que tanto los individuos como las instituciones, inspirándoseconstantemente en ella, promuevan, mediante la enseñanza y la educación, elrespeto a estos derechos y libertades, y aseguren, por medidas progresivas decarácter nacional e internacional, su reconocimiento y aplicación universales yefectivos, tanto entre los pueblos de los Estados Miembros como entre los de losterritorios colocados bajo su jurisdicción. 


\section{ANEXO 4 \\ Una versión simplificada de la declaración Universal de los Derechos Humanos (1948)}

1. Todos los seres humanos nacen libres e iguales. Somos iguales en dignidad y derechosy tenemos los mismos derechos de todo el mundo. Esto es porque todos estamosdotados de razón y conciencia para distinguir el bien del mal y por lo tanto debemoscomportarnos fraternalmente los unos con los otros.

2. Todos tenemos los mismos derechos y libertades, sin distinción alguna de la raza, sexoo color. Tampoco debe importar la nacionalidad, el idioma, la religión o la opiniónpolítica que tengamos o si somos ricos o pobres.

3. Todo individuo tiene derecho a la vida, a la libertad y a la seguridad de su persona.

4. Nadie estará sometido a esclavitud ni a servidumbre; la esclavitud y la trata deesclavosestán prohibidos en todas sus formas.

5. Nadie será sometido a torturas ni a penas o tratos crueles, inhumanos o degradantes.

6. Todo ser humano tiene derecho, en todas partes al reconocimiento de su personalidadjurídica.

7. Todos somos iguales ante la ley y tenemos, sin distinción, derecho a que la ley nosproteja por igual.

8. Si los derechos ante la ley son violados se tiene el derecho a un tribunal imparcial quevelepor que se haga justicia.

9. Nadie podrá ser arbitrariamente detenido, preso ni desterrado.

10. Toda persona tiene derecho, en condiciones de plena igualdad, a ser o í d apúblicamentey con justicia por un tribunal independiente e imparcial.

11. Toda persona tiene derecho a que se presuma su inocencia hasta que se pruebe suculpabilidad. Nadie será condenado por actos que en el momento de cometerse nofueron elictivos.

12. Nadie será objeto de injerencias arbitrarias en su vida privada, su familia, sudomicilio o su correspondencia, ni de ataques a su honra o a su reputación.

13. Toda persona tiene derecho a circular libremente y elegir su residencia en elterritorio de su país. Toda persona tiene derecho a salir de cualquier país, incluso elpropio, y a regresar cuando lo desee.

14. En caso de persecución, toda persona tiene derecho a buscar asilo, y a disfrutar de él,en cualquier país.

15. A nadie se privará arbitrariamente de su nacionalidad.

16. Los hombres y las mujeres, a partir de la edad núbil, tienen derecho, sin restricciónalguna por motivos de raza, nacionalidad o religión, a casarse y fundar una familia.

17. Ambos tienen que estar de acuerdo con el matrimonio y disfrutarán de igualesderechos en cuanto al matrimonio, durante el matrimonio y en caso de disolución delmatrimonio.

18. Toda persona tiene derecho a la propiedad, individual y colectivamente y nadie seráprivado arbitrariamente de su propiedad. 
19. Toda persona tiene derecho a pensar lo que quiera, a tener ideas sobre lo que es buenoy malo, y a creer en la religión que quiera, y podrá cambiar de religión si lo desea,sin ningún impedimento.

20. Toda persona tiene el derecho a decirle a otros lo que piensa y no puede ser callada.Toda persona tiene el derecho de leer los periódicos o escuchar radio y de publicarsus opiniones y enviarlas a donde se le ocurra sin que nadie se lo impida.

21. 20. Toda persona tiene el derecho a la libertad de reunión y asociación pacíficas y estarconquienquiera, pero nadie podrá ser obligado a pertenecer a una asociación.

22. Toda persona tiene el derecho a participar en el gobierno de su país, a quienes eligeenelecciones justas en las que cada voto tiene el mismo valor y el voto de cada cuales privado. Los gobiernos deben hacer lo que la gente quiere, para eso los eligen.

23. Toda persona que viva en este planeta, tiene el derecho a que se le satisfagan lasnecesidades básicas de tal modo que todos puedan vivir con dignidad y llegar a ser loque quieren. Otros países y grupos de países deben colaborar con este propósito

24. Toda persona tiene derecho al trabajo, a la libre elección del trabajo, a pertenecer aun sindicato, a tener condiciones de trabajo seguras y a la protección contra eldesempleo. Toda persona tiene derecho a la misma remuneración que otros querealizan el mismo trabajo, sin favoritismos. Toda persona necesita una remuneracióndecente para que su familia pueda vivir dignamente, esto significa que si no te paganlo suficiente, te deben remunerar de otros modos.

25. Toda persona tiene el derecho al descanso y la diversión, los que incluye la limitacióndel número de horas de trabajo exigidas y a vacaciones periódicas remuneradas.

26. Toda persona tiene el derecho a tener lo suficiente para llevar una vida digna, lo queincluyealimentación, vestido, vivienda y asistencia médica, así como para su familia.

27. Toda persona tiene el derecho a la educación, la que debe ser gratuita y obligatoria,al menos en los primeros años. La educación superior debe estar disponible para losque la deseen y tengan la capacidad de hacerlo. La educación contribuirá a que laspersonas logren lo mejor de ellas y que respeten los derechos humanos de otros en unmundo en paz.

28. Toda persona tiene el derecho de pertenecer al mundo del arte, la música y los libros,para poder disfrutar de las artes y beneficiarse de los progresos que se derivan de losnuevos descubrimientos de la ciencia. El que hay escrito, logrado o descubierto algotiene el derecho a que se le reconozca y se le retribuya por esto.

29. Toda persona tiene el derecho a vivir en un mundo donde los derechos y las libertadessean respetados y efectivos.

30. Todos tenemos responsabilidades con el sitio en el que vivimos y las personas que nosrodean, así que tenemos que apoyarnos mutuamente. Para ejercer la libertad senecesitanleyes y límites que respeten los derechos de todos, que permitan apreciar elsentido de lo bueno y lo malo, mantengan la paz en el mundo y respalden a lasNaciones Unidas.

31. Nada de lo que se ha dicho en esta Declaración se puede usar para disminuir oquitarnos nuestros derechos. 


\begin{abstract}
ANEXO 5.
Artículo 31.

Parte 1. Los Estados Partes reconocen el derecho del niño al descanso y elesparcimiento, al juego y a las actividades recreativas propias de su edad y a participarlibremente en la vida cultural y en las artes.
\end{abstract}

Artículo 32. Parte 1. Los Estados Partes reconocen el derecho del niño a estar protegidocontra la explotación económica y contra el desempeño de cualquier trabajo que puedaser peligroso o entorpecer su educación, o que sea nocivo para su salud o para sudesarrollo físico, mental, espiritual, moral o social. Parte 2. Los Estados Partesadoptarán medidas legislativas, administrativas, sociales y educacionales paragarantizar la aplicación del presente artículo.

Artículo 34. Los Estados Partes se comprometen a proteger al niño contra todas lasformas de explotación y abuso sexuales. Con este fin, los Estados Partes tomarán, enparticular, todas las medidas de carácter nacional, bilateral y multilateral que seannecesarias para impedir: a) la incitación o la coacción para que un niño se dedique acualquier actividad sexual ilegal; b) la explotación del niño en la prostitución u otrasprácticas sexuales ilegales; c) la explotación del niño en espectáculos o materialespornográficos. 

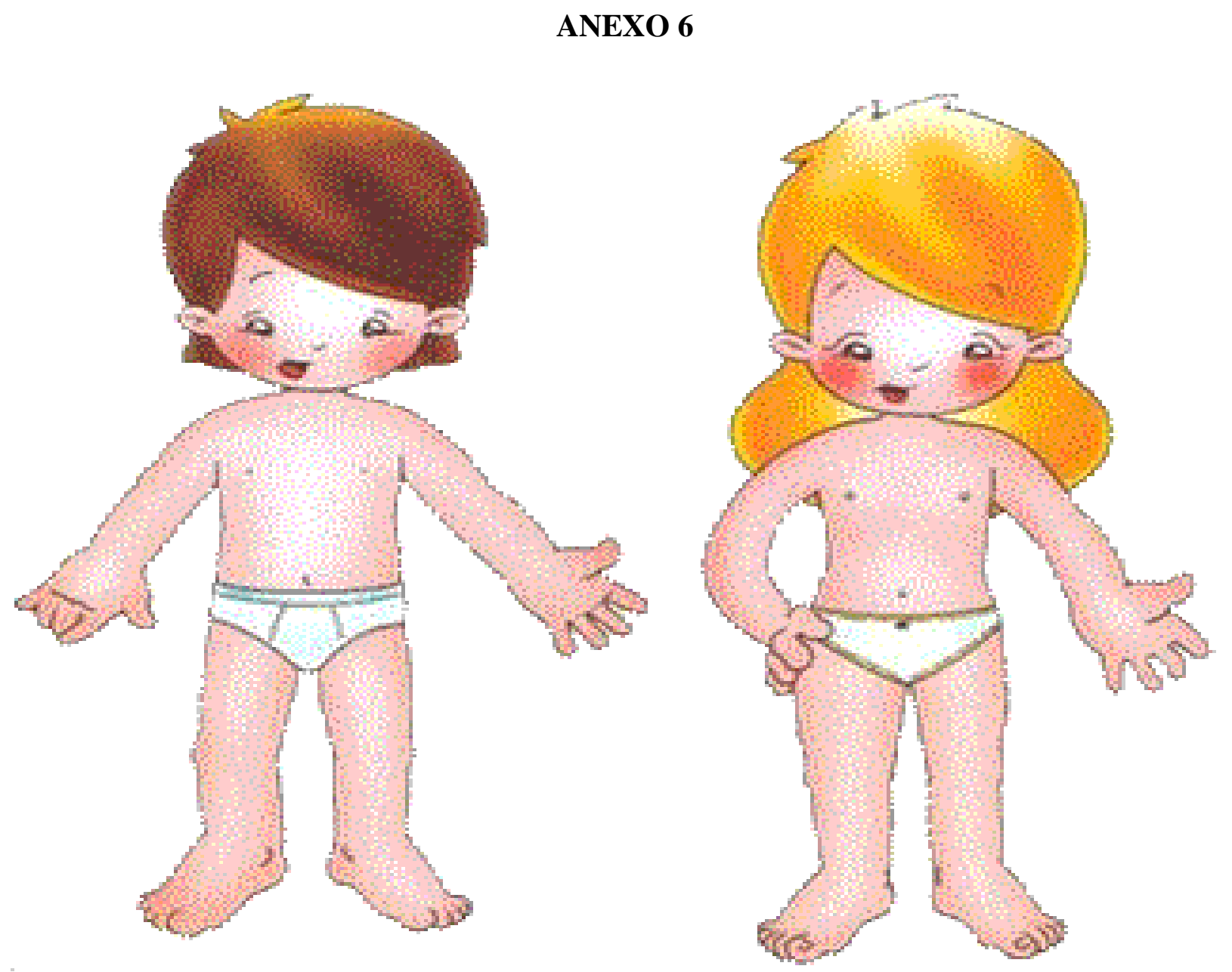


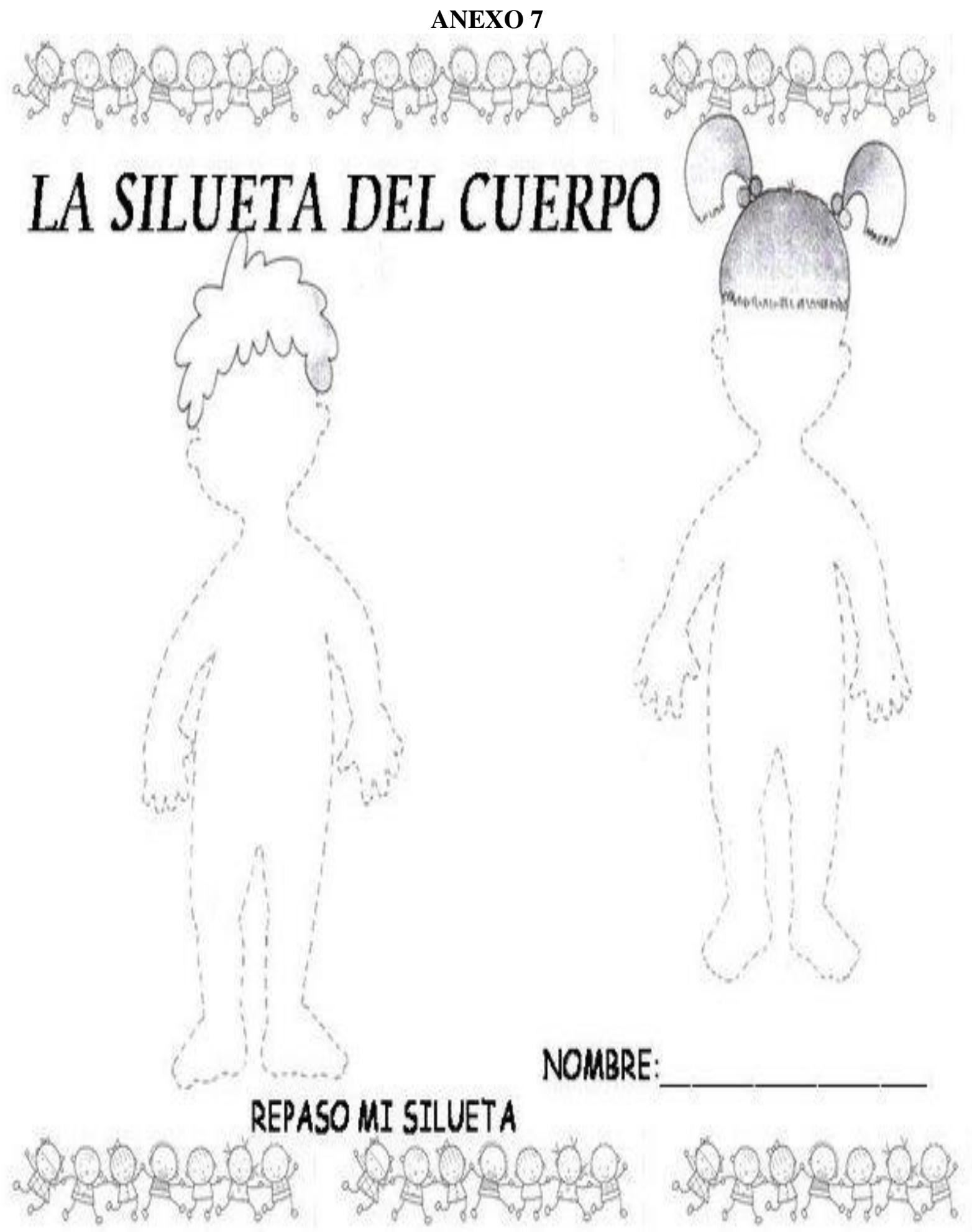


Módulos Educativos para Niños en Condiciones de Vulnerabilidad

ANEXO 8

Muestra de algunos de los trabajos desarrollados en el marco de los módulos me constru-yo en el centro
Cazuca)

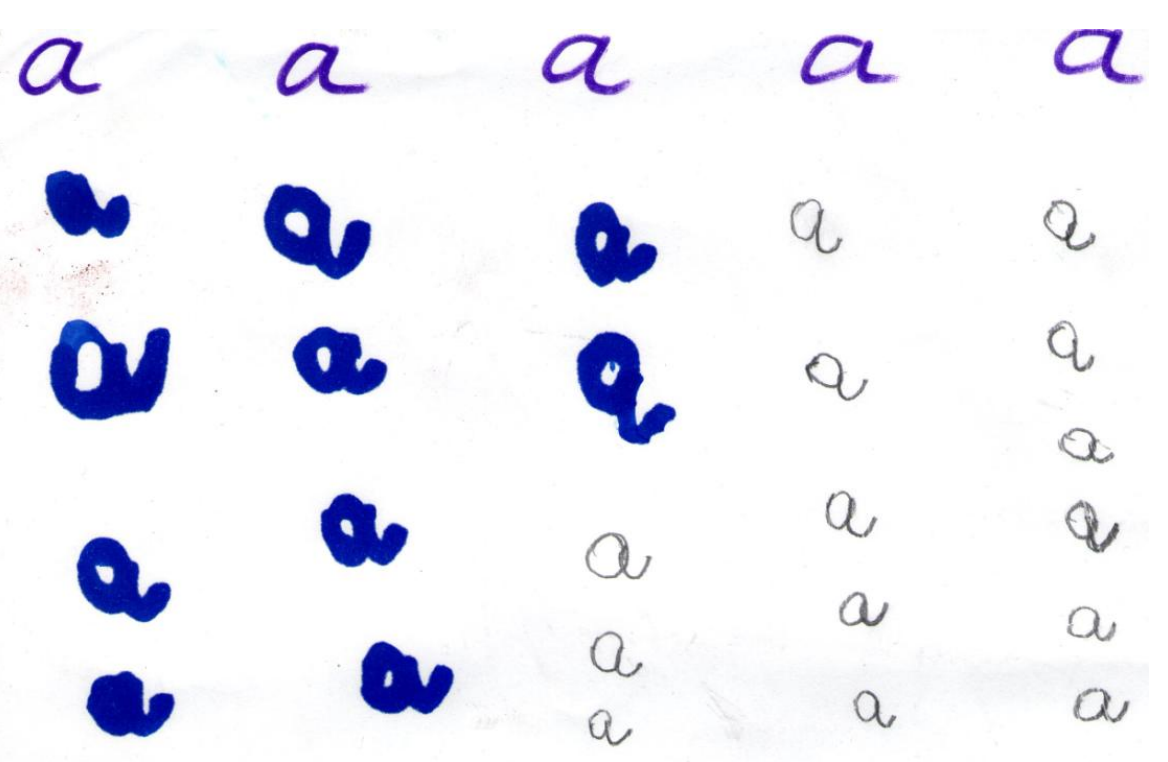

$\begin{array}{lllll}e & e & e & e & e \\ e & e & e & e & e \\ e & e & e & e & e \\ e & e & e & e & e \\ e & e & e & e & e \\ e & e & e & e & e \\ e & e & e & e & e \\ e & e & e & e & e\end{array}$


Módulos Educativos para Niños en Condiciones de Vulnerabilidad

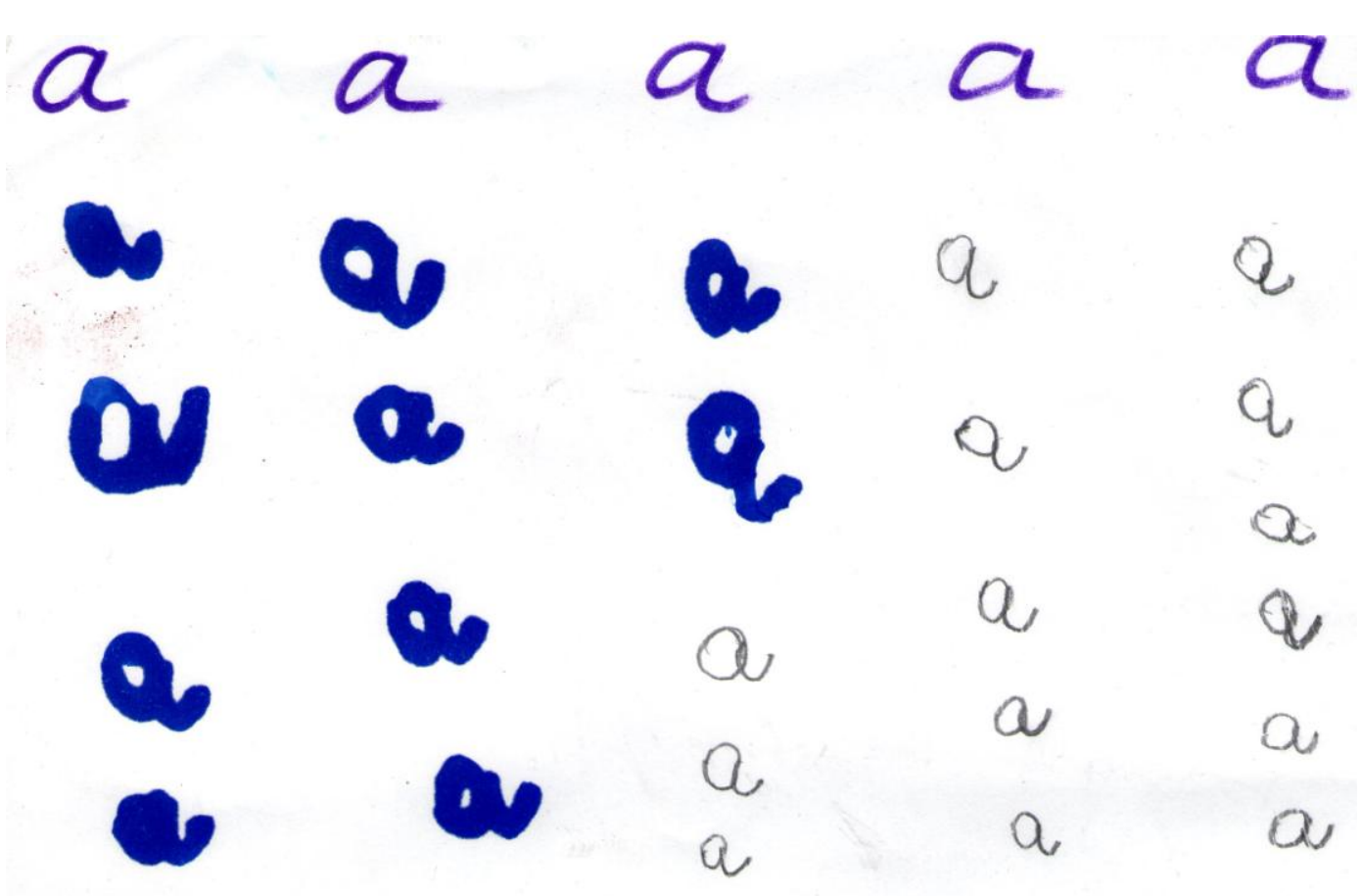

$\begin{array}{lllll}e & e & e & e & e \\ e & e & e & e & e \\ e & e & e & e & e \\ e & e & e & e & e \\ e & e & e & e & e \\ e & e & e & e & e \\ e & e & e & e & e \\ e & e & e & e & e \\ & e & e & e & -\end{array}$

235 


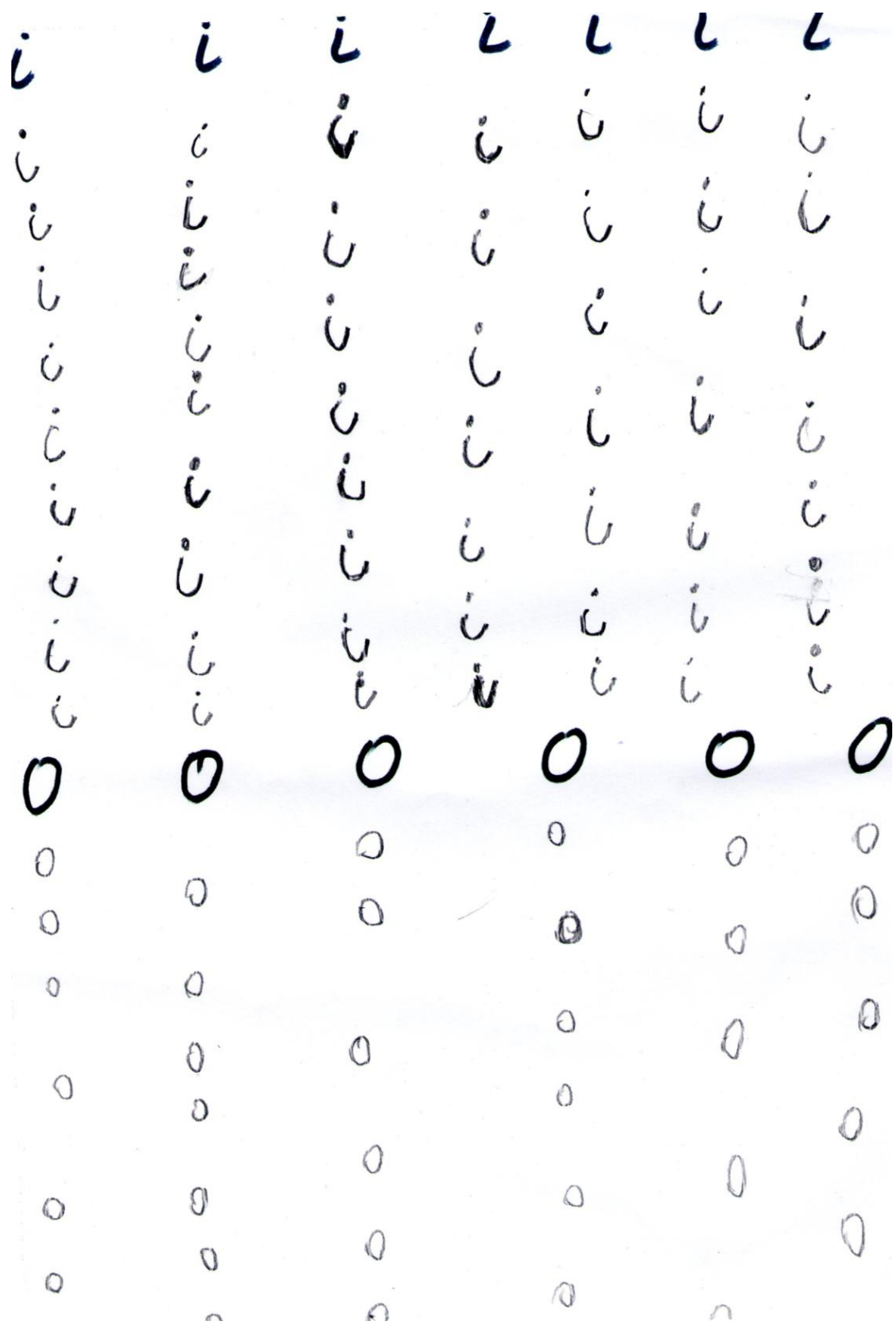


Módulos Educativos para Niños en Condiciones de Vulnerabilidad

Jose Edwin

nis sentimientosill ${ }_{\text {Armando on cuento, }} 11$

"Mis. sentimientos 'crean"

A Julietasele pldio fa mariposa

Evase unavez la ratoncita julieta que tro esaba,

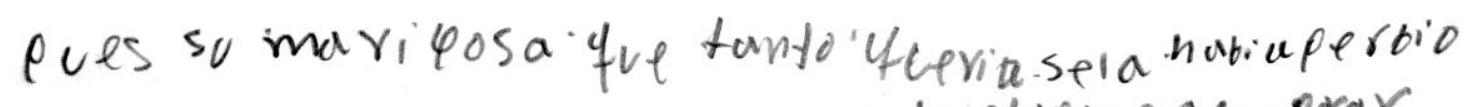

Pura que. J lipta y dino teste tirtejel wamos a comprar

una mariposa nuevaenla tiendarealla' arriba

la mariposa cuesta cinco mil pesosira platase ra

pejiremos a Maviager mama' de Julieta maria. la

nama de. J vli eta es coci bera cocina orroz

la pa. y cho rizo ho colina em panadas vomos a comprarel de. colores o a Ju lieta no estra maviposa es granke omavillas cll y rosadoseon co razones rojos y cieves nuy feliz se sintip ye ta. recibiosu mar. posa Larón. con muaro

237 
Módulos Educativos para Niños en Condiciones de Vulnerabilidad

mis sentimientos: "̈h̆ö́m "Armando un cuento... Missentimientos Crean"

Aulieta se le Perdio la mariposa. evase una vez laratoncita Julieta que triste estaba, pues su mariposa que tanto queria se le habla perdido. Para que julieta ya no esté triste, le vamos a comprar una mariposa nueva en la tienda de allce arriba. la mariposa cuesta cinco mil pesos, la plata se la Pediremos a maria, la mama de Julieta. mariA. la mamá de julieta es cosinero cosina arroz Papa $\times$ chorizo no losina en panadas. vamos a com prarle la marifosa a julieta nuestra mariposa es grande, de colores azulez y rosada con corazones *ojos y flores amarillas cuando Julieta resibio su mariposa mux fcliz se sintio y Jessica la llamó. x la culidararieron a la marieosa en su casita especial Fin

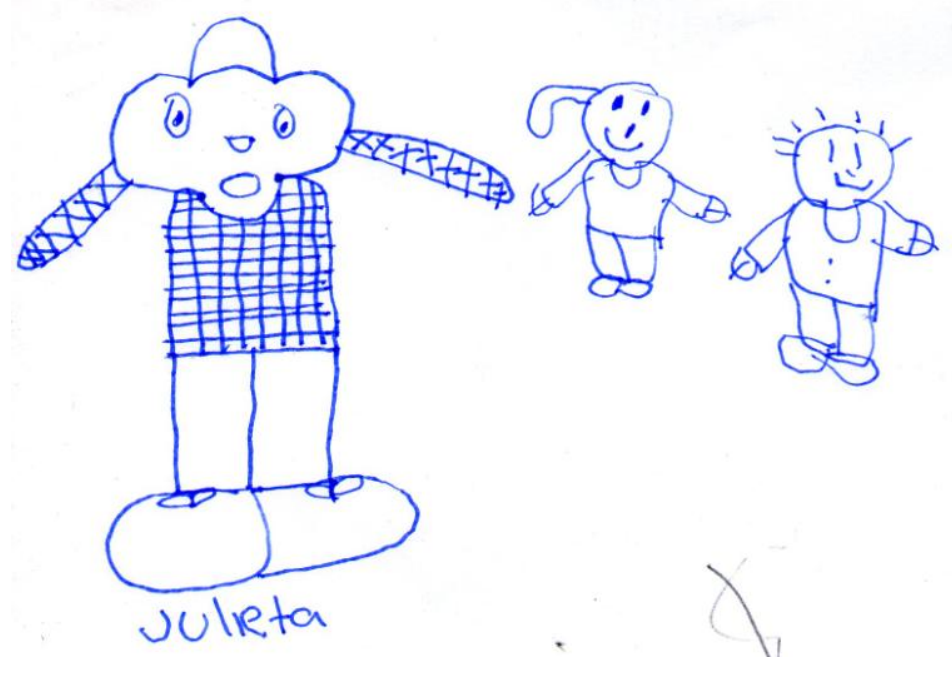

238 
Módulos Educativos para Niños en Condiciones de Vulnerabilidad

$$
\text { MIS SENEIMIEnTOS }
$$

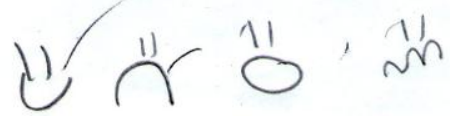
"Armando uncuento... misg entimientos crean"

A Juliesa seleperdio lamariposg.

Erase unavez laratonato (5c) sclieta quetriste estabc pues sumaripos quetanto quería ge le nabía perdid

Para que sulieta la no es re triste levamasa

comprar unamariposa en la tienda de gllarariba La myrip

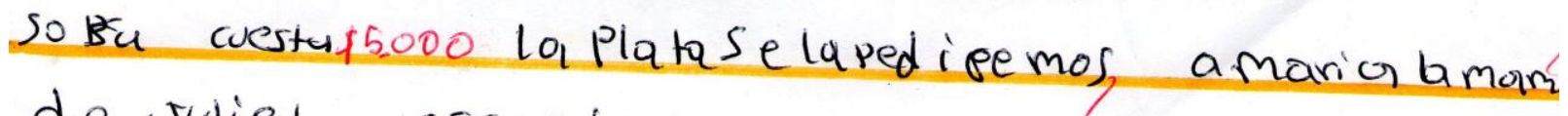
de sulieta escocinera, cocina ároz papacnorizan cocina empanadas vamos acomprarlelama riposa a oulieta, nuestra mariposy en grande deco lores asal rosaso con corazoner rojas iflores arnarillar (uandejulieta recibio sumariposu muy reliz se sintio y Jessica lavamo Juliera sela llevo Pala cosa maria Julieta jessica pedro el papa desuliety pusieron alamariposy ensucasita es pecial y lacuideron con miveno amordurantemuantiem

239 
Módulos Educativos para Niños en Condiciones de Vulnerabilidad

$$
\text { MIS SENEIMIENTOS }
$$

U) "Armando uncuento... misg entimientos crean"

A Julieja seleperdio lamariposg.

Erase unavez laratonato (sc) sclieta quetriste estabc pues sumaripos quetanto quería ge le nabía perdid

Para que sulieta la no es re triste levamasa comprar unamariposa en la tienda de allarariba La myrif

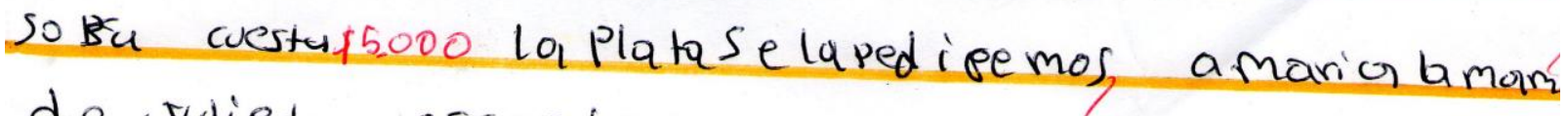
de sulieta escocinera, cocina aroz papacnoriza,na cocina empanadas vamos acomprarlelama jiposa a oulieta, nuestra mariposy en grande deco lores asa rosaso con corazoner rojas y flores avarillar (uande julleta recibio sumariposu muy feliz se sintio y sessica laliamo Juliera sela llevo Pala cosa maria Julieta jessiáa pedro el papa desuliety pusieron alamariposy ensucasita es pecial Y lacuideron con mucho amordurantemuantiem

240 


$$
\begin{aligned}
& \text { Junio } 9 / 2012 \text { hay hai } \\
& \text { El cuidado de nuestroj cuerpo } \\
& \text { primer E Jercicio }
\end{aligned}
$$

- Mi cabello = labarlo ton Sabon o chanpu peinarlo y Areglarlo.

- Mis dientes sepillarlos adiario todos los dias para que esten sanos.

- Mis uñas = de bo are glar las Para que permanejcan sanaj.

- Bañarme adario = debo Bah̆arme para que es te sano y no guela a f

- vacunarme = pasa que este jano y fuerte.

- Alimentarme-para que este sano y no me en ferme.

- veztime bienz para agradarle a las personas y Berme lien-

- Jugary hacer deportes: para estar sanos y divertirme con los segundo eJercicio

¿porque nuestra sociedad es similar a kadelas Hormigas?

R: Porque todos trabajan. porel bienestar de los de mas.

¿Es posible vivir en sociedas total?

$R=$ No, porque tenemos

¿porqueno pode mos hacer las cosas por simis mos he se mos delas demas personas.

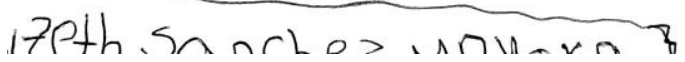


El cuidado ve unestro overpo

micabello = micabello Tocal abarlo y poinarlo y alegrallo.

midientes = baña. lo to dos los Dias para que semevea I.mpios. misunas = imisunas toca in antenerlas limpias 1.marlas,

Bañar mediar ro imañarm ediario y estarsanoy saludable. vacunas = bacunarme para no enermarme yara estarsaludable. Alimentarme para aue es te saño yo nludablea

Sanamente = buñar metodes los has y es tarlimpioso Vestirme = vestivme s.em para Que nosveanlimplos jogarsy hacerdeportos $=$ jugrar ydbertirme corlos demáro

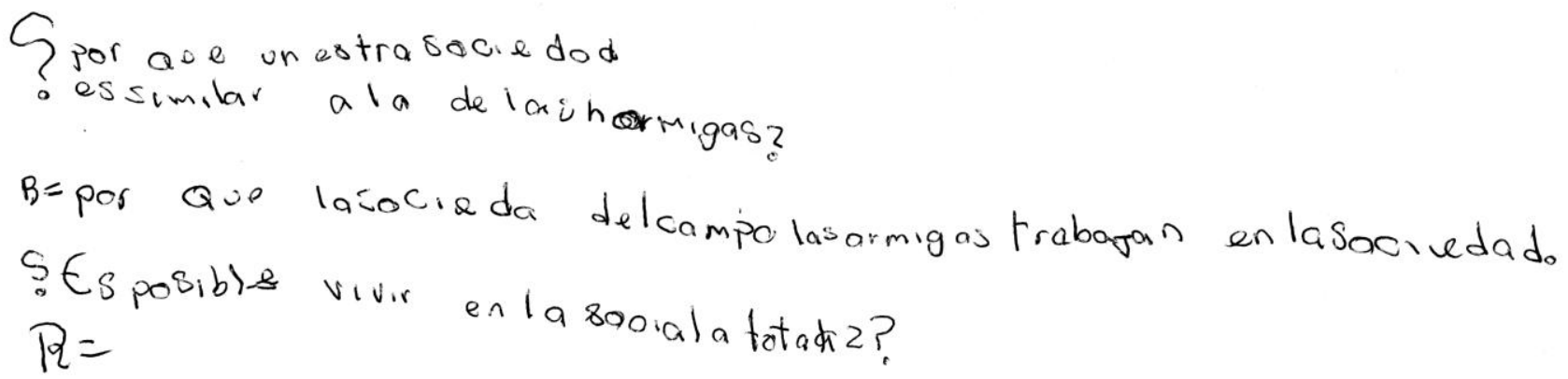

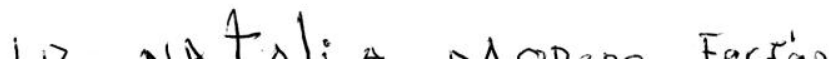


Módulos Educativos para Niños en Condiciones de Vulnerabilidad

Mi Mabelle: Cuidar mi cabello es' ballan do nos el cabello, con Champoo.

2)mis dientes: ballandonos nuestros dientes.

3) mis unios: ballandonos las uñas y cortandonos las unias delas manos, y nuestros pies.

7) Ballarmediario: Para esfar bien. limpios.

) bacunarme Para que no nos de en fermedades.

i) Alimentarme sanumalre: hay que comer bien.

7) vestirme bien: es paraqueno es tefaciula ropa

3) Jugary hacer departes. Para tener energiag, y pary no enfermarnos, fin

$v$ exercice

¿Porque nuestra sociedad

essimilar ollade las narmigas?

Mtucior

Res presty;

Por yue trabajan igual quenosotros como:" construir casa 7 edificias pero las nor migas hacen abugeros.

espocible viver ensoledad total?

nooporque nosotros noqueremus vivir lejos de nelestryfamiliq. y queremos que nos cuiden, qlajon tuecultive, alguien que nos alimente. iporque debemas ayudarnos entre 105 miem bros dela gociedad

delagociedad
Respuesty
porque nos ayudan ay quenos aycdany cuando esta

243 